\title{
Enhanced corrosion protection by microstructural control of aluminium brazing sheet
}

\author{
Ph.D thesis
}

Farid Norouzi Afshar 


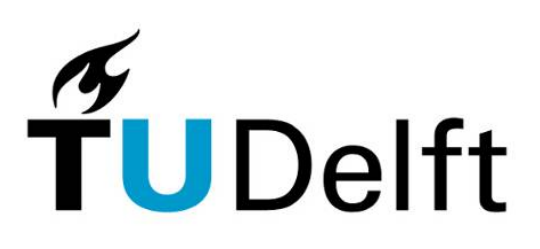

Delft University of Technology

The research described in this thesis was performed in the department of Materials Science and Engineering of Delft University of Technology, Delft, Netherlands.

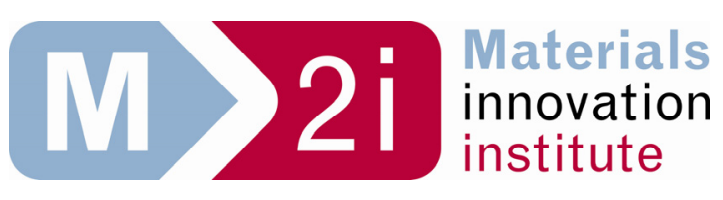

This research was carried out under the project number M21.6.08317 in the framework of the research program of Materials innovation institute M2i (http://www.m2i.nl). 


\title{
Enhanced corrosion protection by microstructural control of aluminium brazing sheet
}

\author{
Proefschrift \\ ter verkrijging van de graad van doctor \\ aan de Technische Universiteit Delft, \\ op gezag van de Rector Magnificus prof. ir. K.C.A.M. Luyben, \\ voorzitter van het College voor Promoties, \\ in het openbaar te verdedigen op vrijdag 30 augustus 2013 om 10:00 uur
}

door

\section{Farid NOROUZI AFSHAR}

Master of Science in Materials Science and Engineering, Delft University of Technology

geboren te Kermanshah, Iran 
Dit proefschrift is goedgekeurd door de promotor(en):

Prof. dr. J.H.W. de Wit

Prof. dr. H. Terryn

Copromotor

Dr. ir. J.M.C. Mol

Samenstelling promotiecommissie:

Rector Magnificus, voorzitter

Prof. dr. J.H.W. de Wit, Technische Universiteit Delft, promotor

Prof. dr. H. Terryn, Vrije Universiteit Brussel, België/ Technische

Universiteit Delft, promotor

Dr. ir. J.M.C. Mol, Technische Universiteit Delft, copromotor

Prof. dr. I.M. Richardson, Technische Universiteit Delft

Prof. dr. K. Nisancioglu, Norwegian University of Science and Technology, Norway

Prof. dr. M. Olivier, University of Mons, België

Dr. I. De Graeve, $\quad$ Vrije Universiteit Brussel, België

Prof. ir. L. Katgerman, Technische Universiteit Delft, reservelid

Keywords: Aluminium brazing sheet, accelerated corrosion test, microstructural characterization, electrochemical characterization, heat treatment

ISBN 978-90-77172-93-3

Copyright (C) 2013 by F. Norouzi Afshar

All rights reserved. No part of the material protected by this copy right notice may be reproduced or utilized in any form or by any means, electronically or mechanically, including photocopying, recording or by any information storage and retrieval system, without written permission from the author.

Printed by: Proefschriftmaken.nl 


\section{Table of contents}

\section{Chapter 1. Introduction}

1.1. Introduction 3

1.2. Aluminium brazing sheet 3

1.3. Long life aluminium brazing sheet and the need for a replacement 3

1.4. Down gauging aluminium brazing sheet and the need for a reliable accelerated corrosion test

1.5. Industrial and scientific aims of the project 5

1.5.1. Industrial aims and application of the project 5

$\begin{array}{ll}\text { 1.5.2. Scientific aims of the project } & 6\end{array}$

$\begin{array}{ll}\text { 1.6. Research approach } & 7\end{array}$

1.6.1. SWAAT analysis $\quad 7$

1.6.2. Corrosion protection enhancement by microstructural control 8

1.7. Research outline 8

1.8. References 11

Chapter 2. Accelerated corrosion testing of aluminium brazing sheet

2.1. Introduction 16

2.2. Experimental 18

2.2.1. Material 18

2.2.2. Brazing procedure 18

2.2.3. Variants specifications 18

2.2.4. SWAAT procedure 19

$\begin{array}{ll}\text { 2.2.5. Statistical analysis } & 20\end{array}$

2.2.6. Potentiodynamic polarization 21

2.2.7. Sample preparation and optical microscopy 21

$\begin{array}{ll}2.3 \text {. Results } & 22\end{array}$

2.3.1. Gauge influence $\quad 24$

2.3.2. Influence of tempering 25

2.3.3. Temperature effect 26

2.3.4. Effect of flux load 27

2.3.5. Effect of re-brazing 28

2.3.6. Comparison of corrosion mechanism in SWAAT and potentiodynamic $\begin{array}{ll}\text { experiments } & 29\end{array}$

2.3.7. Statistical evaluation of the SWAAT results 31

2.4. Discussion $\quad 32$

2.5. Conclusion $\quad 36$

2.6. References $\quad 37$ 


\section{Chapter 3. Microstructural evolution and macro-electrochemical characterization}

3.1. Introduction 42

3.2. Experimental 44

3.2.1. Material 44

3.2.2. Material characterization $\quad 44$

3.2.3. Electrochemical analysis $\quad 45$

3.3. Results 46

3.3.1 Material characterization $\quad 46$

3.3.2 Electrochemical characterization $\quad 51$

3.3.3 Corrosion morphology $\quad 53$

3.4. Discussion 54

3.4.1. Material characterization $\quad 54$

3.4.2. Electrochemical characterization $\quad 56$

3.5. Conclusion 57

3.6. References 59

Chapter 4. Microstructural characterization and electrochemical depth profiling

4.1. Introduction $\quad 64$

4.2. Experimental 66

4.2.1. Materials 66

4.2.2. Brazing procedure 66

4.2.3. Etching pre-treatment 66

4.2.4. Electrochemical investigations 66

4.2.5. Microstructure and composition analysis $\quad 67$

4.2.6. Corrosion attack mechanism investigation 68

4.3. Results 68

$\begin{array}{ll}\text { 4.3.1. Microstructural analysis } & 68\end{array}$

4.3.2. GDOES etching and elemental depth profiling 70

4.3.3. Microstructure and composition analysis $\quad 72$

4.3.4. Anodic and cathodic polarization $\quad 73$

4.3.5. Corrosion morphology $\quad 74$

4.4. Discussion 76

4.4.1. The new approach for electrochemical depth profiling 76

4.4.2. Electrochemical depth profiling of the aluminium brazing sheet 77

4.5. Conclusions 81

4.6. References 82

Chapter 5. Micro-electrochemical characterization of the surface

5.1. Introduction $\quad 88$ 
5.2. Experimental 90

$\begin{array}{ll}\text { 5.2.1. Materials } & 90\end{array}$

$\begin{array}{ll}\text { 5.2.2. Brazing procedure } & 90\end{array}$

5.2.3. Microstructure and composition analysis 90

5.2.4. AFM and SKPFM analysis $\quad 91$

5.2.5. Electrochemical analysis $\quad 92$

5.2.6. Corrosion attack mechanism investigation 93

5.3. Results 93

5.3.1. Microstructural analysis 93

5.3.2. AFM and SKPFM analysis $\quad 95$

5.3.3. Electrochemical characterization 98

5.3.4. Corrosion morphology 100

5. 4. Discussion 102

5.5. Conclusions 105

5.6. References 107

Chapter 6. Cross sectional microstructural and micro-electrochemical characterization

6.1. Introduction 114

6.2. Experimental 116

6.2.1. Materials 116

$\begin{array}{ll}\text { 6.2.2. Brazing procedure } & 117\end{array}$

$\begin{array}{ll}\text { 6.2.3. Microstructure and composition analysis } & 117\end{array}$

6.2.4. AFM and SKPFM analysis 118

$\begin{array}{ll}\text { 6.2.5. Electrochemical analysis } & 119\end{array}$

6.2.6. Corrosion attack mechanism investigation 119

6.3. Results 119

$\begin{array}{ll}\text { 6.3.1. Microstructural analysis } & 119\end{array}$

6.3.1.1. Optical microscopy 119

6.3.1.2. Scanning electron microscopy 121

6.3.1.3. X-ray micro analysis 123

$\begin{array}{ll}\text { 6.3.1.4. EPMA analysis } & 125\end{array}$

$\begin{array}{ll}\text { 6.3.2. AFM and SKPFM analysis } & 127\end{array}$

6.3.3. Electrochemical characterization 132

6.3.4. Corrosion morphology 133

6.4. Discussion 133

6.4.1. Microstructural features and their electrochemical consequences 133

6.4.1.1. Intermetallic particles at the surface 133

6.4.1.2. Solidification shrinkage voids $\quad 134$

6.4.1.3. Al-Si eutectic, continuous GB networks and formation of weak spots 134

6.4.1.4. $\mathrm{Cu}$ distribution $\quad 135$

6.4.1.5. Si distribution 136

6.4.2. SKPFM analysis 136 
6.4.2.1. Cross-sectional VPD measurements 136

$\begin{array}{ll}\text { 6.4.2.2. AFM/SKPFM analysis across grain boundaries } & 137\end{array}$

6.4.3. Potentiodynamic polarization measurement analysis 138

6.4.4. Corrosion attack mechanism 138

6.4.5. Corrosion protection enhancement of the modified brazing sheet 139

6. 5. Conclusions 139

6.6. References 141

\section{Chapter 7. Corrosion protection enhancement}

7.1. Introduction 148

7.1.1. Long life aluminium brazing sheet and the need for a replacement $\quad 148$

7.1.2. Effects of thermal treatment on corrosion resistance of aluminium $\quad 149$

brazing sheet

7.1.3. Summery of the previous characterization results $\quad 150$

7.1.4. The purpose of the current study 152

7.2. Experimental $\quad 152$

7.2.1. Materials 152

7.2.2. Brazing procedure $\quad 152$

7.2.3. Thermodynamic calculations 153

7.2.4. Microstructure and composition analysis $\quad 153$

$\begin{array}{ll}\text { 7.2.4.1. X-ray micro analysis (XMA) } & 153\end{array}$

7.2.4.2. FE-EPMA analysis 153

7.2.4.3. TEM analysis $\quad 153$

7.2.5. AFM and SKPFM analysis $\quad 154$

7.2.6. Electrochemical analysis $\quad 155$

7.2.7. Corrosion attack mechanism investigation $\quad 155$

7.3. Results 155

7.3.1. Determination of the post-braze heat treatment parameters 155

(temperature and time)
7.3.1.1. Determination of the appropriate post-braze heat treatment

temperature

7.3.1.2. Determination of the appropriate post braze heat treatment time $\quad 157$

7.3.2. Characterization of the post-braze heat treated samples 159

$\begin{array}{ll}\text { 7.3.2.1. Microstructural characterization } & 159\end{array}$

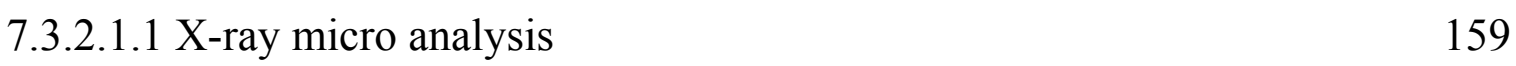

$\begin{array}{ll}\text { 7.3.2.1.2. EPMA analysis } & 160\end{array}$

$\begin{array}{ll}\text { 7.3.2.1.3. TEM analysis } & 161\end{array}$

$\begin{array}{ll}\text { 7.3.2.2. Electrochemical characterization } & 164\end{array}$

$\begin{array}{ll}\text { 7.3.2.2.1. OCP and PD measurements } & 164\end{array}$

7.3.2.2.2. AFM and SKPFM analysis 165

$\begin{array}{ll}\text { 7.3.2.2.3. Corrosion morphology } & 167\end{array}$

$\begin{array}{ll}\text { 7.4. Discussion } & 169\end{array}$

7.4.1. Determination of post braze heat treatment parameters 169 
7.4.1.1. Temperature 169

$\begin{array}{ll}\text { 7.4.1.2. Time } & 170\end{array}$

7.4.2. Characterization of the post-braze heat treated samples $\quad 170$

$\begin{array}{ll}\text { 7.4.2.1. Microstructural characterization } & 170\end{array}$

7.4.2.1.1. X-ray micro analysis 171

$\begin{array}{ll}\text { 7.4.2.1.2. EPMA analysis } & 171\end{array}$

$\begin{array}{ll}\text { 7.4.2.1.3. TEM analysis } & 171\end{array}$

$\begin{array}{lr}\text { 7.4.2.2. Electrochemical characterization } & 172\end{array}$

7.4.2.2.1. OCP and PD polarization 172

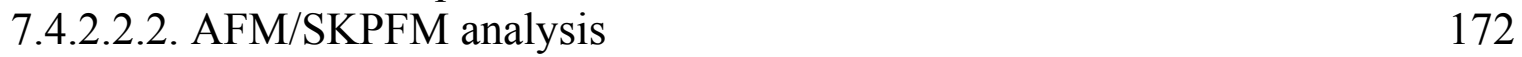

$\begin{array}{ll}\text { 7.4.2.2.3. Corrosion morphology } & 174\end{array}$

7.4.3. Green generation of cost effective and corrosion resistant aluminium 174 brazing sheet

7. 5. Conclusions 175

$\begin{array}{ll}\text { 7.6. References } & 176\end{array}$

\section{Chapter 8. Conclusions}

8.1. SWAAT analysis $\quad 181$

8.2. Corrosion protection enhancement by microstructural control 182

8.2.1. Microstructural effects 182

8.2.2. Electrochemical characterization 183

8.2.3. Corrosion attack mechanism 184

8.2.4. Green generation of cost effective and corrosion resistant aluminium 185 brazing sheet

8.3. Further research for future 186

$\begin{array}{ll}\text { Summary } & 189\end{array}$

$\begin{array}{ll}\text { Samenvatting } & 191\end{array}$

$\begin{array}{ll}\text { List of publications } & 193\end{array}$

$\begin{array}{ll}\text { Acknowledgements } & 197\end{array}$

$\begin{array}{lr}\text { Curriculum vitae } & 199\end{array}$ 


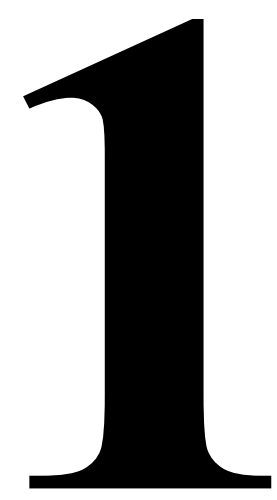





\section{Introduction}

\subsection{Introduction}

The current research work is aimed at developing a fundamental understanding over the correlation between microstructural features and the resulting electrochemical responses of aluminium brazing sheet materials. The detailed and fundamental mechanistic understanding of the effects of microstructural variations and the consequent electrochemical reactivities aims to provide enhanced corrosion protection by microstructural control of aluminium brazing sheet.

\subsection{Aluminium brazing sheet}

Thermal management in a car consists of a number of heat exchangers. In the past 30 years the use of aluminium in automotive heat exchanger applications has been steadily growing. Nowadays the heat exchangers are made up of aluminium brazing sheet. Aluminium brazing sheet comprises of a core alloy clad on one or both sides with a lower melting aluminium-silicon (Al-Si) alloy. The core alloy provides the strength and the clad material acts as a filler material. This thin clad layer usually makes up 5-10 \% of the total thickness of the brazing sheet. It melts and flows during the brazing process, to provide a metallic bond between the components upon cooling. Typical clad and core alloys are the AA4xxx and AA3xxx series respectively $[1,2]$. Typical optical cross sectional micrographs of two aluminium brazing sheet materials clad on one (a) or both (b) sides are shown in Figure 1.1.

\subsection{Long life aluminium brazing sheet and the need for a replacement}

One of the main performance criteria for heat exchanger units is the life time of the product. Today the life time of a typical heat exchanger has to be the same as the life time of the car, namely around 15 years. The main improvement to reach 15 years of life time performance is the development of the so-called long life (LL) alloys. These LL alloys are modified AA3003 and AA3005 alloys, which are low in iron and silicon content [1]. 


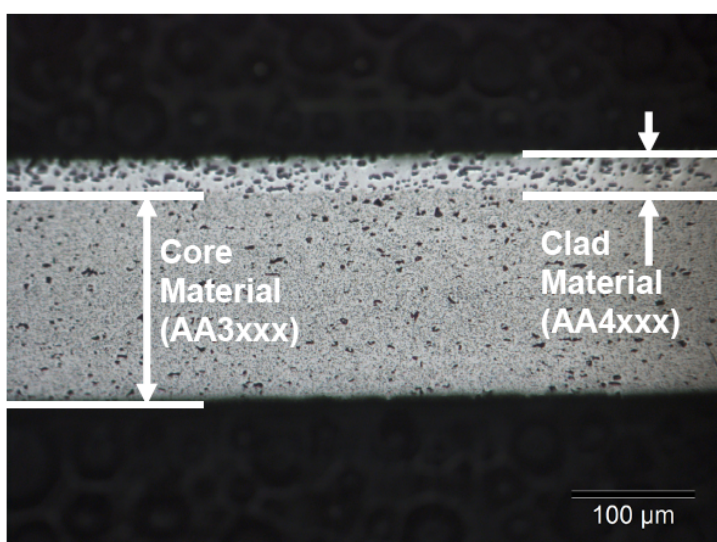

(a)

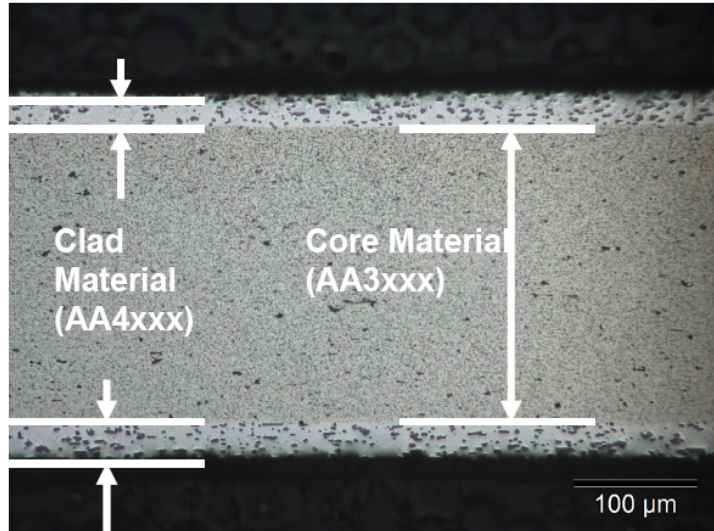

(b)

Figure 1.1. Optical cross sectional micrographs of aluminium brazing sheet materials clad on one (a) or both (b) sides

This low level of both iron and silicon make these alloys more expensive than the traditional AA3003 and AA3005 alloys. The main feature of the LL alloys is that they have a substantial amount of manganese in solid solution at the time of brazing. Due to the inward silicon diffusion during the brazing cycle, the manganese will precipitate in the diffusion layer [1]. The reduction of manganese in solid solution will lower locally the corrosion potential with respect to the remaining core alloy. This diffusion band will now be sacrificial to the core alloy and thus protecting the core alloy [1]. Nowadays cost reductions are key within automotive industry and the LL alloys become less competitive. There is a strong demand for low cost alloys but still with the excellent corrosion protection properties of the expensive LL alloys. The corrosion resistance becomes even more sensitive when the demand for down gauging of heat exchangers is considered. Standard 3003 and 3005 alloy show poor corrosion resistance, but are more cost effective compared to the LL alloys. So therefore investigating the possibilities for improving the corrosion resistance of cost effective aluminium brazing sheet materials are of both scientific and industrial interest.

\subsection{Down gauging aluminium brazing sheet and the need for a reliable accelerated corrosion test}

The demands for reduction in fuel consumption and green house gasses have stimulated ongoing efforts towards the use of lighter and thinner materials in automobile industry [3-5]. Down gauging the aluminum sheet for heat exchangers is an important part of these efforts. Alloy development for down gauged heat exchangers focuses on higher strength in order to maintain the same overall strength of the heat exchanger, and at the same time keeping the other properties at least at the same level. One of these properties is the corrosion resistance [6,7]. Unfortunately there is no consensus in the literature about one specific accelerated corrosion test. There is no agreement either on how corrosion performance should 
be evaluated in accelerated testing, or how test and real lifetime should be correlated. One can look at the corrosion morphology as the most important factor $[8,9]$ or rely on statistical correlation between test and service life [10].

The most common way to measure the corrosion resistance of heat exchanger materials, both for tube and fin alloys is the so called Sea Water Acidified Accelerated Test (SWAAT) [1,11-14]. This is actually a modification of the standard salt spray test (ASTM B117) [15] in which specimens are exposed to a continuous spray of salt water $(5 \mathrm{wt} \% \mathrm{NaCl})$ of $35^{\circ} \mathrm{C}$. SWAAT comprises a repetitive two hours cycle consisting of 30 min spray followed by a 90 min soak at above $98 \%$ humidity [16]. The spray is a solution of $42 \mathrm{~g} / \mathrm{l}$ of sodium chloride and is acidified with $10 \mathrm{ml} / 1$ of glacial acetic acid. The $\mathrm{pH}$ is then adjusted with 10 $\mathrm{wt} \% \mathrm{NaOH}$ solution to a value between 2.8 and 3.0 [16]. However, still some ambiguity exists, indicating that the test suffers from significant scattering of the results [1]. The apparatus for SWAAT testing consists of a fog chamber, a salt solution reservoir, a supply of suitably conditioned compressed air, atomizing nozzles, specimen supports, provision of heating the chamber and necessary means of control [16]. A SWAAT cabinet (a) and some prepared aluminium brazing sheet SWAAT samples on the racks (b) are shown in Figure 1.2.

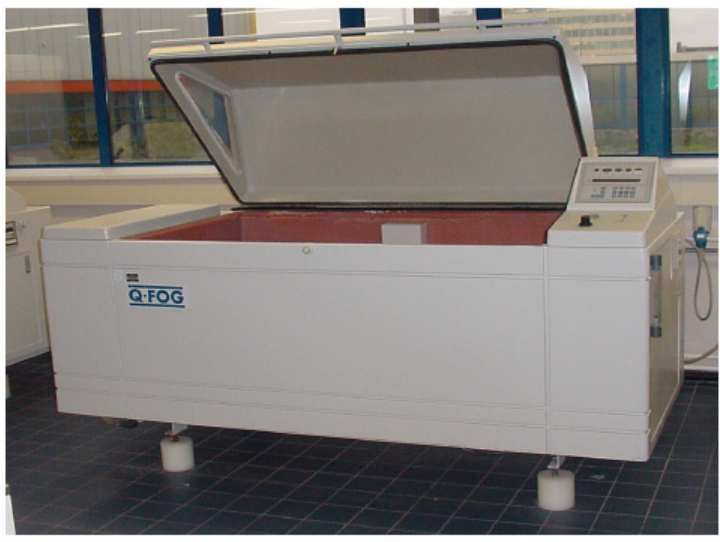

(a)

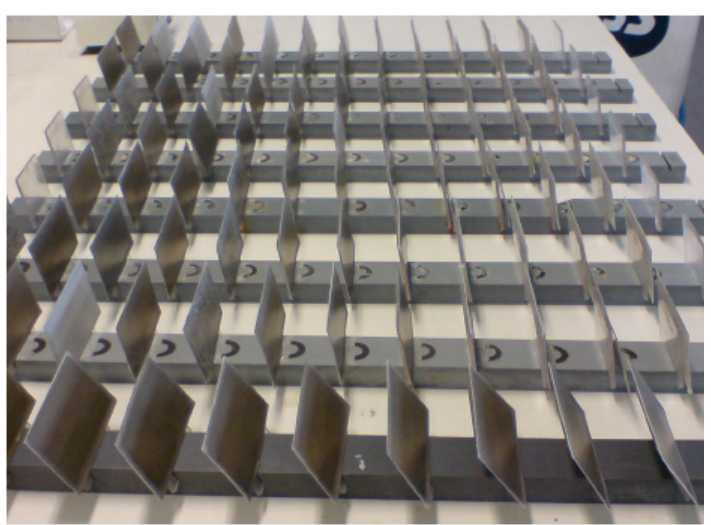

(b)

Figure 1.2. SWAAT cabinet (a) and SWAAT samples (b)

\subsection{Industrial and scientific aims of the project}

\subsubsection{Industrial aims and application of the project}

Two main industrial objectives for this project can be defined. The first objective is to understand the reason for variability of the accelerated corrosion test for brazing sheet (SWAAT). This understanding should narrow the operation window of the test thereby making the test more reproducible and reliable in its correlation with practical operating conditions. The second objective is to obtain a fundamental understanding of the possible metallurgical changes that may result in 
an enhanced corrosion performance in SWAAT. This fundamental understanding of the changes responsible for the improved corrosion performance should, if applicable, result in a change of the thermo-mechanical processing of cost effective alloys. These cost effective alloys with the modified processing should then have at least equivalent or better corrosion properties as the more expensive alloys used these days.

\subsubsection{Scientific aims of the project}

At first, a statistical and in-depth analysis of the critical parameters of the SWAAT should be performed. Although the SWAAT is being used in industry to evaluate materials and components, the statistical relevance can be questioned. This is mainly caused by the spread of the data obtained by the SWAAT [1]. At present time a thorough sensitivity analysis of the SWAAT has not been carried out and therefore no statement can be made on the influence of variations in the testing conditions on the corrosion performance of the materials and/or components. At the same time the initiation and corrosion mechanism of aluminium brazing sheet in SWAAT should be clarified. Some studies have been initiated in the past and present time to understand the resistance against SWAAT, but a fundamental knowledge on initiation and propagation of corrosion is still missing. In short the following questions will be addressed:

1. How reliable is the SWAAT test?

2. Which parameter or parameters are dominant and responsible for the observed variability?

3. With the obtained knowledge would it be possible to make the SWAAT test more statistically reliable?

Secondly, detailed understanding of the effect of alloy composition and microstructure as well as thermo-mechanical processing is still an enigma. Especially the change of performance of low cost alloys in SWAAT when processed differently proves to be critical. In depth knowledge of how these changes caused by processing alter the corrosion performance is crucial to allow production of cost effective alloys with sufficient mechanical and electrochemical properties in the near future. Processing can have a significant impact on the microstructure of the used alloys. The volume fraction, the size and the chemistry of precipitates change during processing. Also the distribution of precipitates near grain boundaries could have an impact since the change in the local alloy chemistry determines the local electrochemistry. A fundamental understanding of the correlation between microstructural features and the resulting electrochemical responses of aluminium brazing sheet materials needs to be achieved. This knowledge is expected to provide possibilities for improving the corrosion resistance of the material. 


\subsection{Research approach}

A schematic presentation of the approach in this research work is presented in Figure 1.3.

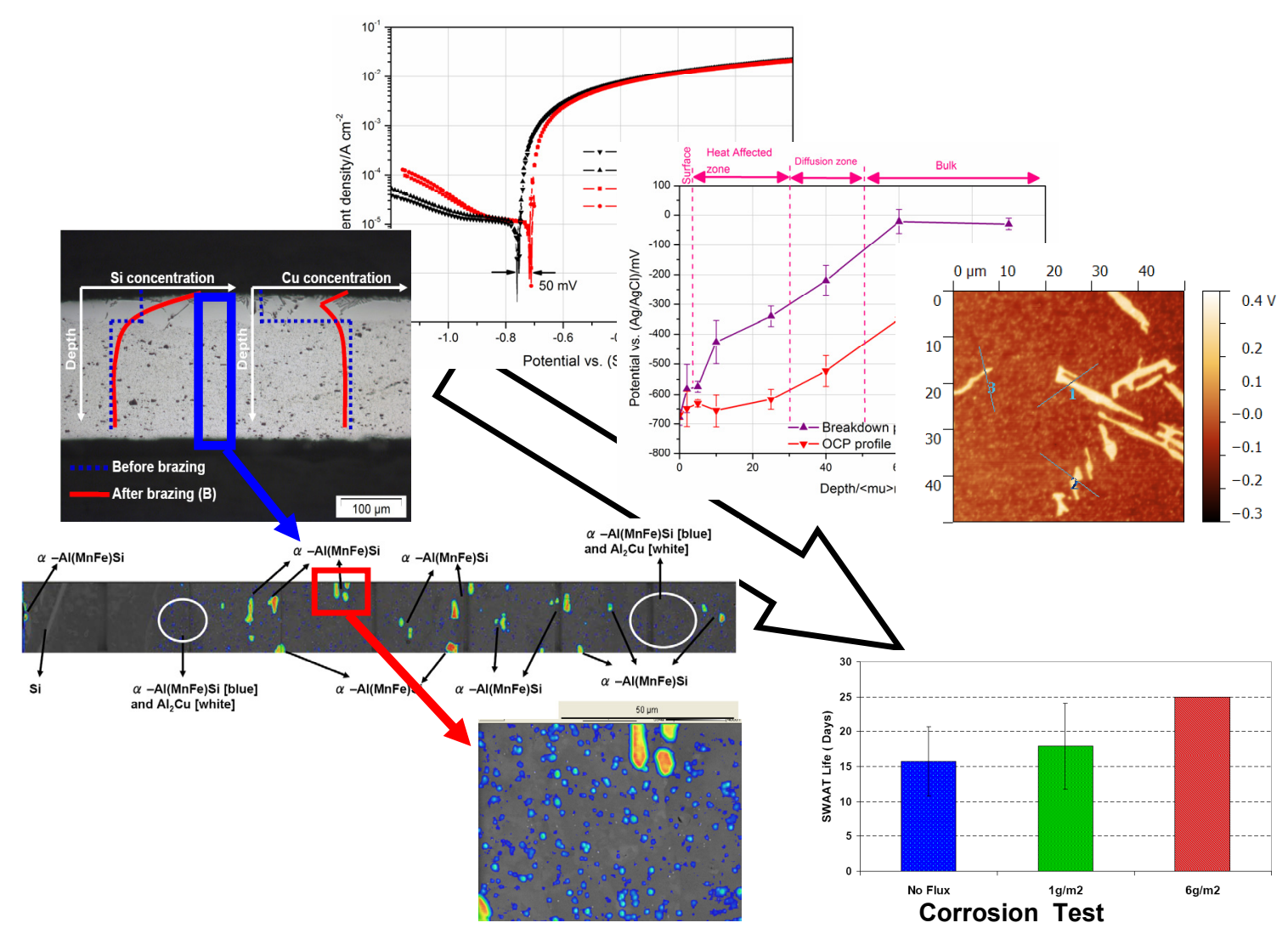

Figure 1.3. A schematic presentation of the research approach.

\subsubsection{SWAAT analysis}

The objective of this part of the research is to understand the reason for the variability of accelerated corrosion test results, and to develop a statistical approach for reliability analysis and interpretation of the SWAAT results. By keeping the climatic parameters (concentration of $\mathrm{NaCl}$, humidity cycle, temperature and $\mathrm{pH}$ ) constant, the correlation between the variation of the test results and the actual fundamental differences in the material condition i.e. temper and brazing condition will be elucidated. Parameters that potentially could influence the outcome of the SWAAT test will be investigated. The most dominant parameters are screened and examined according to industrial experiences. The results are used to narrow the operation window of the test and making it more reproducible and reliable. 


\subsubsection{Corrosion protection enhancement by microstructural control}

A full microstructural characterization of the material needs to be obtained. A complete electrochemical characterization of the structure at macro, localized and micro scales should be achieved and correlated to the microstructural features developed as consequences of brazing treatment. The results are used to explain the corrosion propagation mechanism through the structure of the brazed material and to investigate possibilities for improving the corrosion resistance of the brazed structure.

\subsection{Research outline}

The thesis consists of three parts:

- In part A investigation of the SWAAT test and the development of a statistical reliability evaluation and interpretation method are discussed.

- In part B a full microstructural characterization of the material is obtained. A complete electrochemical characterization of the material at macro, localized and micro scales are achieved and correlated to the microstructural features developed as consequences of brazing treatment.

- In part $\mathrm{C}$ an innovative technique for improving corrosion resistance of a modified AA4xxx/AA3xxx aluminium brazing sheet is developed.

Chapter 2 forms the first part (part A) of this thesis. In chapter 2 the reasons for the variability of accelerated corrosion test results are discussed. A statistical approach for reliability analysis and interpretation of the test results is developed. The presence of some interrelations between SWAAT and potentiodynamic measurements for aluminum brazing sheet is investigated.

Chapters 3-6 form the second part (part B) of this thesis. In chapter 3 the microstructure of an aluminium brazing sheet before and after a brazing process is characterized and correlated to the macro-electrochemical reactivities.

In chapter 4 the evolution of electrochemical responses through the aluminum brazing sheet is evaluated. The localized electrochemical reactivities are then correlated to the microstructural features developed due to the brazing process in the material. 


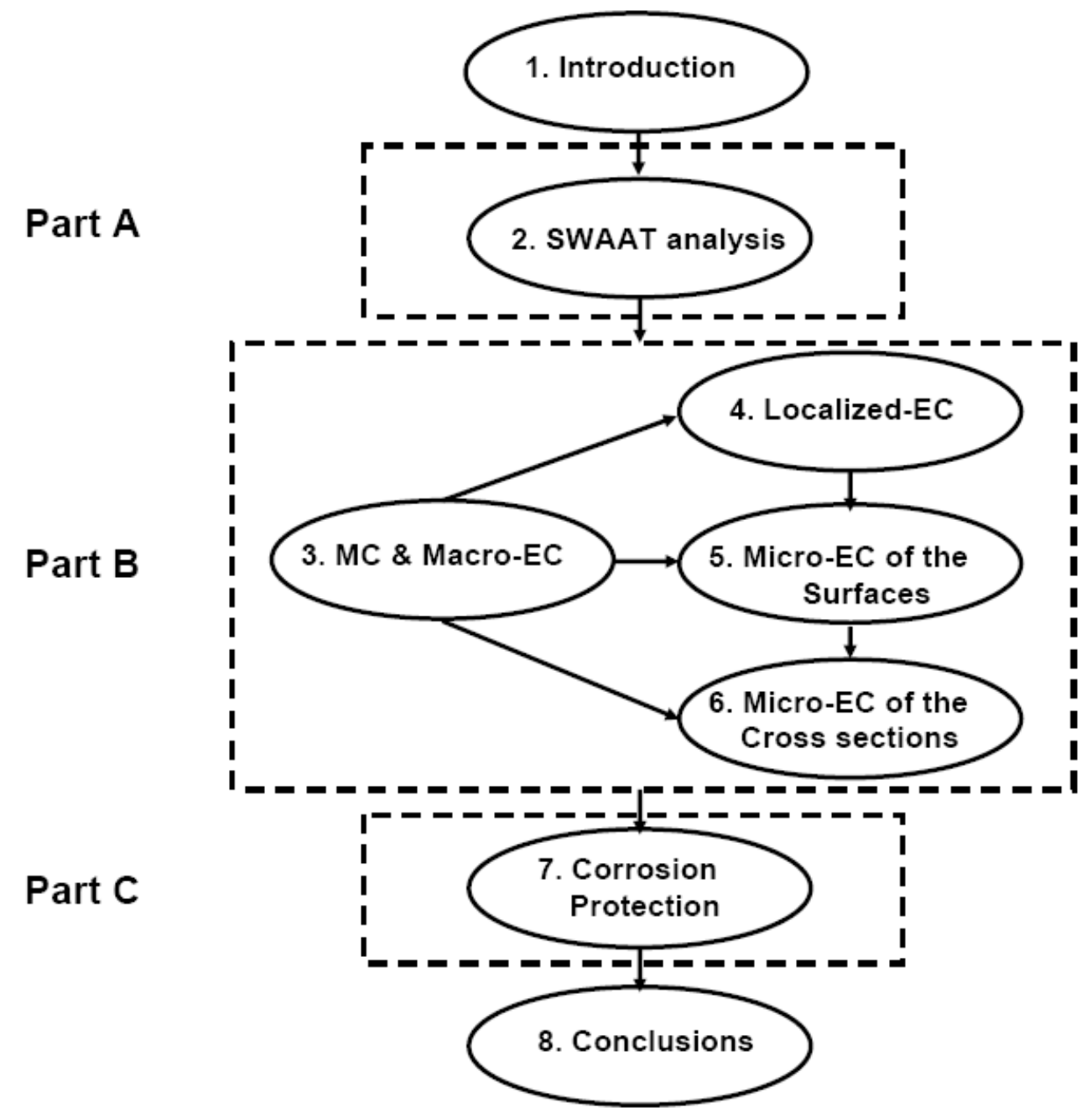

-- MC: Microstructural characterization

-- EC: Electrochemical characterization

Figure 1.4. Schematic structure of the thesis chapters.

In chapter 5 the suitability of the scanning Kelvin probe force microscope (SKPFM) analysis technique for corrosion performance prediction of aluminium brazing sheet material is investigated. The micro-electrochemical properties of the clad and the core surfaces of the material, developed during the brazing process are evaluated.

In chapter 6 the electrochemical nature of the overall microstructure and through depth microstructural heterogeneities of the brazing sheet is investigated. The electrochemical characterization is then correlated to the corresponding microstructural features. The results are used to explain the corrosion propagation mechanism through the structure of the brazed material and investigate possibilities for improving the corrosion resistance of the brazed structure.

Chapter 7 forms the third part (Part C) of this thesis. In chapter 7 the development of a proper post-braze heat treatment to improve the corrosion resistance of the 
aluminium brazing sheet is investigated. The proper temperature and timing range are defined. The changes in the microstructural features, electrochemical reactivities, corrosion resistance and corrosion attack mechanism of the post-braze heat treated structures are analyzed and discussed.

Finally chapter 8 will be a round up of the main findings and recommendations for future development and research on the corrosion behavior of aluminium brazing sheet material. 


\subsection{References}

[1]. S. Meijers, Corrosion of aluminium brazing sheet, PhD Thesis, TU Delft, 2002, ISBN 90-805661-3-6.

[2]. A. Wittebrood, Microstructural changes in brazing sheet due to solid-liquid interaction, PhD thesis, TU Delft, 2009, ISBN: 978-90-805661-6-3.

[3]. G.J. Marshall, A.J.E. Flemming, A. Gray, R. Liewellyn, Development of a long life aluminum brazing sheet alloy with enhanced mechanical performance, SAE Transactions: Journal of Materials and Manufacturing, 103 (1994) 292-300.

[4]. A. Gray, The growth of aluminium in automotive heat exchangers, Aluminium, 81 (2005) 197-201.

[5]. K. Takeuchi, Y. Isobe, T. Toyama, Current status and future of aluminum materials and brazing for automobile heat exchangers, Journal of Japan Institute of Light Metals, 48 (1998) 446-453.

[6]. O. Lunder, J. Lein, Pitting corrosion of aluminium heat exchanger tube materials, in: Proceedings from Aluminium Surface Science and Technology Conference, Beaune, 2006.

[7]. F. Birol, Y. Birol, M. Slamova, Corrosion behaviour of aluminium fin stock alloys, Material Science Forum, 402 (2002) 1511-1516.

[8]. A.C. Scott, R.A. Woods, J.F. Harris, Accelerated Corrosion Test Methods for Evaluating External Corrosion Resistance of Vacuumed Brazed Aluminium Heat Exchangers, SAE Paper No. 910590, 1991.

[9]. A.C. Scott, Corrosion Performance of Long-Life Automobile Radiators, SAE Paper No. 971857, 1997.

[10]. R. Rungta, G. Tomasov, Laboratory Testing of Automotive Evaporators for External Corrosion Durability in the Field, SAE Technical Paper C496/060/95, 1995.

[11]. M. Yoshino, M. Edo, S. Kuroda, M. Asano, K. Tohma, Effect of additional Si and $\mathrm{Cu}$ on strength and corrosion resistance of sacrificial anode fin stock for automotive heat exchangers, Journal of Japan Institute of Light Metals, 59 (2009) 229-235.

[12]. S. Iwao, M. Asano, Influence of heat treatment on corrosion resistance of aluminum alloy brazing sheet, Journal of Japan Institute of Light Metals, 57 (2007) 589-594.

[13]. Z. Connor, G. Murty, Recent improvements in aluminum brazing sheet for use in heat exchanger applications, especially radiator tube stock, SAE Transactions, Journal of Materials and Manufacturing, 114 (2006) 852-858.

[14]. M. Syslak, G. Stakkestad, J.D. Evensen, X.J. Jiang, S. Bjo, S. Bo, Brazing Sheet, Patent Number US6921584, 2002.

[15]. ASTM standard, Designation B 117, Standard Practice for Operating Salt Spray (Fog) Apparatus, 2009.

[16]. ASTM Standard, Designation G85, Standard Practice for Modified Salt Spray (Fog) Testing, 2006. 


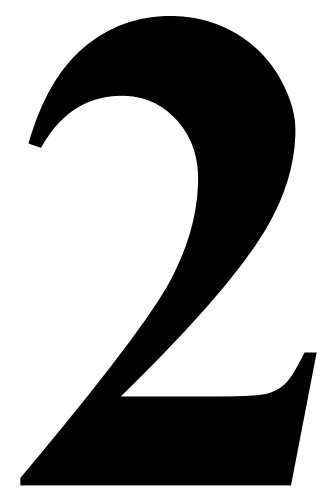

* This chapter has been published as a scientific paper:

F.N. Afshar, E. Szala, A. Wittebrood, R. Mulder, J.M.C. Mol, H. Terryn, J.H.W. de Wit, Influence of material related parameters in sea water acidified accelerated test, reliability analysis and electrochemical evaluation of the test for aluminium brazing sheet, Corrosion Science 53 (2011) 3923-3933. 



\section{Accelerated corrosion testing of aluminium brazing sheet}

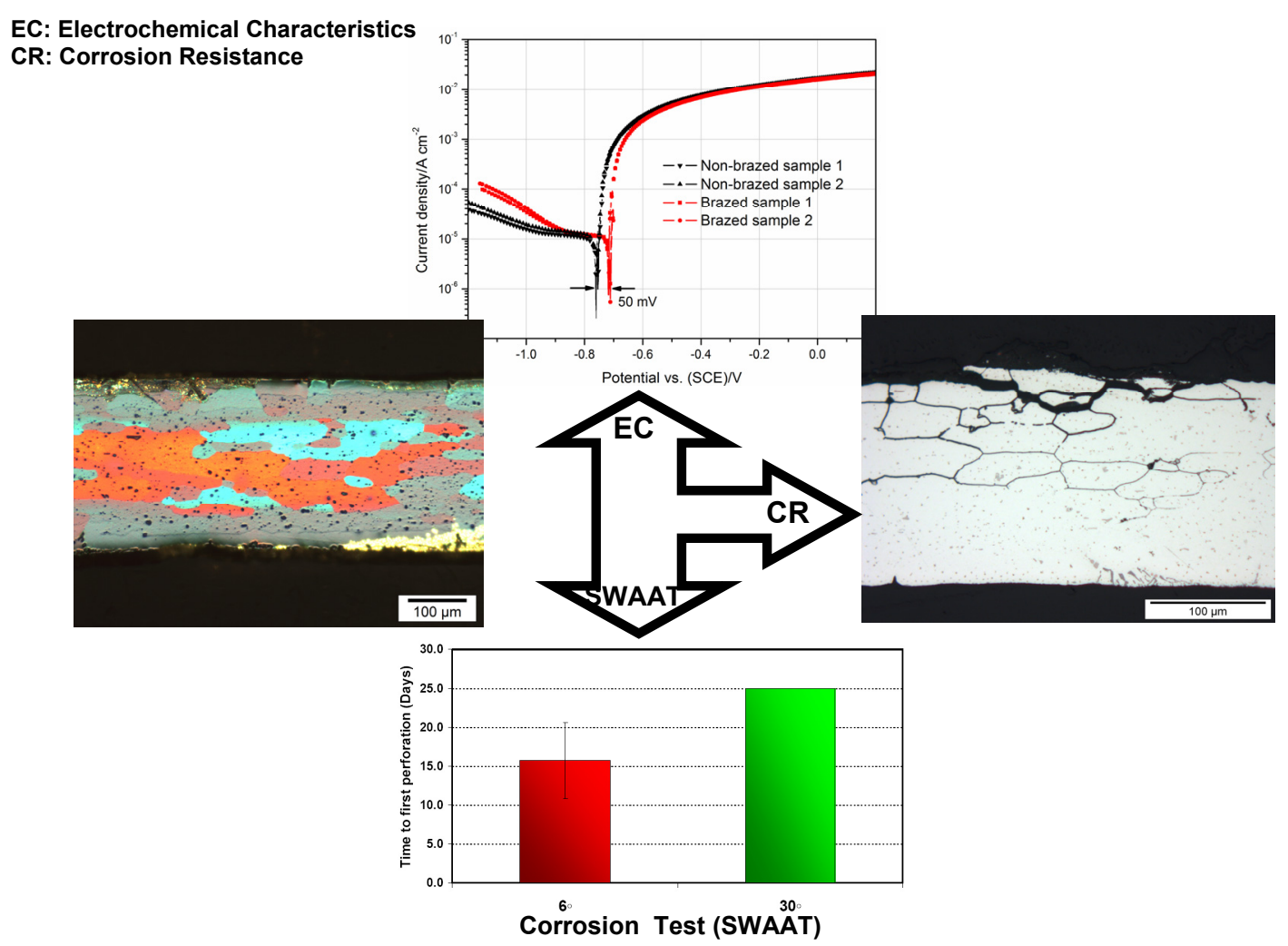

Abstract

The most common accelerated corrosion test used for aluminium brazing sheet is the Sea Water Acidified Accelerated Test (SWAAT). However, still some ambiguity exists, indicating that the test suffers from significant scattering of the results.

Keeping the climatic parameters constant, this study elucidates how the variations of the test results are material dependent. Applying a new statistical reliability evaluation and interpretation method, it was shown that the SWAAT test is valid for product performance comparison purposes. Comparing the corrosion mechanism and morphology of attack it was proved that the SWAAT performance of the material can be reflected in potentiodynamic responses. 


\subsection{Introduction}

The demands for reduction in fuel consumption and green house gasses have stimulated ongoing efforts towards the use of lighter and thinner materials in automobile industry [1-3]. Down gauging the aluminum sheet for heat exchangers is an important part of these efforts. Alloy development for down gauged heat exchangers focuses on higher strength in order to maintain the same overall strength of the heat exchanger, and at the same time keeping the other properties at least at the same level. One of these properties is the corrosion resistance [4,5]. Unfortunately there is no consensus in the literature about one specific accelerated corrosion test. There is no agreement either on how corrosion performance should be evaluated in accelerated testing, or how test and real lifetime should be correlated. One can look at the corrosion morphology as the most important factor [6,7] or rely on statistical correlation between test and service life [8]. Kaiser Aluminum [6] tried to compare corrosion morphologies of the field retrievals to various accelerated corrosion tests. From the study it followed that only the Sea Water Acidified Accelerated Test (SWAAT) was a reliable corrosion test. In a study by General Motors [8] several accelerated tests were considered and the salt/ $\mathrm{SO}_{2}$ as defined by ASTM G85 [9] was selected as the best representative test. They used time to perforation as test criterion, which was correlated to time to perforation of field service. They conclude that the mode of corrosion (pitting or intergranular) depends more on microstructure than on the environmental conditions. Yamauchi et al. [10] used four different accelerated tests to evaluate aluminium brazing sheet, but none was chosen as the best representative test. All tests were evaluated based on the maximum corrosion depth. The Dew test which was developed by Calsonic [11] is a very severe test and is based on pit depth measurement. Another developed test with an electrolyte with low conductivity was developed by Isobe et al. [12] and used time to perforation as the judgment criterion.

The most common way to measure the corrosion resistance of heat exchanger materials, both for tube and fin alloys is the so called Sea Water Acidified Accelerated Test (SWAAT) [13-17]. This is actually a modification of the standard salt spray test (ASTM B117) [18] in which specimens are exposed to a continuous spray of salt water $(5 \mathrm{wt} \% \mathrm{NaCl})$ of $35^{\circ} \mathrm{C}$. The standard salt spray test can be modified to four different procedures: Acetic Acid Salt Spray testing (AASS), Cyclic Acidified Salt Fog testing (CASF), SWAAT and Salt/SO $\mathrm{SO}_{2}$ spray testing. The details of each test can be found in the research work by Meijers [17]. The author also explains some other corrosion tests that are not described in standards, less used or are self developed because of dissatisfaction with existing tests. The apparatus for SWAAT testing consists of a fog chamber, a salt solution reservoir, a supply of suitably conditioned compressed air, atomizing nozzles, specimen supports, provision of heating the chamber and necessary means of control [9]. Considering the explanations made in the SWAAT related standards 
namely ASTM G85 and ASTM B117 [9,18]. Some experimental parameters such as size of the cabinet, positioning of different constituents, exposure zone temperature $\left(24-49^{\circ} \mathrm{C}\right)$, and $\mathrm{pH}$ range, specimen inclination $\left(15^{\circ}\right.$ and $\left.30^{\circ}\right)$ are not defined unambiguously. Combination of these open choices may affect the SWAAT results for any specimen.

Altmayer [19] claims that the corrosion mechanisms in the SWAAT test are oxygen concentration cell formation and galvanic effects, accelerated by the use of an electrolyte with chloride content of $5 \mathrm{wt} \%$ by weight, elevated temperature, fine-fog mist and inclination of the specimen. According to Scott [6], it is generally accepted that SWAAT test provides similar corrosion attack and morphology within a few days representative of several years of service life. However, there exist arguments that the test suffers from scattering of the results $[17,18]$. According to Meijers [17], as aluminium corrodes locally, small heterogeneities in the material may lead to different test results. According to ASTM B117 [18], reproducibility of results in the salt spray exposure is highly dependent on the type of the specimens and the evaluation criteria selected, as well as the control of the operating variables. Based on ASTM B117, variability is observed when similar specimens are tested in different fog chambers even though the testing conditions are nominally similar and within the ranges specified in this reference.

There are various material related parameters that can affect the SWAAT performance. Some of these parameters such as processing route and material gauges are directly related to the initial material condition and some others such as brazing temperature and flux load are related to the secondary metallurgical changes which are applied to the material during manufacturing processes. Fluxes and special atmospheres are designed to prevent oxide formation or to chemically reduce oxidation that occurs during initial heating. The primary function of the fluxes is to improve wetting of the base metal with the filler metal. Flux must be able to dissolve any oxide on the surface of the base metal after it has been cleaned and any oxides in the liquid filler metal. It is generally acknowledged that the presence of the residual flux layer formed during the brazing cycle gives improved air-side corrosion protection [20]. As any heat treatment of the material will produce related metallurgical changes which may result in different responses from the material, re-brazing may also be detrimental to some materials. In the production process, heat exchangers may be subjected to a second brazing cycle in order to pass the qualification test (leakage proof test).

The objective of this work is to understand the reason for the variability of accelerated corrosion test results, to develop a statistical approach for reliability analysis and interpretation of the test results and to investigate the presence of some interrelations between SWAAT and potentiodynamic measurements for aluminium brazing sheet. 
Keeping the climatic parameters (concentration of $\mathrm{NaCl}$, humidity cycle, temperature and $\mathrm{pH}$ ) constant, this study aims to elucidate how the variation of the test results are correlated to actual fundamental differences in the material condition of the aluminum brazing sheet i.e. temper and brazing condition. A number of parameters have been investigated that potentially could influence the outcome of the SWAAT test. The most dominant parameters are screened and examined according to industrial experiences. The results are used to narrow the operation window of the test and making it more reproducible and reliable.

\subsection{Experimental}

\subsubsection{Material}

A4 size plates were cut from a rolled long life AA3xxx aluminium alloy $(240 \mu \mathrm{m}$ thick) claded on both sides with an AA4xxx (30 $\mu \mathrm{m}$ thick) and in H24 temper condition. The bulk chemical analysis of the clad and the core materials was obtained with X-Ray fluorescence analysis (XRF). PW2400 equipment with a Rhodium anode and $60 \mathrm{kV}$ acceleration voltage was used. The data was analyzed with UniQuant software and is presented in Table 2.1.

Table 2.1. Chemical composition (wt \%) of the AA3xxx (core) and AA4xxx (clad) material.

\begin{tabular}{cccccccc}
\hline & $\mathrm{Si}$ & $\mathrm{Fe}$ & $\mathrm{Cu}$ & $\mathrm{Ti}$ & $\mathrm{Mn}$ & $\mathrm{Mg}$ & $\mathrm{Al}$ \\
\hline Clad & 10.96 & 0.14 & 0.38 & 0.01 & 0.12 & - & Bal. \\
Core & 0.08 & 0.19 & 0.83 & 0.07 & 0.75 & 0.21 & Bal. \\
\hline
\end{tabular}

\subsubsection{Brazing procedure}

The plates were properly cleaned ultrasonically in ethanol. A baseline material (Variant 1) was defined to be the alloy (300 $\mu \mathrm{m}$ thick, H24 temper condition), brazed in a controlled atmosphere furnace without flux. Controlled atmosphere brazing (CAB) is brazing in a dry, inert gas atmosphere. Mostly nitrogen is used. The brazing cycle that was applied is shown in Figure 2.1. The material is heated up to $600{ }^{\circ} \mathrm{C}$ and is kept at that temperature for 3 minutes and is then cooled down with a specified ramp $\left(60{ }^{\circ} \mathrm{C} / \mathrm{min}\right)$. The holding temperature was selected close to the liquidus temperature of the clad material, reported as $612{ }^{\circ} \mathrm{C}$, while far below the solidus temperature of the core material which is about $640^{\circ} \mathrm{C}$.

\subsubsection{Variants specifications}

Seven variants were defined. Each variant corresponds to an A4 size plate modified with respect to the baseline material. The detailed explanation of these 
variants is specified in Table 2.2. All the plates were brazed in a CAB cycle process.

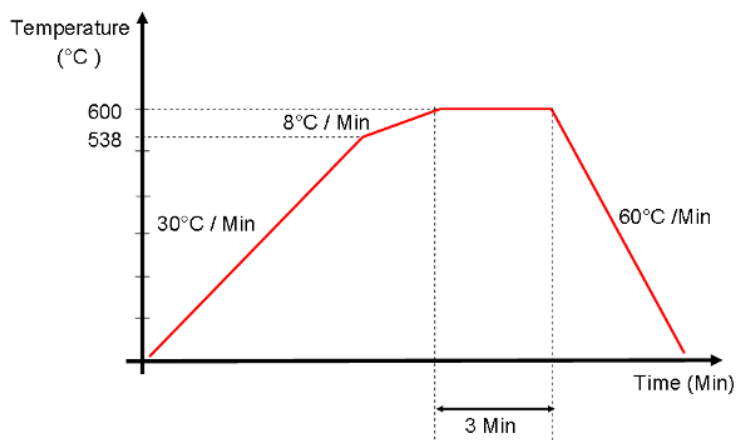

Figure 2.1. Standard controlled atmosphere brazing (CAB) thermal cycle.

Table 2. Specification of different variants.

\begin{tabular}{ccc}
\hline $\begin{array}{c}\text { Variant } \\
\#\end{array}$ & Influencing factor & $\begin{array}{c}\text { Specification (changes with respect to the } \\
\text { baseline material) }\end{array}$ \\
\hline 1 & Baseline & Baseline material \\
2 & Flux load & Brazed $\left(1 \mathrm{~g} / \mathrm{m}^{2}\right.$ flux $)$ \\
3 & Flux load & Brazed $\left(6 \mathrm{~g} / \mathrm{m}^{2}\right.$ flux $)$ \\
4 & Gauge & Thickness $250 \mu \mathrm{m}$ \\
5 & Material temper & O-temper $\left(1 \mathrm{hr}\right.$ at $\left.300^{\circ} \mathrm{C}\right)$ \\
6 & Brazing temperature & Brazed @ $591^{\circ} \mathrm{C}$ \\
7 & Re-brazing & Re- brazed@ $600^{\circ} \mathrm{C}$ \\
\hline
\end{tabular}

\subsubsection{SWAAT procedure}

SWAAT samples of $50 \times 100 \mathrm{~mm}^{2}$ were used. The back side was covered with $3 \mathrm{M}$ Scotch brand tape M470, and the edges were protected with bee wax. The samples were placed in the cabinet, tape side down, at an angle of $15^{\circ}$ and assessed every $24 \mathrm{~h}$ for blisters on the taped side, indicating perforation. The number of days till the first perforation was defined as the SWAAT life. The maximum time for the test was considered to be 25 days.

The test comprises a repetitive two hours cycle consisting of 30 min spray followed by a 90 min soak at above $98 \%$ humidity [9]. The spray is a solution of $42 \mathrm{gr} / \mathrm{l}$ of sodium chloride and is acidified with $10 \mathrm{ml} / \mathrm{l}$ of glacial acetic acid. The $\mathrm{pH}$ is then adjusted with $10 \mathrm{wt} \% \mathrm{NaOH}$ solution to a value between 2.8 and 3.0 [9]. The temperature during spray and soak was kept constant at $49{ }^{\circ} \mathrm{C}$.

SWAAT samples were accurately prepared, numbered and tested in a Q-Fog 
cabinet. During the experiment, the conditions inside the cabinet were kept constant. Regular displacement of the samples in the racks and through the cabinet made sure that all the samples inside the cabinet experienced the same corrosive environment (climatic condition).

\subsubsection{Statistical analysis}

10 SWAAT samples per variant were tested. The required number of samples is dependent on the confidence level of interest. The confidence level indicates the reliability of the estimation that is made. The population mean $(\mu)$ with a given confidence level can be calculated according to Eq. (2.1) in which $\mathrm{n}$ is the number of observations, $\mathrm{S}$ is the standard deviation, $\mathrm{t}$ is a constant depending on the number of observation and the confidence level and $y$ is the sample mean [17]:

$$
\mu=y \pm t s \sqrt{\frac{1}{n}}
$$

In the context of this work $\mathrm{n}=10$ (number of samples per variant) and a confidence level of $99 \%$ was applied. The constant number $t$ can be read from available statistical tables and for 10 samples and $99 \%$ of confidence, is 3.17 [21]. Considering the values for $\mathrm{n}$ and $\mathrm{t},(\mathrm{n}=10$ and $\mathrm{t}=3.17)$ we have

$t \sqrt{\frac{1}{n}}=1$

Applying Eq. (2.2) in Eq. (2.1), any calculated population mean $\mu$, with $99 \%$ confidence, is within the $[y-s, y+s]$ range. The minimum value in this interval $(y-s)$ is suggested to be considered as the basis for any comparison in the SWAAT results. In this research this is referred to as the minimum SWAAT performance. It should be noted that considering the application of these materials (heat exchanger industry) it is the minimum SWAAT performance of the material that has the most importance and is needed to be used for comparison purposes. In this way the presence of a large standard deviation may no longer raise the problem of reliability of SWAAT comparisons. The average life performances of the samples from each variant were calculated and presented in column charts.

In order to develop an understanding over the statistical reliability of the SWAAT test and to generate a statistical interpretation of the results three statistical testing methods have been applied.

For the pair-wise comparison between variants the sign test [22] also known as median test were applied. The test is based on determination of the overall median in the merged set of measurements of two variants (i.e. $2 \times 10=20$ measurements 
in current research) and counting for one variant the number of measurements below their common mean (for example only 2). The test continues with calculating the probability that this or a more extreme number of measurements (in this example the probability of 0,1 or 2 measurements) to be less than the common median under the assumption that the measurements have a common median. These probabilities were calculated. Probability values less than 0.1 are considered as low values and interpreted as the two variants do not come from a distribution with the same median. This means there is a statistical significant difference between the two set of measurements (SWAAT life) and the variants can be distinguished and compared.

In order to make sure that the results of the analysis is not sensitive to the applied statistical test method Pair-wise comparison between variants with the Ranksum (Wilcoxon) [22] test was also performed. In this method a rank number is given to each value in the merged set of measurements (smallest value $=1$, largest value $=$ 20 in present work). The sum of the ranks for one variant is calculated and the probability that this rank sum may achieved is calculated. These probabilities have the same meaning as in the sign test.

Applying Cochran-Mantel-Haenszel test [22], the reliability of the SWAAT for material life performance prediction was checked. The number of perforations after a fixed period of time ( 25 days) was used as the bases for the calculation. The question of reliability of the test was linked to whether the samples can be considered to come out from the same population, given the total number of perforations for each variant and the way that they have been distributed among samples. The answer of this question for each variant was calculated as probabilities.

\subsubsection{Potentiodynamic polarization}

Using a potentiostat and a three-electrode electrochemical cell, potentiodynamic polarization measurements were performed. Considering the emphasis of this research work on corrosion performance and morphology of the aluminium brazing sheet, the anodic polarization responses of the materials have been measured and investigated. The working electrodes (samples) were circular plates with a diameter of $2 \mathrm{~cm}$. The reference electrode was a saturated calomel electrode (SCE) and the counter electrode was Pt. The SWAAT solution was chosen as the applied electrolyte. The samples were scanned in the potential range between 10 $\mathrm{mV}$ below and $1.3 \mathrm{~V}$ above the open circuit potential of each variant. The scans started after 15 minutes of open circuit potential measurement. A scan rate of 0.5 $\mathrm{mV} / \mathrm{s}$ was applied. The reproducibility of the test results were checked by two times repetition of each experiment.

\subsubsection{Sample preparation and optical microscopy}


Cross sections of each variant after SWAAT and potentiodynamic polarization were prepared, ground and polished down to $1 \mu \mathrm{m}$. Optical images were taken from the polished surfaces. In addition polarized light optical microscopy after 2 min etching in Barker solution at $20 \mathrm{~V}$ was performed.

\subsection{Results}

Optical images of the material under investigation both before and after brazing are shown in Figure 2.2.
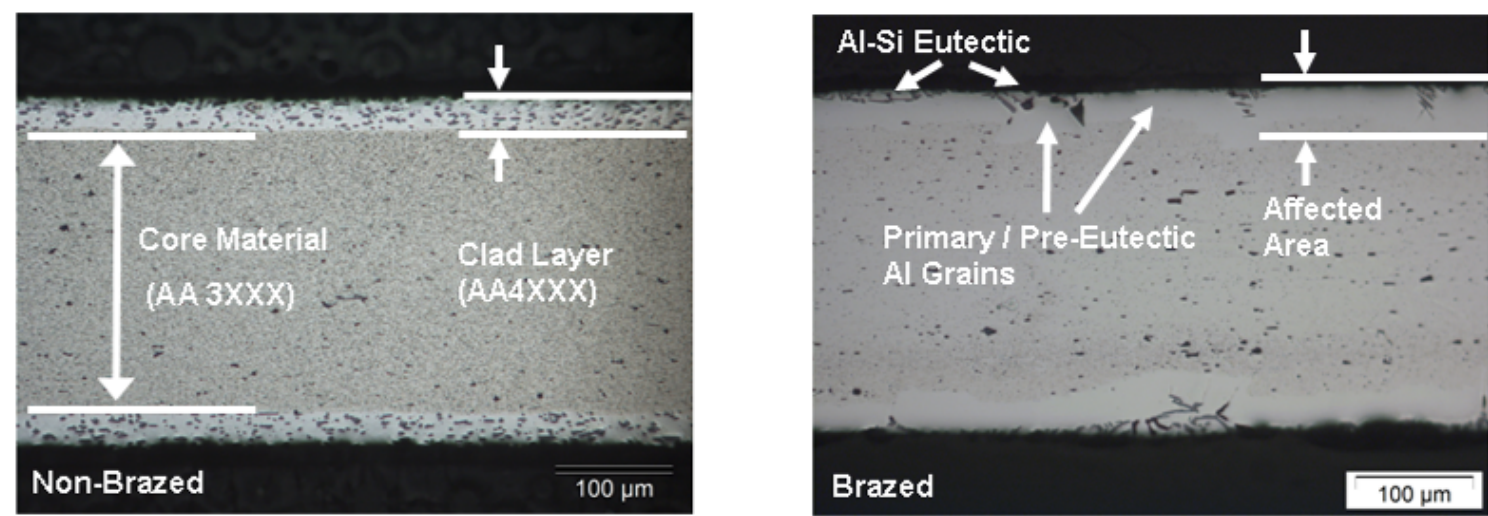

Figure 2.2. Optical images of the brazing sheet structure before and after brazing.

The image of the material before brazing shows the clad layer with brighter contrast. Elongated coarse particles with a dark gray contrast in the clad layer are $\mathrm{Si}$ particles. In the core material a wider variety of particles exists with different size and chemical composition.

At brazing temperature the liquid clad is in intimate contact with the solid core material. During this stage where the two phases co-exist, an interaction between the two can take place. This interaction is explained in detail by Wittebrood [23]. According to Schmatz et al. the liquid originating at the clad core interface progresses into the core alloy as a film, changing the element distribution on its way [24]. This area is the affected area which has been designated in Figure 2.2. The area is free from precipitates. The Al-Si eutectic phase is shown to be accumulated at the surface and in between the pre-eutectic aluminium grains.

The average life performances of the samples for all variants in the SWAAT are presented in Figure 2.3. Standard deviation for each of the variants is calculated and shown as error bars on top of the columns. The column without error bar is representative of samples from variant 3 (brazed with $6 \mathrm{~g} / \mathrm{m}^{2}$ flux) which did not fail after the maximum test duration of 25 days. Figure 2.3 shows that there exist standard deviations of 5-6 days for most of the variants. 


\section{SWAAT LIFE}

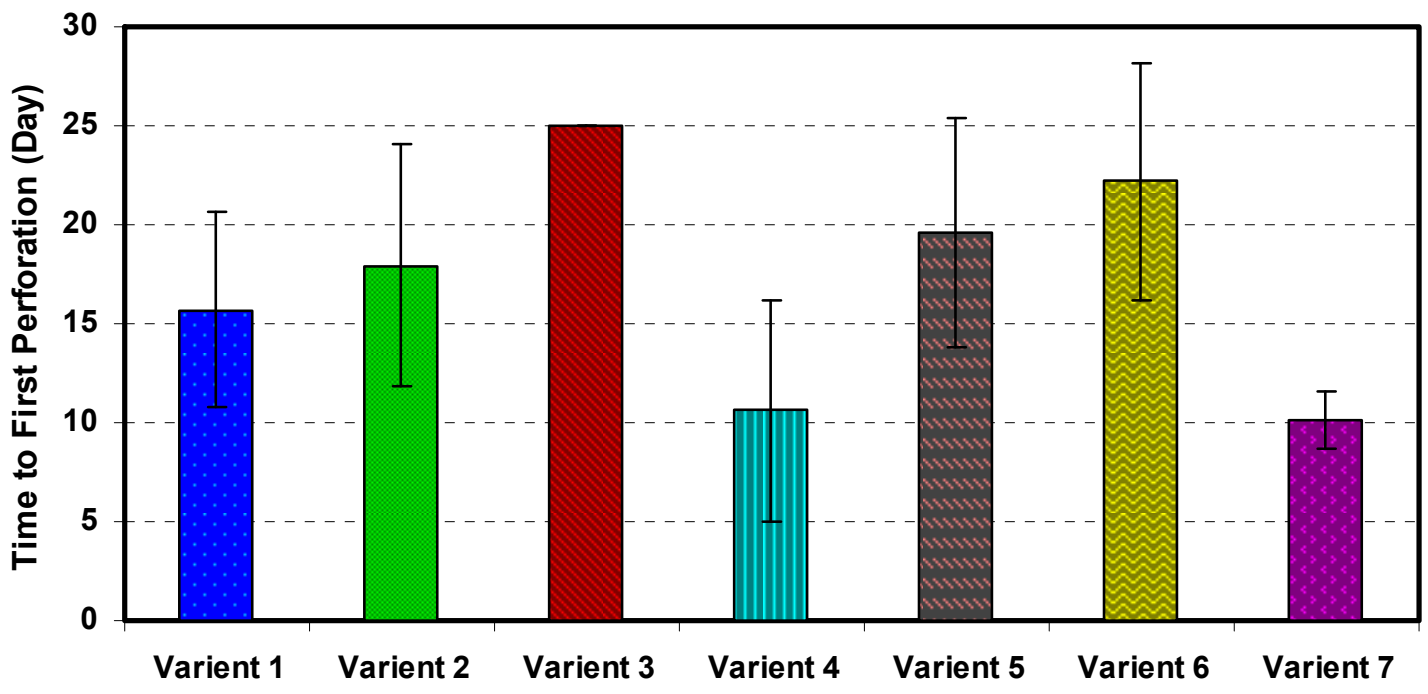

Figure 2.3. Average lifetime performances of the 10 samples in each variant in SWAAT.

In order to develop an understanding over the detailed performance of the samples, the baseline material (variant 1) was chosen and the SWAAT performance of all its samples is shown in Figure 2.4. It can be seen that $80 \%$ of the samples show close life performances within \pm 2 days deviation.

\section{Variant 1}

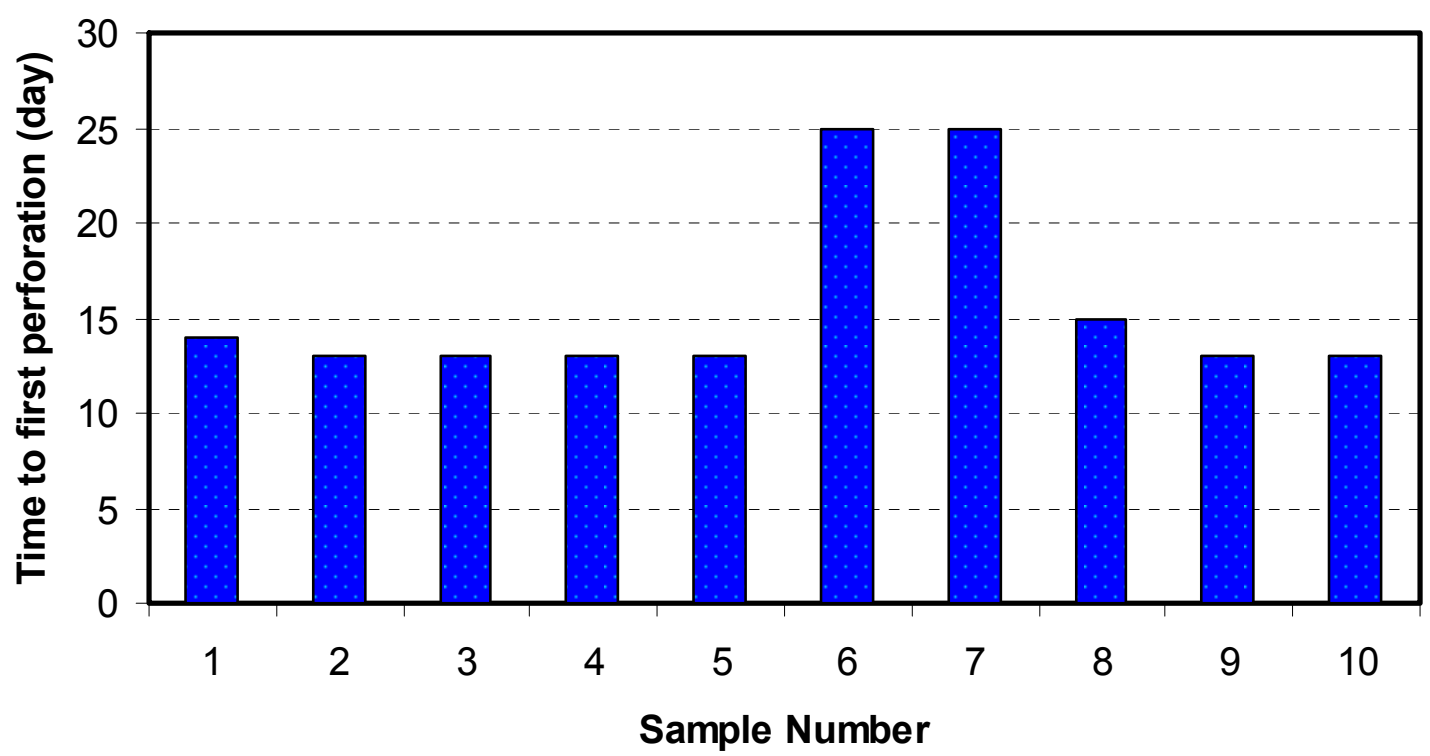

Figure 2.4. SWAAT performance of samples from variant 1. 
During the study, it was also observed that in most of the samples from each variant, there was not a continuous increase in the number of blisters after the initial perforations. Increasing the size of the blisters was observed but the number of the blisters did not change for a noticeable time afterwards. As a representative example the perforation profiles for variant 1 are shown in Figure 2.5.

SWAAT Performance

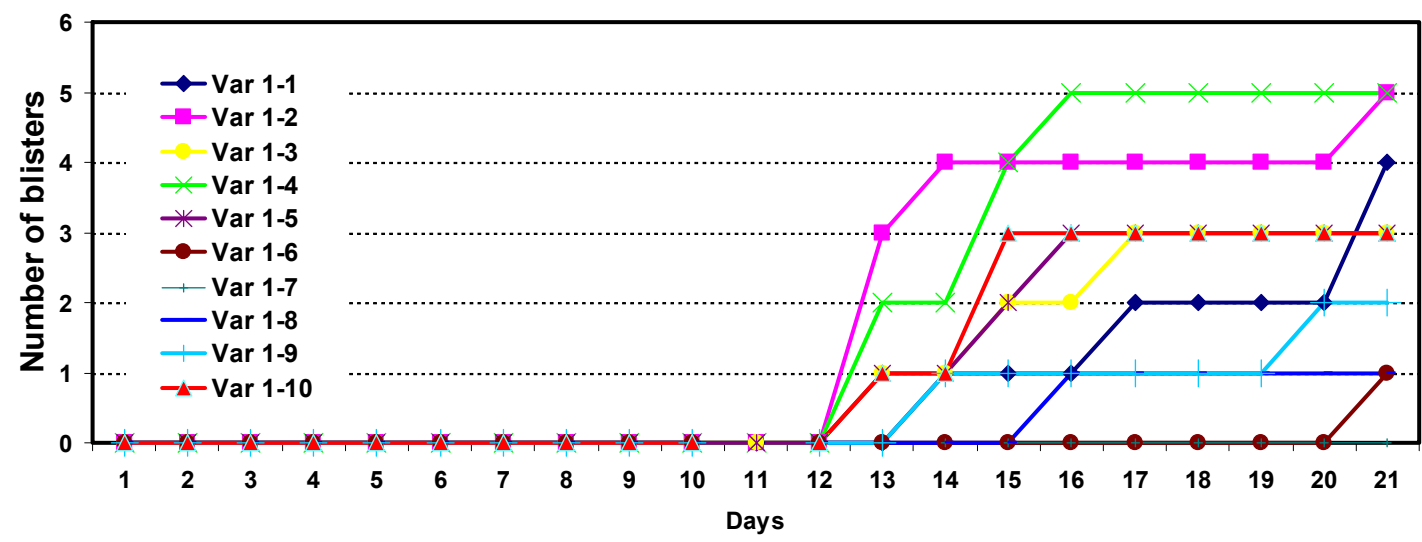

Figure 2.5. Blister development profiles during the SWAAT for the samples in variant 1.

At this stage the SWAAT performance of each variant was compared with the baseline (variant1) material. The electrochemical validity of the existing differences was checked by potentiodynamic measurements with which the electrochemical response from each material was compared with that of the baseline material.

\subsubsection{Gauge influence}

The gauge influence on corrosion performance was investigated by comparing the results of variants 1 and 4 which are shown in Figure 2.3. The corrosion resistance drops with decreasing gauge of these alloys. Figure 2.3 shows a decrease of 5 days in the average SWAAT performance of the material as the thickness decreases from 300 to $250 \mathrm{~mm}$. This indicates that the reduction in the minimum life performance of the material $(40 \%)$ is not proportional with the reduction in thickness $(17 \%)$.

Potentiodynamic polarization curves for variant 1 and 4 are shown in Figure 2.6. The polarization curves for the baseline material shows that immediately after the OCP a strong increase in the current density is observed corresponding to the breakdown of the material by a relatively rapid initiation and propagation of localized corrosion. Comparing with the baseline material, the electrochemical response of the down gauged material is similar. 


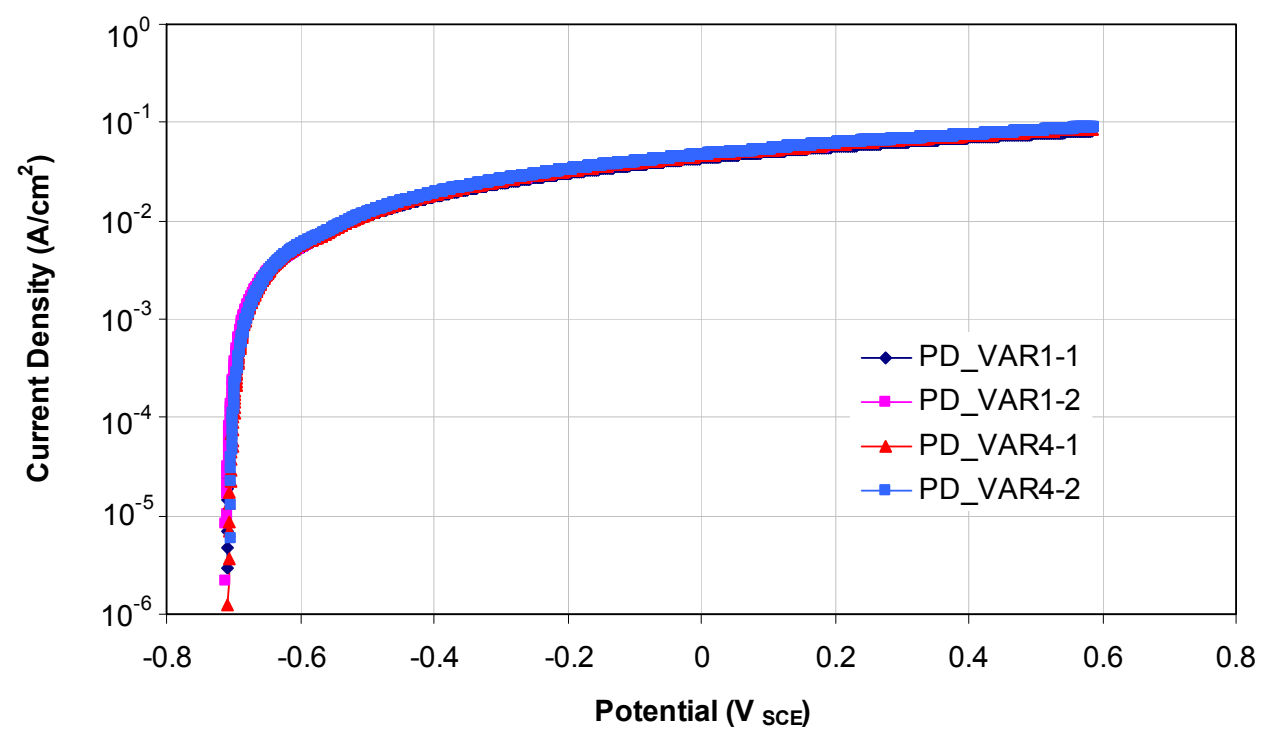

Figure 2.6. Potentiodynamic polarization curves for the baseline and the down gauged material.

\subsubsection{Influence of tempering}

The influence of temper on SWAAT life was investigated by comparing the SWAAT results for variants 1 to 5 . Keeping the baseline material at $300^{\circ} \mathrm{C}$ for 1 hour an O-temper condition variant was made. The pre-brazed structure of the baseline material (variant 1) and material in O-temper condition (variant 5) are presented in Figure 2.7.

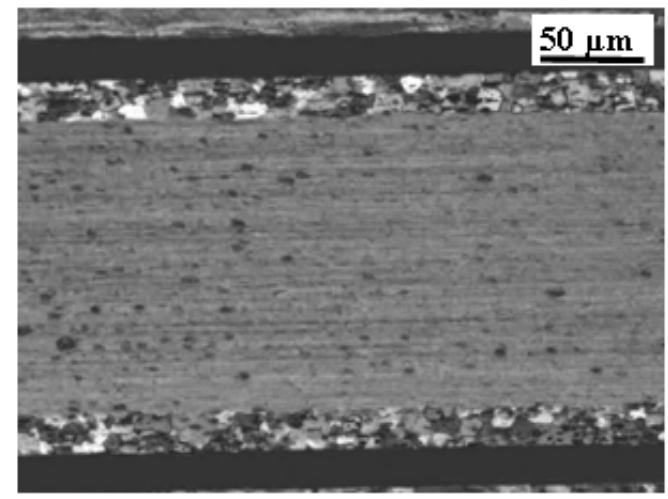

(a) H24 temper AA3xxx alloy

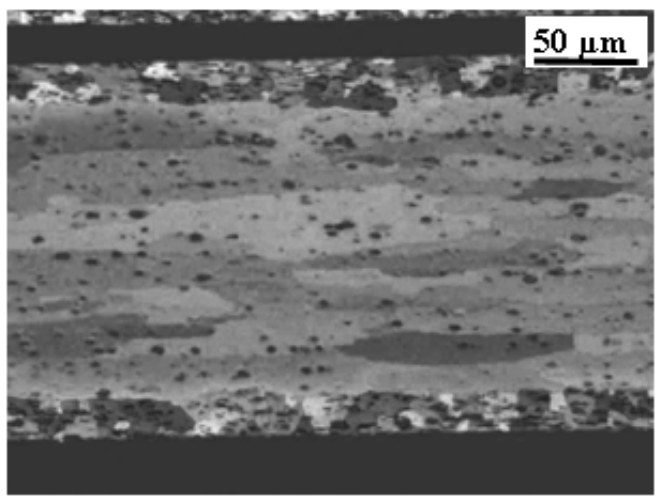

(b) O-temper AA3xxx alloy

Figure 2.7. Microstructure of AA4xxx/AA3xxx/AA4xxx material in $\mathrm{H} 24$ and $\mathrm{O}$ temper conditions.

The non-homogenized, H24-temper material with elongated grains has been changed to the structure of a non-homogenized, O-temper with coarser grain 
structure. The SWAAT life results are given in Figure 2.3. The results show that the minimum life performance of the material has increased by 2 days as the tempering condition is changed from $\mathrm{H} 24$ to O-temper.

Comparison of the potentiodynamic polarization responses for material in Otemper condition with the base line material does not show any significant difference. This result is shown in Figure 2.8.

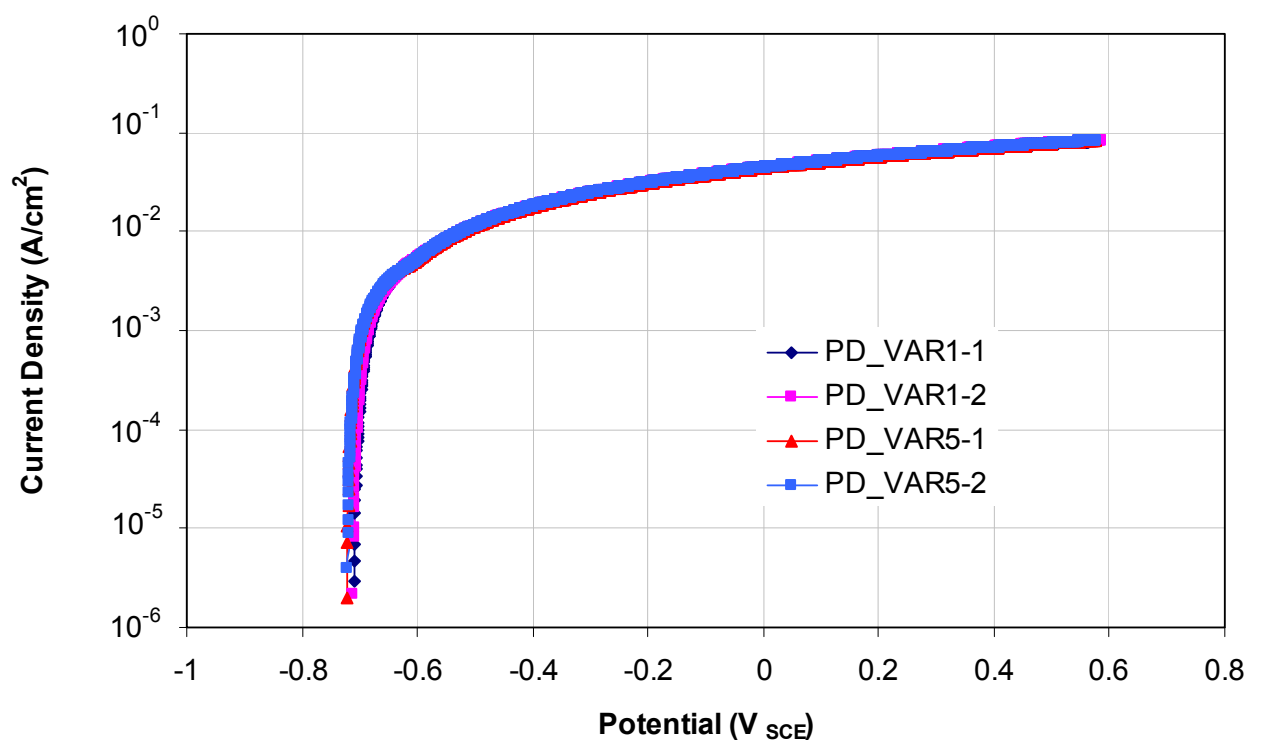

Figure 2.8. Potentiodynamic polarization curves for the baseline and the O-temper material.

\subsubsection{Temperature effect}

Brazing temperature effect has been studied by comparison of the baseline material with variant 6 . The results are shown in Figure 2.3. The figure shows that as the temperature of the brazing decreases by $9^{\circ} \mathrm{C}$ the minimum life performance of the material in SWAAT will increase by $40 \%$.

The electrochemical responses for the material brazed at $591^{\circ} \mathrm{C}$ and the baseline material are compared in Figure 2.9. The two materials do not show any distinguishable difference in their potentiodynamic result. 


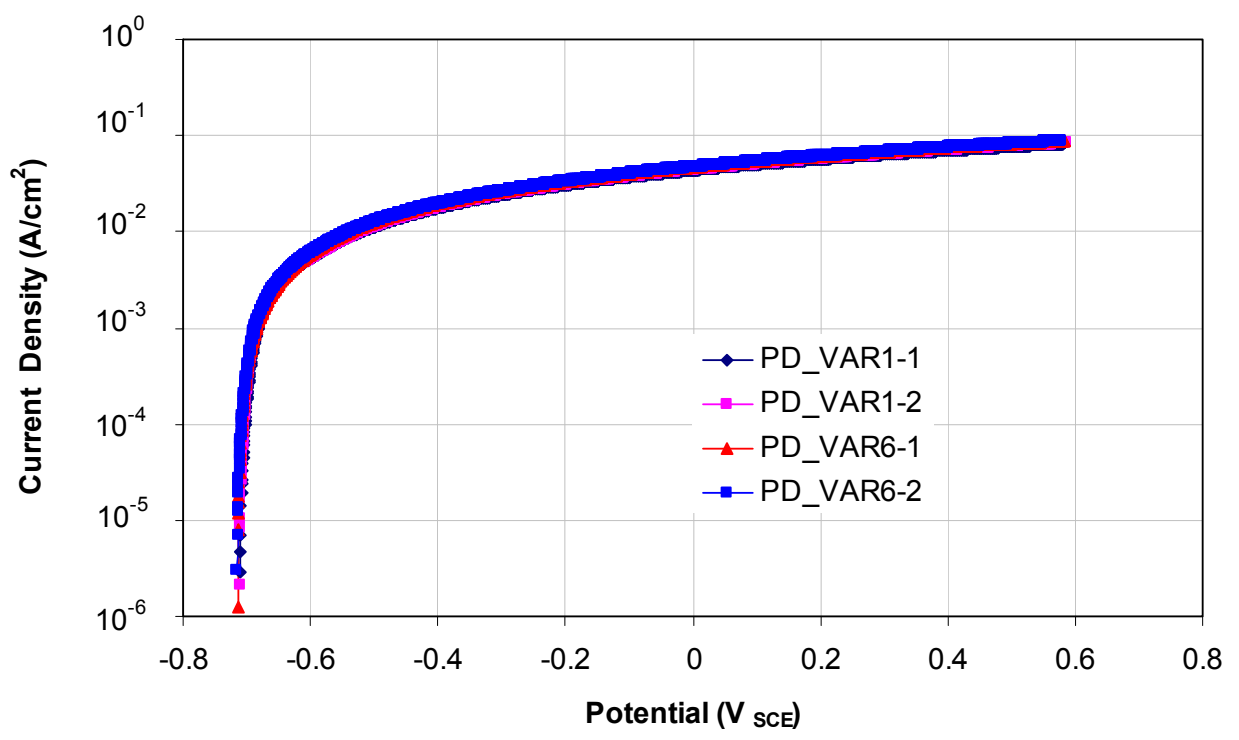

Figure 2.9. Potentiodynamic polarization curves for the baseline and the material brazed at $591{ }^{\circ} \mathrm{C}$.

\subsubsection{Effect of flux load}

Effect of flux load was investigated by comparison between the results from baseline material and variants 2 and 3. Incremental increase of the flux load was applied. The results are shown in Figure 2.3. The figure shows that applying flux has improved the corrosion performance of the material. The minimum life performance of the baseline material has increased by 1 and 13 days, applying 1 $\mathrm{g} / \mathrm{m}^{2}$ and $6 \mathrm{~g} / \mathrm{m}^{2}$ of flux respectively.

Potentiodynamic polarization curves for base line material, material with $1 \mathrm{~g} / \mathrm{m}^{2}$ and $6 \mathrm{~g} / \mathrm{m}^{2}$ are shown in Figures 2.10 and 2.11 respectively. Comparing with the baseline material, the presence of 100 and $150 \mathrm{mV}$ potential difference between the OCPs in Figure 2.10 and $210 \mathrm{mV}$ in Figure 2.11 and the presence of an extra break down potential for fluxed materials are noticeable. The repetition of the result for the material with $1 \mathrm{~g} / \mathrm{m}^{2}$ in Figure 2.10 shows a discrepancy of $50 \mathrm{mV}$. 


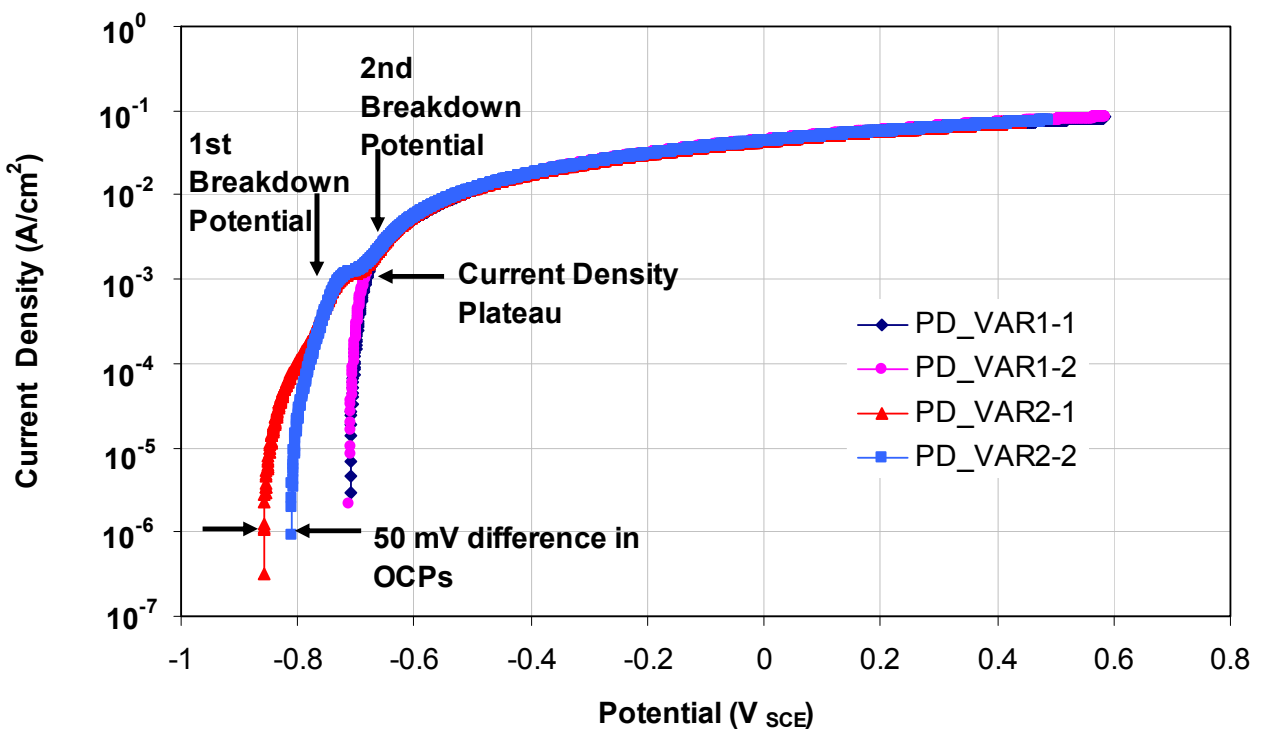

Figure 2.10. Potentiodynamic polarization curves for the baseline and the $1 \mathrm{~g} / \mathrm{m}^{2}$ fluxed material.

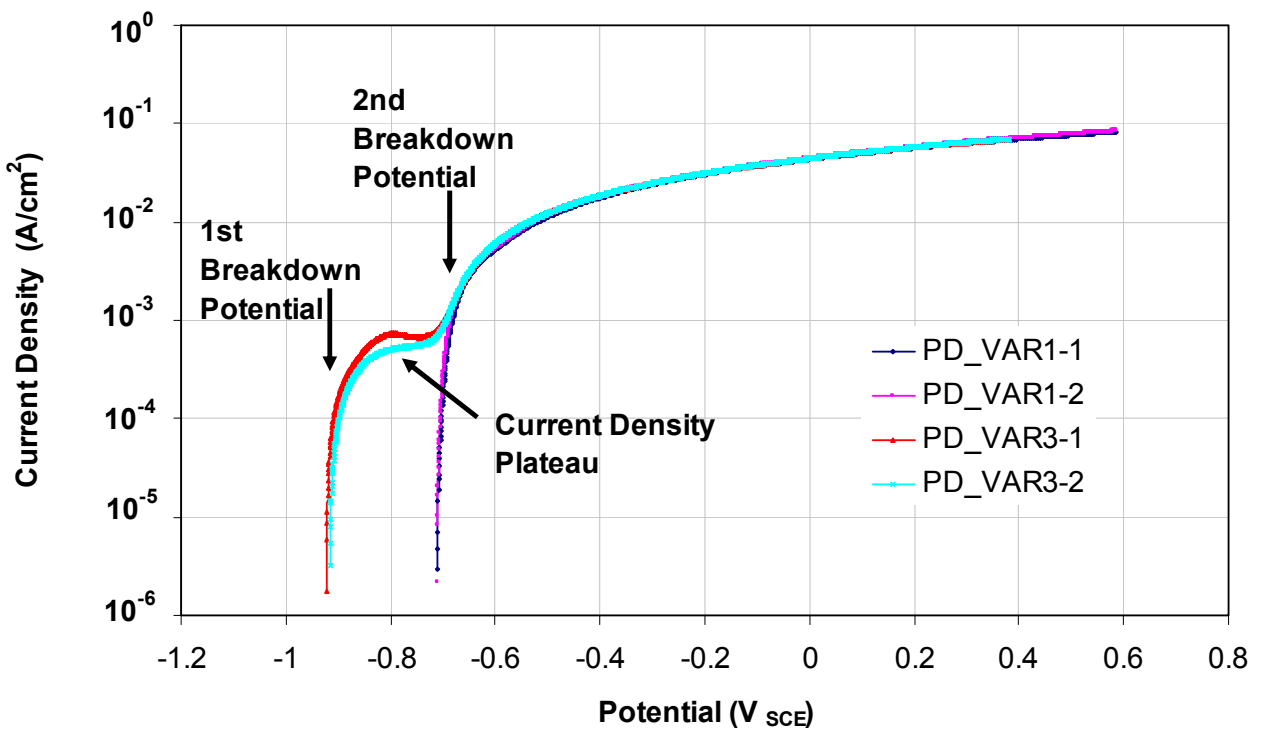

Figure 2.11. Potentiodynamic polarization curves for the baseline and the $6 \mathrm{~g} / \mathrm{m}^{2}$ fluxed material.

\subsubsection{Effect of re-brazing}

The re-brazing effect was investigated by applying an extra brazing cycle on the baseline material. The life performance of the baseline material and the re-brazed material (variant 7) is shown in Figure 2.3. According to the result applying an extra brazing cycle (re-brazing) has caused a reduction of $18 \%$ (from 11 to 9 days) in the minimum life performance of the material. 
Comparing the potentiodynamic polarization responses for the re-brazed material with the base line material does not show any significant difference. This result is shown in Figure 2.12.

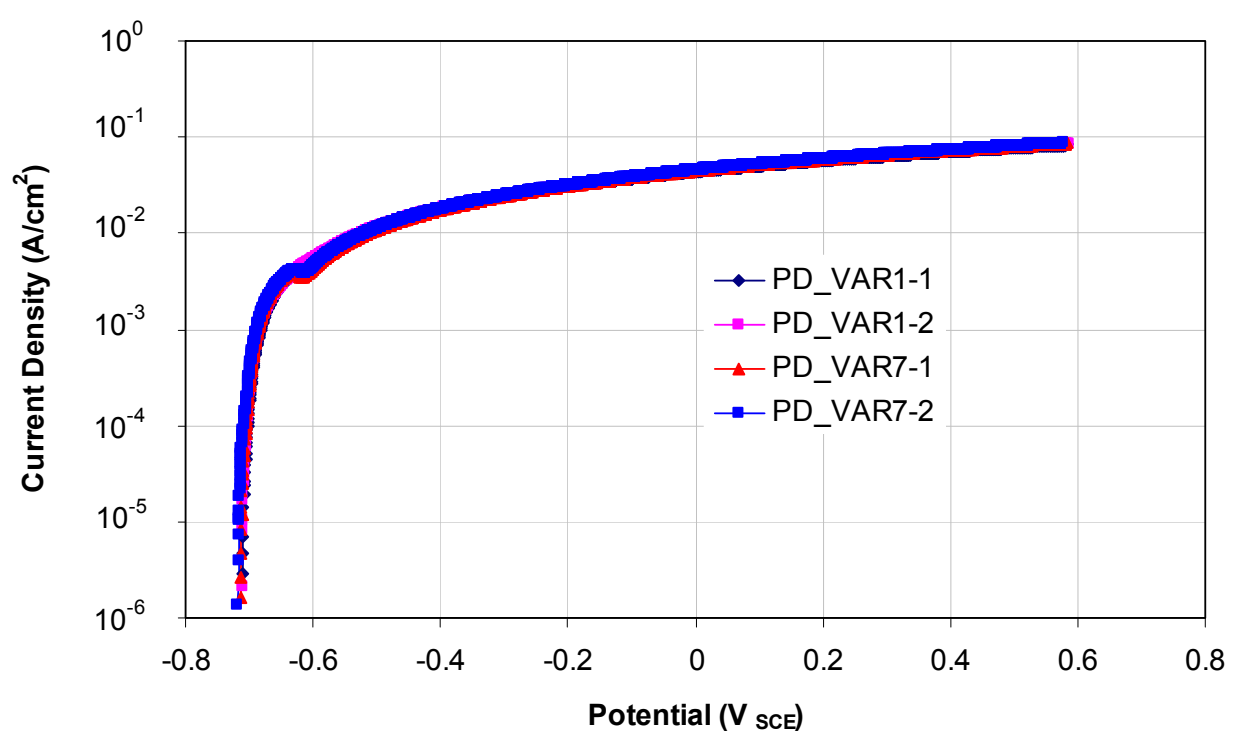

Figure 2.12. Potentiodynamic polarization curves for the baseline and the rebrazed material.

\subsubsection{Comparison of corrosion mechanism in SWAAT and potentiodynamic experiments}

In order to confirm the validity of any comparison between the SWAAT performance and potentiodynamic tests, the corrosion mechanism in both types of experiments were studied. Optical micrographs from the cross-sectional analysis of the samples after SWAAT and potentiodynamic test were investigated. The results for all the variants show that the corrosion mechanism in SWAAT and potentiodynamic tests is similar. These optical micrographs for variants 1,2 and 3 are shown in Figure 2.13. The rest of the variants were found to show a quite similar morphology of attack as that of the base line material. The micrographs of variant 2 and 3 after the potentiodynamic experience shows less dissolution of the clad material comparing to the baseline material. This phenomenon is less evident in micrographs after the SWAAT test.

In both potentiodynamic and SWAAT the corrosion starts with intergranular attack on the clad material. The dissolution of the grains in clad material is the second stage of the corrosion attack. Finally, the intergranular attack in the core material takes place which will result in perforation of the samples. This last stage of the attack needs some time and normally can not be completely reached in potentiodynamic but SWAAT experiments. This is clearly shown in Figure 2.14. The figure shows the intergranular attack of the down-gauged material after 
complete dissolution of the clad layer. This mechanism of attack was found to be valid for all the variants in SWAAT and potentiodynamic tests.

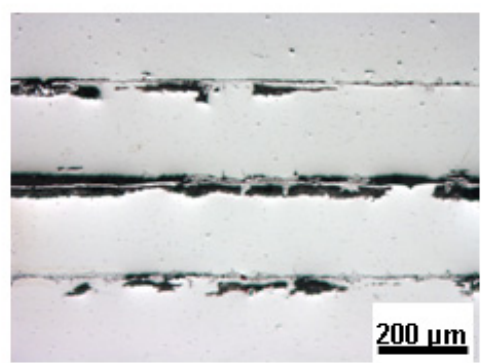

Potentiodynamic -Variant 1

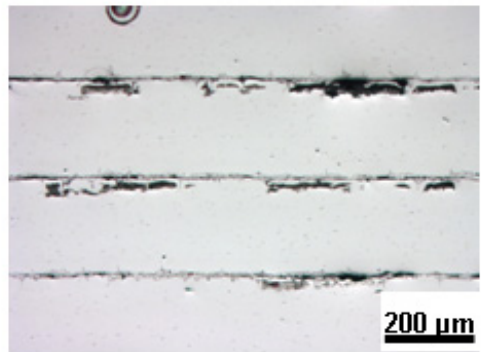

Potentiodynamic -Variant 2

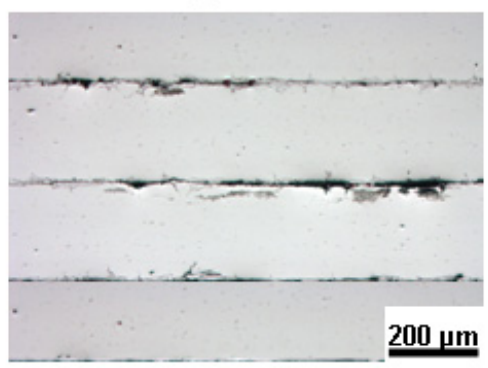

Potentiodynamic -Variant 3

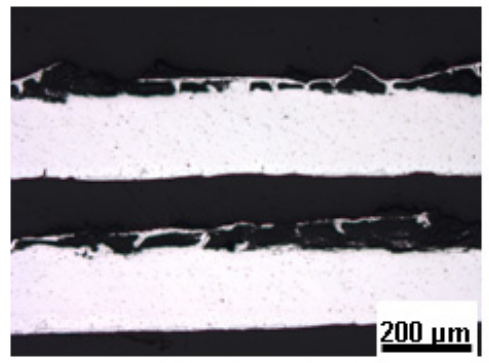

SWAAT -Variant 1

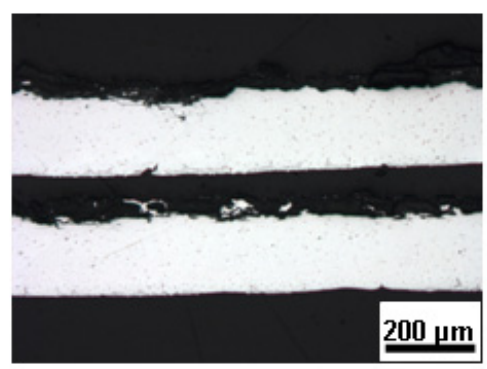

SWAAT -Variant 2

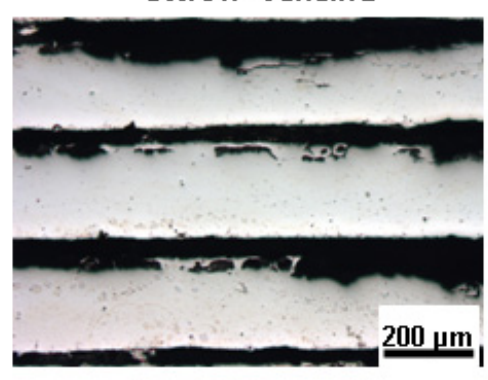

SWAAT -Variant 3

Figure 2.13. Comparison of corrosion attack mechanism and morphology in SWAAT and potentiodynamic test

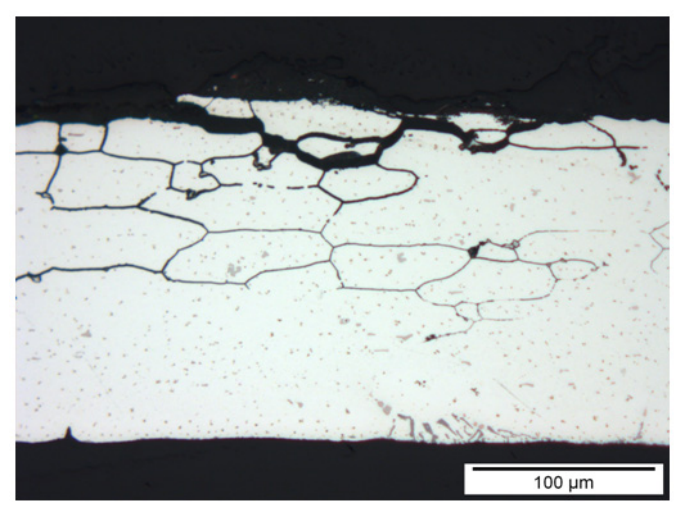

Figure 2.14. Intergranular corrosion attack in the down gauged AA4xxx/AA3xxx/AA4xxx material after complete dissolution of the clad layer in SWAAT. 


\subsubsection{Statistical evaluation of the SWAAT results}

The number of perforations after 25 days of SWAAT for samples from each variant is shown in Table 2.3.

Table 2.3. Number of perforations after 25 days of SWAAT for samples from each variant.

\begin{tabular}{|c|c|c|c|c|c|c|c|c|c|c|c|}
\hline \multirow{3}{*}{ Variant } & \multicolumn{10}{|c|}{ Number of perforations after 25 days of SWAAT } & \multirow{3}{*}{$\begin{array}{l}\text { Total } \\
\text { Number of } \\
\text { Perforation }\end{array}$} \\
\hline & \multicolumn{10}{|c|}{ sample } & \\
\hline & 1 & 2 & 3 & 4 & 5 & 6 & 7 & 8 & 9 & 10 & \\
\hline 1 & 4 & 5 & 3 & 5 & 3 & 1 & 0 & 2 & 3 & 3 & 29 \\
\hline 2 & 0 & 0 & 3 & 4 & 0 & 0 & 2 & 2 & 1 & 1 & 13 \\
\hline 3 & 0 & 0 & 0 & 0 & 0 & 0 & 0 & 0 & 0 & 0 & 0 \\
\hline 4 & 1 & 1 & 1 & 1 & 0 & 6 & 10 & 11 & 8 & 13 & 52 \\
\hline 5 & 0 & 2 & 1 & 0 & 0 & 3 & 0 & 0 & 1 & 1 & 8 \\
\hline 6 & 0 & 3 & 0 & 0 & 0 & 0 & 0 & 8 & 0 & 0 & 11 \\
\hline 7 & 3 & 4 & 7 & 5 & 4 & 3 & 5 & 4 & 2 & 1 & 38 \\
\hline
\end{tabular}

The Sign test (Median test) [22] and Ranksum test (Wilcoxon test) [22] results are presented in Tables 2.4 and 2.5. In most cases the two tests give approximately the same values.

Table 2.4. Median test results.

\begin{tabular}{c|cccccc}
\hline $\begin{array}{c}\text { Median } \\
\text { Test }\end{array}$ & \multicolumn{7}{|c}{ Variants } \\
\hline \multirow{2}{*}{ Variants } & $\mathbf{2}$ & $\mathbf{3}$ & $\mathbf{4}$ & $\mathbf{5}$ & $\mathbf{6}$ & $\mathbf{7}$ \\
\cline { 2 - 8 } & \multicolumn{7}{|c}{ Probabilities } \\
\hline $\mathbf{1}$ & 0.661 & $<0.001$ & 0.002 & 0.033 & 0.009 & $<0.001$ \\
$\mathbf{2}$ &. & 0.004 & 0.003 & 0.349 & 0.075 & $<0.001$ \\
$\mathbf{3}$ &. &. & $<0.001$ & 0.012 & 0.146 & $<0.001$ \\
$\mathbf{4}$ &. &. &. & 0.009 & 0.009 & 0.098 \\
$\mathbf{5}$ &. &. &. &.. & 0.170 & $<0.001$ \\
$\mathbf{6}$ &. &. &. &. &. & $<0.001$
\end{tabular}

Table 2.5. Ranksum test results.

\begin{tabular}{c|cccccc}
\hline $\begin{array}{c}\text { Ranksum } \\
\text { Test }\end{array}$ & \multicolumn{7}{|c}{ Variants } \\
\hline \multirow{2}{*}{ Variants } & $\mathbf{2}$ & $\mathbf{3}$ & $\mathbf{4}$ & $\mathbf{5}$ & $\mathbf{6}$ & $\mathbf{7}$ \\
\cline { 2 - 7 } & \multicolumn{7}{c}{ Probabilities } \\
\hline $\mathbf{1}$ & 0.556 & $<0.001$ & 0.01 & 0.065 & 0.043 & $<0.001$ \\
$\mathbf{2}$ &. & 0.005 & 0.004 & 0.310 & 0.165 & $<0.001$ \\
$\mathbf{3}$ &. &. & $<0.001$ & 0.015 & 0.168 & $<0.001$ \\
$\mathbf{4}$ &. &. &. & 0.002 & $<0.001$ & 0.117 \\
$\mathbf{5}$ &. &. &. &.. & 0.350 & $<0.001$ \\
$\mathbf{6}$ &. &. &. &. &. & 0.001
\end{tabular}


Comparing the calculated probabilities for each of the variants with variant 1 shows that except variant 2 which with high possibility (0.66 in Median test and 0.56 in Ranksum test) behaves the same as variant 1 the rest of the variants are quite different and statistically distinguishable.

The probabilities calculated in Cochran-Mantel-Haenszel test [22] are presented in Table 2.6. Considering the probabilities of the observed perforation distribution for samples in variants $1,2,5$, and 7 , there exist no significant difference $(p>0.1)$ between the corrosion performances of the samples in these variants. However, the samples within variant 4 and variant 6 are statistically different $(p<0.1)$ and may not belong to the same population.

Table 2.6. Cochran-Mantel-Haenszel test results.

\begin{tabular}{c|c}
\hline $\begin{array}{c}\text { Cochran-Mantel-Haenszel } \\
\text { test }\end{array}$ & \multirow{2}{*}{ Probability } \\
\cline { 1 - 1 } Variant & \\
\hline $\mathbf{1}$ & 0.545 \\
$\mathbf{2}$ & 0.125 \\
$\mathbf{4}$ & $<0.001$ \\
$\mathbf{5}$ & 0.213 \\
$\mathbf{6}$ & $<.001$ \\
$\mathbf{7}$ & 0.664 \\
\hline
\end{tabular}

\subsection{Discussion}

Although based on the average sample lifetime in SWAAT, there appears to be noticeable standard deviations (5 to 6 days) for most of the variants, it should be noted that for each variant the majority of the samples failed in a close ( \pm 2 days) time interval. The presence of minority of samples with large difference in their SWAAT life with respect to the rest of the samples has caused the standard deviations to become quite noticeable. This is more clearly shown for variant 1 .

The lifetime measurements of the samples shows that applying tight controls over the brazing process, sample preparation and cabinet conditions has caused the majority of specimens from the same variant to fail in close time intervals. This indicates that the test can be an appropriate technique to compare corrosion performance of different materials as long as 10 samples are tested.

The blisters evolution profiles indicate that the material non-uniformity and weak spots i.e. the non-uniform presence of highly cathodic intermetallics on the surface and segregation of alloying elements play an important role in SWAAT results. In other words, not the whole material but only weak spots are sources for the blisters to occur and as these week spots are corroded at different rates, perforations do not happen at the same time. 
Down gauging causes different corrosion responses form the material, which is not purely thickness related. The corrosion resistance does not decrease proportional to the gauge reduction. This reduction can potentially be the result of the corrosion measurement procedure which is based on the penetration test. It has been reported that the response to re-crystallization during the brazing cycle is highly gauge dependent [23]. This can play a role in non linear behavior of SWAAT result with respect to the material gauges. Iwao, et al, concluded that depending on the alloying elements, type of process and the thickness of the braze liner a specific profile of elemental distribution will form that has a significant influence on corrosion performance [25]. This probably plays an important role in determining down-gauging and corrosion resistance relation. However, potentiodynamic tests revealed that the electrochemical response of the down gauged material is not affected by down gauging process. This means that the life performance reduction in the material under investigation can not be explained based on re-crystallization or alloying element distribution effects. A possible explanation can be related to the reduction of the clad material thickness which is sacrificially protects the core material. Availability of less anodic material to protect the core is expected to be one reason for the observed non proportionality between the life performances of the down gauged and baseline material.

Comparing the electrochemical response of the O-temper material with the material at $\mathrm{H} 24$ temper (baseline material) reveals that no significant difference in the corrosion resistance of these materials can be expected. This is well reflected in the SWAAT result of the O-temper material which shows a 2 days increase in minimum SWAAT life comparing to that of the baseline material.

The results for brazing temperature effect on the SWAAT resistance does coincide with the results from Yamashita et al. [26] who reported that brazing at higher temperatures will cause the corrosion resistance to decrease. However such an influence can not be concluded from the SWAAT result that was obtained for variant 6. This is because based on Cochran-Mantel-Haenszel test (Table 2.6), the SWAAT result for this material are not statistically reliable $(\mathrm{P}<0.001)$. Referring to the potentiodynamic measurements, it can be concluded that such a big increase (5 days) observed in the life performance of the material brazed at $591{ }^{\circ} \mathrm{C}$ is not justified. It should be noted that temperature effects are composition dependent and materials with different chemical composition may have different responses to temperature changes. The influence of cooling rate has also been examined and reported to be composition dependent [27].

The increased SWAAT performance for the fluxed samples coincides with the work of Gray et al [20]. They investigated the corrosion behavior of standard AA3003 based brazing sheet. Salt spray testing of samples brazed using various flux levels showed that the corrosion performance of the standard AA3003 based alloy was significantly reduced at flux levels below $5 \mathrm{~g} / \mathrm{m}^{2}$. Electrochemical 
characterization of brazed surfaces has shown that the flux levels had no effect on the anodic dissolution behavior, while a trend of reduced cathodic activity with increasing flux levels was observed $[28,29]$. The idea that the presence of flux has no effect on anodic dissolution branch in potentiodynamic characterization was not confirmed in this research. The presence of negative shifts in breakdown potentials and the evolution of a second breakdown potential in fluxed materials are well depicted in the test results. The 100 and $150 \mathrm{mV}$ shifts in the first break down potential of the material with $1 \mathrm{~g} / \mathrm{m}^{2}$ is related to the coverage of the surface with a less noble material (the flux). This layer is expected to sacrificially protect the rest of the material in SWAAT test. The fact that the micrographs of variants 2 and 3 after potentiodynamic tests showed less dissolution of the clad material is validating the idea of sacrificial protection by the flux material. During the potentiodynamic test this layer will start to corrode first. As the thickness of the layer is very thin $(<1 \mu \mathrm{m})$, soon there will come a time that the availability of this material becomes the controlling parameter and the corrosion current density starts to reach a limit although the applied potential is increasing. This will result in the formation of a current density plateau and even a decrease in current density till the corrosion potential of the substrate material is reached. Now, as the second material starts to corrode the current density will start to increase. This current density is of course the summation of the oxidation reaction for the flux material and the substrate. This explains the presence of the second break down potential. As the flux material completely corroded away the measured current density will be purely representative of that from the substrate material. This explains why the rest of the measurement follows exactly the same curve as that of the baseline material.

Another explanation for the observed phenomena can be made based on OCP electrochemical characteristics. At the OCP the cathodic corrosion rate must be equal to the anodic corrosion rate [30], therefore the OCP can be affected by changes of the anodic and cathodic current densities or by changes of the areas of the anode and cathode. Considering the experimental set up which had constant cathodic and anodic areas, the only possibility for the reduction observed in the OCPs of the fluxed materials is a decrease in the cathodic reaction rate. The problem with this theory is that the presence of current density plateaus and second break down potential can not be fitted in this explanation. Afseth et al. applied the mixed potential theory to explain the existence of OCP transitions in AA3005 due to annealing at different temperatures [31]. The decrease of OCP was attributed to an increase of the anodic reaction rate, which was associated to an impairment of the passivity of the oxide layer induced by annealing. This is well explained in the $\mathrm{PhD}$ work by Andreatta [32]. As such an increase in anodic reactivity were not observed in the potentiodynamic characterization of the fluxed materials, this explanation can not be true for the material under investigation in this research work. 
The presence of $50 \mathrm{mV}$ difference in the open circuit potentials (OCP) for the potentiodynamic tests of variant 2 is considered to be linked to the low amount of available flux that can not cover the surface properly and there remains fluxless areas which cause the exposure of the substrate to the corrosive environment/ electrolyte as the test starts. Considering the non-uniform distribution of fluxless areas such differences in OCPs can be explained. Comparing with completely fluxed surface in variant 3 , the elimination of such an effect makes the proposed explanation reasonable.

Comparing the electrochemical characterization of the re-brazed material with that of the base line material reveals that no significant changes in corrosion performance of the re-brazed material can be expected. Referring to SWAAT experiment, a reduction of 2 days in minimum performance of the material seems to validate the prediction made by potentiodynamic measurements.

Based on the similarities in corrosion mechanism and morphology of attack between SWAAT and potentiodynamic tests and the observed interconnection between SWAAT life performance and the electrochemical characterization responses, it can be concluded that SWAAT performance of a material can be reflected in its potentiodynamic characterization. Schauble has also found the possibility to simulate the initiation and propagation of corrosion on aluminium brazing sheets by electrochemical techniques in the same way as during SWAAT exposure [33].

The fact that the results from the Median and Ranksum tests (Tables 2.4 and 2.5) are approximately the same shows that, the applied evaluation approach is not sensitive to the applied test method. The similarity of baseline and fluxed material based on Median and Ranksum tests are logical, as the only difference is the application of $1 \mathrm{~g} / \mathrm{m}^{2}$ of flux which because of improper surface coverage has no significant effect on corrosion resistance of the baseline material. Comparing the other variants with the baseline material based on calculated probabilities proves the capability of the SWAAT to make distinction between variants in spite of the large standard deviations present in the average performances.

The results from Cochran-Mantel-Haenszel test (Table 2.6) show that, depending on the material SWAAT test may have scatter which is statistically significant. This was clearly shown for the down gauged and brazed (at $591{ }^{\circ} \mathrm{C}$ ) materials. Considering the low probability result in Cochran-Mantel-Haenszel test $(<0.001)$ the SWAAT lifetime predictions for these materials are not reliable. It is therefore necessary to check for the validity of the SWAAT results before applying the proposed minimum performance comparison method. 


\subsection{Conclusion}

1. SWAAT is capable to distinguish between different material variants and can be applied in material development programs.

2. SWAAT may suffer from scatter. Therefore, for any reliable comparison of the SWAAT results statistical reliability tests need to be performed.

3. Potentiodynamic characterization is capable to predict the behaviour of material in SWAAT.

4. The scatter from the SWAAT test is mainly material dependent and is related to the non-uniform distribution of defects and weak spots in the material. This hypothesis is backed up by the fact that in most of the samples which were tested, the number of blisters after initial perforation was constant and did not change over a long period of time.

5. Applying tight controls over brazing cycles, sample preparation and cabinet conditions can improve the result and narrow the life performance windows of the samples from the same variant.

6. The corrosion resistance of the tested material does not decrease proportional to the gauge reduction.

7. Applying flux improves the corrosion performance of the material. 


\subsection{References}

[1]. G.J. Marshall, A.J.E. Flemming, A. Gray, R. Liewellyn, Development of a long life aluminum brazing sheet alloy with enhanced mechanical performance, SAE Transactions: Journal of Materials \& Manufacturing, 103(1994) 292-300.

[2]. A Gray, The growth of aluminium in automotive heat exchangers, Aluminium, 81(2005) 197-201.

[3]. K. Takeuchi, Y. Isobe, T. Toyama, Current status and future of aluminum materials and brazing for automobile heat exchangers, Journal of Japan Institute of Light Metals, 48(1998) 446-453.

[4]. O. Lunder, J. Lein, Pitting corrosion of Aluminium heat exchanger tube materials, Proceedings from Aluminium Surface Science and Technology conference, Beaune, 2006.

[5]. F. Birol, Y. Birol, M. Slamova, Corrosion behaviour of aluminium fin stock alloys, Material Science Forum, 402(2002) 1511-1516.

[6]. A.C. Scott, R.A. Woods, J.F. Harris, Accelerated corrosion test methods for evaluating external corrosion resistance of vaccumed brazed aluminium heat exchages, SAE paper no.910590, 1991.

[7]. A.C. Scott, Corrosion performance of long-life automobile radiators, SAE paper no.971857, 1997.

[8]. R. Rungta, G. Tomasov, Laboratory testing of automotive evaporators for external corrosion durability in the field, SAE technical paper C496/060/95, 1995.

[9]. ASTM Standard, Designation G85, Standard practice for modified salt spray (fog) testing, 2006.

[10]. S. Yamauchi, Y. Shoji, K. Kato, Y. Suzuki, K. Takeuchi, Y. Isobe, Development of corrosion resistant brazing sheet for drawn cup evaporators, part 1, Alloy development, SAE technical paper no. 900148, 1993.

[11]. A. Jackson, sacrificial layer protection for condenser corrosion resistance, IMechE, paper no. C496/093/95, 1995.

[12]. Y. Isobe, K. Takeuchi, M. Tanaka, M. Mori, S. Yamauchi, Development of corrosion resistant brazing sheet for drawn cup type evaporators part 2: Application to evaporator, SAE technical paper 930149, 1193.

[13]. M. Yoshino, M. Edo, S. Kuroda, M. Asano, K. Tohma, Effect of additional Si and $\mathrm{Cu}$ on strength and corrosion resistance of sacrificial anode fin stock for automotive heat exchangers, Journal of Japan Institute of Light Metals, 59(2009) 229-235.

[14]. S. Iwao, M. Asano, Influence of heat treatment on corrosion resistance of aluminum alloy brazing sheet, Journal of Japan Institute of Light Metals, 57(2007) 589-594.

[15]. Z. Connor, G. Murty, Recent improvements in aluminum brazing sheet for use in heat exchanger applications, especially radiator tube stock, SAE Transactions: Journal of Materials \& Manufacturing, 114(2006) 852-858.

[16]. M. Syslak, G. Stakkestad, J.D. Evensen, X.J. Jiang, S. Bjo, S. Bo, Brazing sheet, Patent Number US6921584,2002.

[17]. S. Meijers, Corrosion of aluminium brazing sheet, $\mathrm{PhD}$ thesis, Delft University of Technology, 2002.

[18]. ASTM standard, Designation B 117, Standard practice for operating salt spray (fog) apparatus, 2009. 
[19]. F. Altmayer, Choosing an accelerated corrosion test, metal finishing, 98(2000) 585591.

[20]. A. Gray, A. Afseth and H-W. Swidersky, The influence of residual flux level on the corrosion behavior of aluminium alloys used in automotive heat exchangers, ASST Proceedings, ATB Metallurgie, 43, No.1-2, 2003.

[21]. O.L. Davies, P.L. Goldsmith, Statistical methods in research and production, 4th edition, Longman, London and New York, 1977.

[22]. G. A. Walker, J. Shostak, Common statistical methods for clinical research with SAS examples, 3rd edition, SAS Institute, North Carolina, 2010.

[23]. A. Wittebrood, Microstructural changes in brazing sheet due to solid-liquid interaction, $\mathrm{PhD}$ thesis, Delft University of Technology, 2009.

[24]. D.J. Schmatz, Welding Journal. Research Supplement, (1983) 267-271.

[25]. S. Iwao, S. Kuroda and M. Asano, Effects of $\mathrm{Cu}$ content in the core, $\mathrm{Zn}$ in the filler, and sheet thickness on the corrosion resistance of a brazing sheet, Welding International, 23(2009) 886-894.

[26]. N. Yamashita, Y. Shoji, Effect of thickness of filler on corrosion resistance of brazing sheet, Journal of Japan Institute of Light Metals, 59(2009) 344-349.

[27]. N. Kooij, Fine tuning of the higher strength brazing alloys, CRDT report 090732, 1998.

[28]. Y. Ando, I. Nita, M. Uramoto, H. Ochiai and T. Fujiyoshi, Development of aluminium radiators using the Nocolok brazing process- corrosion resistance of new aluminium radiators by applying a Nocolok Brazing process, SAE, No.87180, 1987.

[29]. J. Takigawa and T. Okamoto, Materials and process factors in non-corrosive flux brazing for aluminium automobile heat exchangers, Kobeloc technology review, 16 (1993) 139-144.

[30]. M. G. Fontana, Corrosion Engineering, McGraw-Hill, New York, 1986.

[31]. A. Afseth, J.H. Nordlien, G.M. Scamans, K. Nisancioglu, Filiform corrosion of AA3005 aluminium analogue model alloys, Corrosion Science, 44(2002)145.

[32]. F. Andreatta, Local electrochemical behaviour of 7xxx aluminium alloys, $\mathrm{PhD}$ thesis, Delft University of Technology, 2004.

[33]. K. Schauble, Silica passivation layer on aluminium brazing sheets, $\mathrm{PhD}$ thesis, University of Cologne, 2010. 


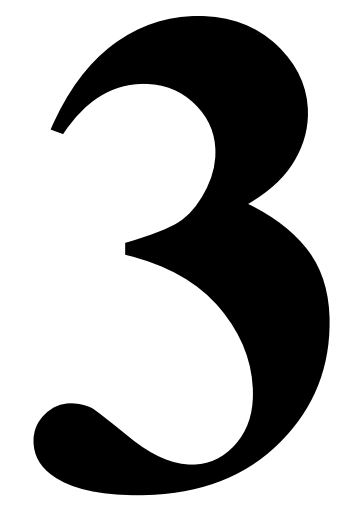

* This chapter has been published as a scientific paper:

F. Norouzi Afshar, J.H.W. de Wit, H. Terryn, J.M.C. Mol, The effect of brazing process on microstructure evolution and corrosion performance of a modified AA4xxx/AA3xxx brazing sheet, Corrosion Science 58 (2012) 242-250. 



\title{
Microstructural evolution and macro-electrochemical characterization
}

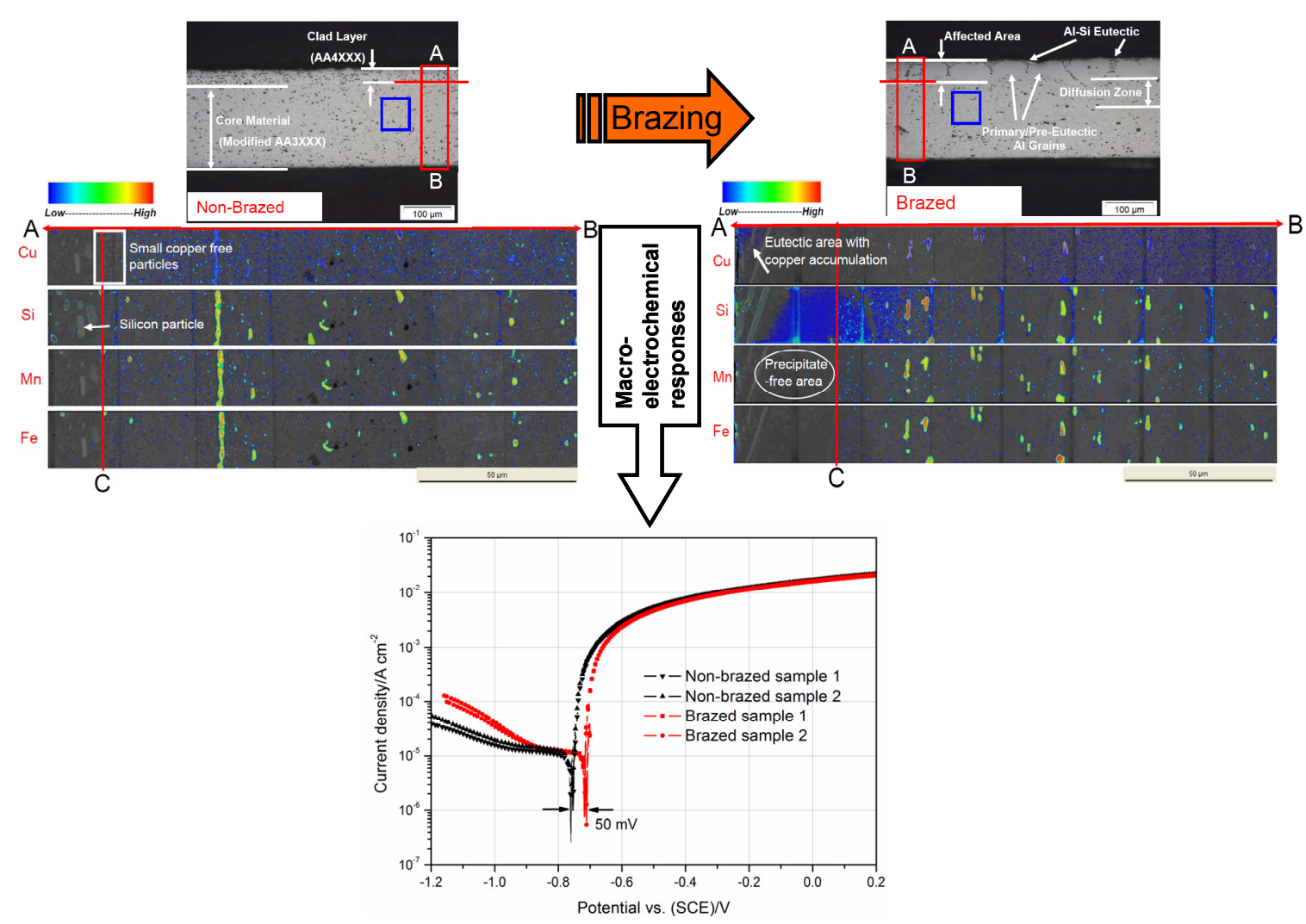

\begin{abstract}
Re-solidification of an AA4xxx cladding, particle formation, distribution and chemical composition in a modified AA3xxx core material before and after brazing were investigated. The cathodic and anodic electrochemical responses of the materials were investigated and correlated to the microstructural changes due to the brazing process. It is found that brazing causes copper accumulation in the eutectic phase which has resulted in a $50 \mathrm{mV}$ increase in the corrosion potential and inter-granular corrosion (IGC) susceptibility of the re-solidified clad material. Formation of $\alpha-\mathrm{Al}(\mathrm{Fe}-\mathrm{Mn}) \mathrm{Si}$ particles on the surface of the brazed material was found to increase the cathodic reactivity of the surface.
\end{abstract}




\subsection{Introduction}

Replacing mechanical assembly by brazing of aluminium alloys has been the trend for automotive heat exchanger producers since the middle of the 1990s [1]. Low density, good thermal conductivity, satisfactory mechanical properties and relatively good corrosion resistance have made aluminium alloys suitable for heat exchangers. The present aluminium brazing sheet is a sandwich material made out of two aluminium alloys. The AA4xxx type alloy allows joining of complex shaped automotive heat exchangers while the modified AA3xxx core alloy supplies the necessary strength to the component. Controlled atmosphere brazing $(\mathrm{CAB})$ is widely used amongst heat exchanger producers. During the brazing process, the parts to be assembled are heated to the melting temperature of the AA4xxx clad material. This process tends to modify the microstructure, type, distribution and chemical composition of the existing particles as well as alloying elements distribution.

During casting, Fe-containing intermetallics, such as Al-Fe, Al-Fe-Si and Al-Fe$\mathrm{Mn}-\mathrm{Si}$ phases, are formed between the aluminium dendrites [2]. The type of phase formed depends mainly on the cooling rate and the Fe to Si ratio of the alloy [3]. In the usual DC-cast extrusion alloys, the unstable monoclinic $\beta$-AlFeSi phase, which has an approximate $\mathrm{Al}_{5} \mathrm{FeSi}$ stoichiometry, is commonly present [4]. The morphology of this phase is plate-like with a thickness of a few tenths of a micrometer and other dimensions of the order of $10 \mu \mathrm{m}$ [5]. The presence of particles of this $\beta$-AlFeSi phase adversely influences the extrusion properties of the alloy. During homogenisation, the $\beta$-AlFeSi phase will transform to a less Si-rich and more spheroidised $\alpha$-phase [6], which is more favourable for extrusion. This $\alpha-$ phase improves ductility because its morphology is less likely to induce microcracks than the planar $\beta$-AlFeSi phase [6]. Furthermore, the $\alpha$-phase will lead to a decrease in pickup defects on the extruded surface [7-9]. For pure Al-Fe-Si alloys, the hexagonal $\alpha$-AlFeSi phase is the stable phase [4], but in most commercial alloys some $\mathrm{Mn}$ is present and the cubic $\alpha-\mathrm{Al}(\mathrm{FeMn}) \mathrm{Si}$ phase becomes the stable phase. This cubic phase has an approximate stoichiometry of $\mathrm{Al}_{12}(\mathrm{Fe}-\mathrm{Mn})_{3} \mathrm{Si}$, where the Mn atoms are interchangeable with the Fe atoms [10].

Several studies have been devoted to the corrosion behaviour of aluminium brazing sheet material. In the studies devoted to the airside corrosion sensitivity of these materials, Scott et al. [11] and Isobe et al. [12] considered that noble Si needles had a detrimental effect on corrosion resistance of the residual cladding. Scott et al. [11] studied the corrosion behaviour of these materials with sea water acidified accelerated test (SWAAT). Isobe et al. [12] used copper accelerated salt spray (CASS) and acetic acid salt spray (AASS) tests. They observed that Si needles acted as active cathodes while the surrounding aluminium dissolved. Al-Si alloys were also studied for other technological applications. In acidic or neutral solutions, it has been shown that Si particles did not have a detrimental effect on 
the corrosion resistance of aluminium alloys $[13,14]$. Some papers devoted to the corrosion of brazed aluminium heat exchangers $[15,16]$ also agree with this point stating that the cathodic reaction mentioned by Scott et al. [11] and Isobe et al. [12] did not occur on Si needles. Kuroda and Tohma [15] and Meijers [16] determined that the oxygen reduction current density on silicon is too low to anodically polarise aluminium. From their point of view, the corrosion susceptibility of the residual cladding arises from a higher sensitivity to pitting of the eutectic (Al) in solutions containing chloride. This has been explained by a lower pitting potential for eutectic (Al) than for the primary (Al).

Few papers have discussed the role of the $\alpha-\mathrm{Al}(\mathrm{Fe}, \mathrm{Mn}) \mathrm{Si}$ phase precipitates on the corrosion resistance of the residual cladding. Isobe et al. [12] considered that large $\mathrm{Al}-\mathrm{Mn}-\mathrm{Fe}-\mathrm{Si}$ intermetallic compounds had a cathodic behaviour similar to that of Si needles. In an electrochemical study dedicated to the behaviour of aluminiumbased intermetallics containing iron, Nisancioglu [17] studied the electrochemical behaviour of $\alpha-\mathrm{Al}(\mathrm{Fe}, \mathrm{Mn}) \mathrm{Si}$ particles isolated from their (Al) matrix. When the $\alpha-$ $\mathrm{Al}(\mathrm{Fe}, \mathrm{Mn}) \mathrm{Si}$ phase particles were immersed in $0.1 \mathrm{M} \mathrm{NaOH}$ solution, $\mathrm{Fe}, \mathrm{Mn}$ and $\mathrm{Si}$ enrichment of the surface of the particle was observed. Due to the evolution of the chemical composition of their surface, Nisancioglu argued that the particles tended to passivate and to become cathodic sites [17]. However, Nisancioglu postulated that silica enrichment of the surface significantly reduced the rate of the cathodic reaction on these particles. He emphasised the complexity of the phenomena occurring in the presence of multi-component intermetallics and did not invoke the influence of possible particle/matrix interactions on the reactivity observed for the $\alpha-\mathrm{Al}(\mathrm{Fe}, \mathrm{Mn}) \mathrm{Si}$ phase particles [18]. Considering these interactions, the role of both $\mathrm{Si}$ and $\alpha-\mathrm{Al}(\mathrm{Fe}, \mathrm{Mn}) \mathrm{Si}$ heterogeneities on the corrosion behaviour of the residual cladding was investigated by Tierce et al. [18]. The results show that Si needles do not participate in the corrosion progress whereas the $\alpha-\mathrm{Al}(\mathrm{Mn}, \mathrm{Fe}) \mathrm{Si}$ particles are preferential sites for corrosion attacks. $\alpha$ $\mathrm{Al}(\mathrm{Mn}, \mathrm{Fe}) \mathrm{Si}$ particle/matrix interactions are responsible for the defective passivation where the $\alpha-\mathrm{Al}(\mathrm{Mn}, \mathrm{Fe}) \mathrm{Si}$ phase particles are mainly concentrated.

The present study is part of a research work devoted to improving the corrosion resistance of a modified aluminium brazing sheet material which is used in manufacturing of heat exchangers. Using a combined theoretical modelling and experimental characterization approach, the present study reveals the microstructure of the material before and after the brazing process. JmatPro software based on thermodynamic calculations was applied to predict the type and percentage of the existing phases. By combining the theoretical calculations, experimental observations and literature, a detailed particle identification was performed. This Particular study aims to investigate the effect of the brazing process on the corrosion performance of a modified AA3xxx/AA4xxx aluminium brazing sheet. The detailed and fundamental mechanistic understanding of the effects of microstructural variations aims to provide enhanced corrosion protection 
by microstructural control of aluminium brazing sheet.

\subsection{Experimental}

\subsubsection{Material}

A4 size sheet was cut from rolled modified AA3xxx aluminium alloy $(185 \mu \mathrm{m}$ thick) claded on one side with an AA4xxx (15 $\mu \mathrm{m}$ thick). The bulk chemical analysis of the clad and the core materials was obtained with X-Ray Fluorescence analysis (XRF). PW2400 equipment with a Rhodium anode and a $60 \mathrm{kV}$ acceleration voltage was used. The data was analyzed with UniQuant software and is presented in Table 3.1.

Table 3.1. Chemical composition (wt \%) of the AA3xxx (core) and AA4xxx (clad) material.

\begin{tabular}{ccccccccc}
\hline & $\mathrm{Si}$ & $\mathrm{Fe}$ & $\mathrm{Cu}$ & $\mathrm{Ti}$ & $\mathrm{V}$ & $\mathrm{Cr}$ & $\mathrm{Mn}$ & $\mathrm{Al}$ \\
\hline Clad & 7.70 & 0.18 & - & 0.01 & - & - & 0.14 & Bal. \\
Core & 0.44 & 0.32 & 0.6 & 0.08 & 0.01 & 0.07 & 1.03 & Bal. \\
\hline
\end{tabular}

The sheet was properly cleaned in ultrasonic bath with ethanol, dried and placed in a Controlled Atmosphere Brazing (CAB) furnace. $\mathrm{CAB}$ is brazing in a dry, inert nitrogen gas atmosphere. The brazing cycle that was applied is shown in Figure 3.1. The material is heated up to $600^{\circ} \mathrm{C}$ and is kept at that temperature for $3 \mathrm{~min}$ and is then cooled down with a specified ramp $\left(60{ }^{\circ} \mathrm{C} / \mathrm{min}\right)$. The holding temperature was selected to be close to the liquidus temperature of the clad material, reported as $612{ }^{\circ} \mathrm{C}$ by Lacaze et al [1], while still being far below the solidus temperature of the core material which is about $640{ }^{\circ} \mathrm{C}$.

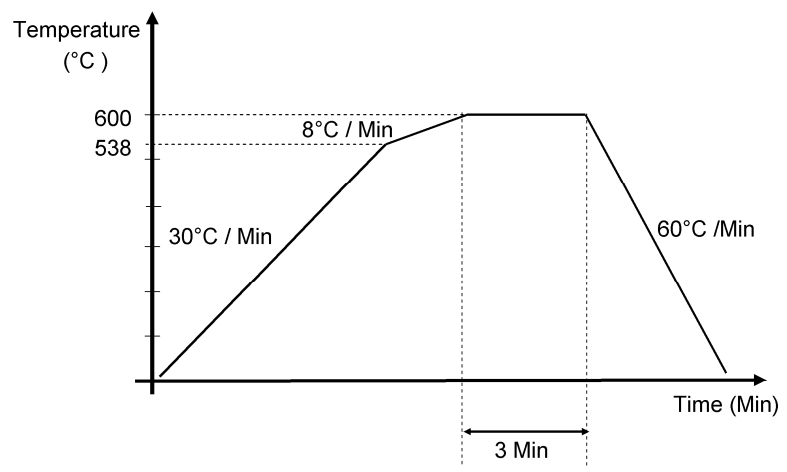

Figure 3.1. Standard CAB brazing cycle.

\subsubsection{Material characterization}

Using Optical Microscopy (OM), JEOL 7001F Scanning Electron Microscope 
(SEM) and Energy-Dispersive X-ray spectroscopy (EDX), the microstructure of the alloy was examined both before and after brazing. For chemical characterization (elemental analysis) spectral imaging data sets (generated X-rays) were collected at $7 \mathrm{kV}$ electron beam energy for the major alloying elements $(\mathrm{Si}$, $\mathrm{Mn}, \mathrm{Cu}$ and $\mathrm{Fe}$ ) and at $12 \mathrm{kV}$ for other low concentration elements ( $\mathrm{Mg}, \mathrm{Ti}, \mathrm{V}, \mathrm{Cr}$, $\mathrm{Zn}$, and $\mathrm{Zr}$ ). NORAN System SIX microanalysis system with two silicon drift detectors was used to acquire and process the data. The results were presented in pseudo colour maps. In order to make the concentration of the elements comparable, the same colour scale has been applied for each element in different maps.

For a comparison of the present material microstructural characterization results with thermodynamic information, JmatPro software (Version 6.0) was applied. JmatPro calculates a wide range of microstructural properties (e.g. equilibrium phases, their weight percentages and the temperature ranges over which various phases are stable) for alloys and is particularly aimed at multi-component alloys used in industrial practice. The software has an extensive database for the calculation of physical properties that can be linked to its thermodynamic calculation capability. The calculations are based on minimization of free energy of the matter at a certain temperature and composition: the state of minimum free energy is the equilibrium state of the system. Entering the chemical composition and the temperature range that the material experiences in a process, the software predicts the material characteristics including stable and metastable phase equilibrium.

\subsubsection{Electrochemical analysis}

Using a Solartron potentiostat and a three-electrode electrochemical cell, potentiodynamic polarization measurements were performed. Considering the emphasis of this research on the microstructural effects on the electrochemical performance of the aluminium brazing sheet, the cathodic and the anodic polarization responses of the materials have been measured and investigated separately. This will prevent any modification of the surface before performing the anodic or cathodic measurements. The working electrodes (samples) were circular plates with a diameter of $2 \mathrm{~cm}$. The reference electrode was a saturated calomel electrode (SCE) and the counter electrode was Pt. The sea water acidified accelerated corrosion test (SWAAT) solution ( $42 \mathrm{gr} / \mathrm{l}$ of $\mathrm{NaCl}$ solution at $\mathrm{pH} 2.8$ ) [19] was chosen as the applied electrolyte. The samples were scanned in the potential range between $10 \mathrm{mV}$ below and $1 \mathrm{~V}$ above the open circuit potential (OCP) for the anodic scans and between $10 \mathrm{mV}$ above and $450 \mathrm{mV}$ below the OCP for the cathodic scans. The scans started after 15 min of OCP measurement. A scan rate of $0.5 \mathrm{mV} / \mathrm{s}$ was applied. The reproducibility of the test results was checked by repetition of each experiment. The OCP variations before cathodic and anodic polarizations have been averaged and presented separately. 


\subsection{Results}

\subsubsection{Material characterization}

Optical images of the material under investigation both before and after brazing are shown in Figure 3.2. The image of the material before brazing shows the clad layer with a brighter contrast. Elongated coarse particles with a dark gray contrast in the clad layer are Si particles. EDX analysis revealed also the presence of some small additional precipitates containing $\mathrm{Al}, \mathrm{Fe}, \mathrm{Cu}$, and $\mathrm{Si}$. In the core material a wider variety of particles exists with different sizes and chemical compositions.
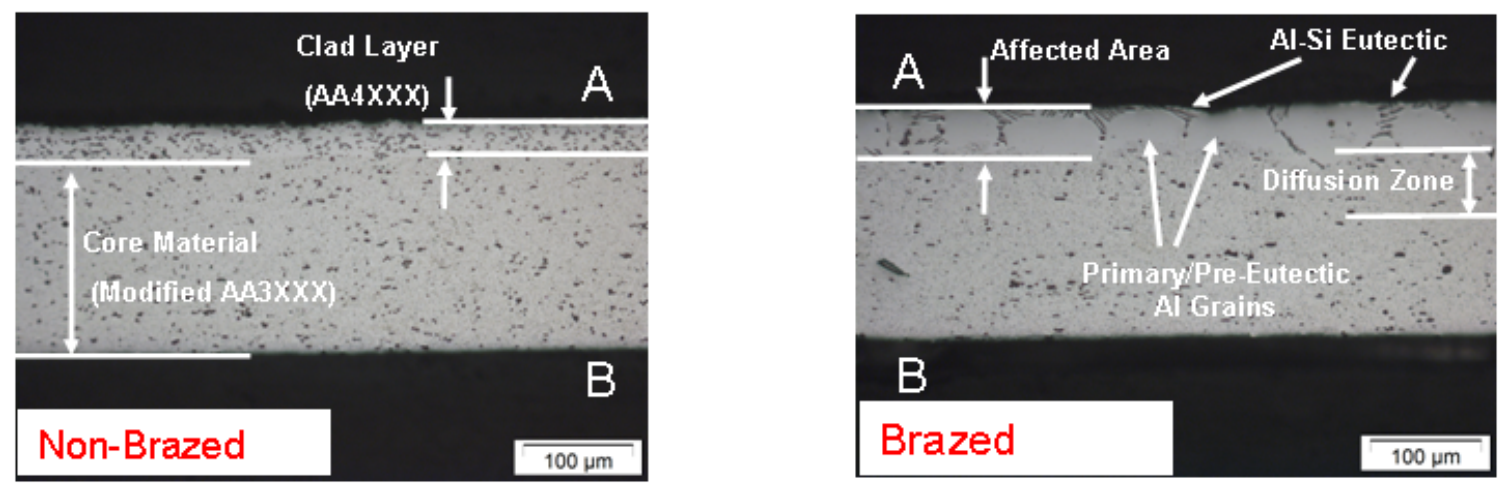

Figure 3.2. Optical images of the brazing sheet structure before and after brazing.

At brazing temperature the liquid clad is in intimate contact with the solid core material. During this stage where the two phases co-exist, an interaction between the two can take place. This interaction is explained in detail by Wittebrood [20]. According to Schmatz et al [21] the liquid originating at the clad-core interface progresses into the core alloy as a film, changing the element distribution on its way. This area is the affected area which has been designated in Figure 3.2. The area is free from precipitates. The Al-Si eutectic phase is shown to be accumulated at the surface and in between the pre-eutectic aluminium grains. As silicon is the most diffusive element that diffuses into the core material the diffusion path of this element is considered to be the diffusion layer. This layer was measured to be about $40 \mu \mathrm{m}$.

Spectral data for the major alloying elements ( $\mathrm{Si}, \mathrm{Mn}, \mathrm{Cu}$ and $\mathrm{Fe}$ ) and low concentration elements ( $\mathrm{Mg}, \mathrm{Ti}, \mathrm{V}, \mathrm{Cr}, \mathrm{Zn}$, and $\mathrm{Zr}$ ) both before and after brazing were collected. The areas over which the data was obtained, the rectangle for the major alloying elements and the square for the low concentration elements, are shown in Figure 3.3. EDX analysis for the major alloying elements before and after brazing is presented in Figures 3.4 and 3.5 respectively. 

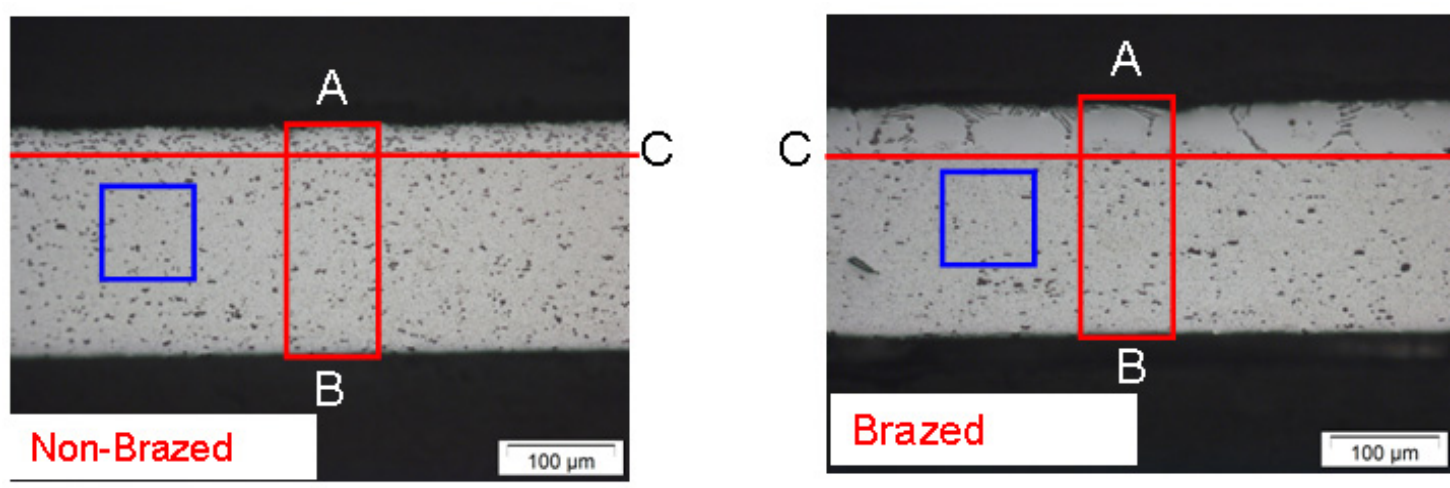

Figure 3.3. Areas (the rectangle and the square) over which the spectral data was collected.

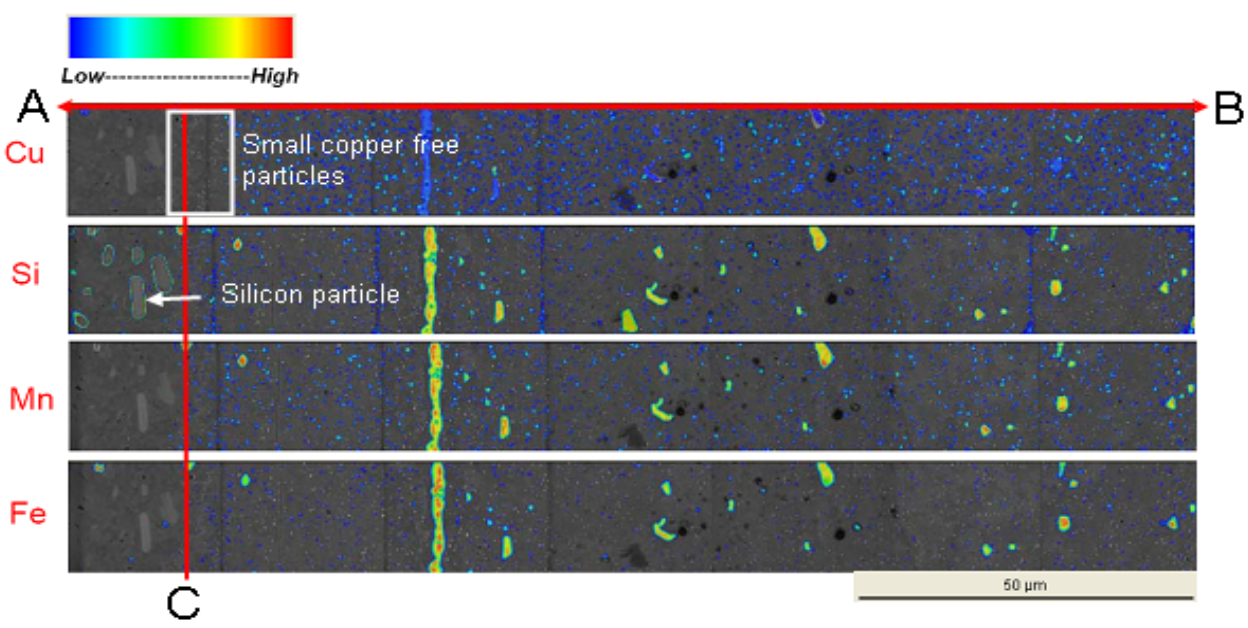

Figure 3.4. EDX elemental maps of the material before brazing.

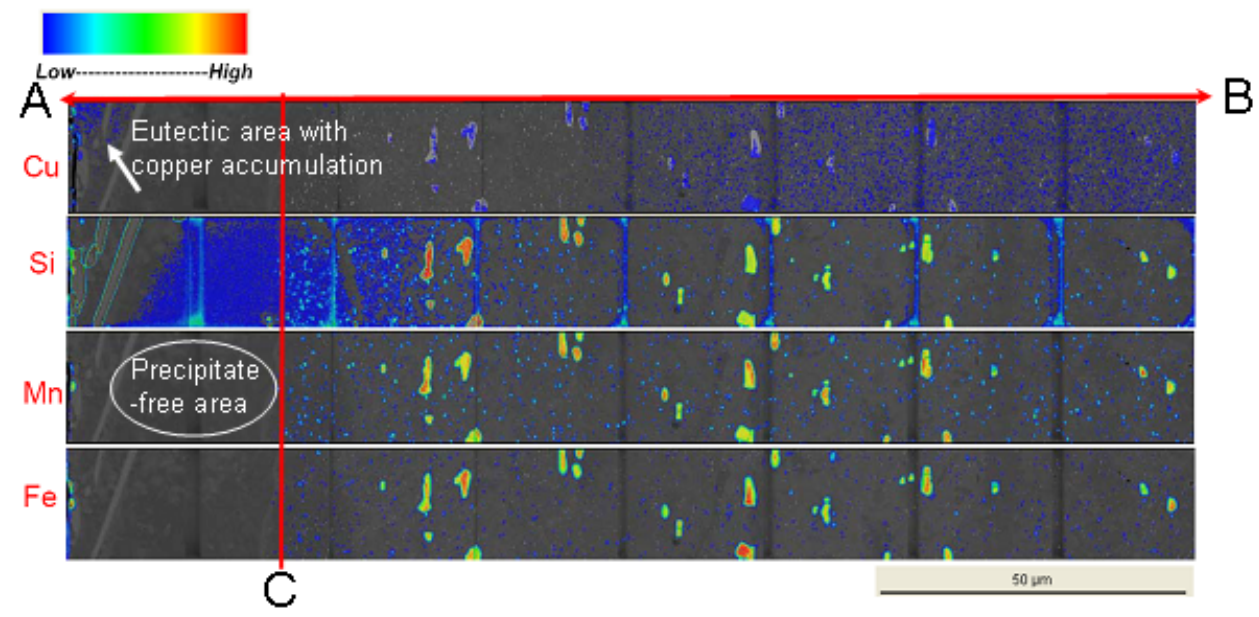

Figure 3.5. EDX elemental maps of the material after brazing. 
The same designations (A, B, C) as in Figure 3.3 are used to show the directions and areas of the analysis. The silicon particles in the Si maps are not coloured because of the pseudo-colour scale that was applied. This was to reveal the $\mathrm{Si}$ concentration differences in other Si containing particles. Based on these figures two different types of particles can be distinguished. One type is the particles which are larger than 1-2 $\mu \mathrm{m}$ and their sizes can reach up to $20 \mu \mathrm{m}$. These particles contain $\mathrm{Si}, \mathrm{Mn}$, and $\mathrm{Fe}$ in addition to aluminium. The elemental map for iron concentration shows that iron is mainly present in these large particles. The second type particles are those with sizes below $1 \mu \mathrm{m}$. A wider variety in chemical composition exists for these small particles. Some of them which seem brighter in the micrographs are shown to be richer in copper. On the contrary, there are other small particles which are completely copper free. These particles are surrounded in a white square in Figure 3.4. Mn, Fe and $\mathrm{Si}$ are the main constituents for these particles and they are mainly accumulated close to the clad-core interface. The copper map shows that copper containing particles are small particles $(<1 \mu \mathrm{m})$ that are distributed through the core material thickness. A limited number of copper containing particles in the clad layer was detected which is the sign of very low copper concentration in the clad layer.

Comparison of the elemental maps in Figure 3.4 and Figure 3.5 shows that the reduction in $\mathrm{Cu}$ concentration of particles and the increase of the Si concentration in the diffusion zone are the major differences that have occurred due to the brazing process. Accumulation of copper in the eutectic aluminium at the surface and the presence of precipitate-free areas (affected area) close to the clad/core interface was also detected.

Elemental distribution maps for the other alloying elements $(\mathrm{Mg}, \mathrm{Ti}, \mathrm{V}, \mathrm{Cr}, \mathrm{Zn}$ and $\mathrm{Zr}$ ) before and after brazing are shown in Figures 3.6 and 3.7. The major alloying elements were also mapped for comparison purposes. The large intermetallics $(>2 \mu \mathrm{m})$ with $\mathrm{Si}, \mathrm{Mn}$ and $\mathrm{Fe}$ content also contain $\mathrm{Cr}$ in low concentrations. The presence of $\mathrm{Cu}$-rich spots on the surface of some of the large particles is also evident. Ti-rich spots were detected which shows that this element is concentrated in small $(<1 \mu \mathrm{m})$ particles. $\mathrm{Mg}, \mathrm{V}$, and $\mathrm{Zr}$ were found to be present at very low concentrations and accumulated in small $(<1 \mu \mathrm{m})$ particles.

Thermodynamic calculations were performed to predict the equilibrium phases, their weight percentages and the temperature ranges through which various phases are stable. The results are shown in Figures 3.8-3.10. In the figures letter M stands for an element of the transition metals ( $\mathrm{Ti}, \mathrm{Cr}, \mathrm{V}$, and $\mathrm{Fe}$ ). 


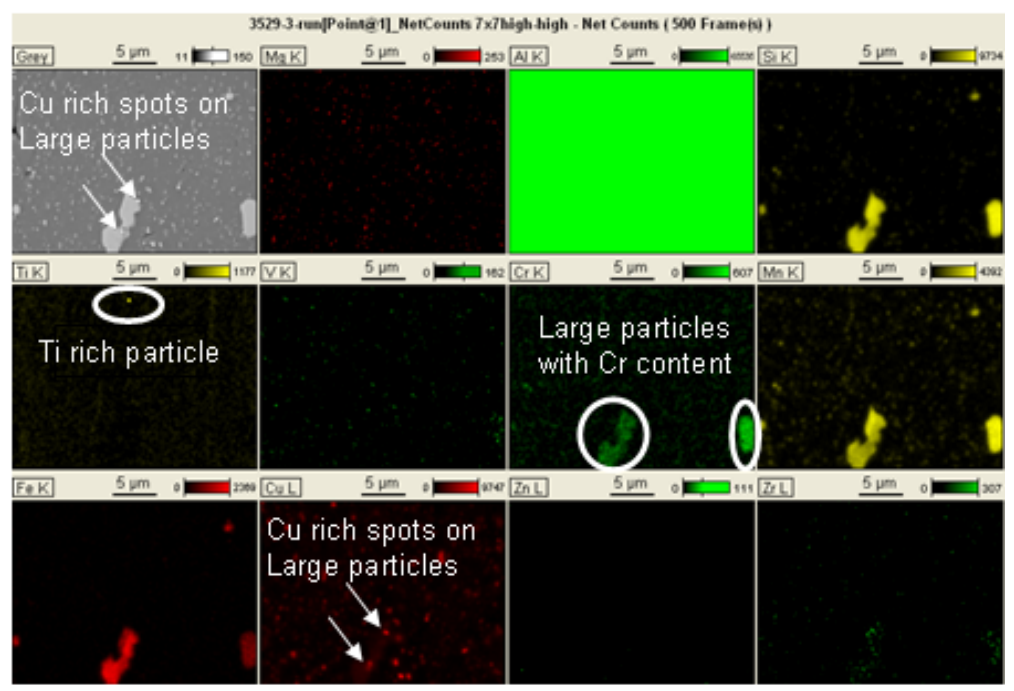

Figure 3.6. EDX elemental maps in the central part of the non-brazed sample.

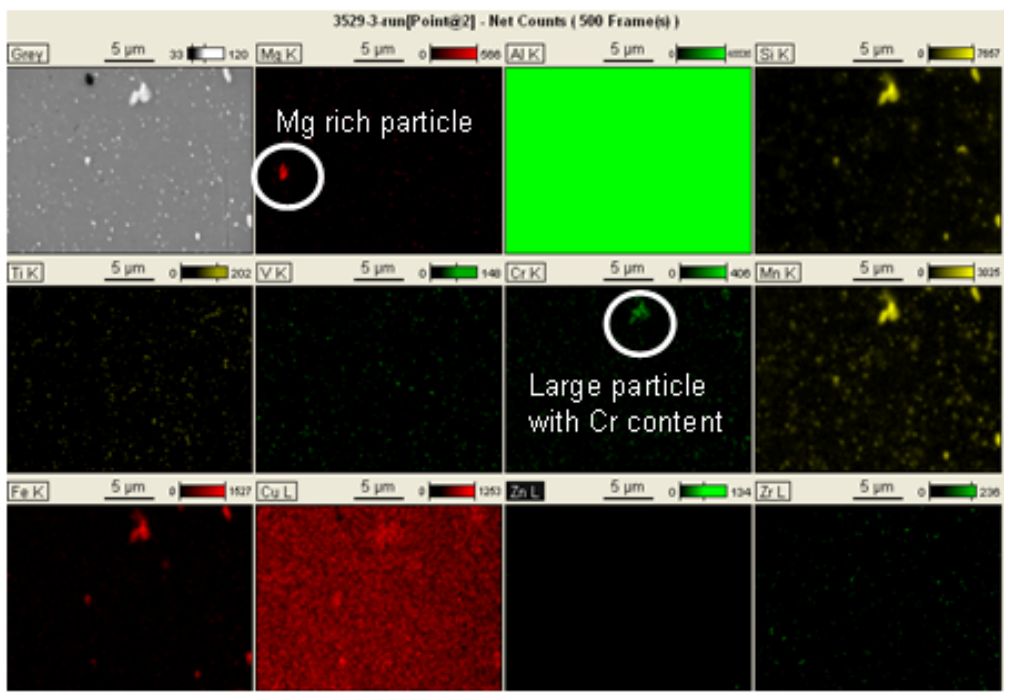

Figure 3.7. EDX elemental maps in the central part of the brazed sample.

Figure 3.8 shows that the liquidus and solidus temperatures for the clad material are $615{ }^{\circ} \mathrm{C}$ and $580{ }^{\circ} \mathrm{C}$ respectively. This is in agreement with the temperatures which are reported in literature [1]. Figure 3.8 indicates that silicon particles are the most dominant phase that can be found in the structure of the clad material. The range of stability for silicon particles are predicted to be between 25 to $580{ }^{\circ} \mathrm{C}$. Based on this calculation, $\beta$-AlFeSi particles with $0.5 \mathrm{wt} \%$ are the second dominant particle inside the clad structure. The presence of $\alpha-\mathrm{Al}(\mathrm{Fe}-\mathrm{Mn}) \mathrm{Si}$, and $\mathrm{Al}_{3} \mathrm{Fe}$ particles are also predicted but the amount is negligible $(<0.2 \mathrm{wt} \%)$. Similar calculations for the core material are presented in Figure 3.9. $\alpha$-Al (Fe-Mn)Si (5.5 $\mathrm{wt} \%), \mathrm{Al}_{6} \mathrm{Mn}(2.5 \mathrm{wt} \%)$ and $\mathrm{Al}_{2} \mathrm{Cu}(1.5 \mathrm{wt} \%)$ are predicted to be the dominant particles that exist in the core structure. $\mathrm{Al}_{13} \mathrm{Cr}_{4} \mathrm{Si}_{4}, \mathrm{Al}_{5} \mathrm{Cu}_{2} \mathrm{Mg}_{8} \mathrm{Si}_{6}, \mathrm{Al}_{3} \mathrm{M}$ (M is Fe, $\mathrm{V}$ or $\mathrm{Cr}$ ) are other intermetallic particles that can also exist. The amount of these particles are negligible $(<0.5 \mathrm{wt} \%)$. 


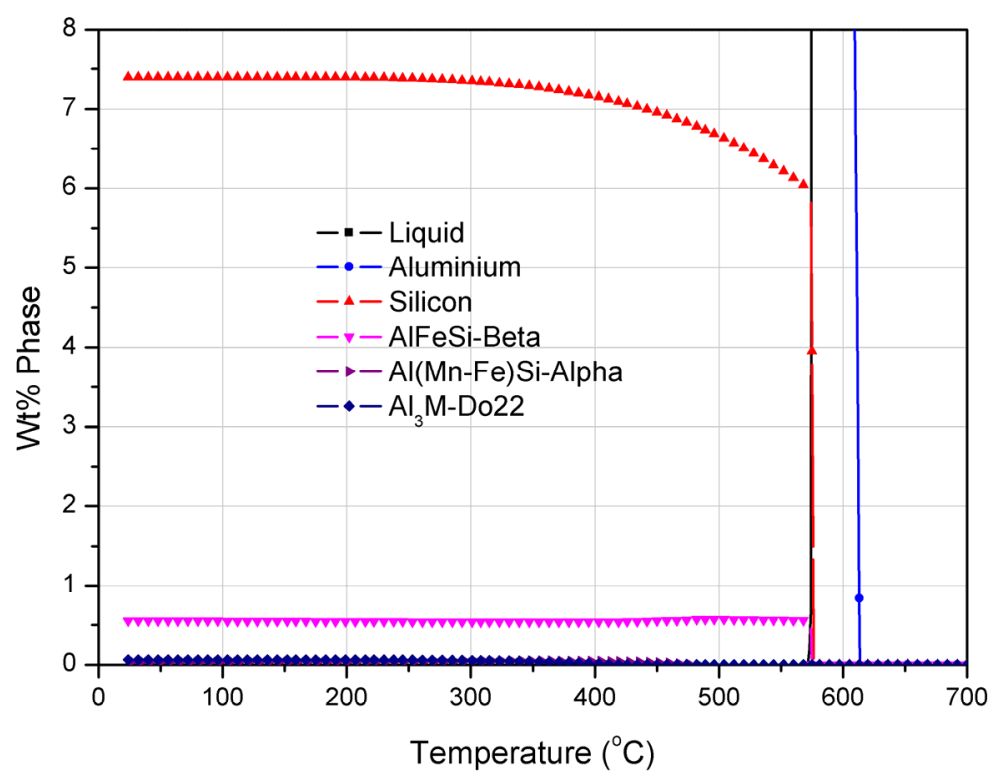

Figure 3.8. JmatPro calculation for equilibrium phases in AA4xxx clad material. Chemical composition (Table 3.1) and the temperature range $\left(25-650{ }^{\circ} \mathrm{C}\right)$, including the brazing process regime, are the input parameters for the JmatPro software calculations.

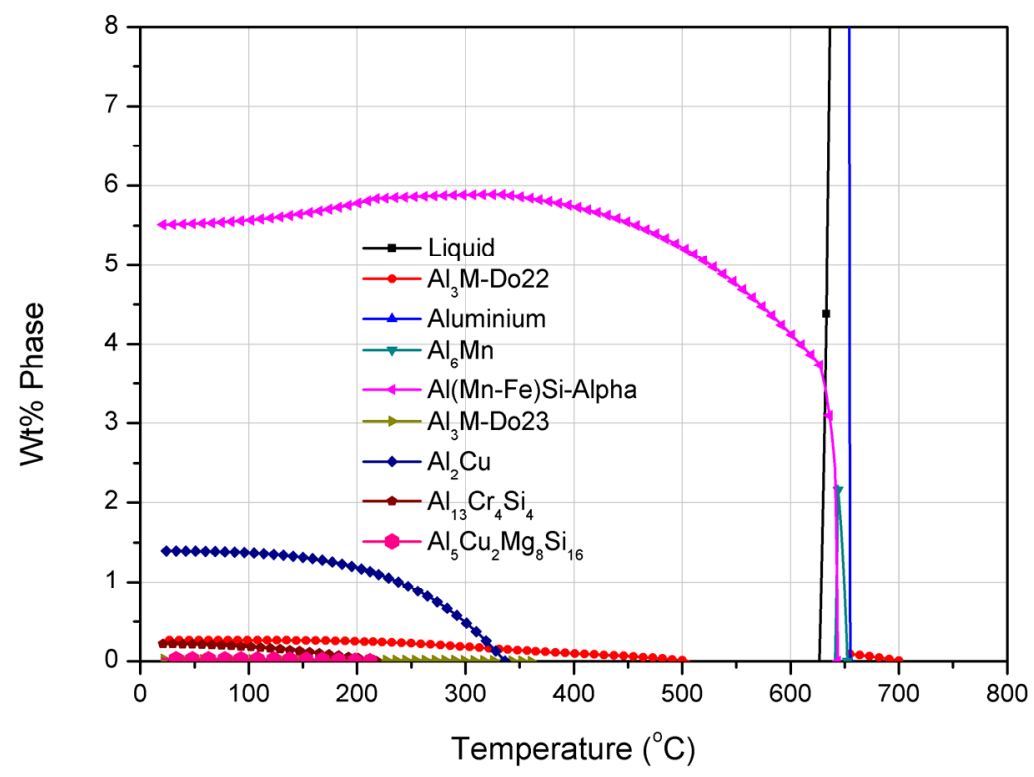

Figure 3.9. JmatPro calculation for equilibrium phases in the modified AA $3 x x x$ core material. Chemical composition (Table 3.1) and the temperature range (25$650{ }^{\circ} \mathrm{C}$ ), including the brazing process regime, are the input parameters for the JmatPro software calculations. 


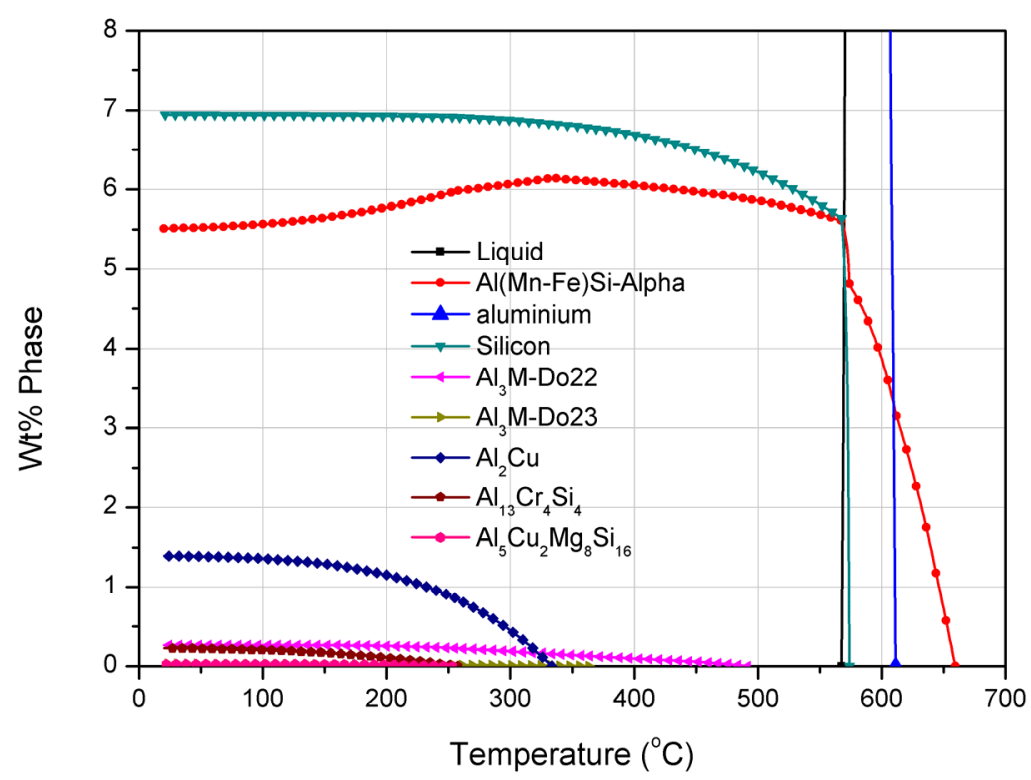

Figure 3.10. JmatPro calculation for equilibrium phases in diffusion zone AA4xxx/AA3xxx brazing sheet. Chemical composition (Table 3.1) and the temperature range $\left(25-650{ }^{\circ} \mathrm{C}\right)$, including the brazing process regime, are the input parameters for the JmatPro software calculations.

Calculation of the phases that can form in the diffusion zone between the clad and the core materials after the brazing process was also performed. The calculation is based on the maximum availability of the alloying elements in the interfaces. The concentration of each element in the clad and core was compared and the maximum value was considered to be the one in the diffusion zone. The predicted phases in the diffusion zone are presented in Figure 3.10. As the maximum concentration of each element (except for silicon) is the one in the core material, the predicted phases are similar to that of the core. The only difference is that no $\mathrm{Al}_{6} \mathrm{Mn}$ is predicted to exist in the diffusion zone.

\subsubsection{Electrochemical characterization}

The averaged OCP of both the brazed and non-brazed materials before anodic and cathodic polarizations are shown in Figure 3.11. The figure shows that the brazed samples have a nobler OCP compared to that of the non-brazed material. For the non-brazed material a potential difference of $10 \mathrm{mV}$ between the averaged initial transient potentials are observed.

The anodic and cathodic responses of both brazed and non-brazed materials are shown in Figures 3.12 and 3.13. Figure 3.12 shows that the anodic responses of the brazed and non-brazed material are quite similar. A sharp increase of the current density at potentials close to the OCP values is observed. The cathodic polarization 
responses of the brazed material show higher reactivity comparing to that of the non-brazed material. The OCP difference $(\sim 50 \mathrm{mV})$ between the brazed and non brazed material is indicated in Figure 3.13.

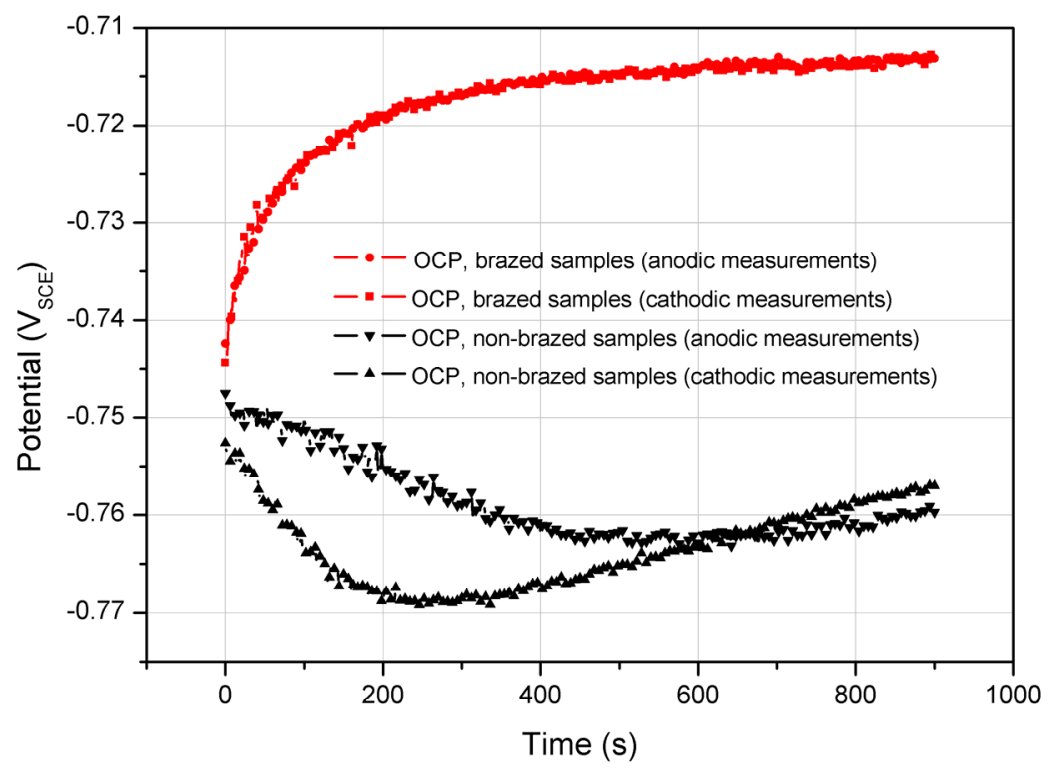

Figure 3.11. Averaged open-circuit corrosion potentials of the brazed and nonbrazed materials after 15 min of immersion in $42 \mathrm{~g} / 1 \mathrm{NaCl}$ solution at $\mathrm{pH} 2.8$, before anodic and cathodic polarizations.

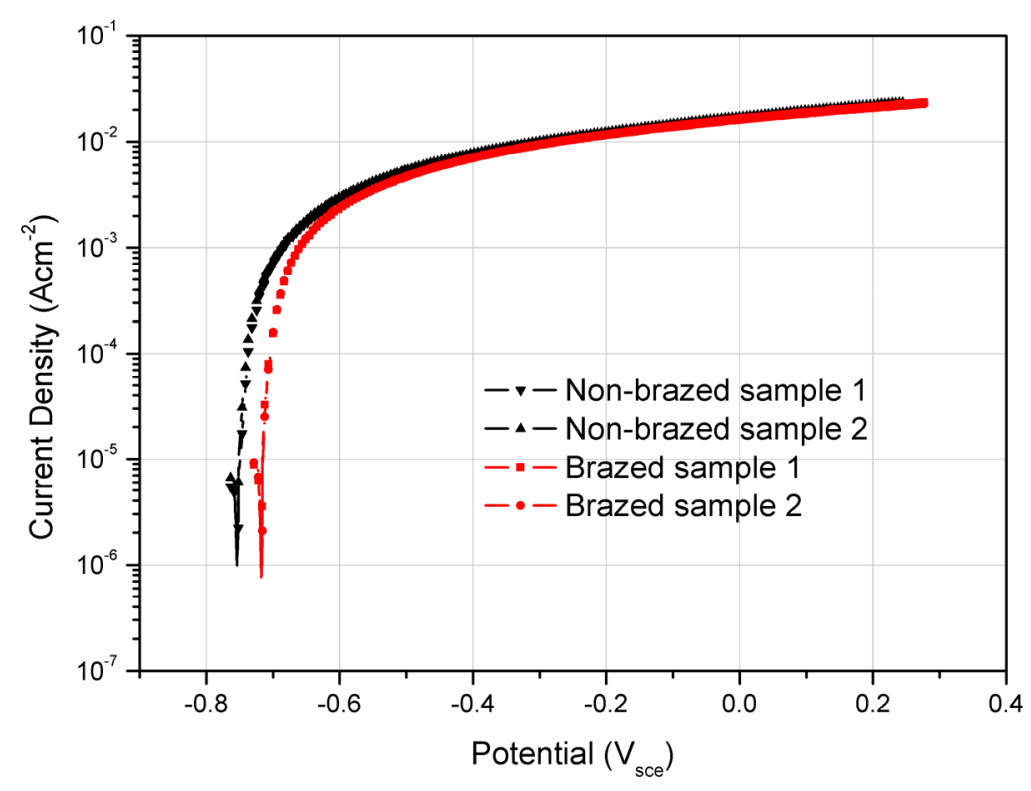

Figure 3.12. Anodic polarization curves for the brazing sheet material before and after brazing after 15 min of OCP measurement in $42 \mathrm{~g} / 1 \mathrm{NaCl}$ solution at $\mathrm{pH} 2.8$ (scan rate $0.5 \mathrm{mV} / \mathrm{s}$ ). 


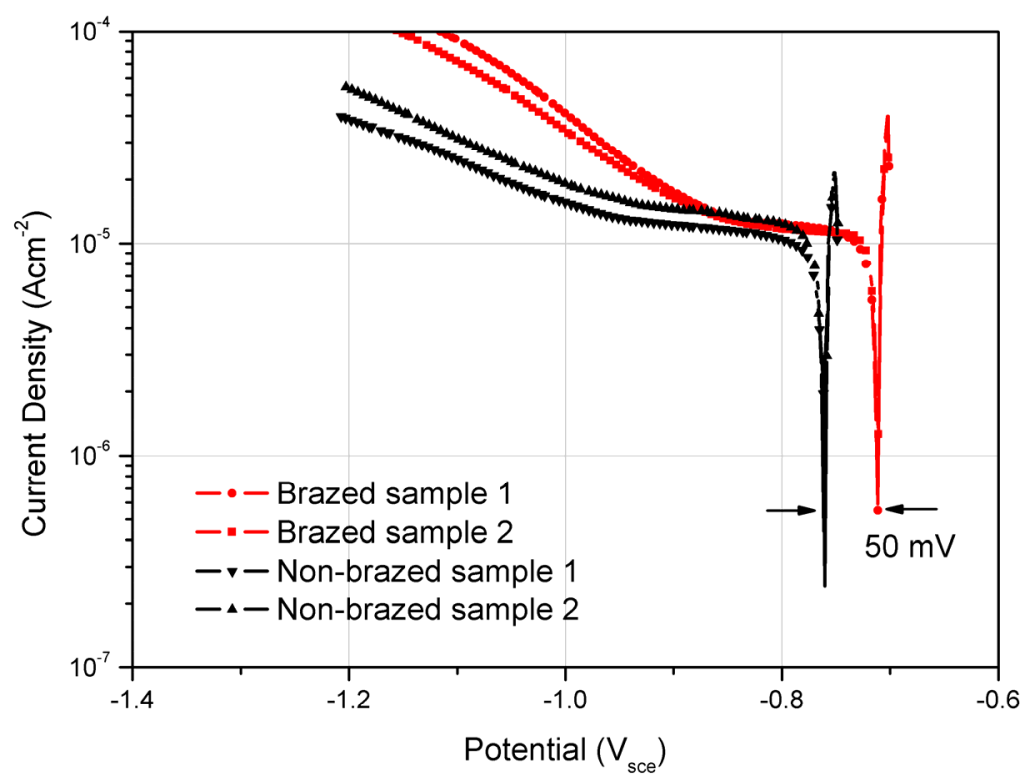

Figure 3.13. Cathodic polarization curves for the brazing sheet material before and after brazing after 15 min of OCP measurement in $42 \mathrm{~g} / 1 \mathrm{NaCl}$ solution at $\mathrm{pH} 2.8$ (scan rate $0.5 \mathrm{mV} / \mathrm{s}$ ).

\subsubsection{Corrosion morphology}

Typical SEM backscattered electron images of the surfaces and cross sections after anodic polarization up to $1 \mathrm{~V}$ above the OCP values are shown in Figure 3.14. Comparing the corroded surfaces in Figures 3.14a (brazed surface) and 3.14b (non-brazed surface) shows that the non-brazed material surface is attacked more uniformly and less severely than the surface of the brazed material. Figures $3.14 \mathrm{c}$ (brazed surface) and 3.14d (non-brazed surface), illustrate that the pitting and intergranular corrosion (IGC) is the corrosion attack mechanism for the brazed material, while for the non-brazed material the uniform pitting corrosion is the dominant mechanism of the attack. Comparing the cross-sections of the corroded samples in Figures 3.14e (brazed sample) and 3.14f (non-brazed sample) demonstrates that the brazed material has a high sensitivity to IGC and the attack has developed deep into the structure of the core material while for the non-brazed material the uniform pitting attack has been restricted to the clad layer. As outlined in the introduction of the manuscript, prior research [13-18] has indicated that $\mathrm{Si}$ particles are ineffective cathodic sites in this material, i.e. inefficient to anodically polarize the surrounding aluminium matrix and therefore may not be considered to be a dominant factor in causing local corrosion at and adjacent to these particles. In line with this, it is important to note that the corrosion mechanism in the unbrazed material originates from densely distributed local attack, resembling a relatively uniform and shallow corrosion attack of the material. 

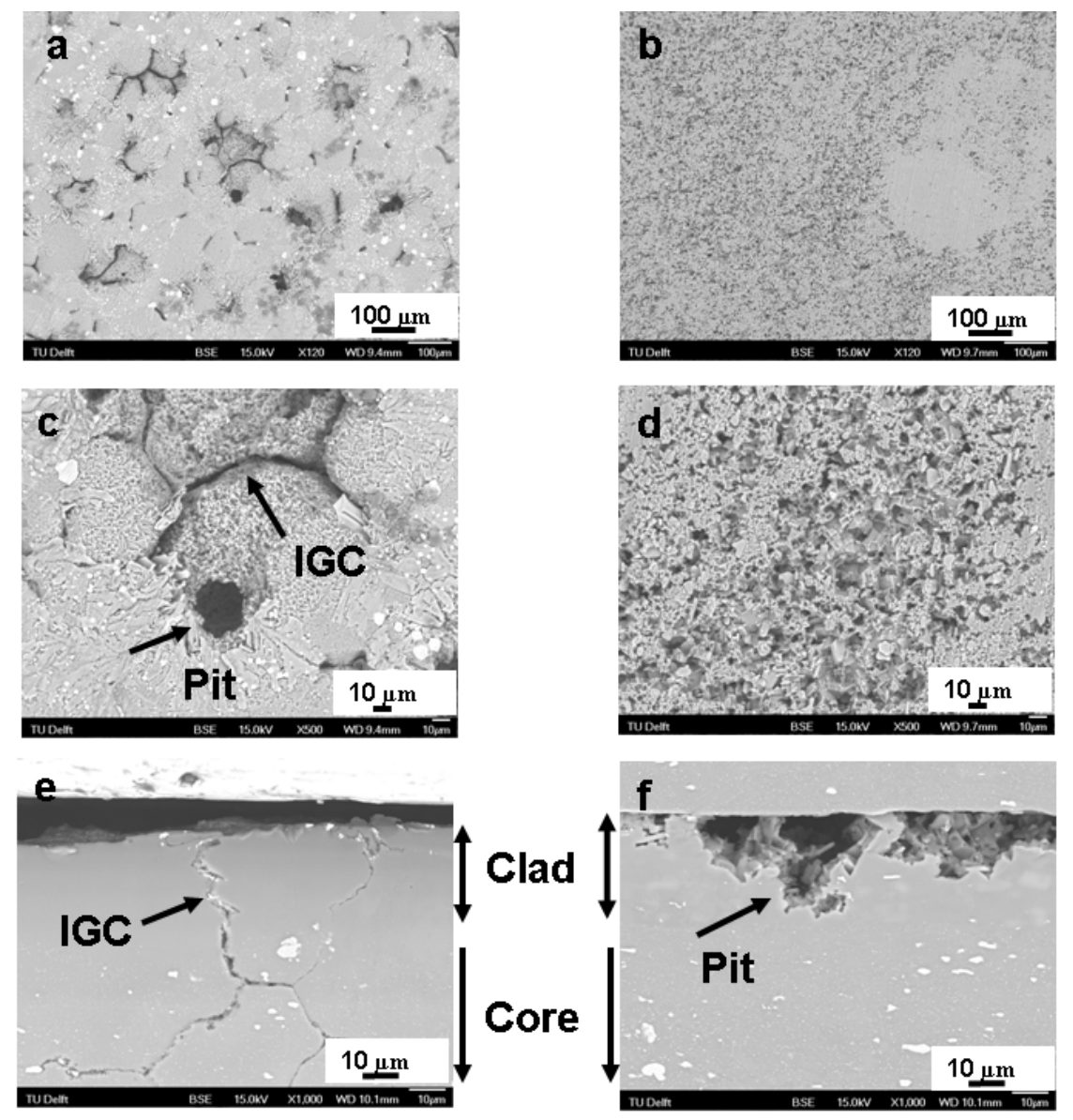

Figure 3.14. SEM backscattered electron images of the brazed (a, c) and nonbrazed (b, d) surfaces and brazed (e) and non-brazed (f) cross sections after anodic polarization up to $1 \mathrm{~V}$ above the OCP values.

\subsection{Discussion}

\subsubsection{Material characterization}

By combining the information from the micro-analysis, thermodynamic calculation and literature, the particles identification was performed. Based on elemental maps in Figure 3.4 and phase prediction in Figure 3.8 besides $\mathrm{Si}$ particles which are clearly identified, the iron containing particles with no $\mathrm{Mn}$ content are expected to be the $\beta$-AlFeSi phase that exists in the clad material before brazing. Although $\mathrm{Al}_{3} \mathrm{Fe}$ particle detection was not possible in the elemental maps of the clad material some $\alpha-\mathrm{Al}(\mathrm{Fe}-\mathrm{Mn}) \mathrm{Si}$ particles were detected. These particles were observed to be present close to the clad/core interface. These predictions are in good compliance with the work by Munson [22]. The author showed the composition domains in the ternary $\mathrm{Al}-\mathrm{Fe}-\mathrm{Si}$ system where $\mathrm{Al}_{3} \mathrm{Fe}$ and various $\mathrm{Al}-\mathrm{Fe}-\mathrm{Si}$ compounds appear. According to Lacaze et al [1] among these 
Al-Fe-Si compounds, the most important for aluminium alloys are hexagonal $\alpha$ AlFeSi and tetragonal (or monoclinic) $\beta$-AlFeSi. Munson [22] showed that when $\mathrm{Mn}$ is added at a level of $0.3 \mathrm{wt} \%$, a cubic $\alpha$-AlMnFeSi phase is stabilized in place of the hexagonal $\alpha$-AlFeSi, at least at low iron content. This phase has been reported to be isomorphic with the $\mathrm{Al}_{15} \mathrm{Mn}_{3} \mathrm{Si}_{2}$ phase generally referred to as $\alpha$ AlMnSi [1, 4, 10]. It should be noted that although Munson [22] indicated a minimum level of $0.3 \mathrm{wt} \%$ for Mn for alpha particle formation, Lacaze et al [1] claim that $0.15 \mathrm{wt} \%$ is sufficient. This would well justify the alpha particles detected in the clad material with a Mn concentration which is below $0.3 \mathrm{wt} \%$.

According to Lacaze et al [1] and Donnadiev et al [10] Mn strongly stabilizes the cubic $\alpha-\mathrm{Al}(\mathrm{Fe}-\mathrm{Mn}) \mathrm{Si}$ phase. This complies with the fact that no beta particle was predicted in the calculated phases for the core material which contains $1.03 \mathrm{wt} \%$ $\mathrm{Mn}$ as shown in Figure 3.9. Based on the phase prediction in Figure 3.9 and the elemental maps in Figures 3.4 and 3.5, the large particles $(>1-2 \mu \mathrm{m})$ and the small $(<1 \mu \mathrm{m})$ copper-free particles (see the copper maps) which contains $\mathrm{Si}, \mathrm{Mn}$, and Fe in addition to aluminium are expected to be $\alpha-\mathrm{Al}(\mathrm{Fe}-\mathrm{Mn}) \mathrm{Si}$ particles. According to $\mathrm{Li}$ et al [23], the constitution of this small particles is approximately $\mathrm{Al}_{12}$ ${ }_{13}(\mathrm{Mn}, \mathrm{Fe})_{3} \mathrm{Si}_{1 \cdot 2-2}$.

Based on elemental analysis of the material in Figure 3.4, in spite of the thermodynamic prediction in Figure 3.9, no $\mathrm{Al}_{6} \mathrm{Mn}$ is detected in pre-brazed condition. This is expected to be the result of the heat treatments (homogenization, annealing and pre-heating) during the material production that has caused the eutectoid transformation of these particles into alpha particles. This has been explained in detail by Li et al and Alexandre et al, [24-26].

Based on Figure 3.9, $\mathrm{Al}_{2} \mathrm{Cu}$ has been predicted to be the other dominant particle inside the core material structure. The copper map in Figure 3.4 shows that these are small particles that have been uniformly distributed through the core material. Comparing with the copper map in Figure 3.5, it seems that brazing has caused $\mathrm{Cu}$ depletion in particles and copper accumulation in the eutectic phases. It is assumed that high solubility of $\mathrm{Cu}$ in the liquid aluminium $(\sim 20 \mathrm{wt} \%$ [27]) accompanied with high diffusivity of copper $\left(6.42 \times 10^{-13} \mathrm{~m}^{2} / \mathrm{s}\right.$ at brazing temperature [28] $)$ in aluminium matrix is the major reason for this phenomenon.

Thermodynamic calculations presented in Figure 3.10 shows that a high $\mathrm{Si}$ content, which represents $\mathrm{Si}$ diffusion into the core material, has resulted in complete disappearance of the $\mathrm{Al}_{6} \mathrm{Mn}$ particles and increasing the amount of $\alpha$ $\mathrm{Al}(\mathrm{Fe}-\mathrm{Mn}) \mathrm{Si}$ particle in the alloy.

The result of particle identification and distribution analysis for the material before and after brazing is summarized in Figures 3.15 and 3.16, respectively. 


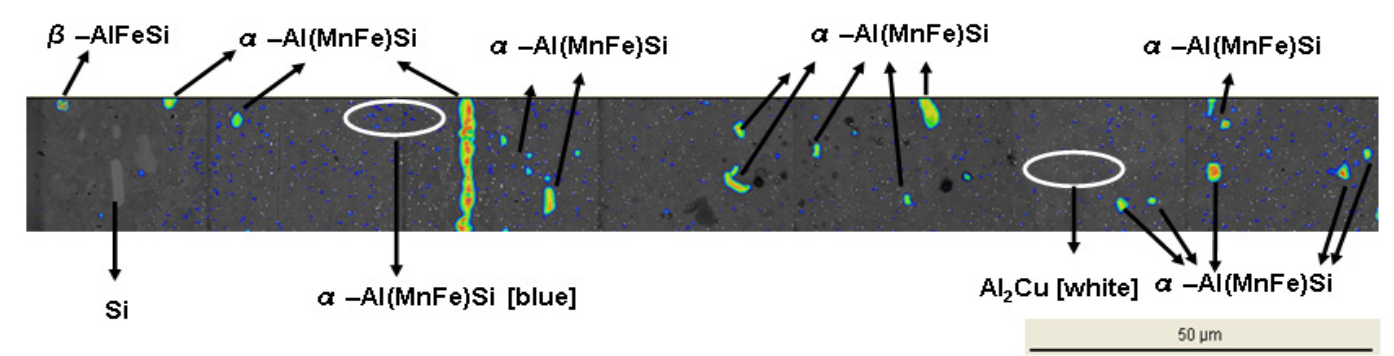

Figure 3.15. Particle identification on Fe spectrum for a non-brazed sample.

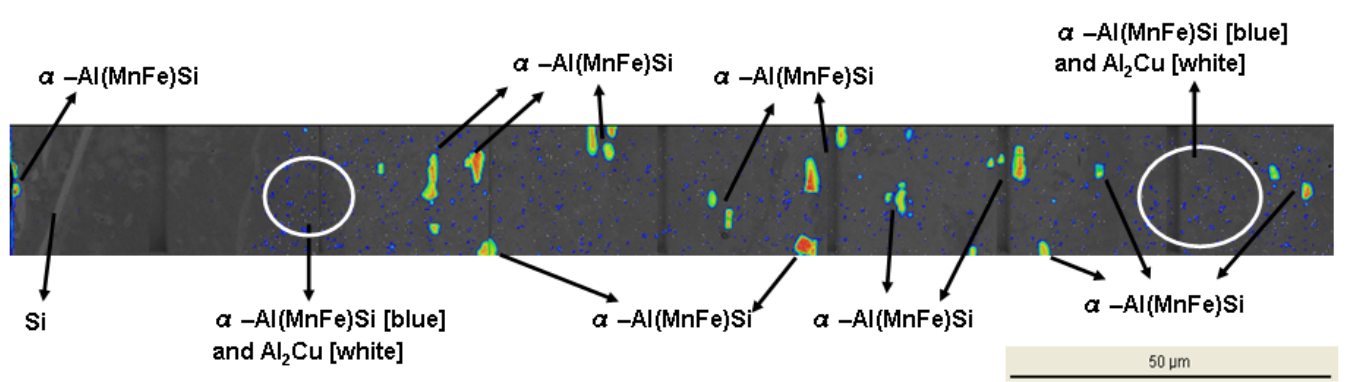

Figure 3.16. Particle identification on Fe spectrum for a brazed sample.

\subsubsection{Electrochemical characterization}

Applying the knowledge from the material characterization work, the corrosion performance of the structure before and after brazing is compared and correlated to the microstructural changes due to the brazing process. The nobler OCP for the brazed material can be attributed to the copper diffusion into the clad material. Although the diffusion of silicon from the clad to the core is expected to decrease the corrosion potential of the clad material, the copper diffusion has a stronger effect. The effect of alloying elements on the corrosion potential of aluminium alloys have been explained in detail by Davis [29] and Meijers [16]. The resulting electrochemical effect of the copper and silicon diffusion process is a $50 \mathrm{mV}$ increase of the open-circuit corrosion potential for the brazed material. This will decrease the capability of the re-solidified clad layer to sacrificially protect the core structure.

The similarity of the anodic polarization responses of the brazed and non-brazed material shows that a similar rate of corrosion in the SWAAT environment can be expected. The presence of a sharp increase in corrosion current density at potentials close to the OCP values in these anodic potentiodynamic responses shows the susceptibility of the structures to localized corrosion attack. Comparing the corrosion morphologies, the more severe and localized corrosion attack on the brazed material will result in a more rapid failure of this structure as compared to the non-brazed material. The susceptibility of the brazed structure to IGC is the result of eutectic transformation which is the last step of the solidification process 
and causes high concentration of copper to exist in the areas forming the grain boundaries. This is expected to cause the presence of copper depleted areas close to the grain boundaries which form a galvanic cell and react as anodes. This theory is the subject of further investigation. The IGC susceptibility of the re-solidified clad material will in return expose the core structure to the corrosive environment. Considering the reduction of copper content of the core material as a result of brazing, the brazed core material has a lower corrosion potential $[16,29]$ as compared to that of the non-brazed core structure and is more prone to be corroded. The brazed core material susceptibility to IGC can not be explained based on the existing material characterization work. The SEM/EDX analysis shows that the presence of the cathodic $\alpha-\mathrm{Al}(\mathrm{Mn}-\mathrm{Fe}) \mathrm{Si}$ intermetallics [17] in the grain boundaries can not be a satisfactory explanation as firstly, they are not continuously settled in grain boundaries and secondly corroded grains with no cathodic intemetallics present can also be observed.

The higher reactivity of the cathodic polarization responses of the brazed material is related to the accumulation of high $\alpha-\mathrm{Al}(\mathrm{Mn}-\mathrm{Fe}) \mathrm{Si}$ intermetallics on the surface, which not only disrupt the continuous oxide layer [18] of the surface but also provides cathodic sites for reduction reactions [17, 18]. Comparing the cathodic current densities of the brazed and non-brazed surfaces proves the lower cathodic reactivity of the silicon particles which are the dominant particles on the surface of the non-brazed material with respect to that of the $\alpha-\mathrm{Al}(\mathrm{Mn}-\mathrm{Fe}) \mathrm{Si}$ intermetallics which are the dominant particles on the surface of the brazed material.

\subsection{Conclusion}

Re-solidification of an AA4xxx cladding as well as the related particle formation and elemental distribution in a modified AA3xxx core material before and after brazing were studied. Based on the material characterization results the effect of the brazing process on the corrosion performance of the brazing sheet material was investigated and correlated to the microstructural evolution due to brazing process. The results showed that:

1. Besides silicon (which is the most dominant particle), $\beta$-AlFeSi and $\alpha-\mathrm{Al}(\mathrm{Fe}-$ $\mathrm{Mn}) \mathrm{Si}$ are the other existing primary particles in the unbrazed clad material. $\alpha$ $\mathrm{Al}(\mathrm{Fe}-\mathrm{Mn}) \mathrm{Si}$ and $\mathrm{Al}_{2} \mathrm{Cu}$ were found to be the primary dominant particles that exist in the core structure.

2. Accumulation of copper on the surface of the re-solidified clad material, the reduction of the copper content of the particles and the increase of silicon concentration in the diffusion zone were found to be the major changes that occurred due to brazing.

3. Regarding the size, two types of particles are distinguished. One is the particles 
which are larger than 1-2 $\mu \mathrm{m}$ and their sizes can reach up to $20 \mu \mathrm{m}$. These are mainly $\alpha$-Al(Fe-Mn)Si particles. The second group contains particles with sizes below $1 \mu \mathrm{m}$. These are mainly $\mathrm{Al}_{2} \mathrm{Cu}$ and $\alpha$-Al(Fe-Mn)Si particles. The $\alpha-\mathrm{Al}(\mathrm{Fe}-$ $\mathrm{Mn}) \mathrm{Si}$ particles are mainly accumulated at the surface, in the diffusion zone and the core material.

5. Copper diffusion has resulted in a $50 \mathrm{mV}$ increase in the open circuit corrosion potential of the re-solidified clad material.

6. Copper accumulation in the eutectic phase is expected to be the cause for the IGC susceptibility of the re-solidified clad material.

7. Formation of $\alpha-\mathrm{Al}(\mathrm{Fe}-\mathrm{Mn}) \mathrm{Si}$ particles on the surface of the brazed material will increase the cathodic reactivity of the surface 


\subsection{References}

[1]. J. Lacaze, S. Tierce, M.C. Lafont, Y. Thebault, N. Pebere, G. Mankowski, C. Blanc, H. Robidou, D. Vaumousse, D. Daloz, Study of the microstructure resulting from brazed aluminium materials used in heat exchangers, Materials Science and Engineering A, 414 (2005) 317-321.

[2]. M.H. Mulazimoglu, A. Zaluska, J.E. Gruzleski, F. Paray, Electron microscope study of Al-Fe- Si intermetallics in 6201 aluminum alloy, Metallurgical and Materials Transactions A, 27 (1996) 929-936.

[3]. N.C.W. Kuijpers, W.H. Kool, P.T.G. Koenis, K.E. Nilsen, I. Todd, S. van der Zwaag, Assessment of different techniques for quantification of a-Al(FeMn)Si and b-AlFeSi intermetallics in AA 6xxx alloys, Materials Characterization, 49 (2003) 409-420.

[4]. H. Tanihata, T. Sugawara, K. Matsuda, S.J. Ikeno, Effect of casting and homogenizing treatment conditions on the formation of $\mathrm{Al}-\mathrm{Fe}-\mathrm{Si}$ intermetallic compounds in $6063 \mathrm{Al}-\mathrm{Mg}-\mathrm{Si}$ alloys, Journal of Materials Science, 34 (1999) 12051210.

[5]. N.C.W. Kuijpers, J. Tirel, D.N. Hanlon, S. van der Zwaag, Quantification of the evolution of the 3D intermetallic structure in a 6005A series aluminum alloy during a homogenisation treatment, Materials Characterization, 48 (2002) 379-392.

[6]. S. Zajac, L.O. Gullman, A. Johansson, B. Bengtsson, Hot ductility of some Al-Mg-Si alloys, Materials Science Forum, 217 (1996) 1193-1198.

[7]. T. Minoda, H. Hayakawa, A.H. Yoshid, The quantitative analysis of alpha-AlFeSi ratio in a 6063 aluminum alloy billet by X-ray diffraction, Journal of Materials Science and Technology, 7 (2000) 13-17.

[8]. M.P. Clode, T. Sheppard, Surface generation and origin of defects during extrusion of aluminium alloys, Proc. Aluminium Technology. Conf., London (UK), 1986; The Institute of Metals, p.230-239.

[9]. C.M. Allen, K.A.Q. O'Reilly, B. Cantor, P.V. Evans, Intermetallic phase selection in 1XXX Al alloys, Materials Science Forum, 217 (1996) 678-684.

[10]. P. Donnadieu, G. Lapasset, T.H. Sanders, Manganese induced ordering in the a-(Al$\mathrm{Mn}-\mathrm{Fe}-\mathrm{Si}$ ) approximant phase, Philosophical Magazine Letters, 70 (1994) 319-326.

[11]. A.C. Scott, R.A. Woods, J.F. Harris, SAE: Conference Proceedings of SAE international Congress, Accelerated corrosion test methods for evaluating external corrosion resistance of vaccumed brazed aluminium heat exchangers, SAE, Warrendale, USA, 1991, paper No. 910590.

[12]. Y. Isobe, K. Takeuchi, M. Tanaka, M. Mori, S. Yamauchi, K. Namba, Development of corrosion resistant brazing sheet for drawn cup type evaporators part 2: Application to evaporator, SAE: Conference Proceedings of SAE international Congress, SAE, Warrendale, USA, 1993, paper No. 930149.

[13]. F.M. Al-Kharafi, W.A. Badawy, Corrosion and Passivation of Al and Al-Si Alloys in Nitric Acid Solutions: 2- Effect of Chloride Ions, Electrochimica Acta, 40 (1995) 1811-1817.

[14]. S.S. Abdel Rehim, H.H. Hassan, M.A. Amin, Chronoamperometric studies of pitting corrosion of $\mathrm{Al}$ and (Al-Si) alloys by halide ions in neutral sulphate solutions, Corrosion Science, 46 (2004) 1921-1938.

[15]. S. Kuroda, K. Tohma, Aluminium Alloys: Conference Proceedings of ICAA6, the Japan Institute of Light Metals, Toyohashi, Japan, 1998, p. 1543. 
[16]. S. Meijers, Corrosion of aluminium brazing sheet, PhD Thesis, 2002, ISBN 90805661-3-6.

[17]. K. Nisancioglu, Electrochemical behavior of aluminum-base intermetallics containing iron, Journal of The Electrochemical Society, 137 (1990) 69-77.

[18]. S. Tierce, N. Pebere, C. Blanc, C. Casenave, G. Mankowski, H. Robidou, Corrosion behavior of brazing material AA4343, Electrochimica Acta, 52 (2006) 1092-1100.

[19]. F.N. Afshar, E. Szala, A. Wittebrood, R. Mulder, J.M.C. Mol, H. Terryn, J.H.W. de Wit, Influence of material related parameters in sea water acidified accelerated test, reliability analysis and electrochemical evaluation of the test for aluminium brazing sheet, Corrosion Science, 53 (2011) 3923-3933.

[20]. A. Wittebrood, Microstructural changes in brazing sheet due to solid-liquid interaction, PhD thesis, 2009, ISBN 978-90-805661-6-3.

[21]. D.J. Schmatz, Grain Boundary Penetration During Brazing of Aluminum, Welding Journal, 10 (1983) 267-271.

[22]. D.J. Munson, A clarification of the phases occurring in aluminium-rich aluminiumiron-silicon alloys, with particular reference the ternary phase $\alpha$-AlFeSi Journal of the Institute of Metals, 95 (1967) 217-219.

[23]. Y.J. Li, L. Arnberg, Quantitative study on the precipitation behavior of dispersoids in Dc-cast AA3003 alloy during heating and homogenization, Acta Materialia, 51 (2003) 3415-3428.

[24]. Y.J. Li, L. Arnberg, Evolution of eutectic intermetallic particles in DC-Cast AA3003 alloy during heating and homogenization, Materials Science and Engineering A, 347 (2003) 130-135.

[25]. D.T.L. Alexandre, A.L. Greer, Nucleation of the $\mathrm{Al}_{6}(\mathrm{Fe}, \mathrm{Mn})$ to $\alpha-\mathrm{Al}(\mathrm{Fe}, \mathrm{Mn}) \mathrm{Si}$ transformation in $3 \times x x$ aluminium alloys. I. Roll-bonded diffiusion couples, Philosophical Magazine, 84 (2004) 3051-3070.

[26]. D.T.L. Alexandre, A.L. Greer, Nucleation of the $\mathrm{Al}_{6}(\mathrm{Fe}, \mathrm{Mn})$ to $\alpha-\mathrm{Al}(\mathrm{Fe}, \mathrm{Mn}) \mathrm{Si}$ transformation in $3 \mathrm{xxx}$ aluminium alloys. II. Transformation in cast aluminium alloys, Philosophical Magazine, 84 (2004) 3071-3080.

[27]. ASM handbooks, Vol. 3, Alloy Phase Diagrams, 2011.

[28]. D. Simonovic, M.H.F. Sluiter, Impurity diffusion activation energies in Al from first principles, Phys. Rev. B 79. 054304 (2009).

[29]. J.R. Davis, ASM Specialty Handbook, Aluminium and aluminium alloys, ed. JR Davis, ASM International, Ohio, USA, 1994. 


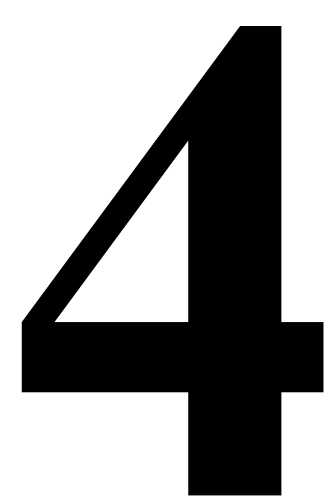

* This chapter has been published as a scientific paper:

F. Norouzi Afshar, R. Ambat, C. Kwakernaak, J.H.W. de Wit, J.M.C. Mol, H. Terryn, Electrochemical depth profiling of multilayer metallic structures: an aluminium brazing sheet, Electrochimica Acta 77 (2012), 285-293. 



\section{Microstructural characterization and electrochemical depth profiling}

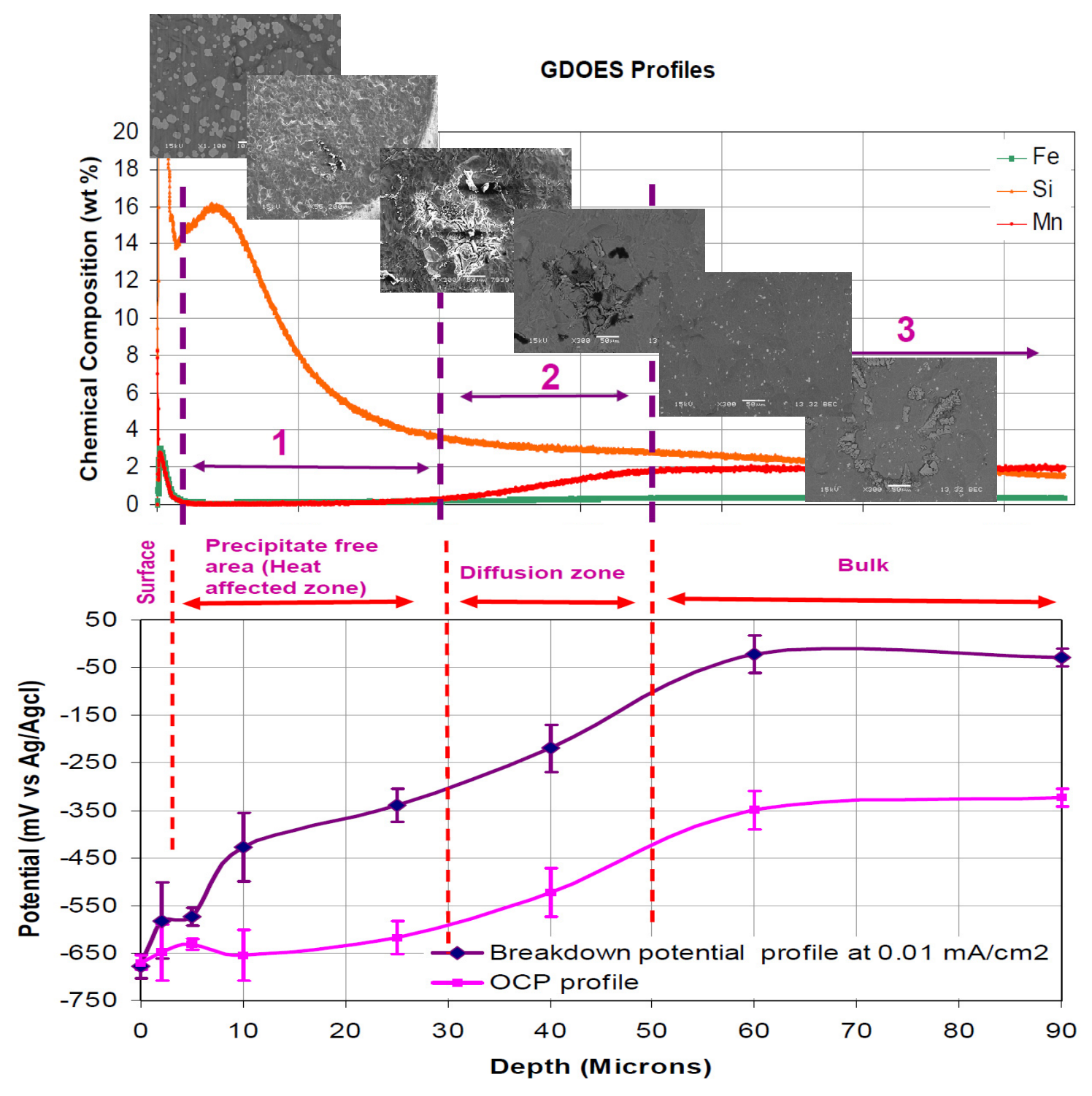




\begin{abstract}
Combinatory localized electrochemical cell and glow discharge optical emission spectrometry (GDOES) measurements were performed to obtain a thorough in depth electrochemical characterization of an aluminium brazing sheet. By defining electrochemical criteria i.e. breakdown potential, corrosion potential, cathodic and anodic reactivities, and tracking their changes as a function of depth, the evolution of electrochemical responses through out the material thickness were analyzed and correlated to the corresponding microstructural features. Polarization curves in 1 $\mathrm{wt} \% \mathrm{NaCl}$ solution at $\mathrm{pH} 2.8$ were obtained at different depths from the surface using controlled sputtering in a glow discharge optical emission spectrometer as a sample preparation technique. The anodic and cathodic reactivity of the top surface areas were significantly higher than that of the bulk, thus indicating these areas to be more susceptible to localized attack. Consistent with this, optical microscopy and scanning electron microscope analysis revealed a relatively high density of fine intermetallic and silicon particles at these areas. The corrosion mechanism of the top layers was identified to be intergranular and pitting corrosion, while lower sensitivity to these localized attacks were detected towards the brazing sheet core. The results highlight the successful application of the electrochemical depth profiling approach in prediction of the corrosion behaviour of the aluminium brazing sheet and the importance of the electrochemical activity of the outer $10 \mu \mathrm{m}$ in controlling the corrosion performance of the aluminium brazing sheet.
\end{abstract}

\title{
4.1. Introduction
}

Aluminium alloys are commonly used for heat exchangers in the automotive industry due to an interesting combination of properties like low density, good thermal conductivity, satisfactory mechanical properties, and relatively good corrosion resistance. Since the mid-1990s, the trend in automotive heat exchangers has been to replace mechanical assembly by brazing of aluminium alloys mainly to decrease the cost [1]. Aluminium brazing sheet consists of multilayer materials composed of an AA3xxx core alloy clad on one or both sides with an AA4xxx alloy. The demands for reduction in fuel consumption and green house gasses have stimulated ongoing efforts towards the use of lighter and thinner materials in automobile industry [2-4]. Down gauging the aluminium sheet for heat exchangers is an important part of these efforts. Alloy development for down gauged heat exchangers focuses on higher strength in order to maintain the same overall strength of the heat exchanger, and at the same time keeping the other properties at least at the same level. One of these properties is the corrosion resistance $[5,6]$. Local electrochemical measurement of substrate surfaces is critical for a fundamental understanding of the local electrochemical behaviour of metals. In recent decades, a range of local electrochemical techniques has been developed to investigate the heterogeneous electrochemical reactivity of surfaces $[7,8]$. The micro-capillary cell is a technique that has been developed to perform 
electrochemical measurements on areas with dimensions in micrometer range [914]. Local investigations are possible by decreasing the size of the exposed area of the sample surface, which is achieved by using a micro-capillary to bring the sample surface locally in contact with the electrolyte. Another localized electrochemical technique uses plastic pipettes with tip diameter sizes ranging from $300 \mu \mathrm{m}$ to $1 \mathrm{~mm}$, which is easy to use and more versatile for many applications for electrochemical analysis of heterogeneous surfaces. A typical localized electrochemical system of this type and design is used by Ambat and coworkers [15-21].

Applying glow discharge optical spectroscopy (GDOES) and a micro-capillary set up, Bello Roderiguez et al [22] investigated the effect of intermetallic particles and rolled-in oxides present in the sub-surface on the AC-electrograining of commercial aluminium alloys. The subsurface was exposed by sputtering the aluminium samples for short times with GDOES. The low energy required for this sputtering technique $(50-200 \mathrm{eV})$ ensures that the material is not deformed or affected by the deposition of other elements [22]. Local electrochemical analysis were conducted with a micro-capillary cell set up developed by Suter and Bohni [11]. Buytaert et al. used GDOES as sample preparation method, which made it possible to compare the electrochemical behaviour at depths of $0.5 \mu \mathrm{m}$ and $10 \mu \mathrm{m}$ to the as received surface of a hot rolled aluminium alloy $\mathrm{AlMg} 0.5$ [23, 24].

Using GDOES sputtering for sample preparation, the highly deformed, micrograined layer on the outermost surface of a rolled Al-Fe-Si-Mn model alloy was electrochemically characterized by Ambat et al. [25]. The working electrodes were prepared by masking the surface outside the craters and macroscopic electrochemical polarization measurements were performed to obtain the electrochemical response as a function of sputter depth.

While some efforts [22-25] have been published on the application of GDOES sputtering as sample preparation technique for electrochemical analysis, no work has been focused on the combination of the localized electrochemical cell technique and GDOES for electrochemical depth profiling analysis. Applying electrochemical criteria i.e. breakdown potential, corrosion potential, pitting potential, cathodic and anodic reactivities and tracking their changes as a function of depth, combined with a through depth microstructural analysis, the current study aims to analyze the evolution of electrochemical responses through the material and correlate them to the microstructural features developed due to the brazing process in a modified aluminium brazing sheet. The detailed and fundamental mechanistic understanding of the developed electrochemical profile aims to predict the corrosion behaviour and finally provide enhanced corrosion protection by microstructural control of the aluminium brazing sheet. 


\subsection{Experimental}

\subsubsection{Materials}

A4 size sheet was cut from rolled modified AA3xxx aluminium alloy $(185 \mu \mathrm{m}$ thick) clad on one side with an AA4xxx (15 $\mu \mathrm{m}$ thick). The bulk chemical analysis of the clad and the core materials was obtained by X-Ray Fluorescence analysis (XRF) of $3 \mathrm{~cm}$ diameter discs of the material. PW2400 equipment with a Rhodium anode and a $60 \mathrm{kV}$ acceleration voltage was used. The data was analyzed with UniQuant software and is presented in Table 4.1.

Table 4.1. Chemical composition (wt \%) of the AA3xxx (core) and AA4xxx (clad)

\begin{tabular}{ccccccccc}
\multicolumn{7}{c}{ material. } \\
\hline & $\mathrm{Si}$ & $\mathrm{Fe}$ & $\mathrm{Cu}$ & $\mathrm{Ti}$ & $\mathrm{V}$ & $\mathrm{Cr}$ & $\mathrm{Mn}$ & $\mathrm{Al}$ \\
Clad & 7.70 & 0.18 & - & 0.01 & - & - & 0.14 & Bal. \\
Core & 0.44 & 0.32 & 0.6 & 0.08 & 0.01 & 0.07 & 1.03 & Bal. \\
\hline
\end{tabular}

\subsubsection{Brazing procedure}

The sheet was cleaned in an ultrasonic bath with ethanol, dried and placed in a Controlled Atmosphere Brazing (CAB) furnace. CAB is brazing in a dry, inert nitrogen gas atmosphere. The material is heated up to $600{ }^{\circ} \mathrm{C}$ and is kept at that temperature for $3 \mathrm{~min}$ and is then cooled down with a specified ramp $\left(60^{\circ} \mathrm{C} / \mathrm{Min}\right)$. The holding temperature was selected to be close to the liquidus temperature of the clad material, reported as $612^{\circ} \mathrm{C}$ by Lacaze et al. [26] while far below the solidus temperature of the core material which is about $640^{\circ} \mathrm{C}[27]$.

\subsubsection{Etching pre-treatment}

The brazed samples were etched to different depths using glow discharge optical emission spectroscopy (GDOES) argon ion sputtering. The argon pressure was kept at $650 \mathrm{~Pa}$ and $40 \mathrm{~W}$ power was applied. The calibration of depth versus etching time for the GDOES craters was carried out using a Wyko Vertical Scanning Interferometry (VSI) surface profiler. The diameter of the GDOES crater was $4 \mathrm{~mm}$. In depth distribution of alloying elements ( $\mathrm{Fe}, \mathrm{Mn}, \mathrm{Cu}$ and $\mathrm{Si}$ ) were further examined by GDOES depth profiling analysis. This was used to identify the area through the depth of the brazing sheet where the crater was made. The result was also used to explain the electrochemical responses of the material at different depths.

\subsubsection{Electrochemical investigations}

The anodic and cathodic reactivity of the material at different depths was studied 
using potentiodynamic polarization experiments on specimens that were etched to different depths by GDOES sputtering. All the electrochemical experiments were performed with a Dualscope EC localized electrochemical cell with a $1 \mathrm{~mm}$ diameter pipette tip. The system involves the use of an electrochemical head consisting of necessary reference and counter electrodes, open to a reservoir cavity to which the plastic tip with micron scale opening is attached to make the contact with the working electrode similar to glass tip in the case of high resolution microelectrochemical systems. This system uses an open tip with a hanging droplet and during measurements the tip will be positioned with a gap of approximately 100 $\mu \mathrm{m}$ from the test surface. The hanging droplet is achieved using an airtight system with a precise solution pushing mechanism [15,16,28-31]. Prior to positioning the tip to the surface of the test specimen, a small amount of solution is always purged out followed by a gentle cleaning of the tip by rubbing against a flat surface to ensure no extra solution at the tip. This ensures a tip with solution layer exactly to the tip opening, while wetting of the surface is achieved by gently collapsing the tip to the surface followed by retracting the tip by $100 \mu \mathrm{m}$ to ensure a gap between tip and surface. Surface tension will guarantee wetting of the surface, stability and shape of the droplet.

Electrochemical polarization experiments were performed relative to a saturated $\mathrm{Ag} / \mathrm{AgCl}$ reference electrode. A polarization scan was carried out either in the anodic (from OCP up to $300 \mathrm{mV}$ vs. OCP) or cathodic (from OCP down to -200 $\mathrm{mV}$ vs. OCP) direction at a rate of $1 \mathrm{mVs}^{-1}$, after allowing a steady-state potential to develop for $10 \mathrm{~min}$. The open circuit potential of the samples was monitored as a function of time.

A solution of $1 \mathrm{wt} \% \mathrm{NaCl}$ with $\mathrm{pH}$ of 2.8 (adjusted with $\mathrm{HCl}$ and $\mathrm{NaOH}$ ) was used as the electrolyte. All experiments were conducted at room temperature. The solution was prepared using the salt specified for Sea Water Acidified Accelerated Test (SWAAT) in deionised water. SWAAT is the most common accelerated corrosion test used for aluminium brazing sheet [32].

\subsubsection{Microstructure and composition analysis}

The microstructure and surface morphology of the corroded surfaces as well as that of the brazing sheet material before and after brazing were characterized using optical and scanning electron microscope (SEM, JEOL JSM 6500F). The SEM is equipped with an energy dispersive spectrometer (EDS, Thermo Fisher Ultra Dry detector $\left(30 \mathrm{~mm}^{2}\right)$ operated with Noran System 7 for X-ray micro analysis (XMA)).

Applying Electron Probe X-ray Micro Analysis (EPMA), quantitative line scans were recorded crossing the outer $50 \mu \mathrm{m}$ layer of the brazed structure. The measurements were performed with a JEOL JXA 8900R microprobe using an 
electron beam with energy of $15 \mathrm{keV}$ and a beam current of $50 \mathrm{nA}$ employing Wavelength Dispersive Spectrometry (WDS). The composition at each analysis location of the sample was determined using the X-ray intensities of the constituent elements after background correction relative to the corresponding intensities of reference materials. The points of analysis were located along a line with increments of $1 \mu \mathrm{m}$ for the quantitative line scans.

\subsubsection{Corrosion attack mechanism investigation}

The most common way to measure the corrosion resistance of heat exchanger materials, both for tube and fin alloys is the so called SWAAT [32]. SWAAT samples of $50 \mathrm{~mm} \times 100 \mathrm{~mm}$ were prepared. The back side was covered with $3 \mathrm{M}$ Scotch brand tape M470, and the edges were protected with bee wax. The test comprises a repetitive 2-h cycle consisting of 30 minutes spray followed by a 90 minutes soak at above $98 \%$ humidity [32]. The spray is a solution of $42 \mathrm{~g} / 1 \mathrm{of}$ sodium chloride and is acidified with $10 \mathrm{ml} / 1$ of glacial acetic acid. The $\mathrm{pH}$ is then adjusted with $10 \mathrm{wt} \% \mathrm{NaOH}$ solution to a value between 2.8 and 3.0 [32]. The temperature during spray and soak was kept constant at $49{ }^{\circ} \mathrm{C}$. Optical micrographs from the cross-sectional analysis of the samples after SWAAT were investigated.

\subsection{Results}

\subsubsection{Microstructural analysis}

Optical images of the material under investigation both before (a) and after brazing (b) are shown in Figure 4.1.

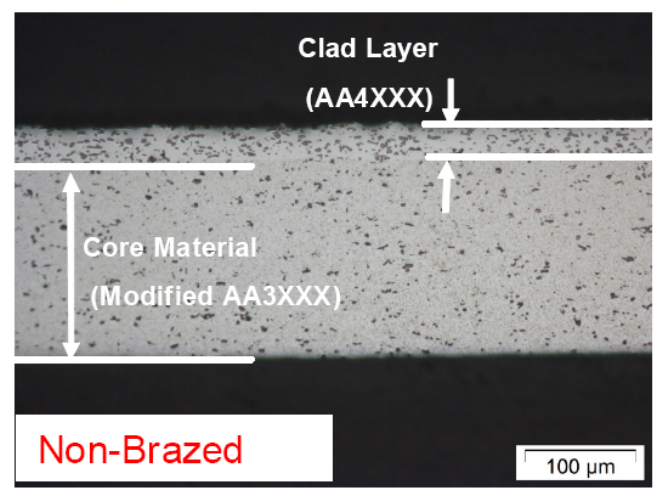

(a)

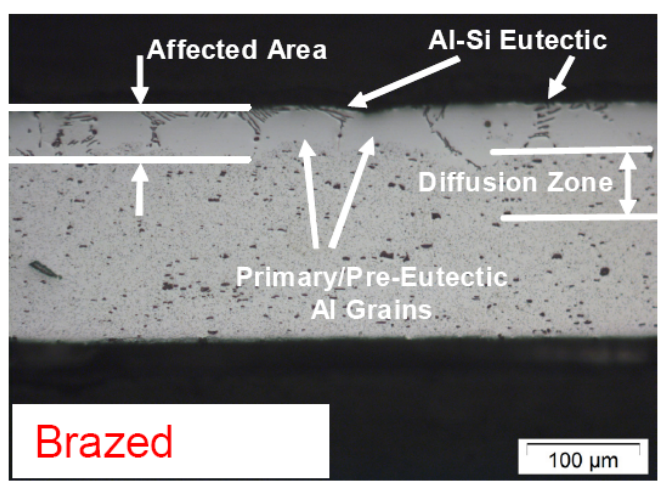

(b)

Figure 4.1. Optical images of the brazing sheet structure before (a) and after brazing (b).

The image of the material before brazing shows the clad layer with a brighter contrast. The elongated coarse particles with a dark gray contrast in the clad layer are Si particles. X-ray micro analysis revealed also the presence of some small 
additional precipitates containing $\mathrm{Al}, \mathrm{Fe}, \mathrm{Cu}$, and $\mathrm{Si}$. In the core material a wider variety of particles exists with different sizes and chemical compositions. Regarding the size, two types of particles are distinguished. One is the particles which are larger than 1-2 $\mu \mathrm{m}$ and their sizes can reach up to $20 \mu \mathrm{m}$. These are mainly $\alpha-\mathrm{Al}(\mathrm{Fe}-\mathrm{Mn}) \mathrm{Si}$ particles. The second group contains particles with sizes below $1 \mu \mathrm{m}$. These are mainly $\mathrm{Al}_{2} \mathrm{Cu}$ and $\alpha$-Al(Fe-Mn)Si particles. The detailed microstructural characterization of the material has been discussed in chapter 3 .

At brazing temperature the liquid clad is in intimate contact with the solid core material. During this stage where the two phases co-exist, an interaction between the two can take place. The liquid originating at the clad-core interface progresses into the core alloy as a film, changing the element distribution on its way [34,35]. This area is the affected area which has been designated in Figure 4.1b. The area is free from precipitates. The Al-Si eutectic phase is shown to be accumulated at the surface and in between the pre-eutectic aluminium grains. As silicon is the most diffusive element that diffuses into the core material the diffusion path of this element is considered to be the diffusion layer. This layer was measured to be about $40 \mu \mathrm{m}[33]$.

The EPMA analysis results and the position of the line scan are shown in Figure 4.2 $\mathrm{a}$ and $\mathrm{b}$. Quantitative line scans for the elements $\mathrm{Mn}, \mathrm{Fe}, \mathrm{Cu}, \mathrm{Si}$ and $\mathrm{Al}$ across the outer $50 \mu \mathrm{m}$ layer of the brazed structure are presented in Figure 4.2.

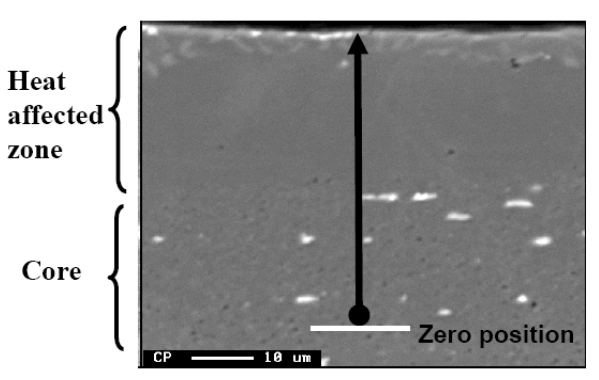

(a)

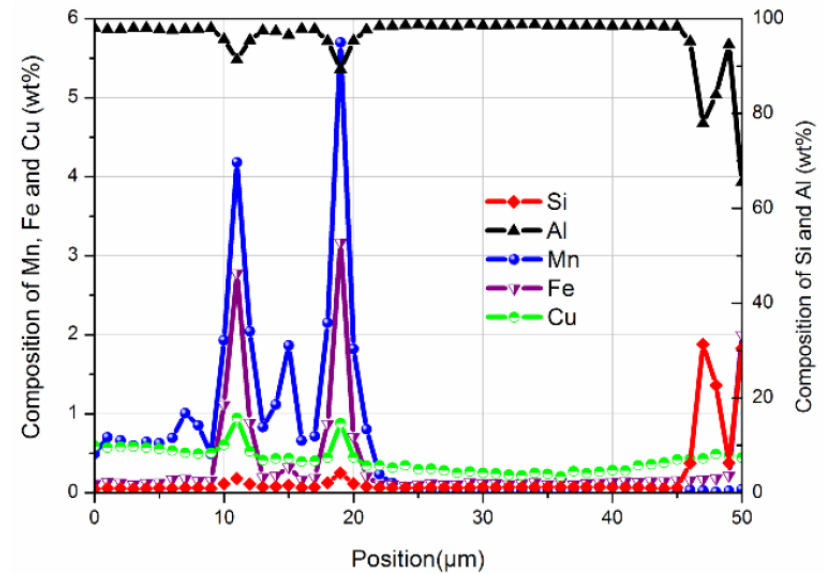

(b)

Figure 4.2. Position of the EPMA quantitative line scan (a) and the EPMA quantitative line scan analysis (b).

For the elements $\mathrm{Mn}, \mathrm{Fe}$ and $\mathrm{Cu}$, the left side vertical axis and for the elements $\mathrm{Si}$ and $\mathrm{Al}$ the right side vertical axis are applied. It should be noted that the position through the structure is defined with reference to the starting point of the experiment in the material. Zero position is about $50 \mu \mathrm{m}$ into the brazed structure. 
The presence of the peaks in the areas between 10 and $20 \mu \mathrm{m}$ position are related to the $\alpha-\mathrm{Al}(\mathrm{Fe}-\mathrm{Mn}) \mathrm{Si}$ particles [33]. These particles are clearly visible with white contrast in the core area in Figure 4.2a. The Si peaks close to the surface (45-50 $\mu \mathrm{m}$ position) corresponds to the Si particles that are concentrated in eutectic areas which are presented in Figure 4.1b. The measured composition at the positions 0$10 \mu \mathrm{m}$ (the core material) shows that the concentrations of $\mathrm{Mn}$ and $\mathrm{Cu}$ in solid solution (matrix composition) are $0.7 \mathrm{wt} \%$ and $0.6 \mathrm{wt} \%$ respectively. In the heat affected zone (20-45 $\mu \mathrm{m}$ position), the Mn concentration drops noticeably and is about $0.04 \mathrm{wt} \%$ and the $\mathrm{Cu}$ concentration is $0.25 \mathrm{wt} \%$. The concentration of copper close to the surface (45-50 $\mu \mathrm{m}$ position) increases and reaches $0.4 \mathrm{wt} \%$.

\subsubsection{GDOES etching and elemental depth profiling}

An example of a GDOES crater image (after 360 seconds of sputtering) and the applied calibration curve (the depth of penetration versus the time of sputtering) are shown in Figure 4.3a and b.

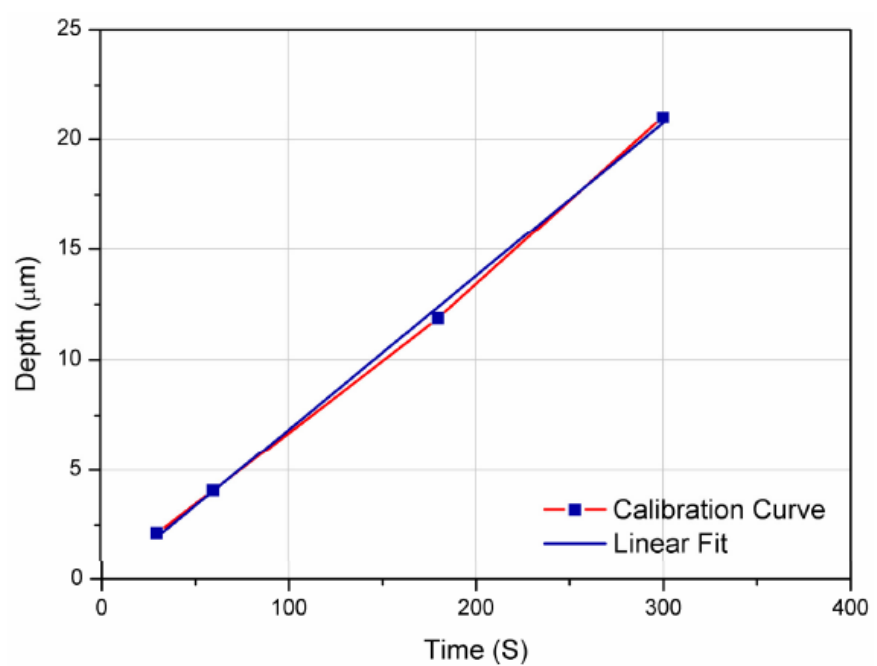

(a)

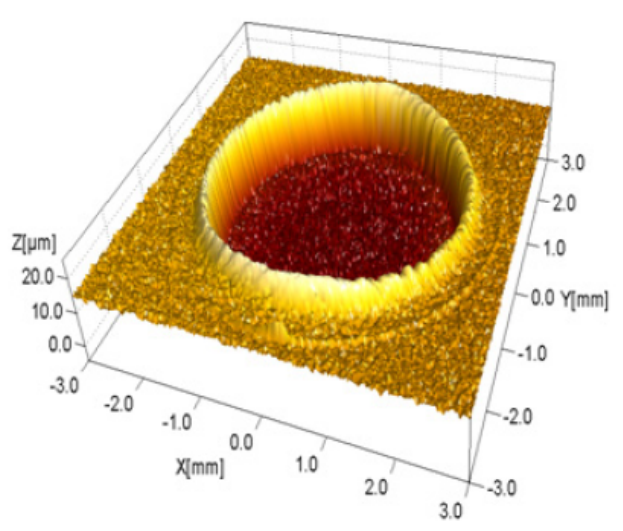

(b)

Figure 4.3. Depth versus etching time calibration curve (a), GDOES crater on AA4xxx/AA3xxx brazing sheet after 360 seconds etching (b).

GDOES elemental profiling analysis and the corresponding through depth microstructure of the brazed material are shown in Figure 4.4. Four different areas were distinguished and designated. The elemental analysis shows that the surface area $(0-5 \mu \mathrm{m})$ of the brazed material is the richest in $\mathrm{Si}, \mathrm{Fe}$ and $\mathrm{Mn}$. The heat affected zone (area 1), is free of precipitates, and has a high concentration $(4<\mathrm{x}<$ $16 \mathrm{wt} \%$ ) of $\mathrm{Si}$ and the $\mathrm{Fe}$ and $\mathrm{Mn}$ contents are below $0.1 \mathrm{wt} \%$. The $\mathrm{Cu}$ concentration in area 1 is about $0.2 \mathrm{wt} \%$ (see Figure $4.4 \mathrm{a}$ ). Area 2 is distinguished by a transient increase in the Mn concentration which is related to the interface between the diffusion zone and the heat affected zone. The core material (area 3) is characterized by a constant concentration of the $\mathrm{Mn}$, and Fe of about 2 and $0.5 \mathrm{wt} \%$ 
respectively. A high density of particles can be observed at the surface (see Figure $4.4 \mathrm{~b}$ ). Corresponding through depth areas, based on GDOES elemental analysis are depicted on a cross-sectional optical micrograph of the brazing sheet and is shown in Figure 4.4c.

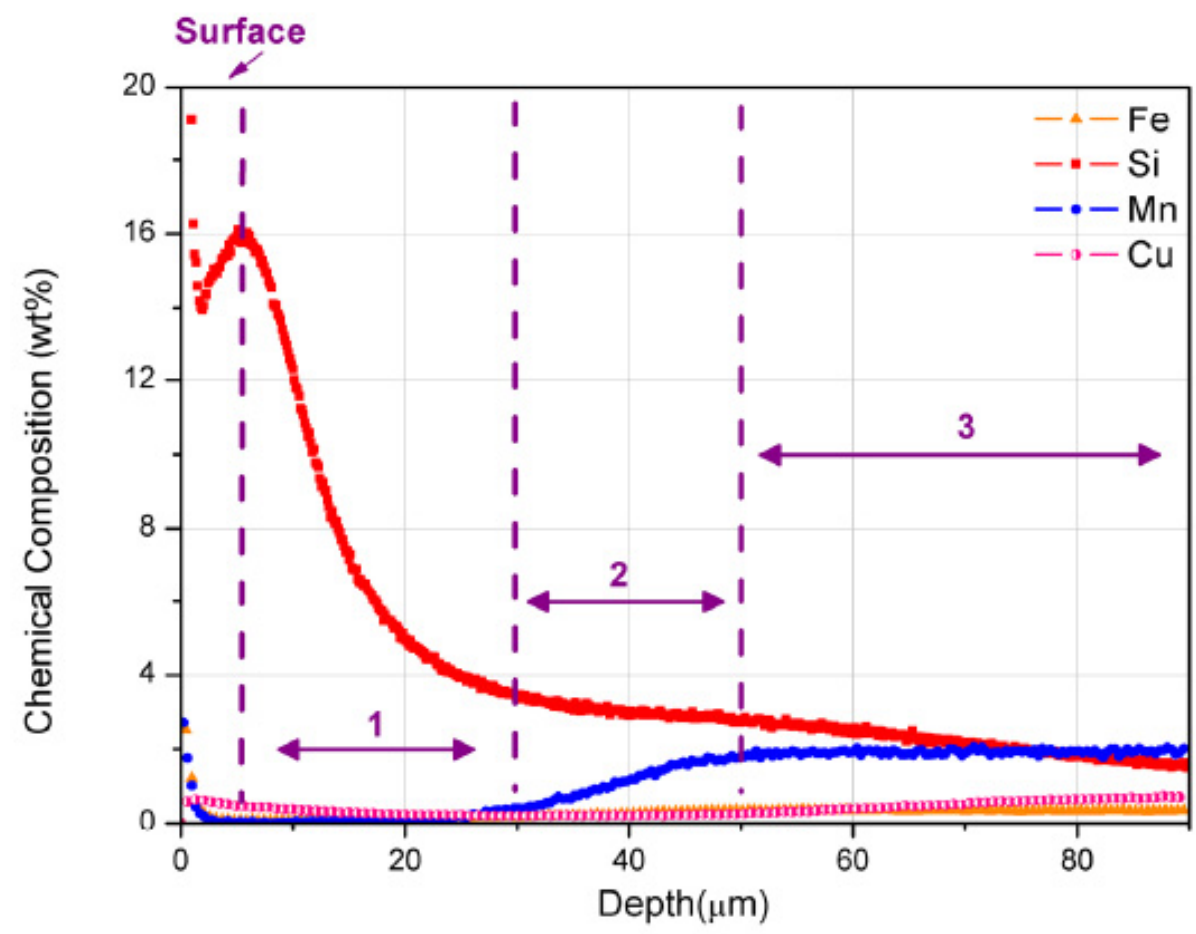

(a)

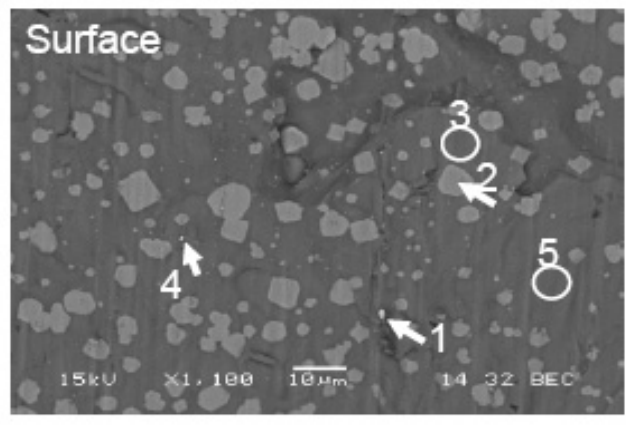

(b)

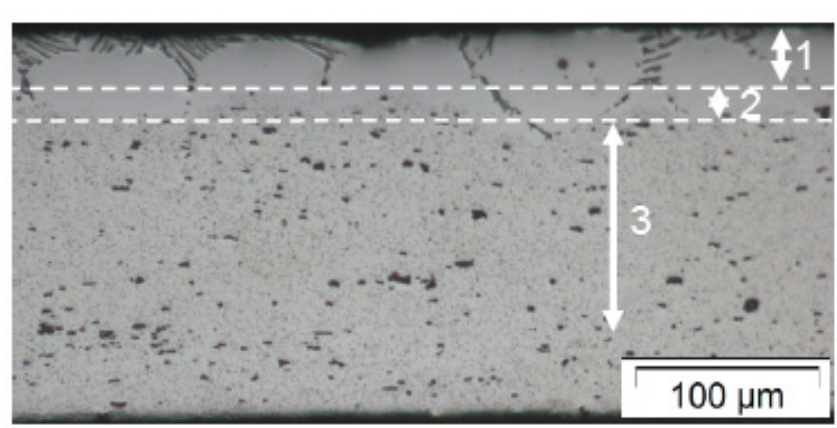

(c)

Figure 4.4. GDOES depth profiles of Fe, Si, Cu and Mn (a) SEM backscattered picture (b) cross-sectional optical micrograph (c) in the $4 \times x \times / 3 x x x$ brazing sheet after brazing. 


\subsubsection{Microstructure and composition analysis}

$\mathrm{X}$-ray micro analysis revealed that $\mathrm{Si}, \mathrm{Fe}$ and $\mathrm{Mn}$ are the main constituents of the irregular shape particles on the surface (see Table 4.2 and Figure 4.4b). A high concentration $(42-58 \mathrm{wt} \%)$ of $\mathrm{Si}$ was detected in the matrix of the surface. The bright particles in the image were found to be rich in $\mathrm{Fe}$ or $\mathrm{Cu}$ (locations 1 and 4).

Table 4.2. Chemical composition (wt\%) analysis of the surface locations, indicated in Figure 4.4b.

\begin{tabular}{ccccccc}
\hline Location & $\mathrm{Si}$ & $\mathrm{Fe}$ & $\mathrm{Cu}$ & $\mathrm{Cr}$ & $\mathrm{Mn}$ & $\mathrm{Al}$ \\
\hline 1 & 7.59 & 78.07 & - & - & 1.02 & 13.32 \\
2 & 10.57 & 12.93 & - & 1.49 & 15.44 & 59.68 \\
3 & 58.56 & - & - & - & - & 41.44 \\
4 & 2.28 & - & 1.29 & - & - & 96.43 \\
5 & 42.44 & - & - & - & - & 57.56 \\
\hline
\end{tabular}

Micrographs of the surface at different depths after GDOES etching are shown in Figure 4.5.
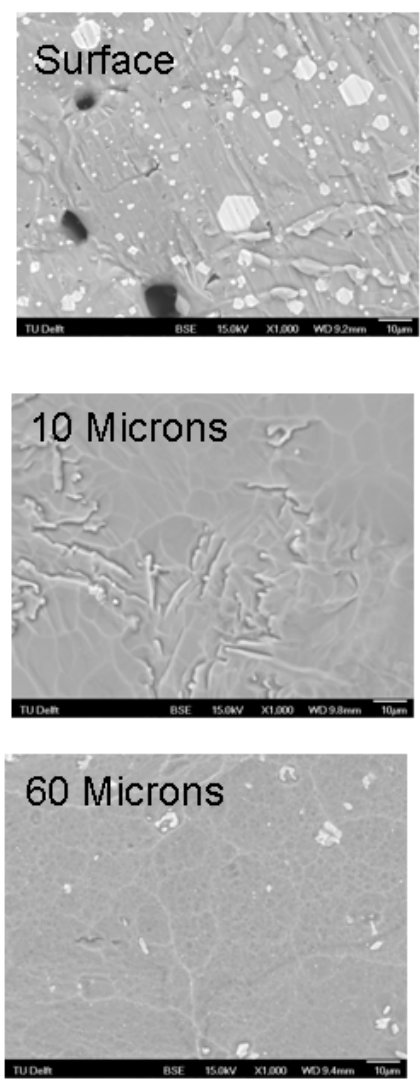
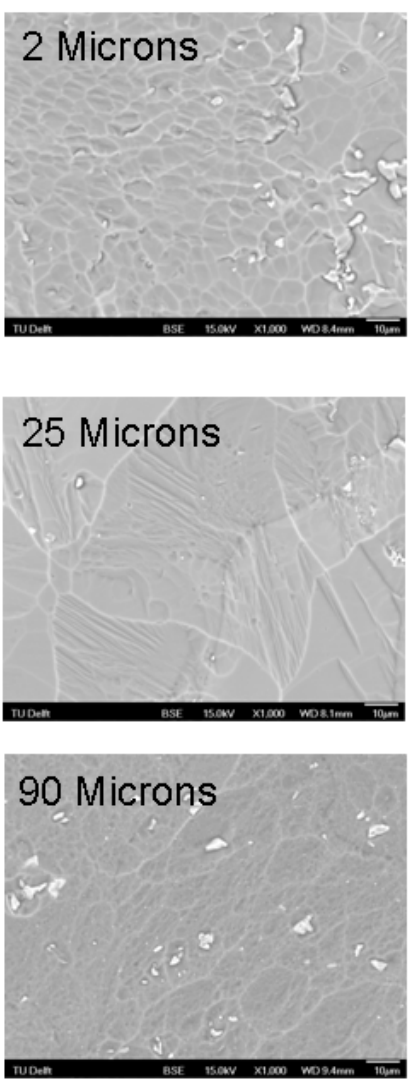
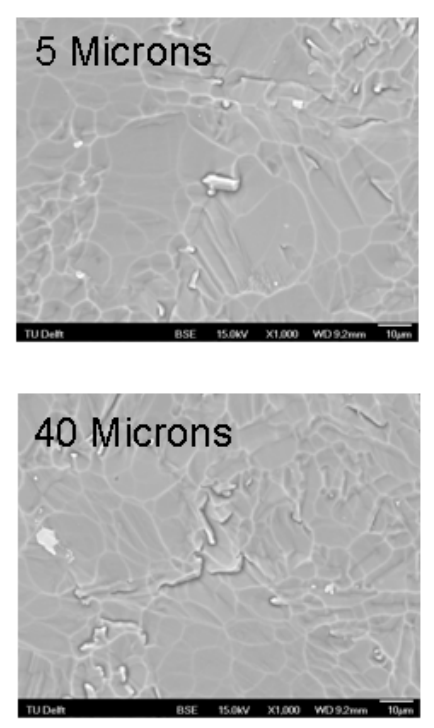

Figure 4.5. SEM backscattered electron images of the surface at different depths after GDOES etching. 
The intermetallic particles are irregular in shape and X-ray micro analysis showed that the majority of them contain $\mathrm{Si}, \mathrm{Mn}$, and Fe besides Al. The microstructure observations reveal that the density of the particles at the very surface, diffusion zone and in the core material (depth $>40 \mu \mathrm{m}$ ) is significantly higher than in the affected area $(5 \leq \mathrm{x} \leq 40 \mu \mathrm{m})$. The voids (dark spots) observed in the microstructure are due to shrinkage upon solidification (see the surface in Figure $4.5)$.

\subsubsection{Anodic and cathodic polarization}

The anodic polarization curves at different depths are shown in Figure 4.6. Applying small anodic potentials versus OCP values, the surface areas (depth $<10$ $\mu \mathrm{m})$ have high current densities $\left(>10^{-2} \mathrm{~mA} / \mathrm{cm}^{2}\right)$, which shows that these surfaces are highly active. These surfaces do not show a passive behaviour defined as a part of the anodic polarization diagram in which, in spite of increasing applied anodic potential no significant changes in the current densities can be observed. The curves for depths $\geq 10 \mu \mathrm{m}$ exhibit a passive region followed by a breakdown potential which is defined as the potential where the current density reaches $10^{-2}$ $\mathrm{mA} / \mathrm{cm}^{2}$. This behaviour is correlated to the start of localized corrosion attack.

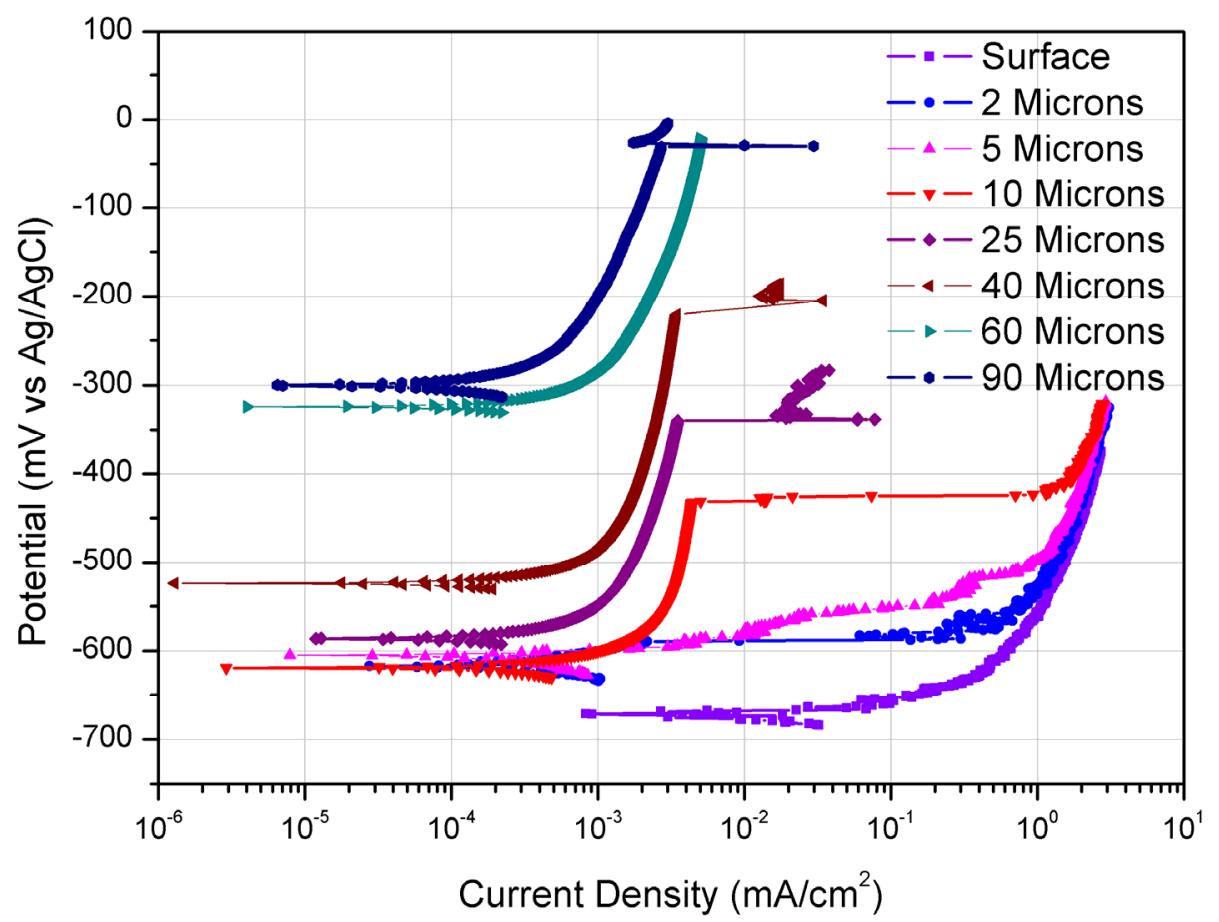

Figure 4.6. Anodic polarization curves at different depths after $10 \mathrm{~min}$ of OCP measurement in $1 \mathrm{wt} \% \mathrm{NaCl}$ solution at $\mathrm{pH} 2.8$ (scan rate $1 \mathrm{mV} / \mathrm{s}$ ). 
The cathodic polarization curves at different depths are shown in Figure 4.7. The cathodic current density of the very surface is an order of magnitude larger than that for the precipitate free areas $(5 \leq x \leq 40 \mu \mathrm{m})$.

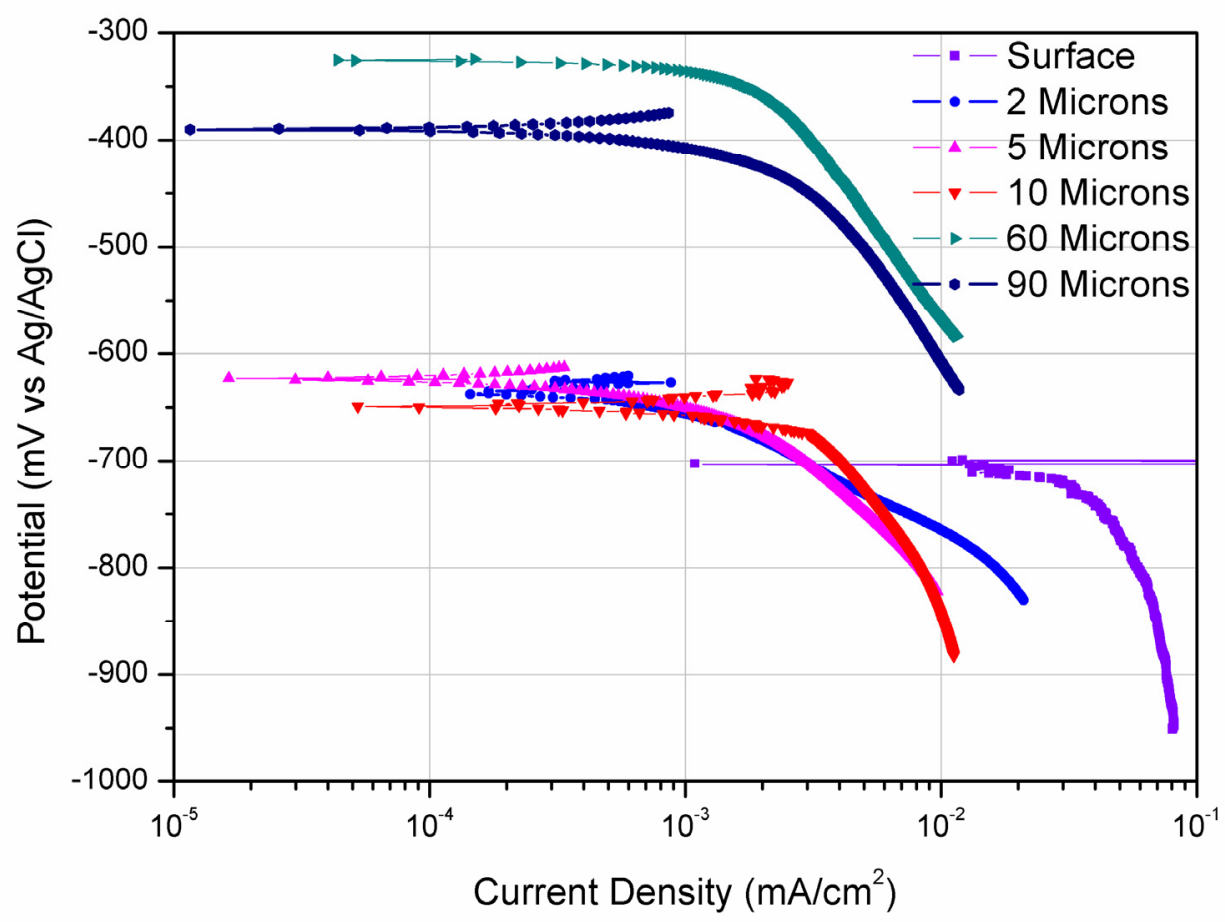

Figure 4.7. Cathodic polarization curves at different depths after $10 \mathrm{~min}$ of OCP measurement in $1 \mathrm{wt} \% \mathrm{NaCl}$ solution at $\mathrm{pH} 2.8$ (scan rate $1 \mathrm{mV} / \mathrm{s}$ ).

The open-circuit corrosion potential as a function of time at different depths are shown in Figure 4.8. Each curve is the average of 3 measurements. The OCP values close to the surface areas (0-5 $\mu \mathrm{m}$ depths) show lower ( more active) values and a large number of pitting events compared to more noble and no (meta-stable) pitting activity for the OCP curves of surfaces deeper $(>5 \mu \mathrm{m})$ in the material.

\subsubsection{Corrosion morphology}

SEM backscattered electron images of the surfaces after potentiodynamic anodic polarization up to $300 \mathrm{mV}$ above the OCP values are shown in Figure 4.9. The investigation shows that pitting and intergranular corrosion are the dominant corrosion attack mechanisms at the top surfaces $(0-40 \mu \mathrm{m}$ depths) of the material. The deeper areas $(>40 \mu \mathrm{m})$ show a lower sensitivity to these localized corrosion attacks. 


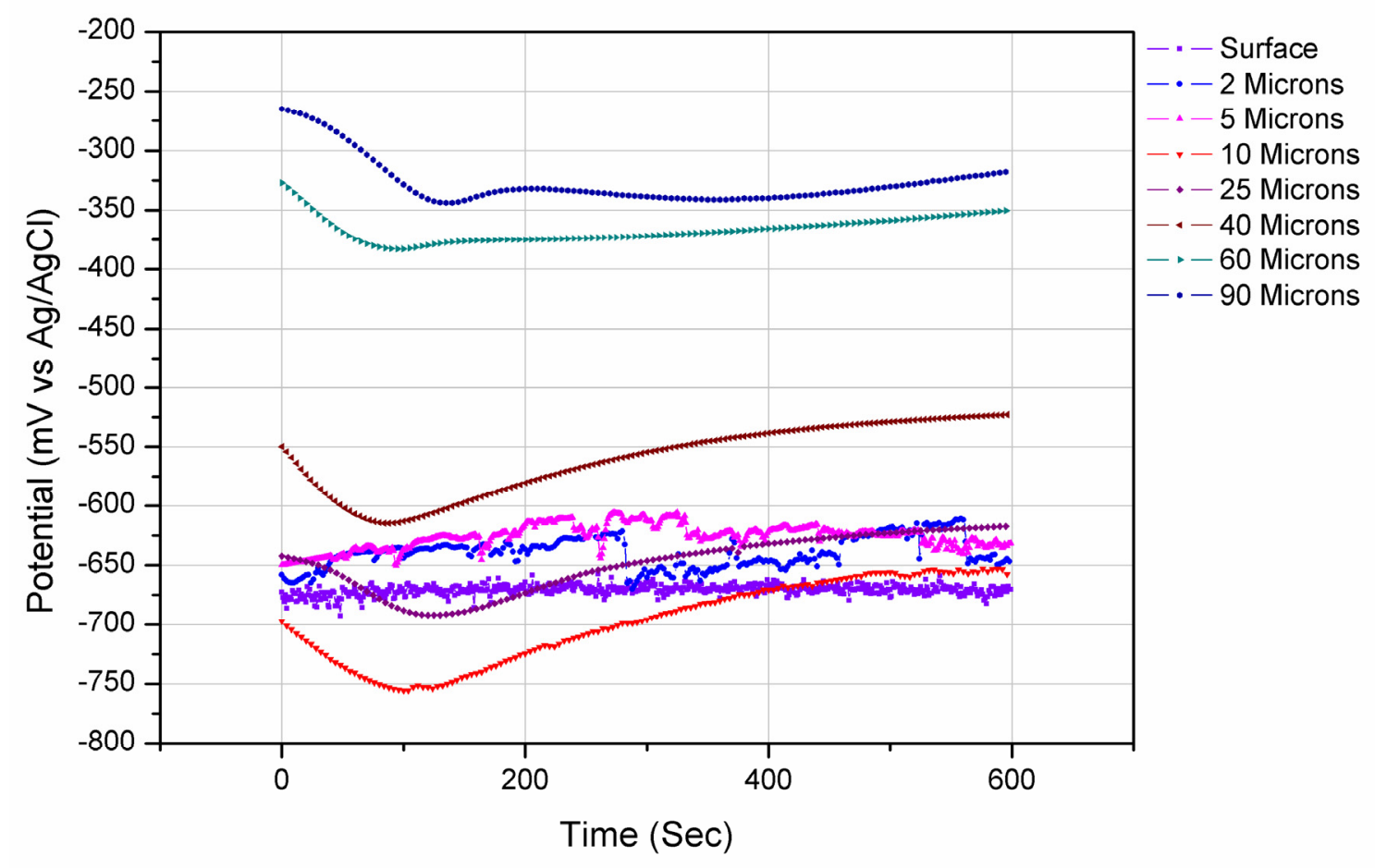

Figure 4.8. Variation of OCP as a function of time at different depths in $1 \mathrm{wt} \%$ $\mathrm{NaCl}$ solution at $\mathrm{pH} 2.8$, before anodic and cathodic polarizations. Meta-stable pitting activity is reflected in the OCP variations for the top surface areas $0 \leq \mathrm{x} \leq 5$ $\mu \mathrm{m}$.
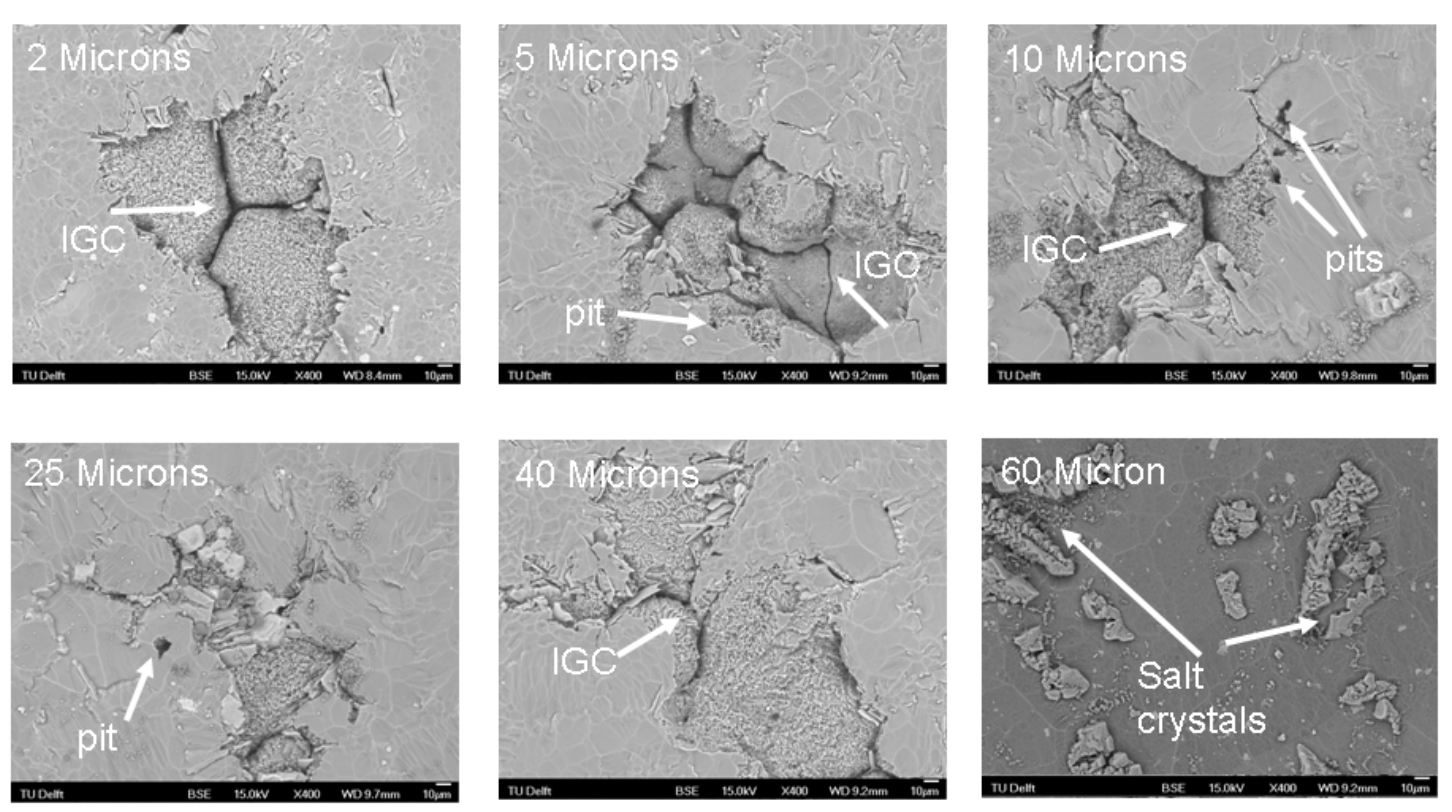

Figure 4.9. Surface morphology of the different depths in the brazing sheet after anodic polarization in $1 \mathrm{wt} \% \mathrm{NaCl}$ solution at $\mathrm{pH} 2.8$. 
Optical micrographs from the cross-sectional analysis of the samples after 1,2, and 3 days of SWAAT are presented in Figure $4.10 \mathrm{a}, \mathrm{b}$ and $\mathrm{c}$. The results show that the first stage of the corrosion attack of the aluminium brazing sheet is pitting and dissolution of the eutectic aluminium. This first stage of the corrosion is very fast and complete penetration of the clad by IGC follows within one day of SWAAT. Non-uniform dissolution of pre-eutectic aluminium grains succeeds the localized attacks as soon as these areas are exposed to the corrosive environment (see Figure 4.10 a). As the test continues (after 2 and 3 days) the IGC attack proceeds into the diffusion zone and the core material and the remainder of the clad starts to dissolve (see Figures $4.10 \mathrm{~b}$ and $\mathrm{c}$ ).

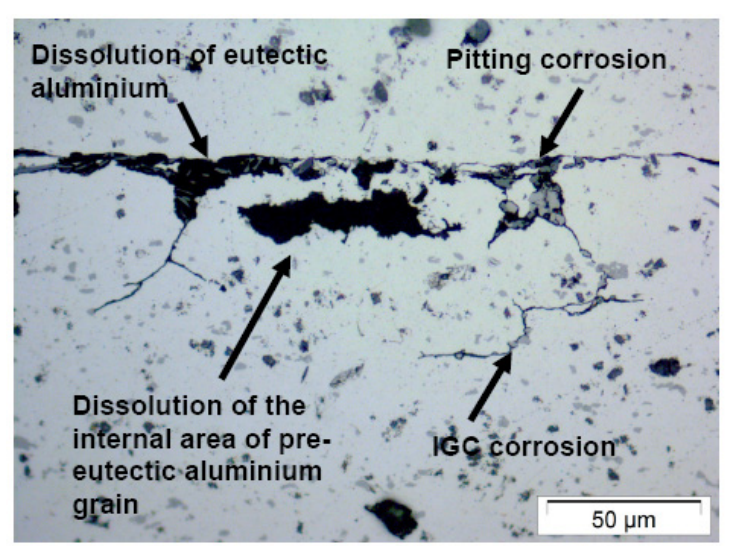

(a)

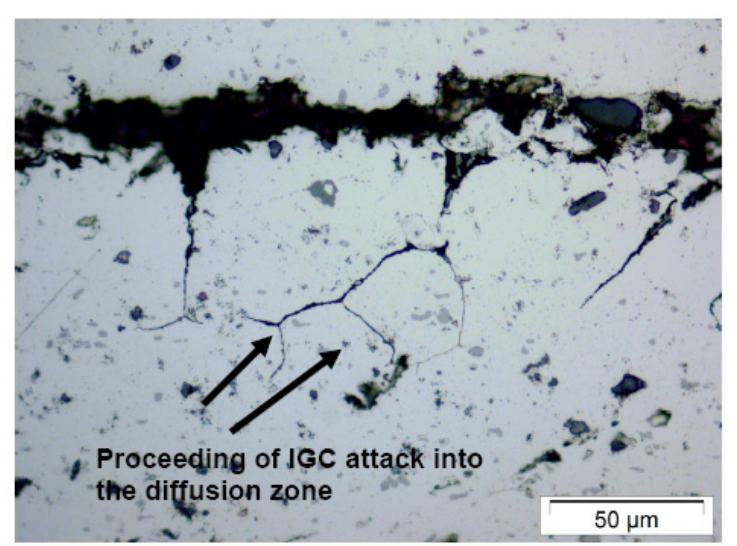

(b)

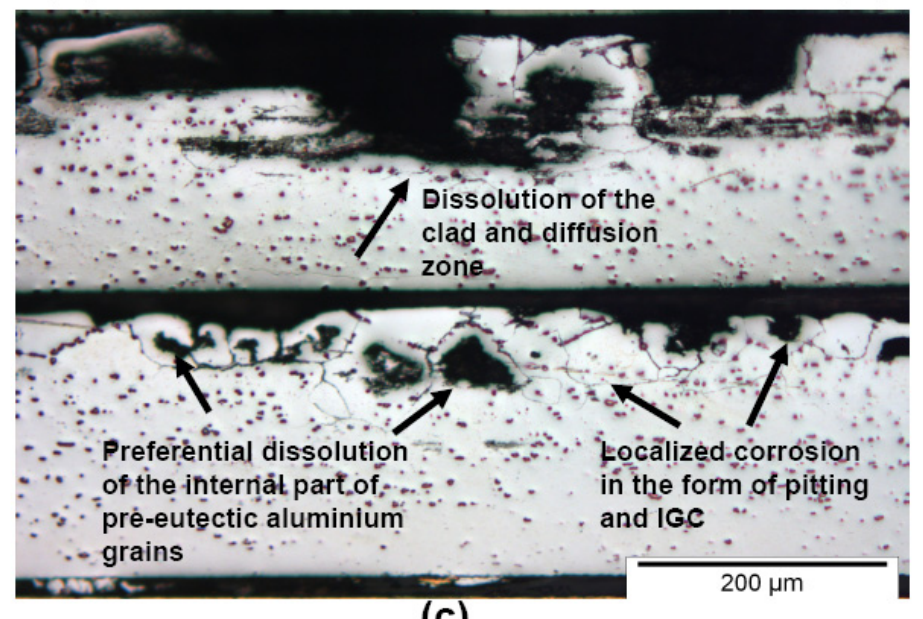

(c)

Figure 4.10. Optical micrographs from the cross-sectional analysis of the corroded sample after 1 day (a) 2 days (b) 3 days (c) in SWAAT cabinet.

\subsection{Discussion}

\subsubsection{The new approach for electrochemical depth profiling}

Applying the localized electrochemical cell technique in the current investigation in place of normal electrochemical measurements within masked craters is to 
prevent several problems related to defective masking of the crater edges and walls. The proper masking of the walls of a crater is difficult and may result in local crevice corrosion. Furthermore, during polarization of the higher depth samples, pitting may preferentially take place at the crater edges by being galvanically coupled to the crater bottom surface. Localized electrochemical cell measurements serve the purpose of providing relative data without running into the above mentioned difficulties.

In a localized electrochemical cell, the sample area is small, the volume of electrolyte is restricted, and the capillary/pipette geometry of the cell constricts the flow of current from the electrode. Polarization measurements may thus be affected by a large ohmic resistance and changes in the electrolyte composition during measurement. Moreover, localized electrochemical measurements would depend on the microstructure and composition of the location where the measurement is made. Applying a $1 \mathrm{~mm}$ capillary pipette for the current investigation overcomes these drawbacks and allows to measure the effect of heterogeneous surfaces on the electrochemical response. Based on the microstructural characterization information [33], none of the metallurgical features in the structure will exceed the size of the applied capillary and we are always sure that a localized electrochemical effect from all the features present at a certain depth is contributing to the obtained results. This will also reduce the scattering in the results compared with applying smaller capillaries. Regarding to reliability of the measurement and the effects of geometrical restrictions it should also be considered that the obtained result from a localized electrochemical cell should be compared in relative terms rather in absolute terms. Following the same strategy, in the current research work we are using the obtained electrochemical results for relative comparison of electrochemical behavior at different depths of the brazing sheet material with its corresponding microstructural and compositional features.

\subsubsection{Electrochemical depth profiling of the aluminium brazing sheet}

The high density particles at the surface of the brazing sheet (Figure 4.4b), in the diffusion zone and in the core (depth $>40 \mu \mathrm{m})$ are frequently identified as $\alpha-\mathrm{Al}(\mathrm{Fe}-$ Mn)Si paticles [33,35-40]. These Intermetallic particles are catalytic sites for cathodic reduction reactions [25]. The higher cathodic reactivity of the surface is the result of the presence of a relatively high density of these particles. The high anodic reactivity of the surface up to $10 \mu \mathrm{m}$ depth is consistent with the microstructural observations of numerous intermetallic particles that could act as cathodes. High localized corrosion sensitivity of these areas is evident through the lack of any passivity in the anodic polarization experiments. The presence of $\alpha$ $\mathrm{Al}(\mathrm{Fe}-\mathrm{Mn}) \mathrm{Si}$ particles at the surface, in the diffusion zone and in the core has increased the cathodic reactivity. Comparing the cathodic activities of the surface and $2 \mu \mathrm{m}$ depth with precipitate free areas $(10 \leq \mathrm{x} \leq 40 \mu \mathrm{m}$ depth) shows that both 
silicon and $\alpha-\mathrm{Al}(\mathrm{Fe}-\mathrm{Mn}) \mathrm{Si}$ particles increase the cathodic reactivity but $\alpha-\mathrm{Al}(\mathrm{Fe}-$ $\mathrm{Mn}) \mathrm{Si}$ particles have a much stronger effect. This result is in agreement with the work of Meijers showing that although silicon is nobler than aluminium, the current density of oxygen reduction on silicon is too low to make silicon particles become active cathodic sites [41]. The precipitate free area $(10 \leq x \leq 40 \mu \mathrm{m}$ depth) is more resistant to localized corrosion and shows the presence of a passive range during anodic polarization. This is expected to be the result of a more homogeneous microstructure in this precipitate free area $[25,43,44]$. The higher resistivity to localized corrosion attack in the deeper areas inside the brazing material ( $>40 \mu \mathrm{m}$ depth) is explained by high concentration of $\mathrm{Mn}$ and $\mathrm{Cu}$ in the matrix which increases the corrosion potential of the structure to a more noble level $[25,41]$. Manganese is known to supersaturate easily during direct chill casting of aluminum alloys; the degree of super saturation depends upon the cooling rate and may far exceed the equilibrium solubility [41,42]. Referring to the EPMA result in the current research the $\mathrm{Mn}$ and $\mathrm{Cu}$ concentrations in solid solution are around $0.7 \mathrm{wt} \%$ and $0.6 \mathrm{wt} \%$ respectively. Considering the potential increasing effect for $\mathrm{Mn}$ and $\mathrm{Cu}[41]$ the potential shift $(\sim 170 \mathrm{mV})$ from a depth of $40 \mu \mathrm{m}$ to $60 \mu \mathrm{m}$ could be attributed to the higher concentration of both $\mathrm{Cu}$ and $\mathrm{Mn}$ in the matrix. This will decrease the potential differences between the intermetalics and the matrix and therefore improves the corrosion resistance of the structure. The presence of a high concentration of cathodic intermetallic particles in this area $(40-60 \mu \mathrm{m})$ will also contribute in increasing the OCP values of this area comparing with that of the precipitate free $(10-40 \mu \mathrm{m})$ areas.

The difference between Mn concentration reported in Table 4.1 (XRF result) and Figure 4.4 (GDOES depth profiling) could be confusing. The non-uniform distribution and size of the $\alpha-\mathrm{Al}(\mathrm{Fe}-\mathrm{Mn}) \mathrm{Si}$ particles [33] in the structure and especially through the depth of the material is one of the potential reasons for the differences in the reported values. The areas with higher particle density will show higher concentration of Mn. It is also important to note that the XRD experiment was performed on the outer surface of the core material with an area of investigation of around $7 \mathrm{~cm}^{2}$ (a disc of $3 \mathrm{~cm}$ diameter). The bigger area of investigation makes XRD result more reliable representative of the bulk composition for the core comparing to the information from a $0.12 \mathrm{~cm}^{2}$ area (a disc of $4 \mathrm{~mm}$ diameter) in GDOES profiling experiment. However, none of these experimental approaches are able to distinguish between the concentration of alloying elements in the particles and the matrix. The effect of the alloying elements on the electrochemical performance of the structure is determined by both the solid solution concentration of the elements and the particles chemical composition. Therefore the results from EPMA quantitative line scans are applied as the bases of explanations for electrochemical responses of the material at different depths.

It is widely accepted that pitting is initiated at flaws present at the alumina layer. 
Those flaws can either be metallurgical, mechanical or compositional [43, 44]. From this point of view, the lower breakdown potential sustained by the superficial areas when compared to clean affected areas can be explained by the interface between $\mathrm{Si}$ and $\alpha-\mathrm{Al}(\mathrm{Fe}-\mathrm{Mn}) \mathrm{Si}$ particles and matrix acting as an initiation point for pitting.

The lower OCP values for the surface areas $(0 \leq \mathrm{x} \leq 10 \mu \mathrm{m}$ depths $)$ compared with the bulk suggest that the cathodic enhancement is smaller than anodic enhancement.

The breakdown potential and OCP profiles through the structure of the material are summarized and presented in Figure 4.11. Scattering of the results are presented through error bars in this figure. The breakdown potential was measured at $10^{-2}$ $\mathrm{mA} . \mathrm{cm}^{-2}$ current density. The OCP values represent the potential of the surfaces at the start of polarization measurements after $10 \mathrm{~min}$ of stabilizing.

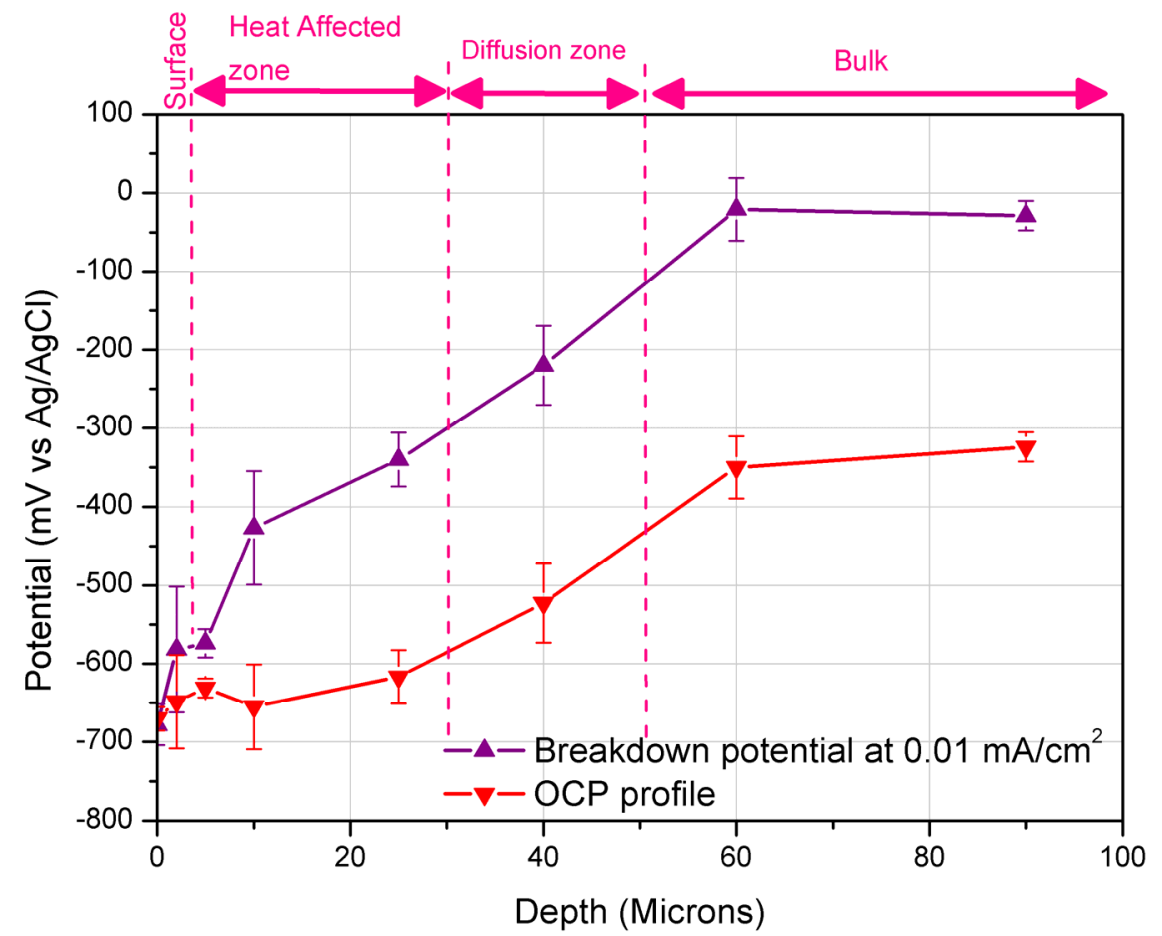

Figure 4.11. The electrochemical depth profiling of the AA4xxx/AA3xxx brazing sheet material.

Considering the existing corrosion potential profile through the structure, it may be assumed that the outer layers can sacrificially protect the core areas. However the susceptibility of the outer layers to the localized attack is expected to significantly decrease the effectiveness of this protection. In spite of the overall increased corrosion resistivity with material depth, which is reflected by more noble OCP values, the resistivity for localized corrosion attack is not improving further with depth. This is reflected in the constant potential difference $(\sim 300 \mathrm{mV})$ between the 
OCP and breakdown potential curves at surface areas deeper than $10 \mu \mathrm{m}$. The superficial $10 \mu \mathrm{m}$ layer will be attacked quickly and depending on the type of the environment there is the possibility for localized attack of the core and the failure of the whole material. In fact the localized attack of the $10 \mu \mathrm{m}$ outer surface will expose the inner parts of the material to the corrosive environment and provide a strong galvanic coupling between the inner layers of the material and the highly cathodic sites at the surface and stimulates the propagation of the corrosion attack into the depth of the aluminium brazing sheet. Corrosion mechanism prediction based on the summarized corrosion potential profiles through the structure is a combination of preferential corrosion of the outer layers (galvanic corrosion) combined with localized attack of the top layers $(<10 \mu \mathrm{m})$. This is in good agreement with the corrosion behaviour of the samples after SWAAT as shown in Figure 4.10. It is generally accepted that SWAAT test provides similar corrosion attack and morphology within a few days representative of several years of service life [32]. Referring to the optical micrographs of corroded samples in Figure 4.10, the first stage of the corrosion attack of aluminium brazing sheet (pitting and dissolution of the eutectic aluminium) can be explained from the microstructure of the re-solidified clad. The eutectic aluminium is the last part of the filler alloy to solidify. This aluminium will be different from the pre-eutectic aluminium. All the alloying elements that were not incorporated in the pre-eutectic aluminium during the first stage of solidification will be concentrated in the eutectic aluminium. These will be incorporated in solid solution and/or precipitate as small intermetallics [41]. The corrosion potential of the intermetallics often differs significantly from the aluminium matrix resulting in local corrosion attack [41]. It is also important to note that $\mathrm{Si}$ has a corrosion potential of $-260 \mathrm{mV}_{\mathrm{SCE}}$ whilst aluminium (depending on the alloy) has a corrosion potential of approximately $720 \mathrm{mV}_{\text {SCE }}$ [41]. Consequently Si can act as a cathode and promote the dissolution of aluminium. Obviously the eutectic aluminium close to Si needles will dissolve easiest anodically. After this first stage of the corrosion attack and exposure of the internal layers of the material to the corrosive environment and the galvanic coupling with the cathodic sites which are mainly the $\alpha-\mathrm{Al}(\mathrm{Fe}-\mathrm{Mn}) \mathrm{Si}$ particles and in less extent $\mathrm{Si}$ needles, the corrosion proceeds into the core structure. It is assumed that the presence of the solidification voids on the top layers of the material $(<10 \mu \mathrm{m})$ will have a similar detrimental galvanic coupling effects.

Based on the above explained phenomena, elimination of high localized corrosion susceptibility of the surface is key in improving the electrochemical performance of the aluminium brazing sheet material. The study has also highlighted that the combination of localized electrochemical cell measurements and glow discharge optical emission spectrometry (GDOES) can be applied as a successful electrochemical depth profiling analysis approach for prediction of corrosion behaviour of the aluminium brazing sheet. 


\subsection{Conclusions}

Combinatory micro-capillary and glow discharge optical emission spectrometry measurements were performed to obtain a thorough in depth electrochemical characterization of an aluminium brazing sheet. By defining electrochemical criteria i.e. breakdown potential, corrosion potential, cathodic and anodic reactivities and tracking their changes as a function of depth, the evolution of electrochemical responses through out the material thickness were analysed and correlated to the corresponding microstructural features and corrosion behaviour of the structure. The results highlight that:

1. Combination of micro-capillary measurement and glow discharge optical emission spectrometry (GDOES) can be applied as a successful electrochemical depth profiling analysis approach for prediction of corrosion behaviour of the aluminium brazing sheet.

2. The presence of high density of $\alpha-\mathrm{Al}(\mathrm{Fe}-\mathrm{Mn}) \mathrm{Si}$ and Si particles on the surface areas (up to $5 \mu \mathrm{m}$ depth) of the brazed $4 \times \mathrm{xx} / 3 \mathrm{xxx}$ material provides active cathodic sites that can galvanically coupled with the internal layers of the brazing sheet and cause dissolution and IGC attack of the internal layers of the brazing sheet.

3. Elimination of high localized corrosion susceptibility of the outer layer (up to $10 \mu \mathrm{m}$ below the surface) is key in improving the corrosion performance of the aluminium brazing sheet material. 


\subsection{References}

[1]. S. Tierce, N. Pebere, C. Blanc, C. Casenave, G. Mankowski, H. Robidou, Corrosion behaviour of brazed multilayer material AA4343/AA3003/AA4343: Influence of coolant parameters, Corrosion Science, 49 (2007) 4581.

[2]. G.J. Marshall, A.J.E. Flemming, A. Gray, R. Liewellyn, Development of a long life aluminum brazing sheet alloy with enhanced mechanical performance, SAE Transactions: Journal of Materials \& Manufacturing, 103 (1994) 292.

[3]. A. Gray, The growth of aluminium in automotive heat exchangers, Aluminium, 81 (2005) 197.

[4]. K. Takeuchi, Y. Isobe, T. Toyama, Current status and future of aluminum materials and brazing for automobile heat exchangers, Journal of Japan Institute of Light Metals, 48 (1998) 446.

[5]. O. Lunder, J. Lein, Proceedings from Aluminium Surface Science and Technology conference, Beaune, 2006.

[6]. F. Birol, Y. Birol, M. Slamova, Corrosion behavior of aluminum finstock alloys, Materials Science Forum, 402 (2002) 1511.

[7]. K. Fushimi, S. Yamamoto, R. Ozaki, H. Habazaki, Cross-section corrosion-potential profiles of aluminum-alloy brazing sheets observed by the flowing electrolyte scanningdroplet-cell technique, Electrochimica Acta, 53 (2008) 2529.

[8]. R.M. Wightman, D.O. Wipf, in: A.J. Bard (Ed.), Electroanalytical Chemistry, 15, Marcel Dekker, New York, 1997.

[9]. H. Böhni, T. Suter, A. Schreyer, Micro- and nano techniques to study localized corrosion, Electrochimica Acta, 40 (1995) 1361.

[10]. M.M. Lohrengel, Interface and volume effects in biological cells and electrochemical microcells, Electrochimica Acta, 42 (1997) 3265.

[11]. T. Suter, H. Böhni, Microelectrodes for corrosion studies in Microsystems, Electrochimica Acta, 47 (2001) 191.

[12]. F. Andreatta, H. Terryn, J.H.W. de Wit, Corrosion behaviour of different tempers of AA7075 aluminium alloy, Electrochimica Acta, 49 (2004) 2851.

[13]. N. Birbilis, B.N. Padgett, R.G. Buchheit, Limitations in microelectrochemical capillary cell testing and transformation of electrochemical transients for acquisition of microcell impedance data, Electrochimica Acta, 50 (2005) 3536.

[14]. L.M. Serna, C.M. Johnson, F.D. Wall, J.C. Barbour, Effect of implanted Cl and deposited oxides on the pitting behavior of aluminium, Journal of the Electrochemical Society, 152 (2005) B244.

[15]. M. Jariyaboon, A.J. Davenport, R. Ambat, B.J. Connolly, S.W. Williams, Effect of cryogenic cooling on corrosion of friction stir welded AA7010-T7651, Anti Corrosion Methods and Materials, 57 (2010) 83.

[16]. M. Jariyaboon, P.Møller, R.E. Dunin-Borkowski, S.I. In, I. Chorkendorff, R.Ambat, The effect of atmospheric corona treatment on AA1050 aluminium, Corrosion Science, $52(2010) 2155$.

[17]. M.S. Jellesen, P. Westermann, D. Minzari, P. Møller, R. Ambat, Corrosion in electronics, Corrosion Management, (September) (2008) 17.

[18]. R. Ambat, P. Møller, Corrosion investigation of material combinations in a mobile phone dome-key pad system, Corrosion Science, 49 (2007) 2866.

[19]. M. Jariyaboon, A.J. Davenport, R. Ambat, B.J. Connolly, S.W. Williams, D.A. 
Price, The effect of welding parameters on the corrosion behaviour of friction stir welded AA2024-T351, Corrosion Science, 49 (2007) 877.

[20]. R. Ambat, M. Jariyaboon, S.W. Williams, A. Wescott, D. Price, A.J. Davenport, Corrosion protection of friction stir welds using laser surface melting, ATB Metallurgie, 43 (2003) 258.

[21]. R. Ambat, M. Jariyaboon, A.J. Davenport, S.W. Williams, D.A. Price, A. Wescott, 15th International Corrosion Congress, Granada, Spain, September 22-29, 2002.

[22]. B. Bello Rodriguez, J.M.C. Mol, B. Kernig, J. Hasenclever, H. Terryn, Influence of the surface activation and local pitting susceptibility on the AC-electrograining of aluminium alloys, Corrosion Science, 53 (2011) 930.

[23]. G. Buytaert, Premendra, J.H.W. de Wit, L. Katgerman, B. Kernig, H.J. Brinkman, H. Terryn, Electrochemical investigation of rolled-in subsurface layers in commercially pure aluminium alloys with the micro-capillary cell technique, Surface and Coatings Technology, 201 (2007) 4553.

[24]. G. Buytaert, B. Kernig, H.J. Brinkman, H. Terryn, Investigation of the (sub) surface of commercially pure rolled aluminium alloys by means of total reflectance, r.f. GDOES, SEM/EDX and FIB/TEM analysis, Surface and Interface Analysis, 38 (2006) 272.

[25]. R. Ambat, A.J. Davenport, A. Afseth, G.M. Scamans, Electrochemical behavior of the active surface layer on rolled aluminum alloy sheet, Journal of the Electrochemical Society, 151 (2) (2004) B53.

[26]. J. Lacaze, S. Tierce, M.C. Lafont, Y. Thebault, N. Pebere, G. Mankowski, C. Blanc, H. Robidou, D. Vaumousse, D. Daloz, Study of the microstructure resulting from brazed aluminium materials used in heat exchangers, Materials Science and Engineering A, 413414 (2005) 317.

[27]. F.N. Afshar, E. Szala, A. Wittebrood, C.J.G. Van Hoek, J. Van der Hoeven, A. Buerger, J.M.C. Mol, H. Terryn, J.H.W. de Wit, New approach in microstructural analysis of a modified AA4xxx/AA3xxx brazing sheet before and after brazing, Vehicle Thermal Management Systems Proceedings (VTMS 10), Gaydon, UK, 2011.

[28]. V. Chidambaram, J. Hald, R. Ambat, J. Hattel, A corrosion investigation of solder candidates for high-temperature applications, Journal of the Minerals, Metals \& Materials Society, 61 (2009) 59.

[29]. D. Minzari, M.S. Jellesen, P. Møller, P.Wahlberg, R. Ambat, Electrochemical migration on electronic chip resistors in chloride environments, IEEE Transactions on Reliability, 9 (2009) 392.

[30]. S. Jellesen, P. Westermann, D. Minzari, P. Møller, R. Ambat, Corrosion in electronics, In print Corrosion Management, Corrosion Management, (September) (2008) 17.

[31]. M. Jariyaboon, A.J. Davenport, R. Ambat, B.J. Connolly, S.W. Williams, The effect of cryogenic CO2 cooling on corrosion behaviour of friction stir welded AA2024-T351, Corrosion Engineering, Science and Technology, 44 (2009) 425.

[32]. F.N. Afshar, E. Szala, A. Wittebrood, R. Mulder, J.M.C. Mol, H. Terryn, J.H.W. de Wit, Influence of material related parameters in Sea Water Acidified Accelerated Test, reliability analysis and electrochemical evaluation of the test for aluminum brazing sheet, Corrosion Science, 53 (2011) 3923.

[33]. F. Norouzi Afshar, J.H.W. de Wit, H. Terryn, J.M.C. Mol, The effect of brazing process on microstructure evolution and corrosion performance of a modified AA4xxx/AA3xxx brazing sheet, Corrosion Science, 58 (2012) 242-250. 
[34]. A. Wittebrood, Microstructural changes in brazing sheet due to solid-liquid interaction, PhD Thesis, TU Delft, 2009.

[35]. D.J. Schmatz, Grain boundary penetration during brazing of aluminum, Welding Journal, 10 (1983), 267s.

[36]. S. Zajac, L.O. Gullman, A. Johansson, B. Bengtsson, Hot ductility of some AI-MgSi alloys, Materials Science Forum, (1996) 217.

[37]. T. Minoda, H. Hayakawa, A.H. Yoshid, The quantitative analysis of alpha-AlFeSi ratio in a 6063 aluminum alloy billet by X-ray diffraction, Materials Science and Technology, 7 (2000) 13.

[38]. M.P. Clode, T. Sheppard, surface generation and origin of defects during extrusion of al alloys, Proceedings of the Conference on Aluminium Technology, London (UK): The Institute of Metals, (1986) 230.

[39]. C.M. Allen, K.A.Q. O'Reilly, B. Cantor, P.V. Evans, Nucleation of phases in ALFE-SI alloys, Materials Science Forum, (1996) 679.

[40]. P. Donnadieu, G. Lapasset, T.H. Sanders, Manganese-induced ordering in the (A1Mn-Fe-Si) approximant phase, Philosophical Magazine Letters, 70 (1994) 319.

[41]. S. Meijers, Corrosion of aluminium brazing sheet, PhD Thesis, Tu Delft University of Technology, 2002, ISBN 90-805661-3-6.

[42]. M. Zamin, Role of $\mathrm{Mn}$ in the corrosion behavior of Al-Mn alloys. Corrosion, 37(1981) 627.

[43]. G.T. Burstein, R.M. Organ, Repassivation and pitting of freshly generated aluminium surfaces in acidic nitrate solution, Corrosion Science, 47 (2005) 2932.

[44]. A.J. Dowell, Influence of metallurgical features in ac etching for lithoplates, Transactions of the Institution of Metal Finishing, 64 (1986) 85. 


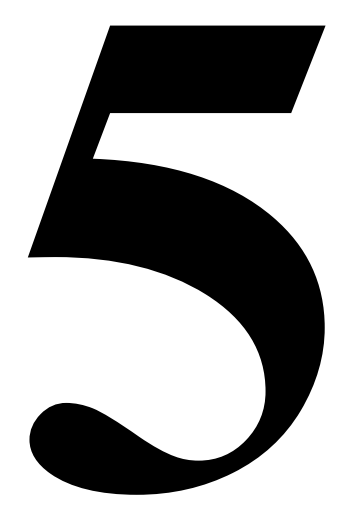

* This chapter has been published as a scientific paper:

F. Norouzi Afshar, J.H.W. de Wit, H. Terryn, J.M.C. Mol, Scanning Kelvin probe force microscopy as a means of predicting the electrochemical characteristics of the surface of a modified AA4xxx/AA3xxx (Al alloys) brazing sheet, Electrochimica Acta 88 (2013) 330-339. 



\section{Micro-electrochemical characterization of the surface}

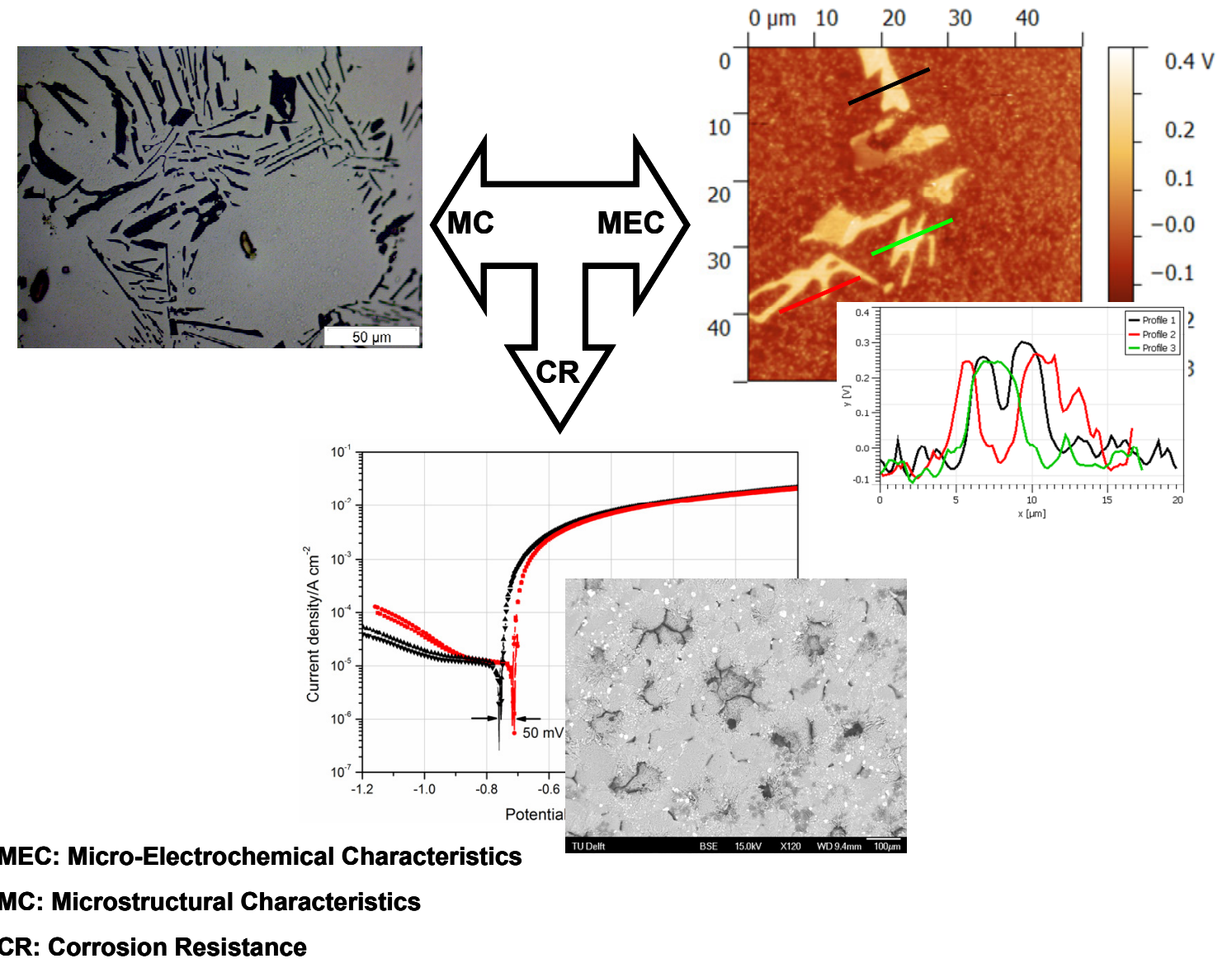

\section{Abstract}

Macro- and micro-electrochemical properties of clad and core surfaces of a modified AA4xxx/AA3xxx brazing sheet material, before and after brazing, have been evaluated and compared. By scanning Kelvin probe force microscopy (SKPFM), the Volta potential distribution over the brazed and non-brazed clad surfaces was measured. The changes in the Volta potential maps were correlated to the macro-electrochemical responses of the surfaces and the microstructural features that evolve as a result of brazing. By performing potentiodynamic 
polarization experiments and microscopic analysis of the corroded surfaces and cross sections, the suitability of SKPFM analysis for corrosion performance prediction of the aluminium brazing sheet material in a sea water acidified accelerated test (SWAAT) environment was confirmed. Considering the purity of Si phase in the structures of both brazed and non-brazed material, it is suggested that $\mathrm{Si}$ can be applied as a reliable local reference in both structures to compare the changes in Volta potential differences as the result of different heat treatments of aluminium brazing sheet. Increasing the copper content of the re-solidified clad material as a result of brazing treatment was found to increase the Volta potential of the matrix which in turn reduces the cathodic protection power of the resolidified clad material towards the core material.

\subsection{Introduction}

Aluminium brazing sheet is a sandwich material made out of two aluminium alloys (AA4xxx/AA3xxx) and is widely used in automotive heat exchangers. Alloy development for down-gauged heat exchangers focuses towards a higher intrinsic strength in order to maintain the same overall mechanical strength of the heat exchanger, and at the same time keeping the other material properties at least at the same level. One of these properties is the corrosion resistance. Several studies have been devoted to the corrosion behaviour of aluminium brazing sheet material. In the studies focused on the airside corrosion sensitivity of these materials, Scott et al. [1] and Isobe et al. [2] considered that noble Si needles had a detrimental effect on corrosion resistance of the residual cladding. Scott et al. [1] studied the corrosion behaviour of these materials in the sea water acidified accelerated test (SWAAT). Isobe et al. [2] used copper accelerated salt spray (CASS) and acetic acid salt spray (AASS) tests. They observed that Si needles acted as active cathodes while the surrounding aluminium dissolved. Al-Si alloys were also studied for other technological applications. In acidic or neutral solutions, it was shown that Si particles do not have a detrimental effect on the corrosion resistance of aluminium alloys [3, 4]. Some papers devoted to the corrosion of brazed aluminium heat exchangers $[5,6]$ also agree with this point stating that the cathodic reaction mentioned by Scott et al. [1] and Isobe et al. [2] did not occur on Si needles. Kuroda and Tohma [5] and Meijers [6] determined that the oxygen reduction current density on silicon is too low to anodically polarise aluminium. From their point of view, the corrosion susceptibility of the residual cladding arises from a higher sensitivity to pitting of the eutectic (Al) in solutions containing chloride. This has been explained by a lower pitting potential for eutectic (Al) than for the primary (Al).

During the brazing process, the parts to be assembled are heated to the melting temperature of the AA4xxx clad material. This process modifies the microstructure, i.e. type, distribution and chemical composition of the existing 
particles as well as alloying element distribution. Re-solidification, particle formation and distribution in the material before and after brazing have been already investigated and reported in prior publications of the authors $[7,8]$. The cathodic and anodic electrochemical responses of the materials were investigated and correlated to the microstructural changes due to the brazing process. The results showed that brazing causes copper enrichment at the surface and an increase of $50 \mathrm{mV}$ in the corrosion potential and intergranular corrosion (IGC) susceptibility of the re-solidified clad material [7,9]. Formation of $\alpha-\mathrm{Al}(\mathrm{Fe}-\mathrm{Mn}) \mathrm{Si}$ particles at the surface of the brazed material was found to increase the cathodic reactivity of the surface $[7,9]$.

Considering the capability of the scanning Kelvin probe force microscopy (SKPFM) technique to characterize the electrochemical nature associated with local surface inhomogeneities [10], in the present work the micro-electrochemical characterization of the surface is further continued with Volta potential and topographic maps which were measured using SKPFM and atomic force microscopy (AFM) respectively. The often postulated correlation between Volta potential difference measured by SKPFM and the possible formation of galvanic couples during corrosion is based on the findings of Schmutz and Frankel et al. [11]. They reported on a correlation between corrosion potential of metals and the potential measured by the SKPFM probe technique after immersion and that the Volta potential differences measured on aluminium alloy surfaces correlate with localized corrosion behaviour [12-14]. It was suggested that the Volta potential measured in air provides a measure of the local nobility and it was demonstrated that Volta potential values for $\mathrm{Cu}$ containing intermetallics in polished AA2024 are nobler than that of the matrix [11]. This is in line with trends in corrosion potential values observed in $\mathrm{NaCl}$ solutions [15]. Many other researchers have also applied Volta potential differences determined by SKPFM in air to characterize alloy surfaces and to predict the localized corrosion behaviour of various alloy systems in solution [16-23]. Electrochemical micro-cell measurements in combination with SKPFM and scanning electron microscopy (SEM) analysis on AA7075 to establish a correlation between Volta potential difference and breakdown potential have been reported by Andreatta et al. [24-25]. Premenda et al. performed a combined SKPFM and transmission electron microscopy (TEM) investigation of the surface layers on rolled AA5050 aluminium [26]. Given the self-evident desirability of being able to extract local corrosion potential values from SKPFM data, Cook et al. established a rigorous demonstration of SKPFM calibration in terms of corrosion potential under controlled atmospheric conditions of known humidity [27]. A discussion of the problems that may be encountered in simply extrapolating the findings of Frankel et al. [11-14] to other alloy systems, i.e. using the Volta potential measured on freshly polished surfaces to predict subsequent corrosion behaviour in solution is reported by Rohwerder and Turcu [28]. 
This study aims to investigate the suitability of the SKPFM analysis technique for corrosion performance prediction of aluminium brazing sheet material and to evaluate the macro- and micro-electrochemical properties of the clad and the core surfaces of a modified brazing sheet material, developed during a controlled atmosphere brazing (CAB) process. Applying optical microscopy (OM), SEM, AFM and SKPFM techniques, combined with open circuit potential (OCP) and potentiodynamic polarization measurements, the purpose of this paper is to investigate the electrochemical nature of the overall surface microstructure and surface microstructural heterogeneities, of a modified AA3xxx/AA4xxx brazing sheet. The results are interpreted and discussed with reference to prior detailed microstructural and electrochemical characterization of the same material, which have been reported separately in related papers of the authors [7-9].

\subsection{Experimental}

\subsubsection{Materials}

A4 size sheet was cut from rolled modified AA3xxx aluminium alloy $(185 \mu \mathrm{m}$ thick) clad on one side with an AA4xxx (15 $\mu \mathrm{m}$ thick). The bulk chemical analysis of the clad and the core materials was obtained by X-Ray Fluorescence analysis (XRF) of $3 \mathrm{~cm}$ diameter discs of the material. PW2400 equipment with a Rhodium anode and a $60 \mathrm{kV}$ acceleration voltage was used. The data was analyzed with UniQuant software and is presented in Table 5.1.

Table 5.1. Chemical composition (wt \%) of the AA3xxx (core) and AA4xxx (clad) material.

\begin{tabular}{ccccccccc}
\hline & $\mathrm{Si}$ & $\mathrm{Fe}$ & $\mathrm{Cu}$ & $\mathrm{Ti}$ & $\mathrm{V}$ & $\mathrm{Cr}$ & $\mathrm{Mn}$ & $\mathrm{Al}$ \\
\hline Clad & 7.70 & 0.18 & - & 0.01 & - & - & 0.14 & Bal. \\
Core & 0.44 & 0.32 & 0.6 & 0.08 & 0.01 & 0.07 & 1.03 & Bal. \\
\hline
\end{tabular}

\subsubsection{Brazing procedure}

The sheet was cleaned in an ultrasonic bath with ethanol, dried and placed in a Controlled Atmosphere Brazing (CAB) furnace. $\mathrm{CAB}$ is brazing in a dry, inert nitrogen gas atmosphere. The material is heated up to $600{ }^{\circ} \mathrm{C}$ and is kept at that temperature for $3 \mathrm{~min}$ and is then cooled down with a specified $\operatorname{ramp}\left(60^{\circ} \mathrm{C} / \mathrm{min}\right)$. The holding temperature was selected to be close to the liquidus temperature of the clad material, reported as $612{ }^{\circ} \mathrm{C}$ by Lacaze et al. [29] while far below the solidus temperature of the core material which is about $640{ }^{\circ} \mathrm{C}$ [7].

\subsubsection{Microstructure and composition analysis}

The microstructure and surface morphology of the brazing sheet material before 
and after brazing were characterized, using optical and scanning electron microscope (SEM, JEOL JSM 6500F). The SEM is equipped with an energy dispersive spectrometer (EDS, Thermo Fisher Ultra Dry detector $\left(30 \mathrm{~mm}^{2}\right)$ operated with Noran System 7 for X-ray micro analysis (XMA)).

\subsubsection{AFM and SKPFM analysis}

Atomic force microscopy, digital instrument Nanoscope III multimode, was used to investigate the electrochemical nature of the silicon and intermetallics, in particular their Volta potential with respect to the aluminium matrix. The maps of the Volta potential of the specimens with respect to the AFM tip were recorded using the standard feedback loop provided by the Extender ${ }^{\mathrm{TM}}$ Electronics Module. The mapping of the surface Volta potential difference is usually made in the so called lift mode, which is a two pass technique, i.e. each line of the image is scanned twice. In the first step of each scan, no external voltage is applied to the tip and the topography of the sample is determined and recorded using the tapping mode. When operating in this mode, the AFM measures the topography by tapping the surface with the tip, which is oscillated near its resonant frequency by a piezoelement. The vertical position of the scanner at each point necessary to keep the oscillation amplitude constant is recorded to form the topographic image of the line. This is done using a feedback system based on a laser deflection detector, where the top side of the cantilever serves as a reflector. This topographic information is then used during the second scan of the line, when the tip is lifted at a selected distance, termed the lift scan height, above the recorded surface and the Volta potential is measured. During this second step, the feedback loop that controls the vertical piezo-element is turned off and a DC bias potential and an oscillating AC potential, with frequency equal to the resonant frequency of the cantilever free vibrations, is applied to the tip. The application of an AC voltage is necessary to produce an alternating electrical force between tip and the sample. A second electronic feedback loop, which is provided by the Extender ${ }^{\mathrm{TM}}$ Electronics Module and based on the same laser deflection detector used for the topographic image, adjusts the DC bias on the tip in order to nullify the vibration amplitude of the cantilever and hence the electrostatic force. The required bias voltage is recorded and by reversing the sign, the Volta potential map of the sample with respect to the tip is obtained. Repeating this procedure for each line along the slow-scan axis creates the topographic and Volta potential images. A more detailed explanation of the AFM/SKPFM principles of operation has been reported by Rohwerder et al [28], de Wit [17] and Campestrini [30].

As explained by Rohwerder et al. [28] the signal which is measured during the SKPFM analysis is strongly tip-sample distance dependent and as the distance increases the contribution of the cantilever in the detected signal becomes more and more important. Scanning over substrate areas with inhomogeneous topographical and compositional features and also the presence of AC electric field 
between the tip and the sample can also affect the SKPFM signal. All these interferences could yield wrong values of the measured Volta potential which are not representative of the sample under investigation [28].

All the measurements were carried out in air at ambient temperature, pressure and humidity. A lift scan height of $100 \mathrm{~nm}$ was applied and a phase difference between the reference signal and the deflection signal of the cantilever set to $-90^{\circ}$, which was found to be the proper value to enhance the sensitivity of the potential measurement. It should be noted that the phase of the deflection signal relative to the AC-drive voltage is tip dependent [31]. So therefore each time that the tip is changed the phase of the reference must be adjusted to maximize the output of the lock-in amplifier. Using the same tip for the full set of measurements reported in this article, this value was found to be $-90^{\circ}$. An appropriate procedure to determine the proper phase value has been described by Jacobs et al [31]. The procedure is based on establishing a phase value which makes the output of the lock-in amplifier zero and then subtracting $90^{\circ}$ from that value to obtain the maximum feedback signal. The potential difference and the topographical maps were sampled with the same pixel density of $256 \times 256$ pixels per image and at a scan frequency of $0.5 \mathrm{~Hz}$. The $\mathrm{AC}$ voltage applied to the tip had amplitude of $6 \mathrm{~V}$. For all measurements Antimony (n) doped silicon tips, coated on both sides with $20 \mathrm{~nm}$ platinum/iridium, were used. The tip is characterized by a resistivity of 0.01-0.025 $\Omega . \mathrm{cm}$ and supported on a cantilever $200-250 \mu \mathrm{m}$ long, $23-33 \mu \mathrm{m}$ wide and 2.5 $3.5 \mu \mathrm{m}$ thick. Prior to each experiment the tip was checked by performing a potential measurement on a reference sample which was cut from the non-brazed material under investigation. All the measurements were performed on polished surfaces using the finest grade of $0.25 \mu \mathrm{m}$. The polishing was aimed to remove only a very thin layer of the clad material and provide a smooth surface for the AFM/SKPFM measurements. After the polishing a smooth surface of the very top area of the clad material was exposed. The samples were ultrasonically cleaned in ethanol and air dried to limit any effect of adsorbed species to the Volta potential measurements. The representation of the topography and potential is defined such that the brightness is proportional to height and potential, respectively.

In order to clarify the nature of the measured Volta potential values a uniform designation system is introduced. The Volta potential difference between sample surface features and the AFM tip is referred to as "VPD" whereas the Volta potential difference between sample surface features is referred to as "VPD difference".

\subsubsection{Electrochemical analysis}

Using a Solartron potentiostat and a three-electrode electrochemical cell, potentiodynamic polarization measurements were performed. Considering the emphasis of this research on the microstructural effects on the electrochemical 
performance of the aluminium brazing sheet, the cathodic and the anodic polarization responses of the materials have been measured and investigated separately. The working electrodes (samples) were circular plates with a diameter of $2 \mathrm{~cm}$. The reference electrode was a saturated calomel electrode (SCE) and the counter electrode was Pt. The sea water acidified accelerated corrosion test (SWAAT) solution [32] was chosen as a representative electrolyte. The samples were scanned in the potential range between $10 \mathrm{mV}$ below and $1 \mathrm{~V}$ above the open circuit potential (OCP) for the anodic scans and between $10 \mathrm{mV}$ above and 450 $\mathrm{mV}$ below the OCP for the cathodic scans. The scans started after 15 min of OCP measurement. A scan rate of $0.5 \mathrm{mV} / \mathrm{s}$ was applied. The reproducibility of the test results was checked by triplication of each experiment.

\subsubsection{Corrosion attack mechanism investigation}

The most common way to measure the corrosion resistance of heat exchanger materials, both for tube and fin alloys is the so called Sea Water Acidified Accelerated Test (SWAAT) [32]. Comparing the corrosion mechanism and morphology of attack it has been proven that the SWAAT performance of the aluminium brazing sheet material can be reflected in potentiodynamic responses [32]. SEM and Optical micrographs from the surface and cross-sectional analysis of the samples after anodic polarization were investigated. The corrosion of this material starts from the re-solidified clad layer. This is the surface which in practice is exposed to the corrosive environment. Therefore, for the corrosion investigation, the surface and cross-sectional analysis of the samples after the anodic polarization of the clad side of the material has been investigated. The potentiodynamic polarization results are already presented in a previous publication of the authors [7]. The same experimental procedure as explained in section 5.2.5 was applied.

\subsection{Results}

\subsubsection{Microstructural analysis}

Optical images of the material under investigation both before (a) and after brazing (b) are shown in Figure 5.1. The image of the material before brazing shows the clad layer with a brighter contrast. The elongated coarse particles with a dark gray contrast in the clad layer are Si particles. X-ray micro analysis revealed also the presence of some small additional precipitates containing $\mathrm{Al}, \mathrm{Fe}, \mathrm{Cu}$, and $\mathrm{Si}$. In the core material a wider variety of particles exists with different sizes and chemical compositions. Regarding the size, two types of particles are distinguished. One is the particles which are larger than $1-2 \mu \mathrm{m}$ and their sizes can reach up to $20 \mu \mathrm{m}$. These are mainly $\alpha-\mathrm{Al}(\mathrm{Fe}-\mathrm{Mn}) \mathrm{Si}$ particles. The second group contains particles with sizes below $1 \mu \mathrm{m}$. These are mainly $\mathrm{Al}_{2} \mathrm{Cu}$ and $\alpha$-Al(Fe-Mn)Si particles. The detailed microstructural characterization of the material has been published 
recently by Afshar et al $[7,8]$ (chapter 3).

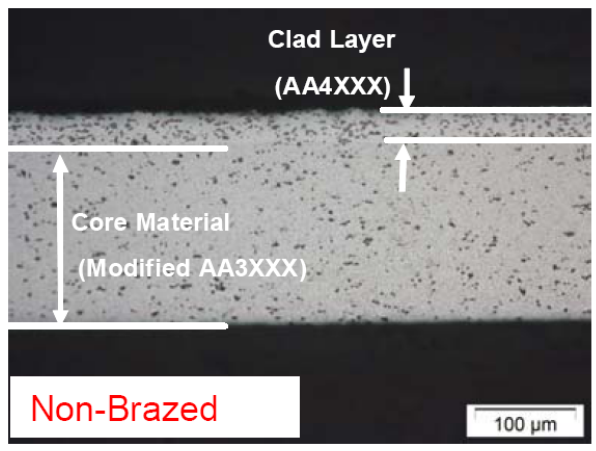

(a)

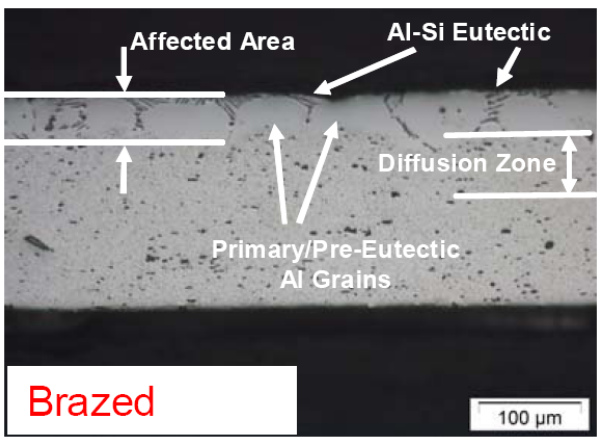

(b)

Figure 5.1. Cross-sectional optical images of the brazing sheet structure before (a) and after brazing (b) [7].

At brazing temperature the liquid clad is in intimate contact with the solid core material. During this stage where the two phases co-exist, an interaction between the two can take place. The liquid originating at the clad-core interface progresses into the core alloy as a film, changing the element distribution on its way [33, 34]. This area is the precipitate-free affected area which has been designated in Figure 5.1b. The Al-Si eutectic phase is shown to be accumulated at the surface and in between the pre-eutectic aluminium grains. As silicon is the most diffusive element that diffuses into the core material the diffusion path of this element is considered to represent the diffusion layer. This layer was measured to be about $40 \mu \mathrm{m}[7,8]$.

Optical micrographs of the surface of the material both before (a) and after brazing (b) are shown in Figure 5.2.

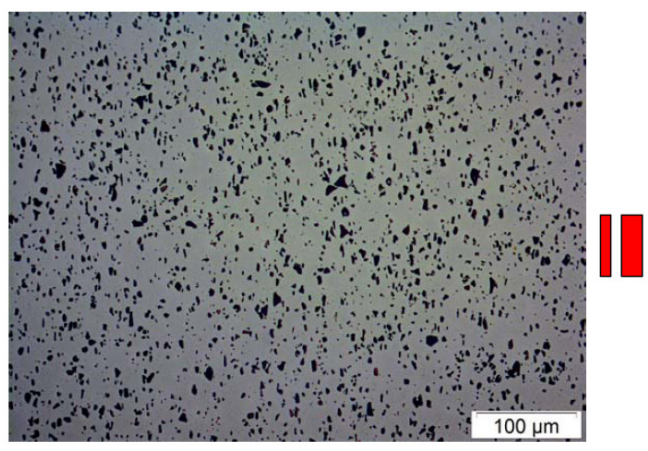

a

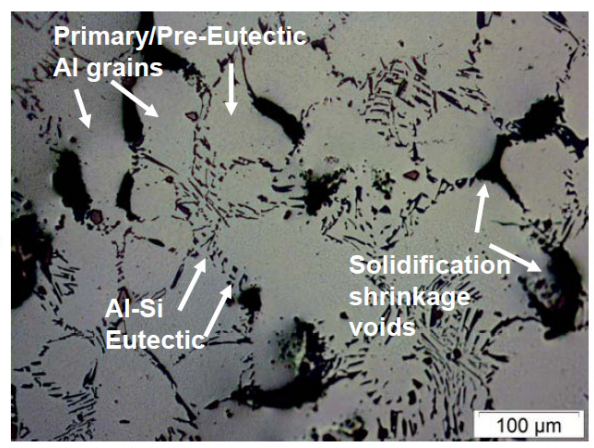

b

Figure 5.2. Optical micrographs of the brazing sheet surface structure before (a) and after brazing (b).

The material surface before brazing (Figure 5.2a) shows the presence of silicon particles in dark contrast, distributed all over the surface. After the brazing process and formation of Al-Si eutectic phase, the structure of the surface will change to 
the one which has been shown in Figure 5.2b. Solidification of the molten clad material which starts with the formation of the primary alpha aluminium grains and ends with accumulation of Al-Si eutectic has resulted in solidification void formation which has been shown in Figure 5.2b. These surfaces have been further examined with AFM and SKPFM analysis techniques.

\subsubsection{AFM and SKPFM analysis}

The VPD values, topographical maps and the results of the line scan section analysis on the polished surfaces of the material before (Figure 5.3a, c and e) and after brazing treatment (Figure 5.3b, d and f) are presented in Figure 5.3.
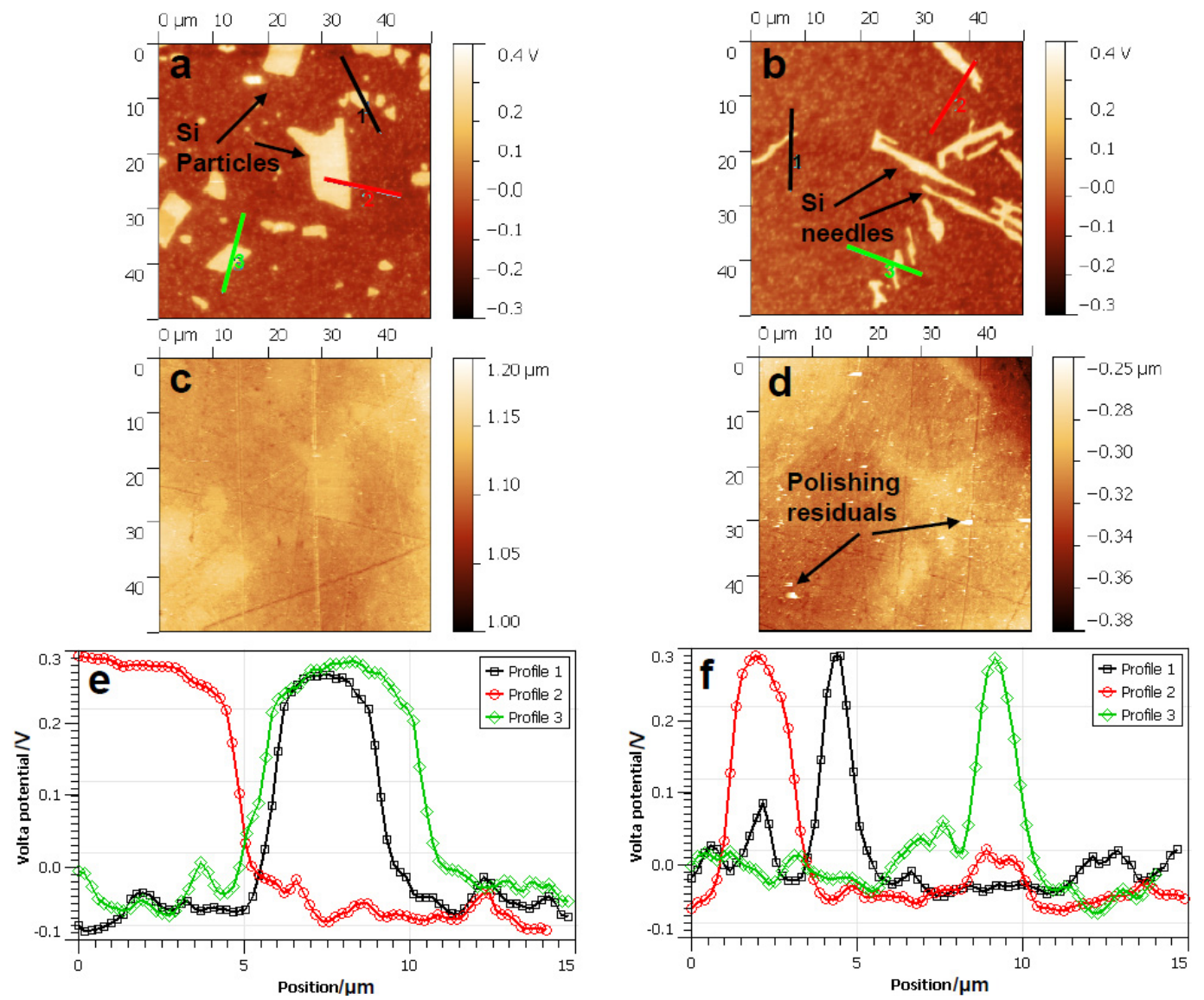

Figure 5.3. Volta potential (a and b), topographical maps (c and d) and line scan section analysis results (e and $\mathrm{f}$ ) obtained from AFM/SKPFM analysis of the polished surfaces before (a, c and e) and after brazing (b, $d$ and $f$ ).

In order to avoid any artificial changes of the measured Volta potential differences, no post-treatment has been applied on the presented Volta potential results. The areas under investigation in these experiments correspond to the precipitation free 
areas. Therefore Si particles/needles are the main reason of bright contrast in the maps in Figure 5.3a and b. From the topographical images (Figure 5.3c and d) it can be noted that even after ultrasonic cleaning with ethanol some contamination is still left on the surface. These polishing residuals are clearly visible in Figures $5.3 \mathrm{~d}$ as small dots with a brighter contrast with respect to the matrix.

Comparison of the VPD differences between the Si particles and the matrix for the materials before and after brazing was performed, applying section analysis. The positions of the sectioning profiles are indicated in Figures 5.3a and b. Three line profiles per each sample were investigated. The results for the Volta potential section analysis before (e) and after (f) brazing treatment are also presented in Figure 5.3. The peak potentials correspond to the VPD of Si in both graphs (Figure 5.3e and f). This potential is around $300 \mathrm{mV}$. Comparing the graphs in Figure 5.3e and $f$, it seems that the brazing treatment has increased the VPD of the matrix. Further investigation on the matrix potentials for the materials both before and after brazing is presented in Figure 5.4. The positions of the cross sectional line analysis in the matrix are shown in Figure 5.4a and b. The VPD profile through the $\mathrm{Si}$ is referred to as the reference. These profiles in both of the materials show a very similar behaviour. Comparing the VPD profiles of the matrix in Figure 5.4c and $\mathrm{d}$, it is quite clear that the brazing has had an increasing effect in the VPD of the matrix.

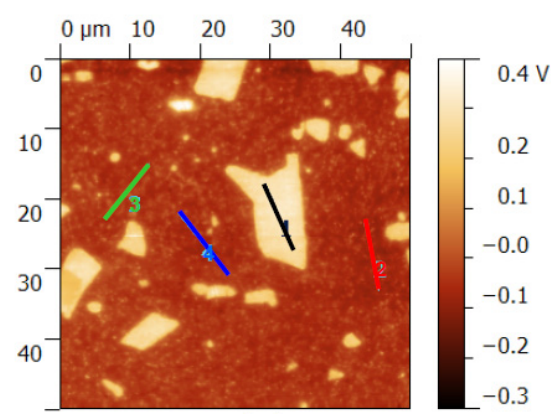

(a)

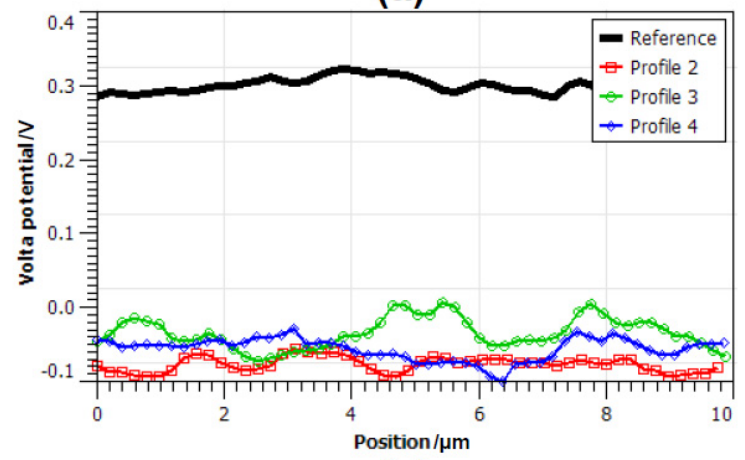

(c)

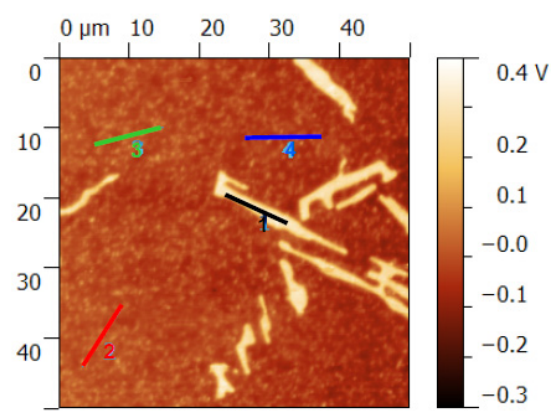

(b)

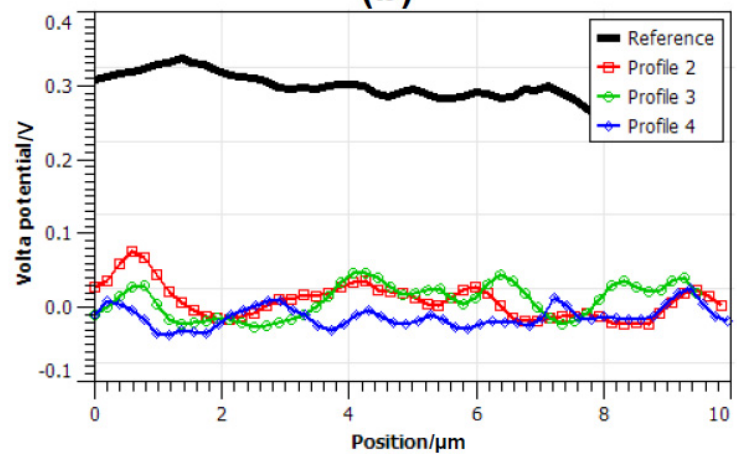

(d)

Fig 5.4. Volta potential maps ( $a$ and $b$ ) and section analysis, before (c) and after (d) brazing treatment. 
Comparison of the measured VPD values, while considering the statistical details of the available data is presented in Figure 5.5.

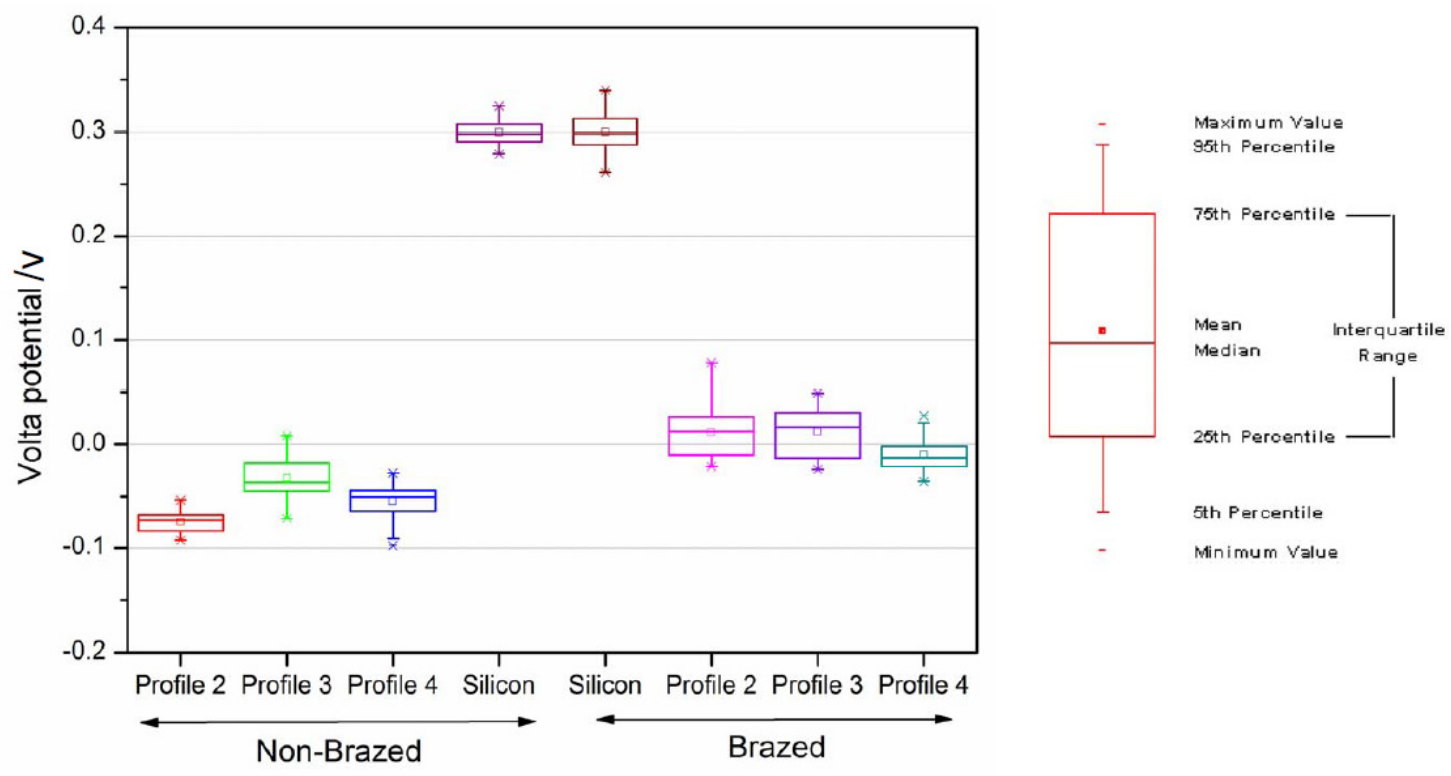

Figure 5.5. Box chart presentation of the Volta potential profiles from cross sectional analysis of the matrix.

The VPD values in both non-brazed and brazed samples are presented as box charts. Each profile of data is represented as a separate box. The profile names supplies the $X$ axis tick labels. The box is determined by the 25 th and 75 th percentiles. The whiskers are determined by the 5th and 95th percentiles. In statistics, a percentile is the value of a variable below which a certain percent of observations fall. For example, the 25 th percentile is the value below which 25 percent of the observations may be found. The maximum, minimum mean and median values are also included in this representation. The data shows a clear increase in the surface VPD of the brazed samples comparing to that of the nonbrazed samples. Comparison of the overall averages of the VPD values of the matrixes before and after brazing shows a $58 \mathrm{mV}$ increase in Volta potential of the brazed samples as a result of the brazing treatment.

It may seem that averaging the data over a defined area to be a better way of presenting the results in Figure 5.5. However, it should be considered that the passage of the cantilever over the phase boundaries between Si particles and the matrix will cause the probe to experience a gradient in composition and significantly affect the measured VPD values. In order to eliminate this effect and to have a reliable and stable VPD values which are relevant to the microstructural features under investigation (Si needles and the matrix), line scans were preferred. Performing a line scan at a proper position, center region of a relatively large $\mathrm{Si}$ 
particle and away from the particle edges or in the aluminium matrix away from small silicon particles, gives consistent and representative data over the $\mathrm{Si}$ and aluminium matrix areas.

\subsubsection{Electrochemical characterization}

The averaged OCP values after a stabilization time of $900 \mathrm{~s}$ for both non-brazed and brazed core and clad materials before anodic (1) and cathodic (2) polarizations are shown in Figures 5.6 and 5.7. Figure 5.6 shows a $40 \mathrm{mV}$ potential difference between the clad and the core material before brazing treatment which makes the clad material to sacrificially protect the core structure. Figure 5.7 demonstrates that for the brazed material the potential difference has been reduced to $15 \mathrm{mV}$.

Comparing the OCP values for the core structures before $(-720 \mathrm{mV})$ and after ($700 \mathrm{mV}$ ) brazing treatment shows an increase of $20 \mathrm{mV}$. This potential difference for the clad material is about $50 \mathrm{mV}$. It is also clear that the brazing treatment has changed the descending OCP profile of the non-brazed core and the clad material into an ascending OCP profile.

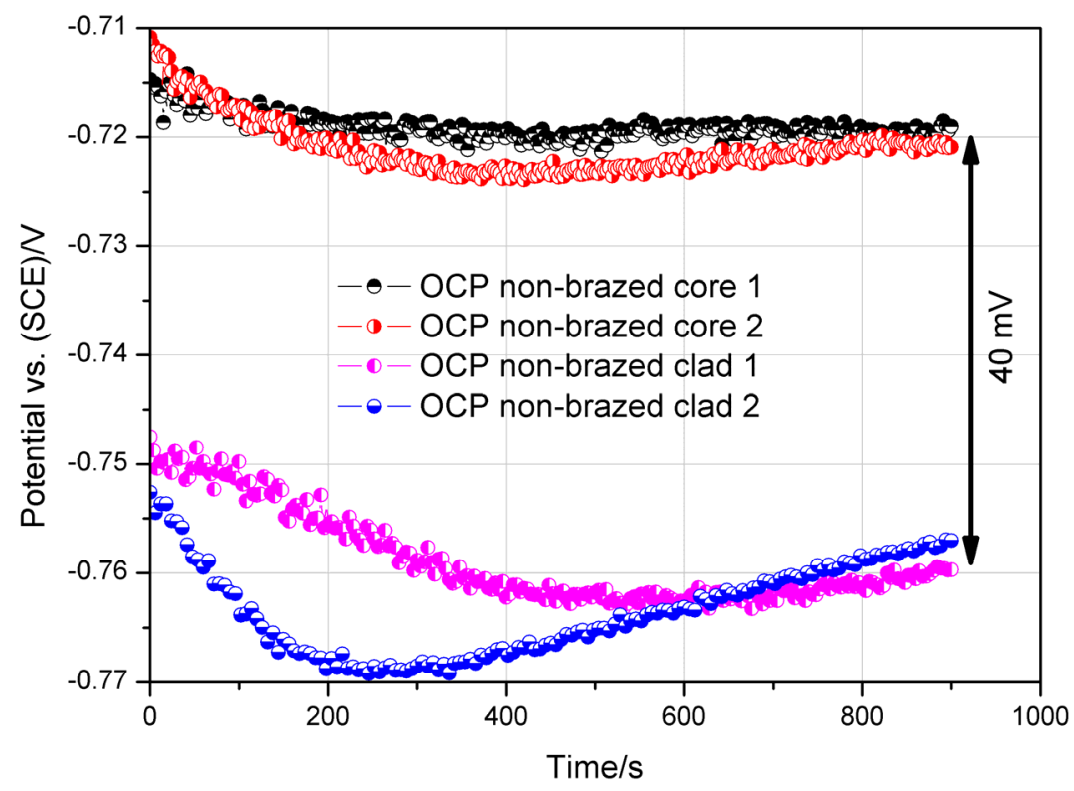

Figure 5.6. Averaged open-circuit corrosion potentials of the non-brazed core and clad materials after 15 min of immersion in $42 \mathrm{~g} / 1 \mathrm{NaCl}$ solution at $\mathrm{pH} 2.8$, before anodic (1) and cathodic (2) polarizations. 


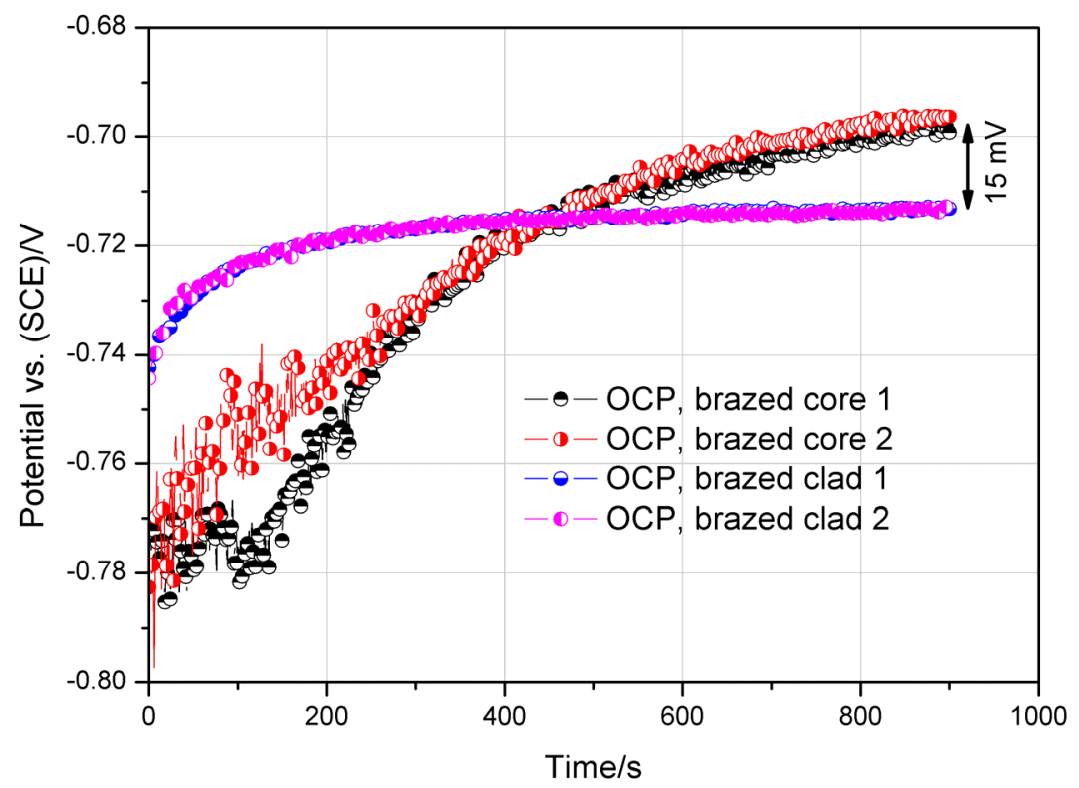

Figure 5.7. Averaged open-circuit corrosion potentials of the brazed core and clad materials after $15 \mathrm{~min}$ of immersion in $42 \mathrm{~g} / \mathrm{l} \mathrm{NaCl}$ solution at $\mathrm{pH} 2.8$, before anodic (1) and cathodic (2) polarizations.

The anodic and cathodic responses of both non-brazed and brazed core materials are presented in Figures 5.8 and 5.9.

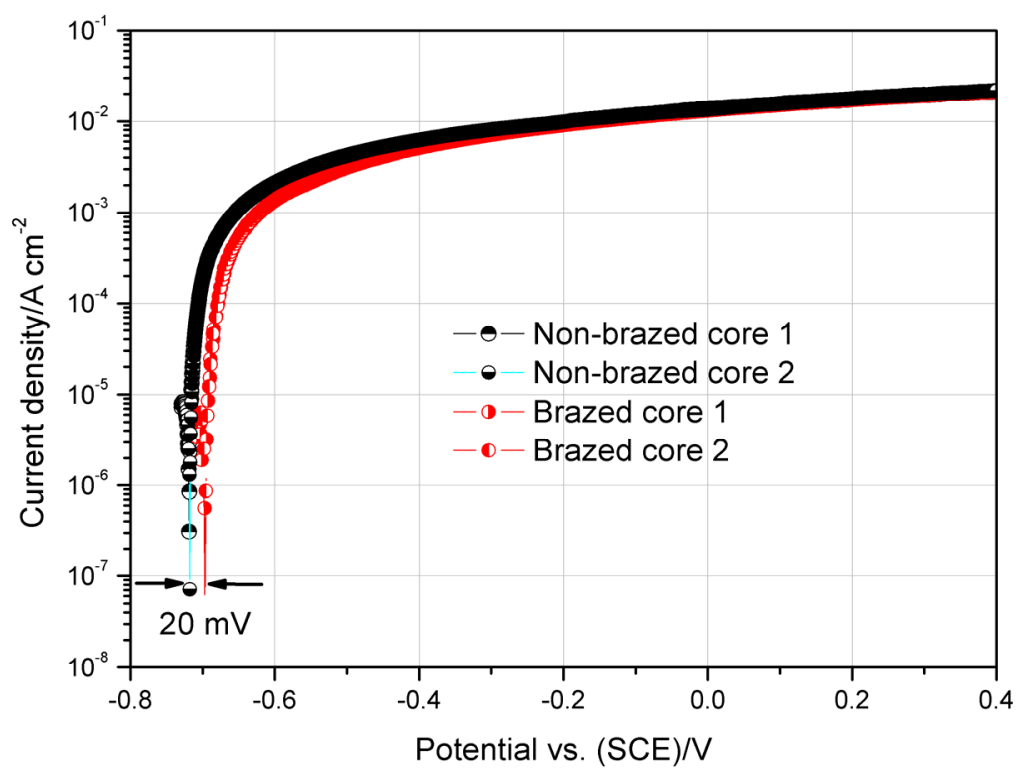

Figure 5.8. Anodic polarization curves for the core materials before and after brazing after 15 min of OCP measurement in $42 \mathrm{~g} / \mathrm{l} \mathrm{NaCl}$ solution at $\mathrm{pH} 2.8$ (scan rate $0.5 \mathrm{mV} / \mathrm{s}$ ). 


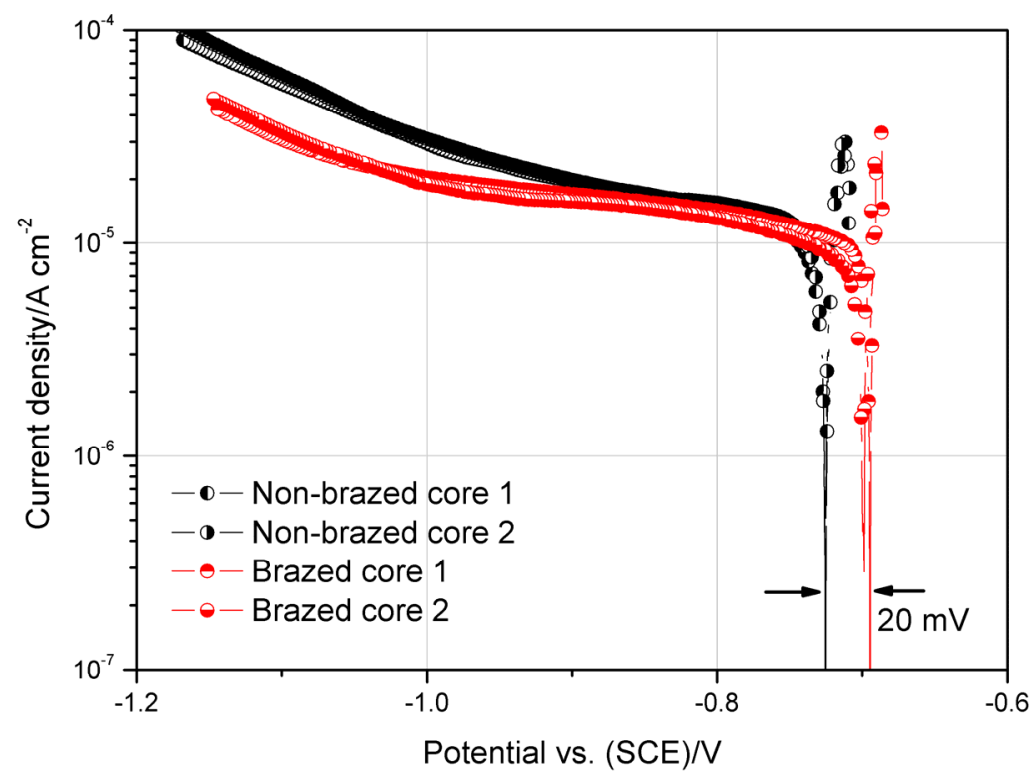

Figure 5.9. Cathodic polarization curves for the core materials before and after brazing after $15 \mathrm{~min}$ of $\mathrm{OCP}$ measurement in $42 \mathrm{~g} / 1 \mathrm{NaCl}$ solution at $\mathrm{pH} 2.8$ (scan rate $0.5 \mathrm{mV} / \mathrm{s})$.

Figure 5.8 shows that the anodic responses of the brazed and non-brazed core materials are quite similar. A sharp increase of the current density at potentials close to the OCP values is observed. The cathodic polarization responses of the brazed core material show lower reactivity, comparing to those of the non-brazed core material. The $20 \mathrm{mV}$ potential shift in OCP values of the core material as a result of brazing treatment is shown in both Figures 5.8 and 5.9.

\subsubsection{Corrosion morphology}

Typical SEM backscattered electron images of the surfaces and cross sections after anodic polarisation of the clad side up to $1 \mathrm{~V}$ above the OCP values are shown in Figures 5.10 and 5.11 respectively. Comparing the corroded surfaces in brazed (Figure 5.10c and d) and non-brazed (Figure 5.10a and b) materials shows that the non-brazed material surface is attacked more uniformly and less severely than the surface of the brazed material. Figure 5.10 illustrates that intergranular corrosion attack is the corrosion mechanism for the brazed material, while for the non-brazed material relatively uniform corrosion is the dominant mechanism of the attack.

Comparing the cross-sections of the corroded samples in Figure 5.11 demonstrates that the clad material in the brazed samples (Figure 5.11a and b) does not provide a proper protection to the core material. The random presence of none, partly and fully attacked pre-eutectic aluminium grains and continuation of corrosion attack in a localized form through the core material are observed. In comparison with the uniform consumption of the clad material in the non-brazed structure (Figure 5.11c and d), it can be concluded that the brazing treatment has a negative effect on the 
cathodic protection of the core by the clad material.

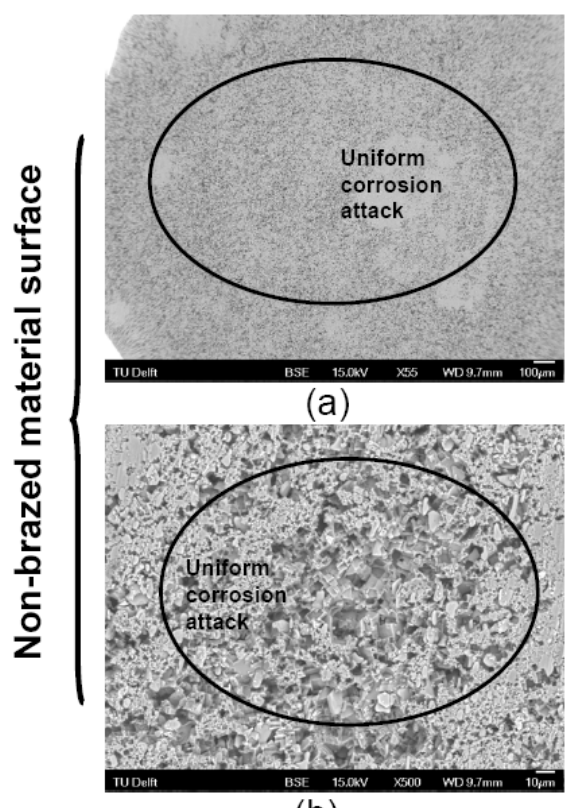

(b)

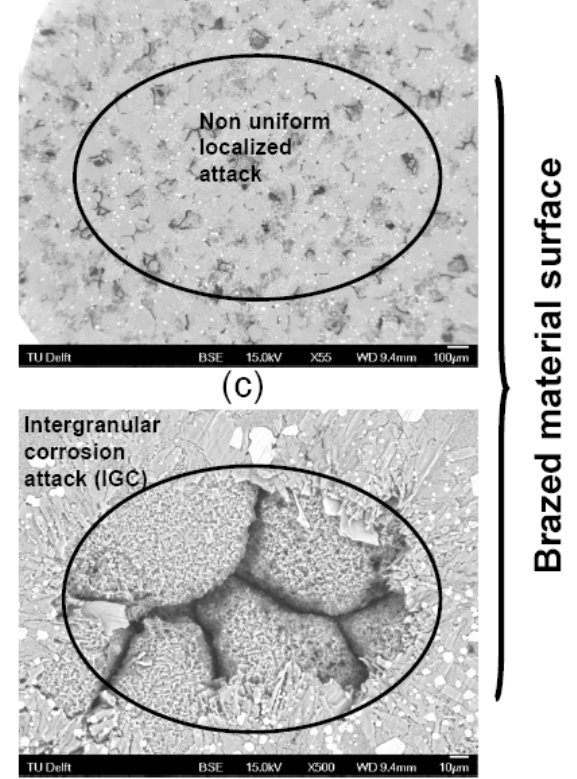

(d)

Fig 5.10. SEM backscattered electron images of the corroded surfaces of nonbrazed ( $a$ and $b$ ) and brazed ( $c$ and d) aluminium brazing sheet samples after anodic polarisation up to $1 \mathrm{~V}$ above the OCP values in a $42 \mathrm{~g} / \mathrm{l} \mathrm{NaCl}$ solution at $\mathrm{pH} 2.8$.

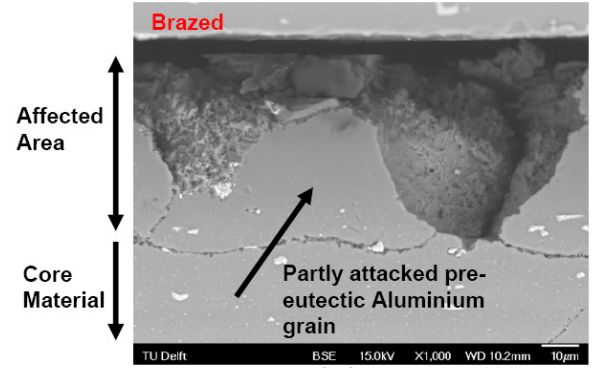

(a)

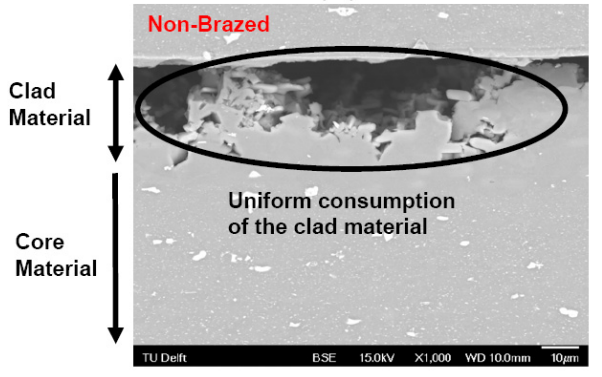

(c)

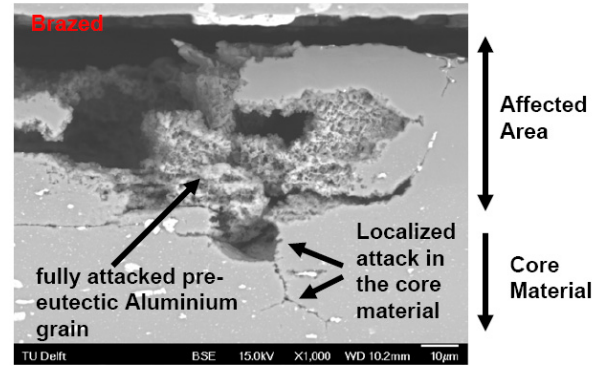

(b)

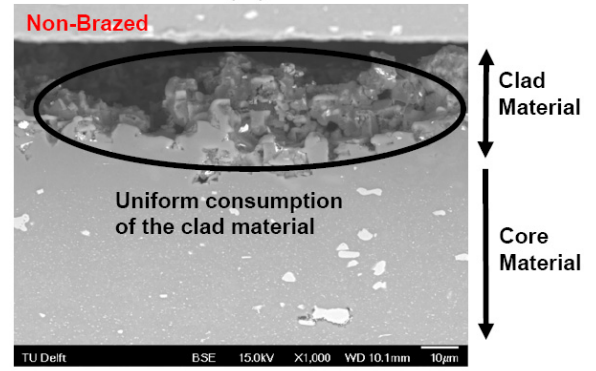

(d)

Figure 5.11. SEM backscattered electron images of the cross sections of brazed (a and $b$ ) and non-brazed (c and d) aluminium brazing sheet samples after anodic polarisation up to $1 \mathrm{~V}$ above the OCP values in a $42 \mathrm{~g} / 1 \mathrm{NaCl}$ solution at $\mathrm{pH} 2.8$. 
Figure 5.12 shows an optical micrograph of the brazed sample cross sections after anodic polarization. Deep attacks into the core structure, non-uniform consumption of the clad material and random presence of non attacked clad areas have been depicted in Figure 5.12.

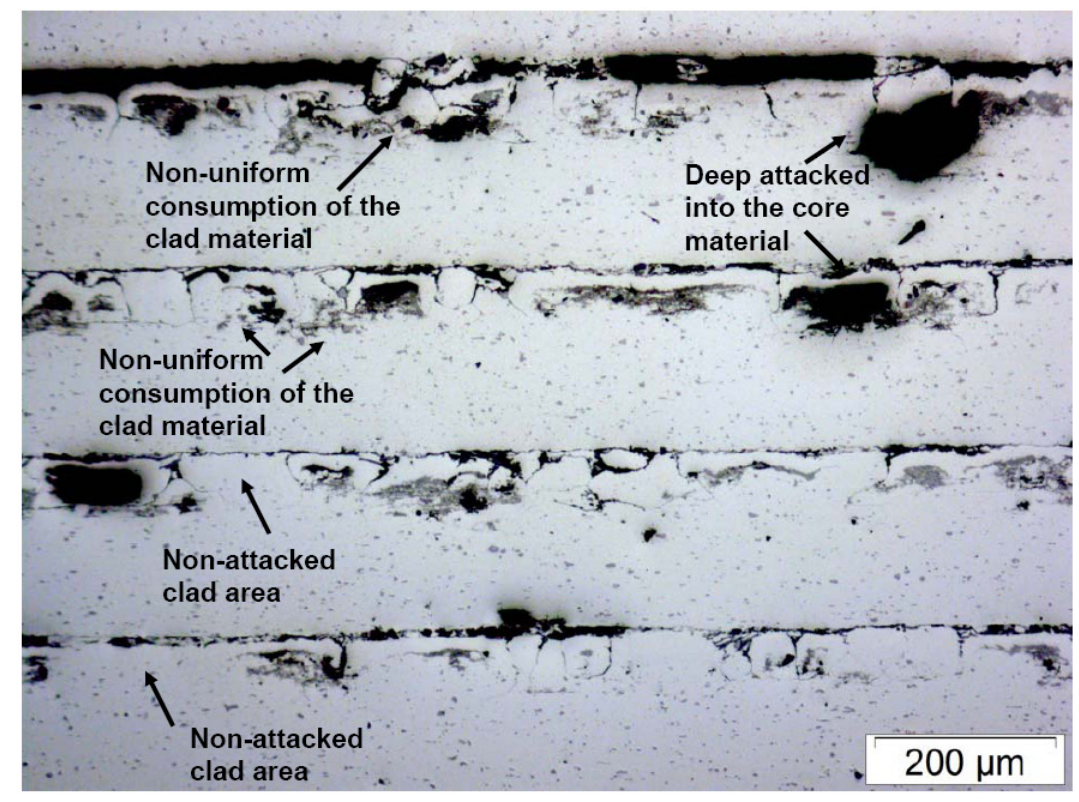

Figure 5.12. Optical micrograph of the aluminium brazing sheet samples after anodic polarisation up to $1 \mathrm{~V}$ above the $\mathrm{OCP}$ values in a $42 \mathrm{~g} / 1 \mathrm{NaCl}$ solution at $\mathrm{pH}$ 2.8 .

\section{4. Discussion}

Based on microstructural characterization of the material $[7,8], \alpha-\mathrm{Al}(\mathrm{Fe}-\mathrm{Mn}) \mathrm{Si}$ and $\mathrm{Al}_{2} \mathrm{Cu}$ have been shown to be the dominant particles present in the core of the material structure. The analysis showed that $\mathrm{Al}_{2} \mathrm{Cu}$ are small particles that have been uniformly distributed through the non-brazed core material and the brazing treatment causes $\mathrm{Cu}$ depletion in particles and copper accumulation in the eutectic phases present in the brazed structure. It was assumed that high solubility of $\mathrm{Cu}$ in the liquid aluminium $(\sim 20 \mathrm{wt} \%)$ accompanied with high diffusivity of copper $(6.42$ $\times 10^{-13} \mathrm{~m}^{2} / \mathrm{s}$ at brazing temperature) in aluminium matrix is the major reason for this phenomenon $[7,8]$.

The last part of the filler alloy to solidify is the eutectic which contains $12.6 \mathrm{wt} \%$ of silicon. The eutectic is characterized by an alternating structure of silicon and $\alpha$ aluminium plates. The $\alpha$-aluminium in the eutectic will be different from the primary $\alpha$-aluminium. This is because all elements that were not incorporated in the primary $\alpha$-aluminium grains will be concentrated in eutectic regions. These will either be incorporated in solid solution in the $\alpha$-aluminium of the eutectic or precipitate as small intermetallics. The eutectic phase will form in between the 
primary $\alpha$-aluminium grains and reaches the surface of the structure which is prone to come in contact with a corrosive environment. This is expected to increase the risk of localized corrosion attack. This prediction is confirmed by the analysis of the corroded surfaces and cross sections, which demonstrates that the localized attack at the surface of the brazed structure occurs at the eutectic phase which has formed at the grain boundaries. The presence of voids on the surface is also expected to stimulate the corrosion attack through the material as it provides a direct contact between the corrosive environment and deeper layers of the material which have already been shown to have a relatively low (active) pitting potential [9].

SKPFM enables direct measurement of the local VPD values resulting from very complicated microstructures due to the thermal history of the produced aluminium alloys. Investigation of the electrochemical responses of the surface of the brazing material both before and after brazing shows that silicon needles have VPDs which are more noble in comparison with the surrounding aluminium matrix. Based on the Al-Si binary phase diagram and the EDX elemental maps of the material under investigation [7], Si can actually contain a very small amount of aluminium (max $0.015 \mathrm{wt} \%$ ) and other alloying elements in solid solution. Therefore Si can be considered as a pure stable phase with minimum compositional changes in the structure of the material both before and after brazing treatment. This provides the advantage of having a reliable local reference in both structures to compare the changes in VPDs as the result of different thermal treatment of aluminium brazing sheet. The same measured VPD values of about $300 \mathrm{mV}$ for Si needles in both structures of the brazed and non-brazed materials, shows the comparability of the VPD maps and cross sectional analysis for both brazed and non-brazed structures. The average of $58 \mathrm{mV}$ increase in the VPD difference between the brazed and nonbrazed clad matrixes as a consequence of brazing process is expected to be the result of diffusion of $\mathrm{Cu}$ into the clad material. This VPD increase is quite comparable with the $50 \mathrm{mV}$ increase in the OCP profile of the brazed clad surface which was already reported comparing Figures 5.6 and 5.7. This change is expected to weaken the cathodic protection power of the re-solidified clad material towards the core. This is more clearly reflected in the $25 \mathrm{mV}$ reduction (changing from $40 \mathrm{mV}$ to $15 \mathrm{mV}$ ) in the OCP profile differences between the clad and the core materials as a result of brazing. From this perspective brazing will diminish the corrosion resistance of the material under investigation. It should be noted that such an increase in VPD of the clad matrix can also be interpreted as reduction of the VPD difference between the cathodic particles i.e. $\mathrm{Si}, \alpha-\mathrm{Al}(\mathrm{Fe}-\mathrm{Mn}) \mathrm{Si}, \mathrm{Al}_{2} \mathrm{Cu}$ and the clad matrix which in turn should reduce the galvanic interaction between these cathodic sites and the clad matrix. This may result in less localized corrosion attack and therefore improvement of the corrosion resistance of the structure. Referring to the previous published literature [7,9] and the corrosion morphology investigation in the current work, this second interpretation is not valid. This can be explained by the fact that although Si particles have a nobler corrosion potential 
with respect to the aluminium matrix, the oxygen reduction current density on silicon is too low to anodically polarise aluminium [5-7,9]. Therefore Si particles are not effective cathodic sites and they have a weak galvanic interaction with the matrix. Considering the distribution of $\alpha-\mathrm{Al}(\mathrm{Fe}-\mathrm{Mn}) \mathrm{Si}$ and $\mathrm{Al}_{2} \mathrm{Cu}$ particles [7,9], after brazing treatment these particles are mainly accumulated at the very top surface and in the core material. So therefore the density of these particles in the clad material (affected area) is low and the galvanic coupling effect is not dominating the corrosion resistance and dissolution mechanism of the clad material.

With regard to the above explanation and the fact that the clad material is expected to sacrificially protect the core structure and prevent any possible contact between the internal layers of the material and corrosive environment, the increase of the OCP profiles is considered to be a detrimental effect. Referring to the SKPFM result this OCP profile changes are comparably reflected in Volta potential changes on the surface.

Apart from the mentioned sources of errors which may affect the Volta potential measurements, as presented in experimental section, it should also be noted that the only information that can be directly obtained from a VPD map is a work function map. Corrosion behaviour depends sensitively on the environment $(\mathrm{pH}$, kind of ions, etc.) and is also determined by the kinetics of the reactions involved [28]. From this it becomes immediately obvious that there can not be a general correlation between the contrasts measured by SKPFM on a freshly prepared surface and its later corrosion behaviour although in many cases such a correlation may be found [28]. Therefore it should be clear that the relation between Volta potential and local electrochemistry is relevant but not trivial. This means that the quantitative interpretation of Volta potential data should be careful and backed up by electrochemical data and information on composition and corrosion morphology [17]. Therefore, to further investigate the predictions from SKPFM analysis, a through potentiodynamic polarization and analysis of the corroded surfaces and cross sections of the materials under investigation was carried out.

The similarity of the anodic polarization responses for the brazed and non-brazed core materials shows that a similar corrosion rate in the SWAAT environment can be expected. The presence of a sharp increase in the corrosion current at potentials close to the OCP values in these anodic potentiodynamic responses shows the susceptibility of both core materials to localized corrosion attacks.

The lower reactivity of the cathodic polarization responses of the brazed core material is expected to be related to dissolution of some of the $\alpha-\mathrm{Al}(\mathrm{Fe}-\mathrm{Mn}) \mathrm{Si}$ and $\mathrm{Al}_{2} \mathrm{Cu}$ particles in the structure as the result of brazing treatment at $600{ }^{\circ} \mathrm{C}$ [7]. Dissolution of these cathodic sites will leave the structure with higher concentration of alloying elements which all are expected to have an increasing 
effect in the corrosion potential of the matrix of the core material. This can well explain the $20 \mathrm{mV}$ increase of the OCP values for the core structures after brazing treatment in spite of the diffusion of $\mathrm{Cu}$ towards the clad material. The effect of alloying elements on the corrosion potential of aluminium alloys have been explained in details by Meijers [6] and Davis [35].

The analysis of the corroded surfaces shows that the brazing treatment has a negative effect on the cathodic protection of the core with the clad material. The brazed clad material has a high sensitivity to localized corrosion and the attack has developed deep into the structure of the core material while for the non-brazed material the uniform pitting attack has been restricted to the clad layer. The results demonstrate lack of proper protection of core material by the clad layer. This is also inline with the OCP and VPD variation as explained before. The localized corrosion susceptibility of the residual cladding arises from a higher sensitivity to pitting of the eutectic (Al) in solutions containing chloride. This has been explained by a lower pitting potential for eutectic (Al) than for the primary aluminium $[5,6]$.

\subsection{Conclusions}

Applying SKPFM and potentiodynamic polarization measurements the electrochemical nature of the overall surface microstructure and surface microstructural heterogeneities for the clad and the core of a modified AA3xxx/AA4xxx brazing sheet both before and after brazing treatment was investigated and compared. The result was interpreted and discussed with reference to the prior detailed microstructural and electrochemical characterization of the same material. The following results were obtained:

1. The suitability of SKPFM analysis for electrochemical investigation of the aluminium brazing sheet material in SWAAT environment was confirmed.

2. Considering the high purity of Si particles in the structure of both brazed and non-brazed material, it was suggested that $\mathrm{Si}$ can be applied as a reliable local reference in the structures to compare the changes in Volta potential differences as the result of different heat treatments of aluminium brazing sheet.

3. Brazing treatment increases the Volta potential of the clad matrix which in turn reduces the cathodic protection power of the re-solidified clad material. The amount of increase in Volta potential was determined to be $58 \mathrm{mV}$ on average comparing to that of the non-brazed clad material. This is in line with the measured $50 \mathrm{mV}$ increase in OCP profiles.

4. Brazing treatment increases the OCP of the core material which is a consequence of dissolution of the $\alpha-\mathrm{Al}(\mathrm{Fe}-\mathrm{Mn}) \mathrm{Si}$ and $\mathrm{Al}_{2} \mathrm{Cu}$ intermetallic 
particles and enrichment of the core matrix with alloying elements which can increase the corrosion potential of the aluminium matrix.

5. The investigation showed that the formation of Al-Si eutectic phase in between the primary $\alpha$-aluminium grains which reaches the surface of the structure may result in susceptibility of the re-solidified clad material to localized corrosion attacks. 


\subsection{References}

[1]. A.C. Scott, R.A. Woods, J.F. Harris, Accelerated corrosion test methods for evaluating external corrosion resistance of vaccumed brazed aluminium heat exchangers, in: Conference Proceedings of SAE International Congress, SAE, Warrendale, USA, 1991 (paper No. 910590).

[2]. Y. Isobe, K. Takeuchi, M. Tanaka, M. Mori, S. Yamauchi, K. Namba, Development of corrosion resistant brazing sheet for drawn cup type evaporators part 2: Application to evaporator, in: SAE: Conference Proceedings of SAE International Congress, SAE, Warrendale, USA, 1993 (paper No. 930149).

[3]. F.M. Al-Kharafi, W.A. Badawy, Corrosion and passivation of al and al-si alloys in nitric acid solutions: 2 - effect of chloride ions, Electrochimica Acta, 40 (1995) 1811.

[4]. S.S. Abdel Rehim, H.H. Hassan, M.A. Amin, Chronoamperometric studies of pitting corrosion of $\mathrm{Al}$ and (Al-Si) alloys by halide ions in neutral sulphate solutions, Corrosion Science, 46 (2004) 1921.

[5]. S. Kuroda, K. Tohma, Aluminium alloys, in: Conference Proceedings of ICAA6, Japan Institute of Light Metals, Toyohashi, Japan, 1998, p. 1543.

[6]. S. Meijers, Corrosion of aluminium brazing sheet, Ph.D. Thesis, TU Delft, 2002, ISBN: 90-805661-3-6.

[7]. F.N. Afshar, J.H.W. de Wit, H. Terryn, J.M.C. Mol, The effect of brazing process on microstructure evolution and corrosion performance of a modified A4xxx/AA3xxx brazing sheet, Corrosion Science, 58 (2012) 242.

[8]. F.N. Afshar, E. Szala, A. Wittebrood, C.J.G. Van Hoek, J. Van der Hoeven, A. Buerger, J.M.C. Mol, H. Terryn, J.H.W. de Wit, New approach in microstructural analysis of a modified AA4xxx/AA3xxx brazing sheet before and after brazing, in: Vehicle Thermal Management Systems Proceedings (VTMS 10), Gaydon, UK, 2011.

[9]. F.N. Afshar, R. Ambat, C. Kwakernaak, J.H.W. de Wit, J.M.C. Mol, H. Terryn, Electrochemical depth profiling of multilayer metallic structures: an aluminium brazing sheet, Electrochimica Acta, 77 (2012) 285.

[10]. V. Guillaumin, P. Schmutz, G.S. Frankel, Characterization of corrosion interfaces by the scanning kelvin probe force microscopy technique, Journal of the Electrochemical Society, 148 (5) (2001) B163.

[11]. P. Schmutz, G.S. Frankel, Corrosion study of AA2024-T3 by scanning Kelvin probe force microscopy and in situ atomic force microscopy scratching, Journal of the Electrochemical Society, 145 (7) (1998) 2295.

[12]. P. Schmutz, G.S. Frankel, Characterization of AA2024-T3 by scanning Kelvin probe force microscopy, Journal of the Electrochemical Society 145 (7) (1998) 2285.

[13]. P. Schmutz, G.S. Frankel, Influence of dichromate ions on corrosion of pure aluminum and AA2024-T3 in $\mathrm{NaCl}$ solution studied by AFM scratching, Journal of the Electrochemical Society, 146 (12) (1999) 4461.

[14]. P. Leblanc, G.S. Frankel, A study of corrosion and pitting initiation of AA2024-T3 using atomic force microscopy, Journal of the Electrochemical Society, 149 (6) (2002) B239.

[15]. R.G. Buchheit, Compilation of corrosion potentials reported for intermetallic phases in aluminum alloys, Journal of the Electrochemical Society, 142 (1995) 3994.

[16]. J.X. Jia, A. Atrens, G. Song, T.H. Muster, Simulation of galvanic corrosion of magnesium coupled to a steel fastener in $\mathrm{NaCI}$ solution, Materials and Corrosion, 56 
(2005) 468.

[17]. J.H.W. de Wit, Local potential measurements with the SKPFM on aluminium alloys, Electrochimica Acta, 49 (2004) 2841.

[18]. P. Campestrini, E.P.M. van Westing, H.W. van Rooijen, J.H.W. de Wit, Relation between microstructural aspects of AA2024 and its corrosion behaviour investigated using AFM scanning potential technique, Corrosion Science, 42 (2000) 1853.

[19]. L. Lacroix, L. Ressier, C. Blanc, G. Mankowski, Combination of AFM, SKPFM, and SIMS to study the corrosion behavior of S-phase particles in AA2024-T351, Journal of the Electrochemical Society, 155 (2008) C131.

[20]. M. Femenia, C. Canalias, J. Pan, C. Leygraf, Scanning Kelvin probe force microscopy and magnetic force microscopy for characterization of duplex stainless steels, Journal of the Electrochemical Society, 150 (2003) B274.

[21]. N. Sathirachinda, R. Pettersson, S. Wessman, U. Kivisäkk, J. Pan, Scanning Kelvin probe force microscopy study of chromium nitrides in 2507 super duplex stainless steel Implications and limitations, Electrochimica Acta, 56 (2011) 1792.

[22]. N. Sathirachinda, R. Pettersson, J. Pan, Depletion effects at phase boundaries in 2205 duplex stainless steel characterized with SKPFM and TEM/EDS, Corrosion Science, 51 (2009) 1850.

[23]. S. Mato, G. Alcalá, T.G. Woodcock, A. Gebert, J. Eckert, L. Schultz, Corrosion behaviour of a Ti-base nanostructure-dendrite composite, Electrochimica Acta, 50 (2005) 2461.

[24]. F. Andreatta, H. Terryn, J.H.W. de Wit, Effect of solution heat treatment on galvanic coupling between intermetallics and matrix in AA7075-T6, Corrosion Science, 45 (2003) 1773.

[25]. F. Andreatta, H. Terryn, J.H.W. de Wit, Corrosion behaviour of different tempers of AA7075 aluminium alloy, Electrochimica Acta, 49 (2004) 2851.

[26]. Premendra, B.S. Tanem, J.M.C. Mol, H. Terryn, J.H.W. de Wit, L. Katgerman, A combined TEM and SKPFM investigation of the surface layers on rolled AA5050 aluminium alloy using ultra-microtomy, Surface and Interface Analysis, 40 (2008) 1157.

[27]. A.B. Cook, Z. Barrett, S.B. Lyon, H.N. McMurray, J. Walton, G. Williams, Calibration of the scanning Kelvin probe force microscope under controlled environmental conditions, Electrochimica Acta, 66 (2012) 100.

[28]. M. Rohwerder, F. Turcu, High-resolution Kelvin probe microscopy in corrosion science: Scanning Kelvin probe force microscopy (SKPFM) versus classical scanning Kelvin probe (SKP), Electrochimica Acta, 53 (2007) 290.

[29]. J. Lacaze, S. Tierce, M.C. Lafont, Y. Thebault, N. Pebere, G. Mankowski, C. Blanc, H. Robidou, D. Vaumousse, D. Daloz, Study of the microstructure resulting from brazed aluminium materials used in heat exchangers, Materials Science and Engineering A, 317 (2005) 413.

[30]. P. Campestrini, Microstructure-related quality of conversion coatings on aluminium alloys, Ph.D. Thesis, TU Delft, 2002, ISBN: 90-407-2342-7.

[31]. H.O. Jacobs, H.F. Knapp, A. Stemmera, Practical aspects of Kelvin probe force microscopy, Review of Scientific Instruments, 70 (1999) 1756.

[32]. F.N. Afshar, E. Szala, A. Wittebrood, R. Mulder, J.M.C. Mol, H. Terryn, J.H.W. de Wit, Influence of material related parameters in sea water acidified accelerated test, reliability analysis and electrochemical evaluation of the test for aluminium brazing sheet, Corrosion Science, 53 (2011) 3923. 
[33]. A. Wittebrood, Microstructural changes in brazing sheet due to solid-liquid interaction, Ph.D. Thesis, TU Delft, 2009, ISBN: 978-90-805661-6-3.

[34]. D.J. Schmatz, Grain boundary penetration during brazing of aluminum, Welding Journal, 10 (1983) 267s.

[35]. J.R. Davis, in: J.R. Davis (Ed.), ASM Specialty Handbook: Aluminium and Aluminium Alloys, ASM International, OH, USA, 1994. 


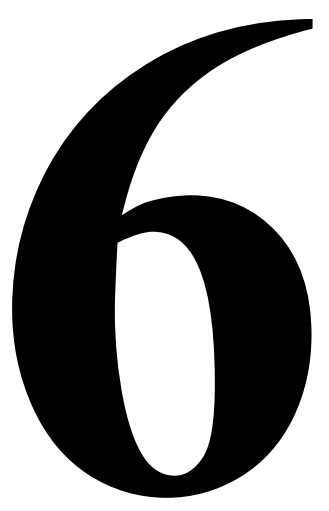

* This chapter has been published as a scientific paper:

F. Norouzi Afshar, A. M. Glenn, J.H.W. de Wit, H. Terryn, J.M.C. Mol, A combined electron probe micro analysis and scanning Kelvin probe force microscopy study of a modified AA4xxx/AA3xxx aluminium brazing sheet, Electrochimica Acta 104 (2013) 48-63. 



\title{
Cross-sectional microstructural and micro-electrochemical characterization
}

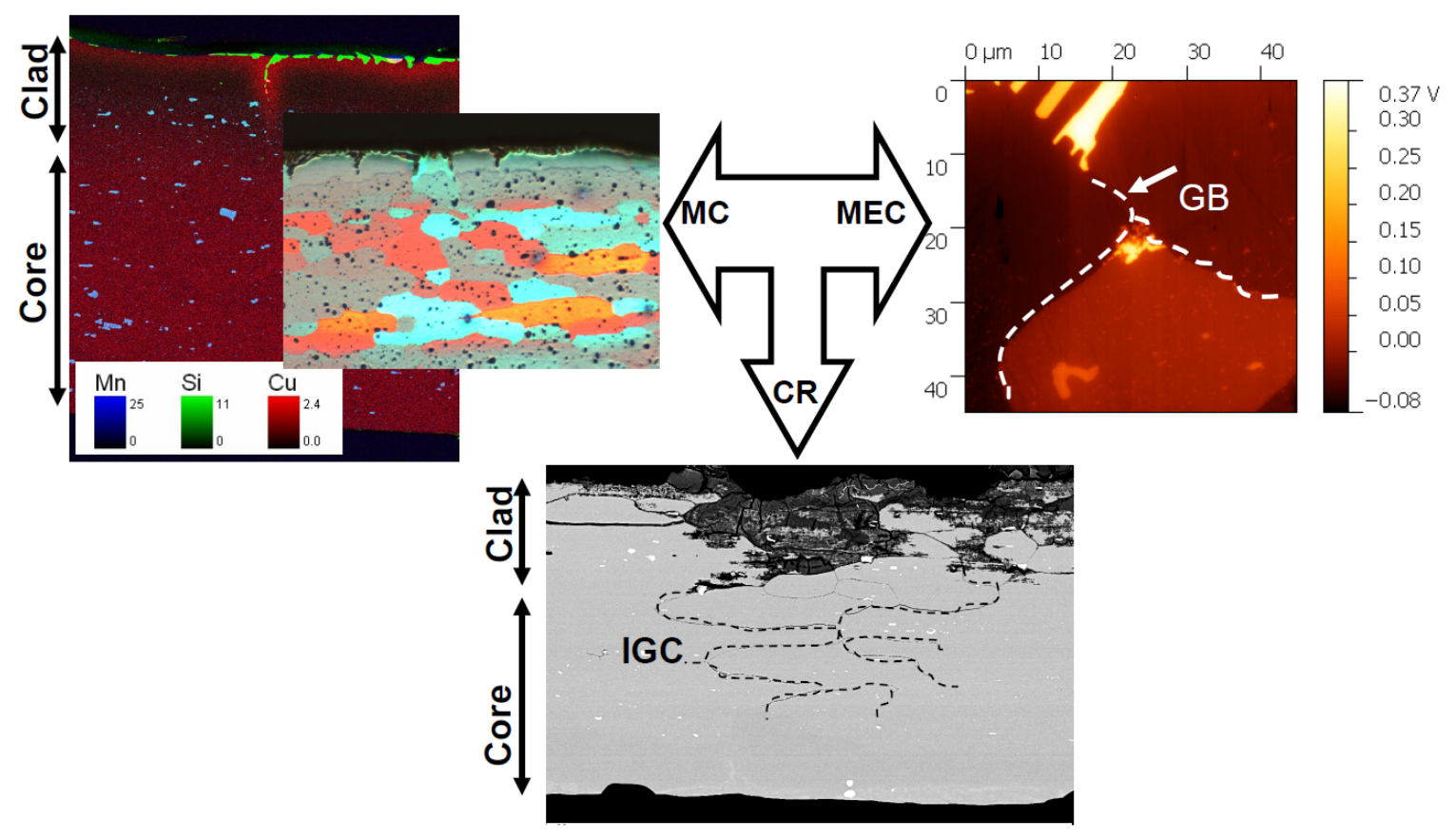

MEC: Micro-Electrochemical Characteristics MC: Microstructural Characteristics

CR: Corrosion Resistance

\begin{abstract}
The electrochemical and microstructural properties of the clad and core from a modified AA3xxx/AA4xxx brazing sheet were investigated before and after brazing. For this, scanning Kelvin probe force microscopy (SKPFM) and field emission electron probe micro analysis (FE-EPMA) were used. The Volta potential difference (VPD) was measured as a function of depth for the brazed and non-brazed sheet. This was correlated with the cross-sectional variation of chemistry and microstructure that result from brazing. Furthermore,
\end{abstract}


potentiodynamic polarization experiments and subsequent microscopic analysis of the corroded samples were used to explore the corrosion mechanism of the modified brazed sheet. The investigation revealed that the major consequences of brazing for the microstructure are: an increase in the Si content of the matrix in the heat affected zone (HAZ); a non-uniform distribution of $\mathrm{Cu}$ in the HAZ; an accumulation of $\mathrm{Cu}$ in $\mathrm{Al}-\mathrm{Si}$ eutectics and around the grain boundaries, including $\alpha-\mathrm{Al}(\mathrm{Mn}, \mathrm{Fe}) \mathrm{Si}$ and $\mathrm{Al}_{2} \mathrm{Cu}$ intermetallics; the presence of some continuous grain boundaries in both the clad and core of the sheet; and the non-uniform precipitation of intermetallics at $\mathrm{Al}-\mathrm{Si}$ eutectic phases. The impact of these microstructural changes on the corrosion behaviour of the brazed sheet were: to increase the VPD of the re-solidified clad matrix; to introduce localized corrosion susceptibility on the brazed clad and core structures; and to reduce the cathodic protection power of the re-solidified clad material. As a result of the correlation between microstructure and electrochemical behaviour, it was concluded that corrosion resistance of the modified aluminium brazing sheet could be improved by applying a post-braze heat treatment.

\subsection{Introduction}

Aluminium brazing sheet is widely used in automotive heat exchangers and consists of a core alloy clad on one or both sides with a lower melting point aluminium-silicon (Al-Si) alloy. This thin clad layer usually makes up 5-10\% of the total thickness of the sheet. It melts and flows during brazing and provides a metallic bond between the heat exchanger components upon cooling. Typical clad and core alloys are the AA4xxx and AA3xxx series, respectively.

Corrosion behaviour of the brazed sheet is critically important since this is the major failure mode for automotive heat exchangers. It has been the subject of several studies [1-7]. Some of these have focused on airside corrosion sensitivity. Scott et al. [2] and Isobe et al. [3] reported that noble Si needles had a detrimental effect on corrosion resistance of the cladding. Scott et al. [2] studied the corrosion behaviour of these materials using a sea water acidified accelerated test (SWAAT). Isobe et al. [3] used copper accelerated salt spray (CASS) and acetic acid salt spray (AASS) tests. They emphasized the active cathodic role of Si needles while the surrounding aluminium dissolved. Al-Si alloys were also studied for other applications. In acidic or neutral solutions, it has been reported that Si particles did not have a detrimental effect on the corrosion resistance of aluminium alloys [4, 5]. Some research, investigating the corrosion of brazed aluminium heat exchangers $[6,7]$, also agreed with this point, stating that the cathodic reaction mentioned by Scott et al. [2] and Isobe et al. [3] did not occur on Si needles. Kuroda and Tohma [6] and Meijers [7] reported that the oxygen reduction current density on silicon is too low to anodically polarise aluminium. They proposed that the higher sensitivity to pitting of the eutectic (Al) in chloride solutions is the root cause for the corrosion susceptibility of the cladding. This suggests a lower pitting 
potential for eutectic (Al) than for the primary (Al).

In the course of brazing, the parts to be joined are heated to the melting temperature of the AA4xxx clad material. This alters microstructural features such as type, distribution and chemical composition of the intermetallic particles. A comparison of brazed and non-brazed structures and the effect of brazing on the microstructure have already been investigated and reported in prior publications of the author $[1,8]$. The cathodic and anodic electrochemical activity of the brazed and non brazed surfaces were studied and correlated to microstructural changes resulting from brazing. It was concluded that brazing causes copper enrichment at the surface and an increase of $50 \mathrm{mV}$ in the corrosion potential of the re-solidified clad material, and increasing its intergranular corrosion (IGC) susceptibility [1,9]. Precipitation of $\alpha-\mathrm{Al}(\mathrm{Fe}-\mathrm{Mn}) \mathrm{Si}$ particles at the surface of the brazed material was found to increase its cathodic activity [1,9]. The micro-electrochemical characterization of the surfaces of the brazed and non-brazed structures was continued with VPD and topographic maps which were measured using SKPFM and atomic force microscopy (AFM), respectively [10]. By performing potentiodynamic polarization experiments and microscopic analysis of the corroded surfaces and cross sections, the suitability of SKPFM for corrosion performance prediction of the aluminium brazing sheet material in SWAAT environment was confirmed [10]. Considering the purity of the Si phase in the structures of both brazed and non-brazed material, it was shown that $\mathrm{Si}$ is a stable local reference in both structures to compare the changes in VPD as the result of different heat treatments of aluminium brazing sheet [10].

The proposed correlation between VPD measured by SKPFM and the possible formation of galvanic couples during corrosion is linked to the findings of Schmutz and Frankel et al. [11-15]. They investigated the interrelation between corrosion potential of metals and the VPD measured by the SKPFM probe technique after immersion. They reported that the VPD measured on aluminium alloy surfaces correlates with localized corrosion behaviour [11-15]. It was proposed that the VPD measured in air provides a measure of the local nobility and it was demonstrated that VPD values for $\mathrm{Cu}$ containing intermetallics in polished AA2024 are nobler than that of the matrix [11]. These findings coincide with the trends in corrosion potential values observed in $\mathrm{NaCl}$ solutions [16].

Many other researchers have also applied VPD values determined by SKPFM in air to characterize alloy surfaces and to predict the localized corrosion behaviour of various alloy systems in solution [17-24]. Andreatta et al. [25-26] reported electrochemical micro-cell measurements in combination with SKPFM and SEM analysis on AA7075 to establish a correlation between VPD and breakdown potential. Premenda et al. [27] performed a combined SKPFM and transmission electron microscopy (TEM) investigation of the surface layers on rolled AA5050 aluminium. A solid demonstration of SKPFM calibration in terms of corrosion 
potential under controlled atmospheric conditions of known humidity has been established by Cook et al. [28]. A discussion of the problems that may be encountered in simply extrapolating the findings of Schmutz and Frankel et al. [11-15] to other alloy systems, e.g. using the VPD measured on freshly polished surfaces to predict subsequent corrosion behaviour in solution is reported by Rohwerder and Turcu [29].

Although a detailed macro- and micro-electrochemical and microstructural characterization of the surfaces of both brazed and non-brazed AA3xxx/AA4xxx structures has been conducted [10], a similar investigation for the cross-section of the same material does not yet exist. This type of investigation is necessary for developing a detailed mechanistic understanding of the corrosion propagation mechanism for the brazed material. This may elucidate the reasons behind corrosion propagation behaviour such as IGC and non-uniform dissolution of the re-solidified clad material, which are observed after potentiodynamic and SWAAT experiments. Such an understanding will assist with solutions for enhancing the corrosion resistance of the brazed material by controlling the microstructure. Consequently, the objectives of the current study were:

1. to investigate the cross sectional macro and micro electrochemical properties of a modified aluminium brazing sheet,

2. to investigate the variation of microstructure as a function of depth in the aluminium brazing sheet,

3. to correlate the electrochemical results with microstructural features, and

4. to explain the corrosion propagation mechanism through the structure of the brazed material and investigate possibilities for improving the corrosion resistance of the brazed structure.

\subsection{Experimental}

\subsubsection{Materials}

A4 size sheet was cut from rolled, modified AA3xxx aluminium alloy $(185 \mu \mathrm{m}$ thick) clad on one side with an AA4xxx (15 $\mu \mathrm{m}$ thick). The bulk chemical analysis of the clad and core material was obtained by X-Ray Fluorescence (XRF) analysis of $3 \mathrm{~cm}$ diameter discs of the material. PW2400 equipment with a Rhodium anode and a $60 \mathrm{kV}$ acceleration voltage was used. The data were analyzed with UniQuant software and are presented in Table 6.1. 
Table 6.1. Chemical composition (wt \%) of the AA3xxx (core) and AA4xxx (clad) material.

\begin{tabular}{ccccccccc}
\hline & $\mathrm{Si}$ & $\mathrm{Fe}$ & $\mathrm{Cu}$ & $\mathrm{Ti}$ & $\mathrm{V}$ & $\mathrm{Cr}$ & $\mathrm{Mn}$ & $\mathrm{Al}$ \\
\hline Clad & 7.70 & 0.18 & - & 0.01 & - & - & 0.14 & Bal. \\
Core & 0.44 & 0.32 & 0.6 & 0.08 & 0.01 & 0.07 & 1.03 & Bal. \\
\hline
\end{tabular}

\subsubsection{Brazing procedure}

The sheet was cleaned in an ultrasonic bath with ethanol, dried and placed in a Controlled Atmosphere Brazing (CAB) furnace. CAB is conducted in a dry, inert nitrogen gas atmosphere. The material is heated to $600{ }^{\circ} \mathrm{C}$ and is kept at that temperature for $3 \mathrm{~min}$ then cooled at $60{ }^{\circ} \mathrm{C} / \mathrm{min}$. The holding temperature was selected to be close to the liquidus of the clad material, reported to be $612{ }^{\circ} \mathrm{C}$ [30], while far below the solidus temperature of the core material which is about $640^{\circ} \mathrm{C}$ [1].

\subsubsection{Microstructure and composition analysis}

The microstructure and surface morphology of the brazed and non-brazed sheet material were characterised using optical and scanning electron microscopy (SEM). The SEM was a JEOL JSM 6500F equipped with an energy dispersive spectrometer (EDS, Thermo Fisher Ultra Dry detector $\left(30 \mathrm{~mm}^{2}\right)$ operated with Noran System 7 for X-ray micro analysis (XMA)).

For chemical characterization (elemental analysis) EDS mapping was conducted on polished cross sections using an FEI quanta 400, field emission, environmental SEM equipped with a Bruker silicon drift EDS detector and Bruker software (Esprit ver. 1.9). Before SEM analysis, samples were coated with a conductive carbon layer of approximately $15 \mathrm{~nm}$ thickness. Mapping conditions were: an electron beam energy of $15 \mathrm{kV}$; a probe current of approximately $10 \mathrm{nA}$; a step size of approximately $0.27 \mu \mathrm{m}$; a total of $800 \times 690$ pixels in $\mathrm{X}$ and $\mathrm{Y}$, respectively.

Using Electron Probe x-ray Micro Analysis (EPMA), quantitative line scans were recorded crossing the outer $50 \mu \mathrm{m}$ layer of the brazed and non-brazed structures. The measurements were performed with a JEOL JXA 8900R microprobe using an electron beam with energy of $15 \mathrm{keV}$ and a beam current of $50 \mathrm{nA}$ employing Wavelength Dispersive Spectrometry (WDS). The composition at each analysis location of the sample was determined using the X-ray intensities of the constituent elements after background correction relative to the corresponding intensities of reference materials. The points of analysis were located along a line with increments of $1 \mu \mathrm{m}$ for the quantitative line scans. 
EPMA maps were also collected using a JEOL 8500F, field emission, electron microprobe, equipped with 5 wavelength dispersive spectrometers (WDS); 2 silicon drift, energy dispersive spectrometers (EDS); an optically encoded stage; and top-referenced sample holder. Mapping parameters used were: electron beam energy of $7 \mathrm{keV}$, probe current of $100.5 \mathrm{nA}$, step size of $160 \mathrm{~nm}$, a total field size of $256 \times 224 \mu \mathrm{m}$ and a dwell time of $50 \mathrm{~ms}$. The WDS spectrometers were tuned to collect the signals of $\mathrm{Mn} \mathrm{L} \alpha, \mathrm{Fe} \mathrm{L} \alpha, \mathrm{Cr} \mathrm{L} \alpha, \mathrm{Si} \mathrm{K} \alpha$ and $\mathrm{Cu} \mathrm{L} \alpha$ characteristic $\mathrm{x}$ rays. All other elements were analysed using EDS. Pure element standards were used for the calculation of K-ratios. All post processing of EPMA maps was conducted using proprietary software, Chimage [31].

\subsubsection{AFM and SKPFM analysis}

Atomic force microscopy, NanoWizard II (JPK Instruments, Germany) and digital instrument Nanoscope III multimode, were used to investigate the electrochemical nature of the silicon-rich and other intermetallic particles, in particular their Volta potential with respect to the aluminium matrix. The maps of the Volta potential for the specimens with respect to the AFM tip were recorded. The detailed explanation of the AFM/SKPFM principles of operation and measurement settings has already been reported in chapter 5 and a prior publication of the author [10]. All the measurements were carried out in air at ambient temperature, pressure and humidity. The potential difference and the topographical maps were sampled with the same pixel density of $256 \times 256$ pixels per image and at a scan frequency of 0.5 Hz. For all measurements, antimony (n) doped silicon tips, coated on both sides with $20 \mathrm{~nm}$ platinum/iridium, were used. The tip is characterized by a resistivity of 0.01-0.025 $\Omega . \mathrm{cm}$ and supported on a cantilever 200-250 $\mu \mathrm{m}$ long, 23-33 $\mu \mathrm{m}$ wide and 2.5-3.5 $\mu \mathrm{m}$ thick.

All the measurements were performed on ion-polished cross-sections. The crosssectional ion polishing method utilizes a low voltage Ar ion beam $(<5 \mathrm{kV})$ to polish and etch materials, eliminating the need for mechanical polishing and chemical etching. Ion-polished surfaces provide a clear view of the global microstructure, including grain boundaries and phase boundaries with enhanced orientation contrast. Cross-sections of the brazed and non-brazed samples were prepared with a cross-section ion polisher (JEOL, SM-09010). The polishing provided a smooth surface for the AFM/SKPFM measurements and revealed the grain boundaries inside the structure. The samples were ultrasonically cleaned in ethanol and air dried to limit any effect of adsorbed species to the Volta potential measurements. In the maps of topography and potential, increasing brightness represents increasing height and potential, respectively. In order to clarify the nature of the measured Volta potential values, a uniform designation system is introduced. The Volta potential difference between sample surface features and the AFM tip is referred to as "VPD" whereas the Volta potential difference between two different sample surface features is referred to as "VPD difference". 


\subsubsection{Electrochemical analysis}

Using a Solartron potentiostat and a three-electrode electrochemical cell, potentiodynamic polarization measurements were performed. Considering the impact of microstructural features on electrochemical performance of the aluminium brazing sheet, the cathodic and anodic polarization responses of the material have been measured separately. The working electrodes (samples) were circular plates with a diameter of $2 \mathrm{~cm}$. The reference electrode was a saturated calomel electrode (SCE) and the counter electrode was Pt. The SWAAT solution [32] was chosen as a representative electrolyte. The samples were scanned in the potential range between $10 \mathrm{mV}$ below and $1 \mathrm{~V}$ above the open circuit potential (OCP) for the anodic scans and between $10 \mathrm{mV}$ above and $450 \mathrm{mV}$ below the OCP for the cathodic scans. The scans started after 15 min of OCP measurement. A scan rate of $0.5 \mathrm{mV} / \mathrm{s}$ was applied. The reproducibility of the test results was checked by triplication of each experiment.

\subsubsection{Corrosion attack mechanism investigation}

The most common way to measure the corrosion resistance of heat exchanger materials is the SWAAT [32]. Comparing the corrosion mechanism and morphology of attack it has been proven that the SWAAT performance of the aluminium brazing sheet material can be reflected in potentiodynamic responses [32]. Therefore, using optical microscopy, cross-sections of the samples after anodic polarization were examined to elucidate the corrosion attack mechanism.

\subsection{Results}

\subsubsection{Microstructural analysis}

\subsubsection{Optical microscopy}

Optical images of the cross-sections ( $a$ and c) and surfaces (b and d) of the material under investigation both before and after brazing, and the applied brazing cycle are shown in Figure 6.1. The elongated coarse particles with a dark contrast in the clad layer (Figure 6.1a) are Si particles. X-ray micro analysis also revealed the presence of some small additional precipitates containing $\mathrm{Al}, \mathrm{Fe}, \mathrm{Cu}$, and $\mathrm{Si}$. In the non-brazed core material (Figure 6.1a) a wider variety of particles exist with different sizes and chemical compositions. With respect to size, two types of particles can be distinguished. First, particles which are larger than 1-2 $\mu \mathrm{m}$ (their sizes can reach up to $20 \mu \mathrm{m})$. These are mainly $\alpha$-Al(Fe-Mn)Si particles. Second, particles with sizes below $1 \mu \mathrm{m}$. These are mainly $\mathrm{Al}_{2} \mathrm{Cu}$ and $\alpha$-Al(Fe-Mn)Si particles $[1,8]$. 


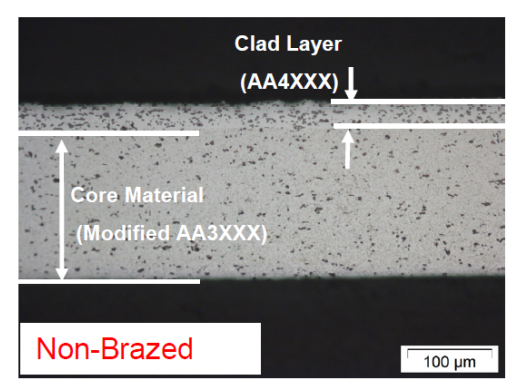

(a)

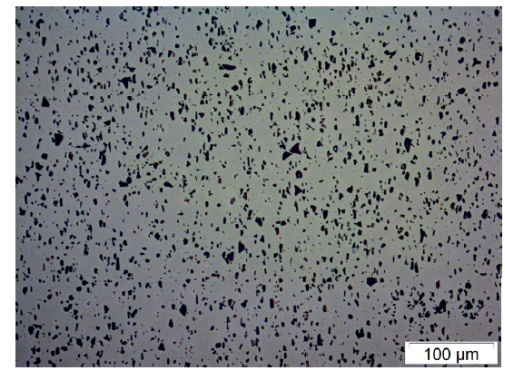

(b)

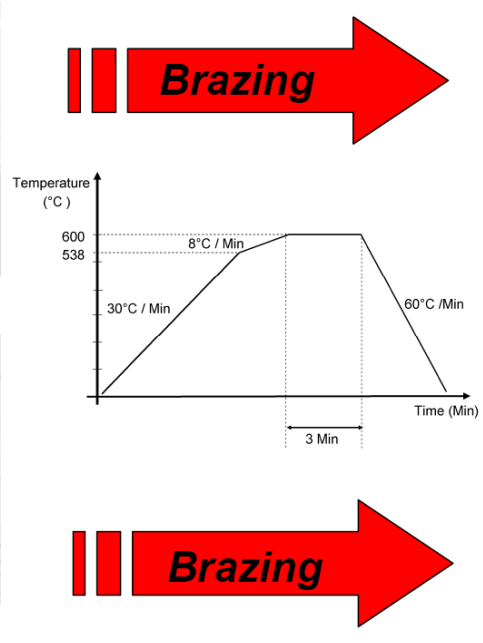

(d)

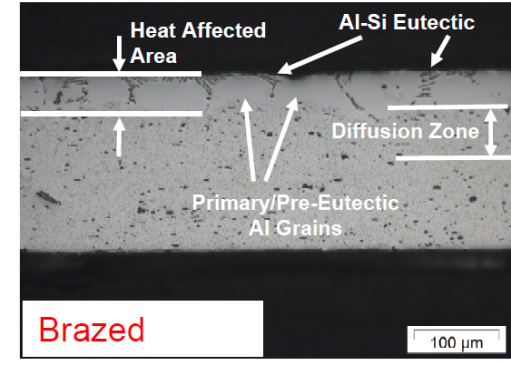

(c)

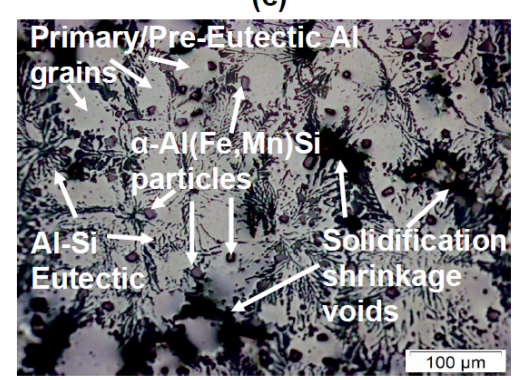

Figure 6.1. Cross-sectional optical images (a and c) and optical micrographs of the surfaces ( $b$ and $d)$ of the brazing sheet structure before ( $a$ and $b$ ) and after brazing (c and d).

At brazing temperature the liquid clad is in intimate contact with the solid core material. During this stage where the two phases co-exist, an interaction between the two can take place. The liquid, originating at the clad-core interface, progresses into the core alloy as a film, changing the element distribution on its way $[33,34]$. This area is the precipitate-free heat affected zone (HAZ) which has been indicated in Figure 6.1c. The Al-Si eutectic phase accumulates at the surface and between the pre-eutectic aluminium grains (Figure 6.1c). From the elements that migrate into the core, $\mathrm{Si}$ has the highest diffusion co-efficient and so the length of its diffusion path is considered to represent the diffusion layer. This layer was measured to be about $40 \mu \mathrm{m}[1,8]$.

The material surface before brazing (Figure 6.1b) shows the presence of silicon particles in dark contrast, distributed all over the surface. After brazing and the formation of the Al-Si eutectic phase, the structure of the surface will change to that shown in Figure 1d. Solidification of the molten clad material, which starts with the formation of the pre-eutectic aluminium grains and ends with accumulation of Al-Si eutectic, has resulted in shrinkage porosity shown in Figure 6.1d. The high density of $\alpha-\mathrm{Al}(\mathrm{Fe}-\mathrm{Mn}) \mathrm{Si}$ particles with dark contrast (Figure 6.1d) at the surface of the re-solidified clad material is also evident. The distribution of alloying elements within these particles was found to be non-uniform $[1,8]$. 


\subsubsection{Scanning electron microscopy}

SEM backscattered electron images of the re-solidified clad surface (Figure 6.2a) and cross-sections of the brazed material are shown in Figures 6.2-6.4. Figure 6.2a shows a high density of particles with bright contrast which have been distributed over the top surface of the re-solidified clad material. These are particles which contain alloying elements of high atomic number such as $\mathrm{Fe}, \mathrm{Cu}$ and $\mathrm{Mn}$ [1]. The presence of solidification shrinkage porosity/void on the surface is also evident. Cross-sectional investigation of the voids and their extension towards the core material is shown in Figures $6.2 \mathrm{~b}$ and $\mathrm{c}$. These figures show that some of these voids have depths exceeding $10 \mu \mathrm{m}$. It is also important to note that most of these voids are in close contact with intermetallic particles (Figures 6.2b and c).
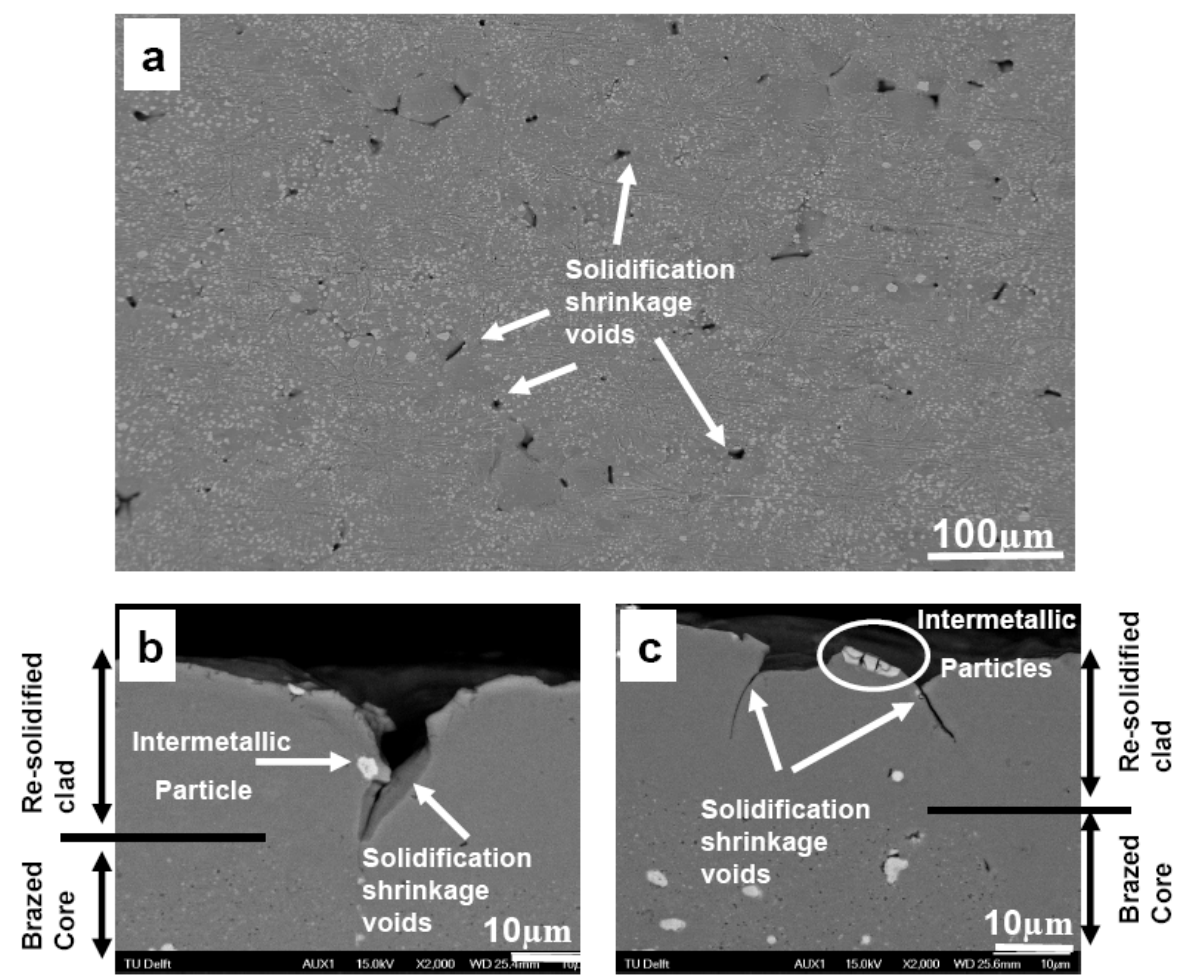

Figure 6.2. SEM backscattered electron images of the surface (a) and cross sections ( $\mathrm{b}$ and $\mathrm{c}$ ) of the brazed AA4xxx/AA3xxx aluminium material.

Backscattered electron images in Figure 6.3 have been taken after etching of 0.25 $\mu \mathrm{m}$ polished cross-sections of the brazed material with Keller's etching solution for 30 seconds. Keller's etchant is a mixture of nitric acid $(2.5 \mathrm{v} / \mathrm{v} \%)$, hydrochloric acid $(1.5 \mathrm{v} / \mathrm{v} \%)$, and hydrofluoric acid $(1 \mathrm{v} / \mathrm{v} \%)$, used to etch aluminium alloys to reveal their grain boundaries. The etchant has been able to reveal the grain boundaries in the structure of the brazed clad and the core material. In order to make the grain boundaries more visible, the path of some of the grain boundaries through the structure have been traced with dashed, white lines. It can be seen that some of these grain boundaries proceed continuously through the entire cross- 
section of the material. Investigation of the re-solidified clad material in these images revealed that the intermetallic particles have been non-uniformly precipitated in the eutectic regions. It is clear that some of the Al-Si eutectic regions are free of precipitates and others have provided suitable nucleation sites for precipitation of the intermetallic particles. This has been clearly demonstrated by the images in Figure 6.3.

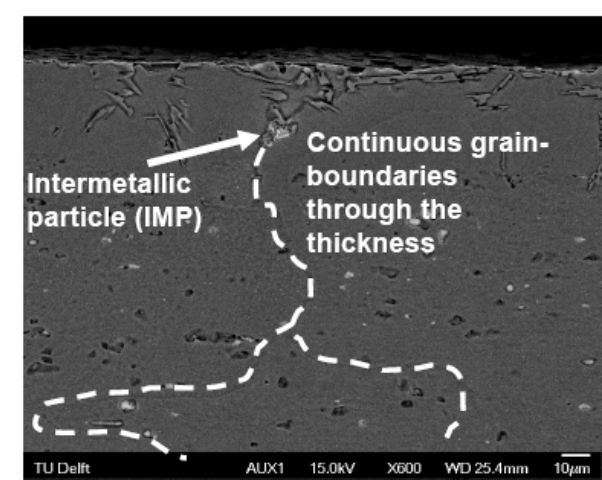

(a)

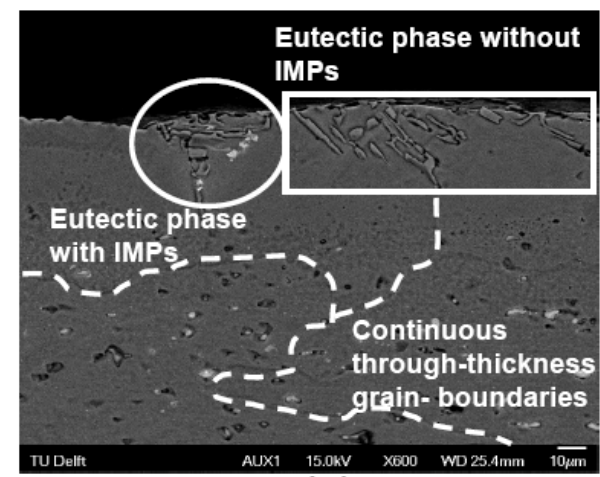

(c)

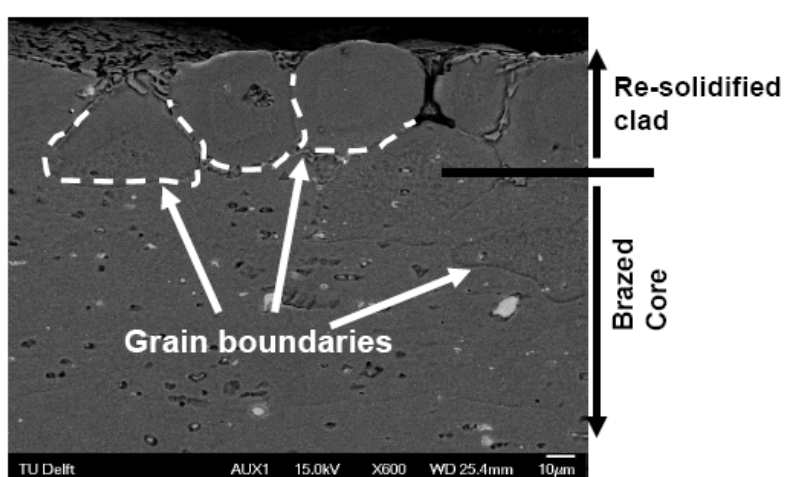

(b)

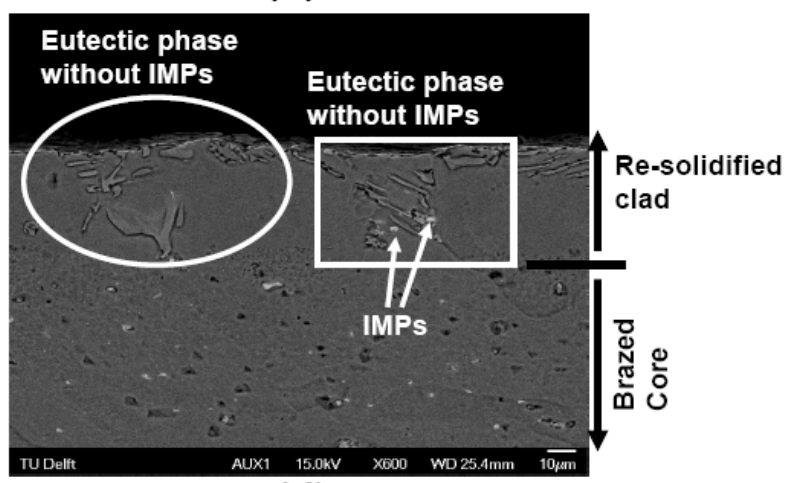

(d)

Figure 6.3. SEM backscattered electron images of the cross sections of the brazed AA4xxx/AA3xxx aluminium material after 30 seconds of etching with Keller's solution.

Considering the fact that the material cross sections have been exposed to Keller's etchant solution, it is necessary to confirm that etching has not caused the removal/dissolution of some of the intermetallic particles, leaving precipitate free eutectic regions behind as an experimental artefact. Investigation of polished cross-sections without etching (Figures 6.4c and d) and comparing with the etched surfaces (Figures 6.4a and $\mathrm{b}$ ) confirms that particle dissolution/removal by etching does not occur. The images in Figure 6.4 show that the precipitation of the intermetallic particles on the Al-Si eutectic regions is non-uniform. The presence of eutectic phases with and without intermetallic particles (IMPs) is distinguishable. These IMPs can be found as isolated (Figures 6.3a and 6.4b) or clustered (Figure 6.4d) particles. Considering the similar atomic number of $\mathrm{Al}$ and $\mathrm{Si}$, the $\mathrm{Si}$ needles on the non-etched aluminium matrix are not easily seen in the backscattered images of Figures $6.4 \mathrm{c}$ and $\mathrm{d}$. The presence of in depth solidification 
shrinkage voids in both Figure $6.4 \mathrm{c}$ and $\mathrm{d}$ is also apparent. X-ray micro analysis of a number of the irregular shape intermetallic particles on the surface of Al-Si eutectic phase (Figure 6.4b) revealed that $\mathrm{Si}, \mathrm{Fe}, \mathrm{Cu}$ and $\mathrm{Mn}$ are the main constituents of these particles. The X-ray micro analysis results are shown in Table 6.2 .

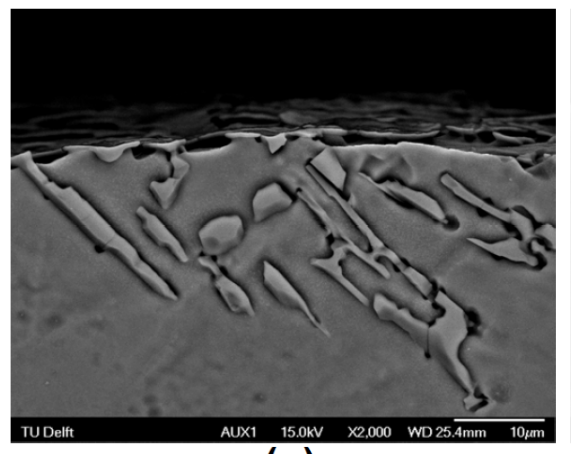

(a)

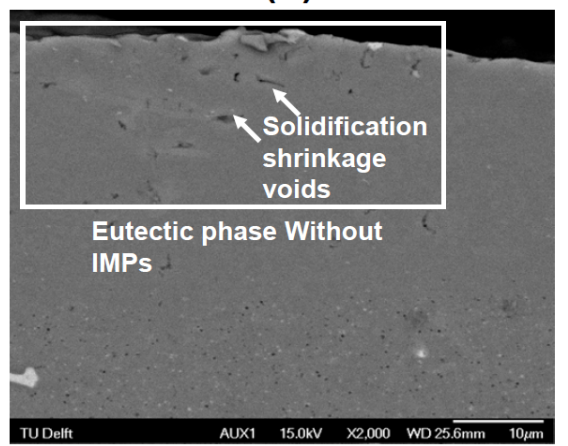

(c)

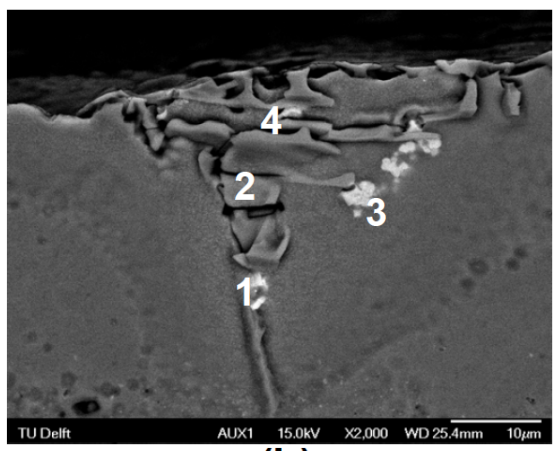

(b)

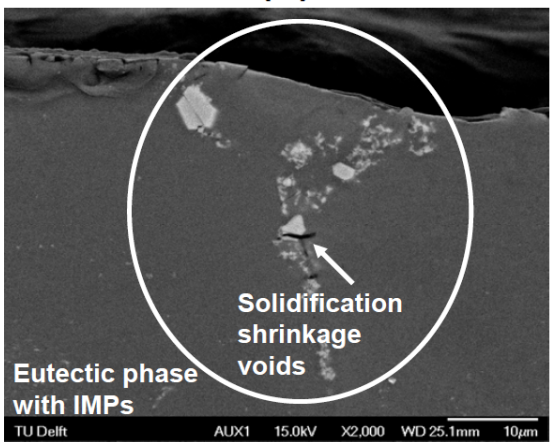

(d)

Figure 6.4. SEM backscattered electron images of the cross sections of the brazed AA4 xxx/AA3 xxx aluminium material with ( $a$ and $b$ ) and without ( $c$ and $d$ ) Keller's etching.

Table 6.2. Chemical composition (wt \%) analysis of the surface locations indicated in Figure 6.4b.

\begin{tabular}{cccccc}
\hline Location & $\mathrm{Si}$ & $\mathrm{Fe}$ & $\mathrm{Cu}$ & $\mathrm{Mn}$ & $\mathrm{Al}$ \\
\hline 1 & - & - & 3.0 & - & $\mathrm{Bal}$. \\
2 & 72.0 & - & 3.0 & - & Bal. \\
3 & 9.0 & 15.9 & 9.0 & 12.1 & Bal. \\
4 & 36.8 & 10.9 & 8.9 & 4.8 & Bal. \\
\hline
\end{tabular}

\subsubsection{X-ray micro analysis}

Using X-ray micro analysis (XMA), qualitative line scans were recorded crossing the core/clad interface of both non-brazed and brazed structures. The results are shown in Figure 6.5. 


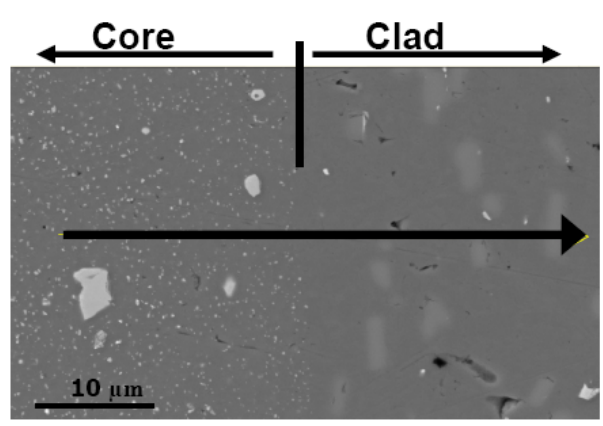

(a)

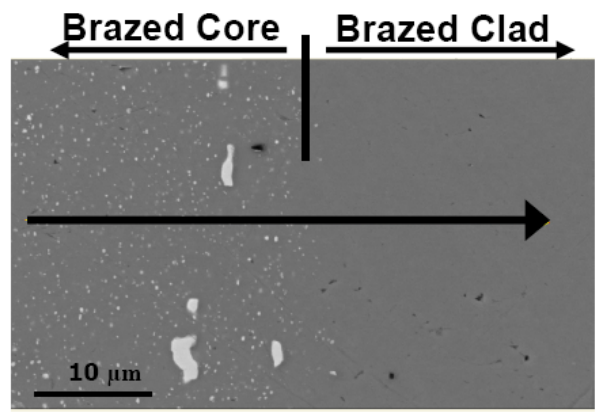

(b)

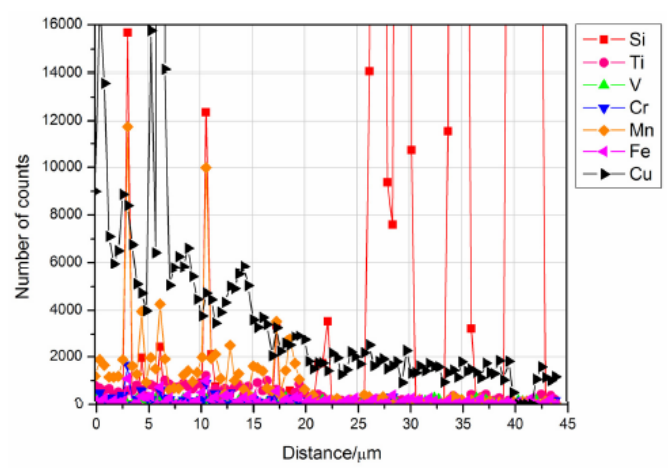

(c)

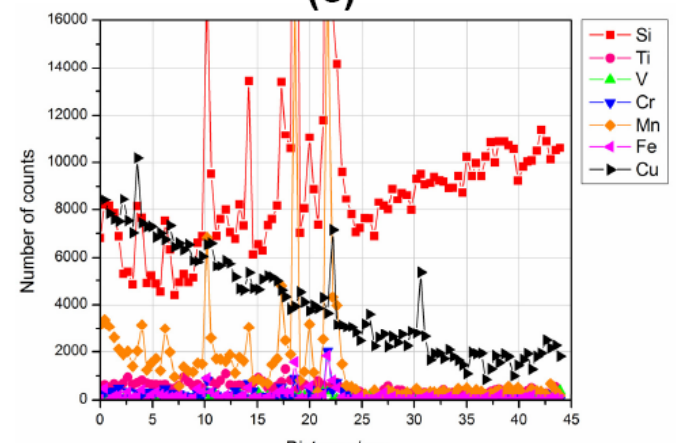

(d)

Figure 6.5. Qualitative x-ray micro-analysis line scans on the interface between the clad and core material, before (a) and after (b) brazing treatment.

Comparison of the analysis results for the non-brazed (Figure 6.5c) and brazed (Figure 6.5d) structures shows that increasing of Si content in solid solution in the matrix of the brazed core and clad materials is the major compositional change that has occurred as a result of brazing process. Investigation of the changes in the distribution profiles of other alloying elements requires a more precise analysis approach.

The results of EDS mapping for the major alloying elements ( $\mathrm{Si}, \mathrm{Mn}, \mathrm{Fe}$ and $\mathrm{Cu}$ ) and the SEM backscattered electron image of the area under investigation are presented in Figure 6.6. The position of the re-solidified clad and the core materials are clearly distinguished. Two Al-Si eutectic regions (1 and 2) are highlighted in the Si map. A noticeable difference between these two eutectic regions is the $\mathrm{Cu}$ content. As can be seen in the $\mathrm{Cu}$ map, the $\mathrm{Al}$ matrix surrounding the $\mathrm{Al}-\mathrm{Si}$ eutectic in region 2 is rich in $\mathrm{Cu}$ while in region 1 it is $\mathrm{Cu}$ lean. The position of some of the grain boundaries in the re-solidified clad on the $\mathrm{Cu}$ map has been highlighted by drawing white lines. Non-uniform distribution of $\mathrm{Cu}$ (presence of $\mathrm{Cu}$ rich and $\mathrm{Cu}$ lean areas) in the re-solidified clad material, and accumulation of $\mathrm{Cu}$ at grain boundaries $(\mathrm{Cu}$ rich $\mathrm{GBs})$ with intermetallic precipitates (mostly $\mathrm{Al}_{2} \mathrm{Cu}, \alpha-\mathrm{Al}(\mathrm{Fe}-\mathrm{Mn}) \mathrm{Si}$ ) are important brazing effects that are apparent in the $\mathrm{Cu}$ map in Figure 6.6. The distribution of IMPs containing $\mathrm{Fe}$ and $\mathrm{Mn}$ are shown in the $\mathrm{Fe}$ and $\mathrm{Mn}$ maps in Figure 6.6. These particles are $\alpha-\mathrm{Al}(\mathrm{Fe}-$ $\mathrm{Mn}) \mathrm{Si}$. Some of these IMPs are shown in the re-solidified clad material. These are 
particles which have been precipitated on a grain boundary in the re-solidified clad material.
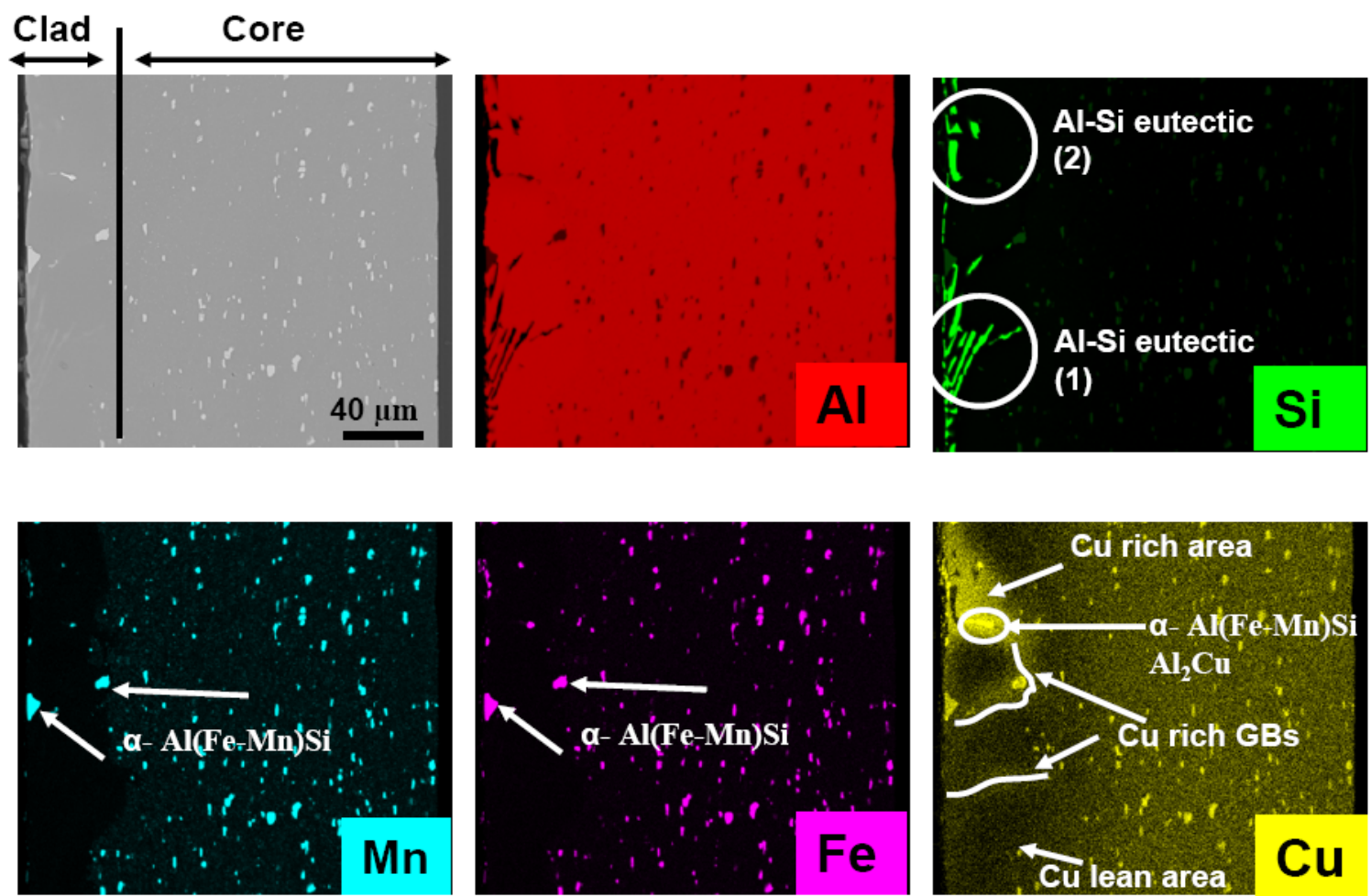

Figure 6.6. X-ray micro-analysis mapping for the $\mathrm{Si}, \mathrm{Mn}, \mathrm{Fe}$ and $\mathrm{Cu}$ alloying elements.

\subsubsection{EPMA analysis}

The EPMA analysis results and the position of the line scans are shown in Figures 6.7 and 6.8. Quantitative line scans for the elements $\mathrm{Si}, \mathrm{Mn}, \mathrm{Fe}, \mathrm{Cu}$ and $\mathrm{Al}$ across the structures of the non-brazed (Figure 6.7) and brazed (Figure 6.8) materials are presented. The $\mathrm{Mn}, \mathrm{Fe}$ and $\mathrm{Cu}$ scale appears on the left side vertical axis and the $\mathrm{Si}$ and $\mathrm{Al}$ scale on the right. It should be noted that the position through the structure is defined with reference to the starting point of the experiment in the material. Zero positions are highlighted with dark filled circles at the scan arrows.

The presence of the peaks in the areas between the 0 and $20 \mu \mathrm{m}$ position (the core area) in Figure 6.7 results from the $\alpha-\mathrm{Al}(\mathrm{Fe}-\mathrm{Mn}) \mathrm{Si}, \mathrm{Al}_{2} \mathrm{Cu}$ particles. These are the dominant precipitates in the core structure of the non-brazed material $[1,8]$. The other peaks in the areas between $40-50 \mu \mathrm{m}$ positions are Si peaks. These are $\mathrm{Si}$ needles in the structure of non-brazed clad material [8]. The measured composition at the positions $20-30 \mu \mathrm{m}$ (non-brazed clad matrix) shows that the concentrations of $\mathrm{Si}, \mathrm{Fe}$ and $\mathrm{Cu}$ in solid solution are $0.18,0.12,0.24 \mathrm{wt} \%$ respectively. $\mathrm{Mn}$ concentration is almost zero. The composition of the $\mathrm{Si}, \mathrm{Fe}, \mathrm{Cu}$ and $\mathrm{Mn}$ in the 
matrix of the re-solidified clad material (HAZ area) has been reported to be 1.12, $0.12,0.3$ and $0.04 \mathrm{wt} \%$ respectively [9].

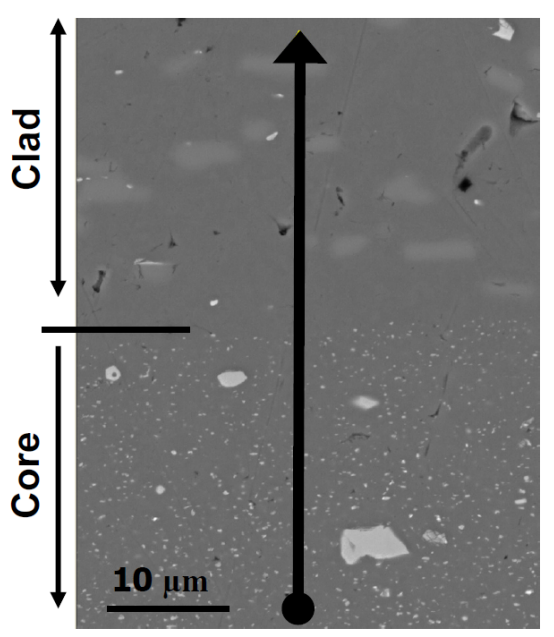

(a)

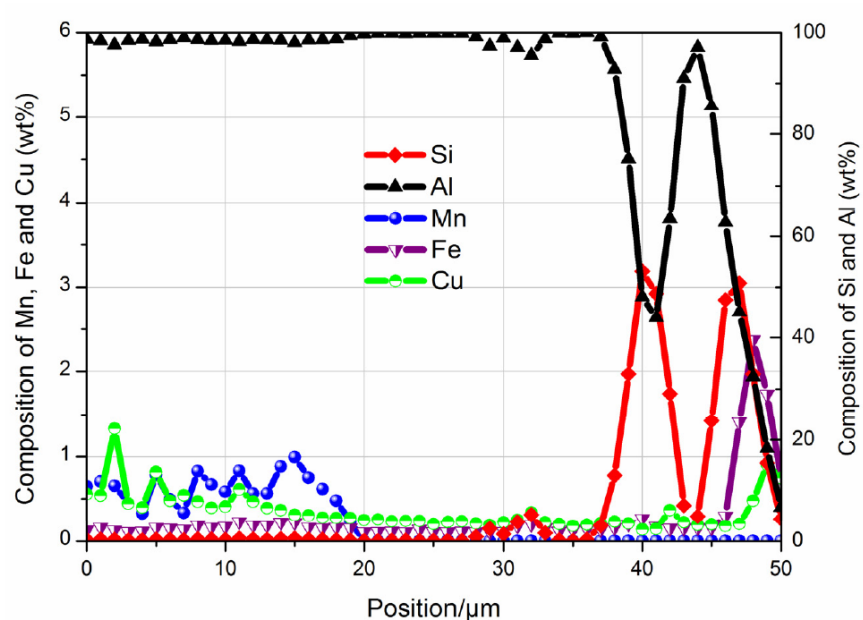

(b)

Figure 6.7. Position of the EPMA quantitative line scan (a) and EPMA quantitative line scan analysis (b) on the non-brazed structure.

A quantitative line scan analysis across an Al-Si eutectic region is shown in Figure 6.8. The cyclic shape of the scan results from the passage of the electron beam over eutectic aluminium and $\mathrm{Si}$ needle phases. The concentration of $\mathrm{Cu}$ in the eutectic aluminium (in between Si needles) was measured to be $0.55 \mathrm{wt} \%$. The concentrations of $\mathrm{Fe}$ and $\mathrm{Mn}$ in the eutectic aluminium were found to be the same as those measured in the HAZ.

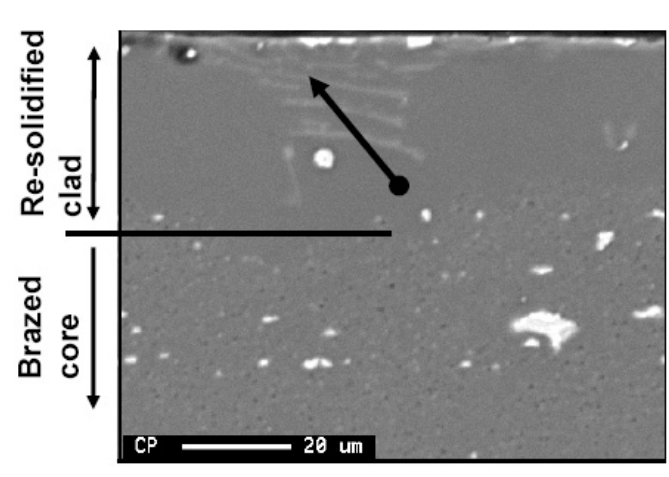

(a)

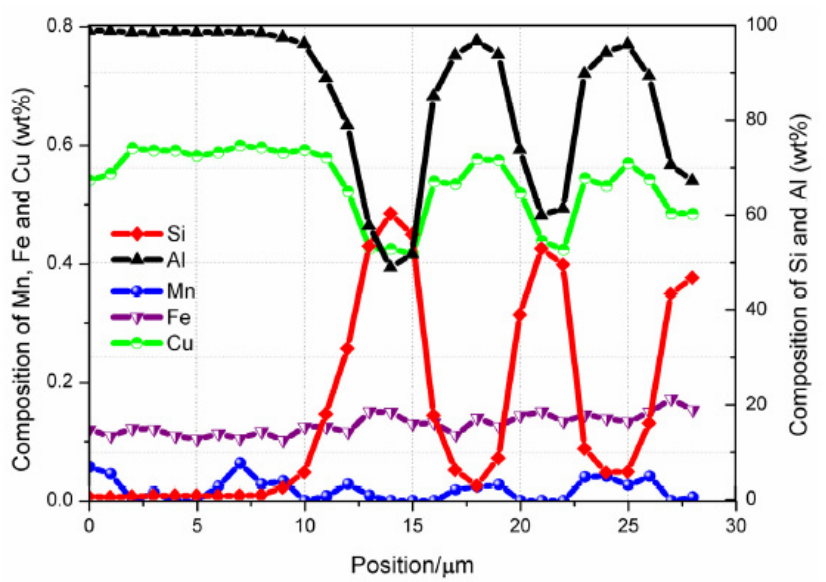

(b)

Figure 6.8. Position of the EPMA quantitative line scan (a) and EPMA quantitative line scan analysis (b) across a eutectic Al-Si phase in the brazed structure. 
The EPMA maps of $\mathrm{Cu}$ and $\mathrm{Si}$ for the brazed material are shown in Figure 6.9. The $\mathrm{Cu}$ map shows that the major consequences of brazing are: formation of $\mathrm{Cu}$-lean areas; accumulation of $\mathrm{Cu}$ at the surface of the re-solidified clad material, within Al-Si eutectic regions, and between eutectic aluminium grains (GBs); and precipitation of intermetallic particles with high $\mathrm{Cu}$ content $\left(\mathrm{Al}_{2} \mathrm{Cu}\right)$. The $\mathrm{Si}$ map shows that the concentration of $\mathrm{Si}$ at the surface of the re-solidified clad material is also quite high.

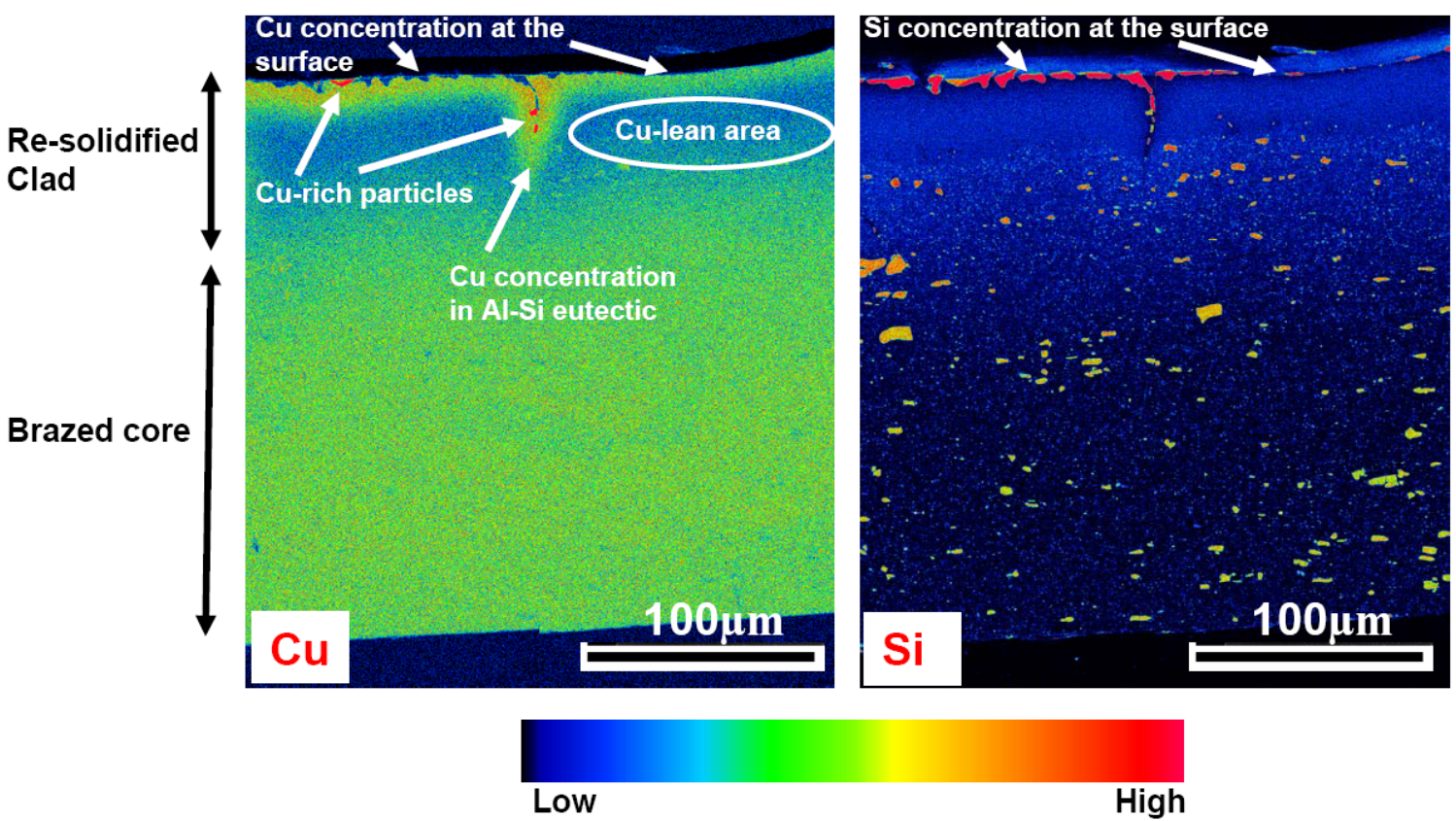

Figure 6.9. EPMA analysis maps of $\mathrm{Cu}$ and $\mathrm{Si}$ alloying elements in the brazed AA4xxx/AA3xxx aluminium material.

\subsubsection{AFM and SKPFM analysis}

The VPD values, topographical maps and results of the line scan section analysis on the polished cross sections of the material before and after brazing treatment are presented in Figures 6.10 and 6.11. To avoid any artificial changes of the measured Volta potential differences, no data post-treatment has been applied on the presented Volta potential results [10]. The Si particles are shown with bright contrast in the VPD maps. The distinction between areas under investigation (clad, core and HAZ) has been clearly made inside these figures. From the topographical images (Figures 6.10a and 6.11a) it can be noted that even after ultrasonic cleaning with ethanol some contamination is still left on the polished surfaces. These polishing residuals are clearly visible in Figures 6.10a and 6.11a having a brighter contrast with respect to the matrix. 

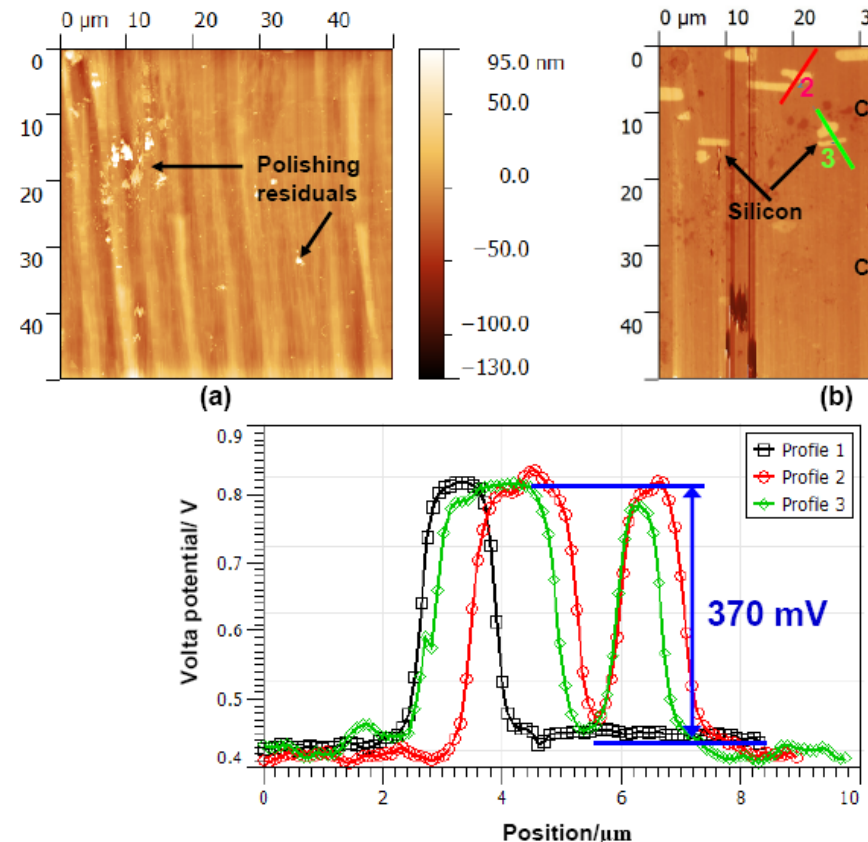

(c)

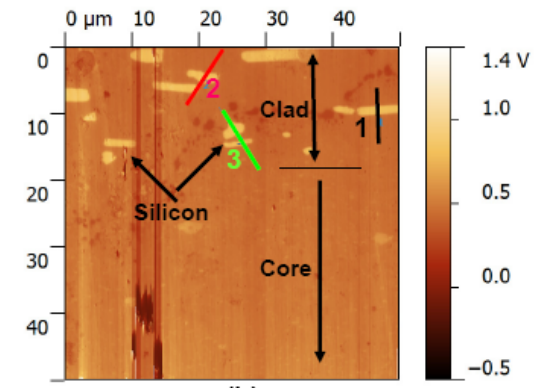

(b)

Figure 6.10. Topographical map (a), Volta potential map (b) and line scan section analysis results (c) obtained from AFM/SKPFM analysis of the polished surfaces before brazing treatment.

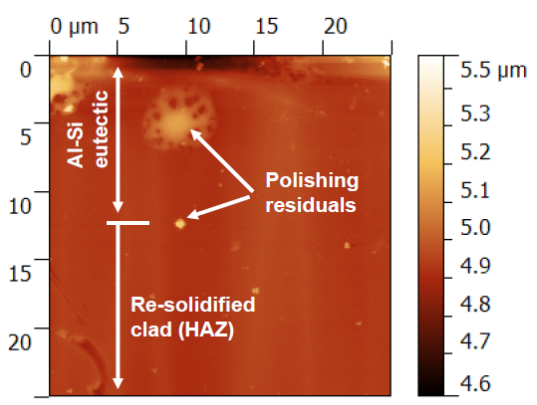

(a)

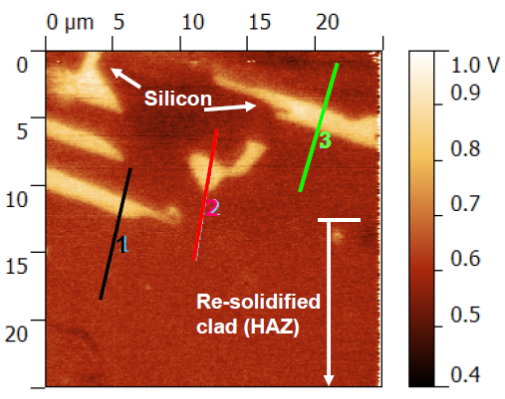

(b)

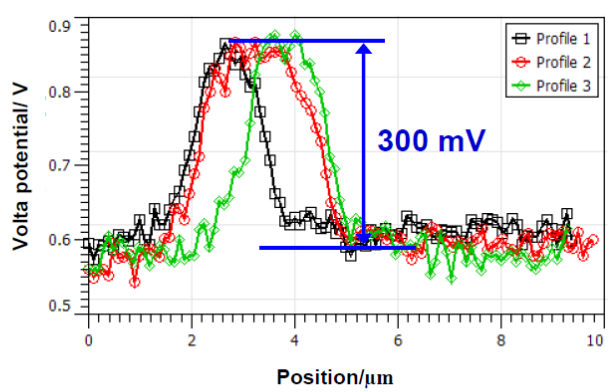

(c)

Figure 6.11. Topographical map (a), Volta potential map (b) and line scan section analysis results (c) obtained from AFM/SKPFM analysis of the polished surfaces after brazing treatment. 
Comparison of the VPD differences between the Si particles and the matrix for the materials before and after brazing was performed, using section analysis. The positions of the sectioning profiles are indicated in Figures $6.10 \mathrm{~b}$ and $6.11 \mathrm{~b}$. Three line profiles for each sample were measured. The results for the Volta potential section analysis before (Figure 6.10c) and after (Figure 6.11c) brazing are also presented in these figures. The peak potentials correspond to the VPD of Si in both graphs (Figures 6.10c and 6.11c). These potentials for the non-brazed and brazed material are around 820 and $840 \mathrm{mV}$ respectively. Comparing the graphs in Figures $6.10 \mathrm{c}$ and $6.11 \mathrm{c}$, it is evident that the brazing treatment has increased the VPD of the matrix. The VPD difference between the Si particles and the clad matrix in the non-brazed structure is $370 \mathrm{mV}$. The VPD difference between the Si needles and the re-solidified clad material is $300 \mathrm{mV}$. Further investigation on the matrix potentials for the materials both before and after brazing is presented in Figure 6.12.

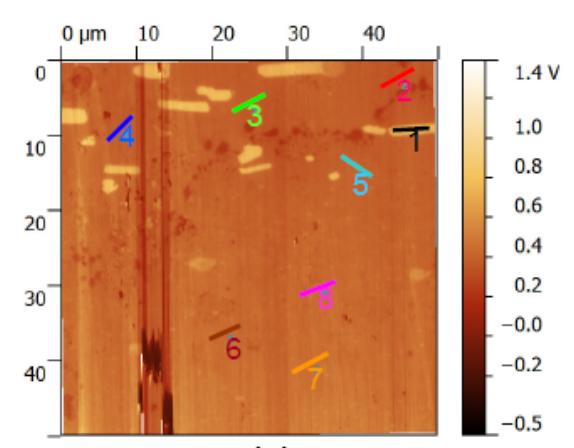

(a)

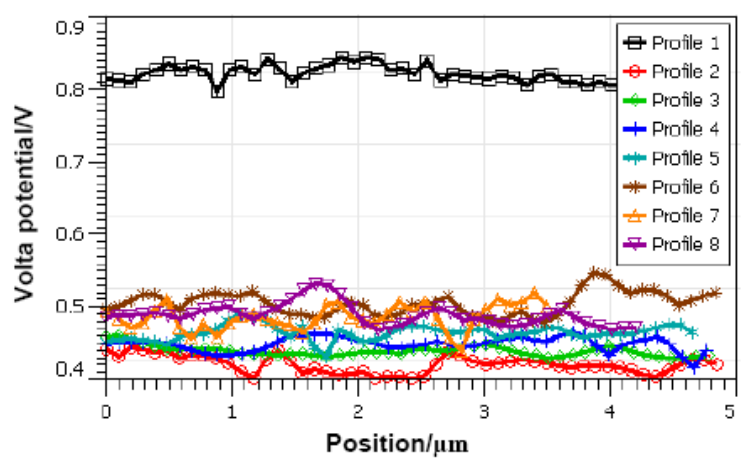

(c)

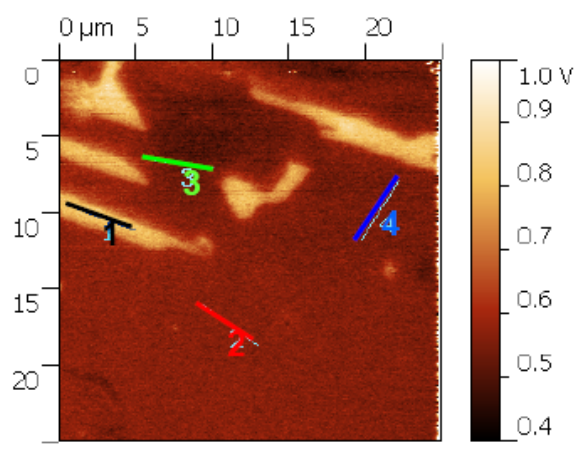

(b)

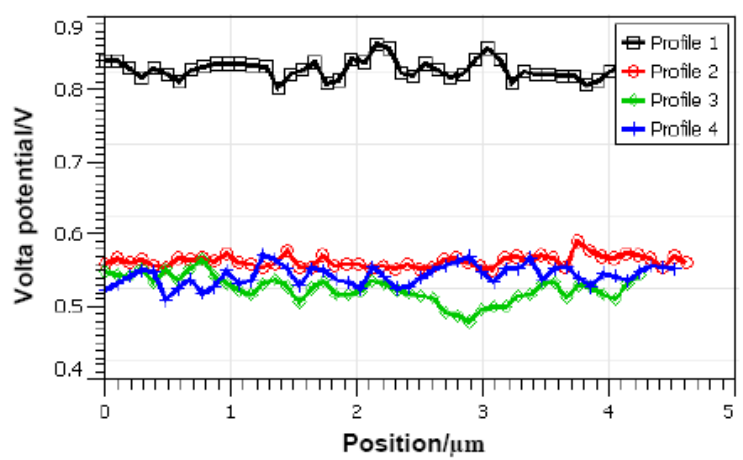

(d)

Figure 6.12. Volta potential maps ( $a$ and $b$ ) and section analysis profiles ( $c$ and $d$ ), before ( $a$ and $c$ ) and after ( $b$ and $d)$ brazing treatment.

The positions of the cross sectional line analysis in the matrix are shown in images 6.12 $\mathrm{a}$ and $\mathrm{b}$. The VPD profile through the Si needles is considered as the reference in each VPD map. This will be the basis of comparison for the changes in VPD differences which have occurred as a result of brazing. The details of this methodology have already been discussed in chapter 5 and a prior publication of the author [10]. Comparing the VPD profiles of the matrix in Figures 6.12c and d, 
it can be seen that brazing has increased the VPD of the re-solidified clad matrix by approximately $100 \mathrm{mV}$. Analysis of the non-brazed core material in Figure 6.12c (profiles 6-7), shows higher VPD values compared to those in the matrix of the non-brazed clad material (profiles 2-4). A comparison of the measured VPD values is presented in Figure 6.13 along with statistical details of the available data.

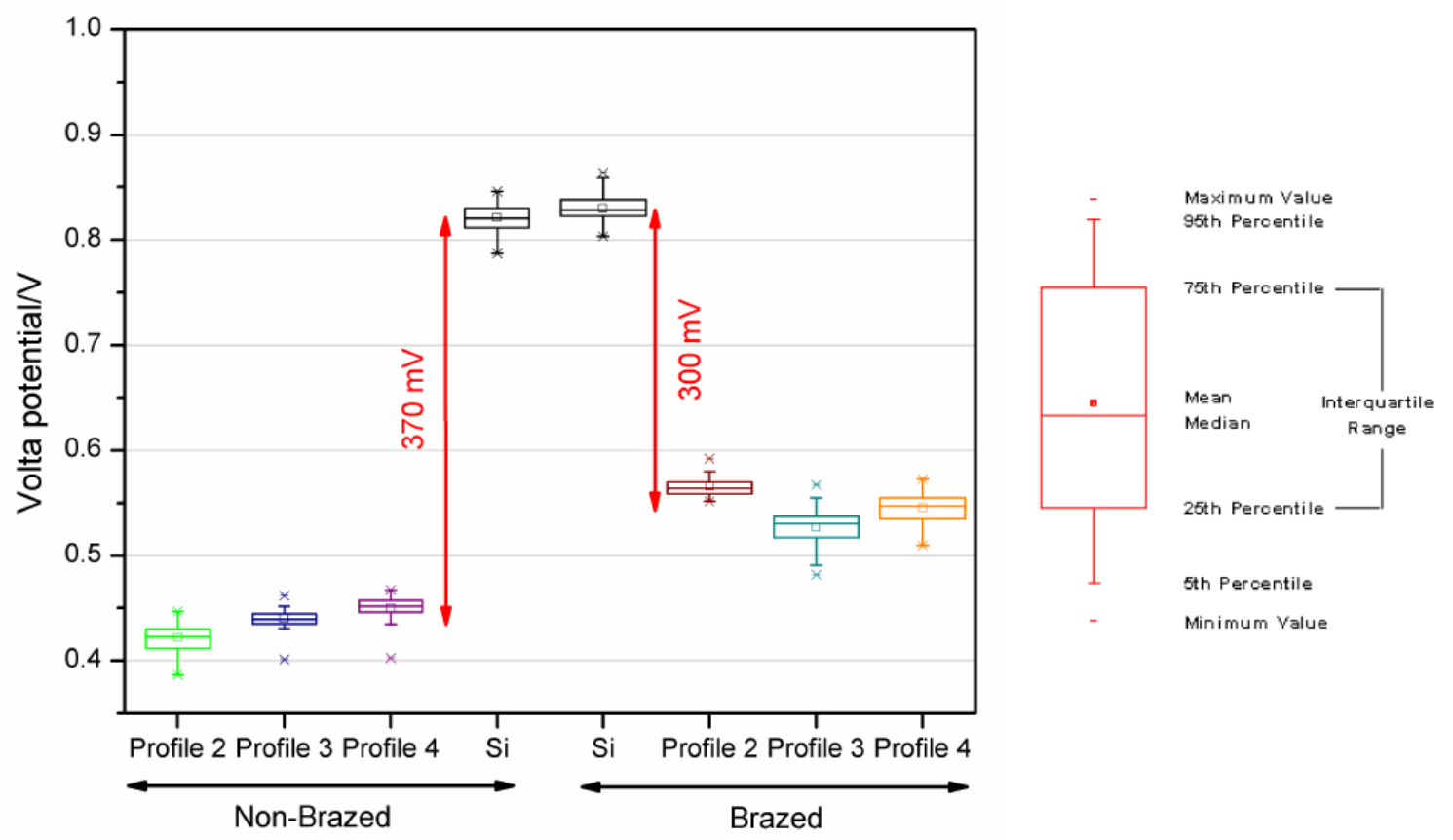

Figure 6.13. Box chart presentation of the Volta potential profiles from cross sectional analysis of the matrix.

The VPD values in both non-brazed and brazed samples are presented as box charts. Each profile of data is represented as a separate box. The profile names are the $\mathrm{X}$ axis tick labels. The box is determined by the 25 th and 75 th percentiles. The whiskers are determined by the 5th and 95th percentiles. In statistics, a percentile is the value of a variable below which a certain percent of observations fall. For example, the 25th percentile is the value below which 25 percent of the observations may be found. The maximum, minimum, mean and median values are also included in this representation. The data show a clear increase in the crosssectional VPD values of the matrix of the re-solidified clad material (eutectic region and HAZ) compared to that of the matrix of the non-brazed clad material. Comparison of the overall averages of the VPD values of the matrices before and after brazing shows a $70 \mathrm{mV}$ increase (with reference to Si needles) in VPD difference of the brazed samples cross sections as a result of brazing. No significant difference between the VPD of the core materials before and after brazing was detected.

It may be considered that averaging the data over a defined area is a better way of 
presenting the results in Figure 6.13. However, it should be noted that the passage of the cantilever over the phase boundaries between Si particles and the matrix will cause the probe to experience a gradient in composition and significantly affect the measured VPD values. In order to eliminate this effect and to have a reliable and stable VPD values which are relevant to the microstructural features under investigation ( $\mathrm{Si}$ needles and the matrix), line scans were preferred. Performing a line scan at a proper position (center region of a relatively large Si particle and away from the particle edges or in the aluminium matrix away from small silicon particles) gives consistent and representative data over the $\mathrm{Si}$ and aluminium matrix phases [10].

The cross-sectional AFM/SKPFM investigation of the brazed structure was continued by analysis of the grains and grain boundaries. The results are presented in Figure 6.14.

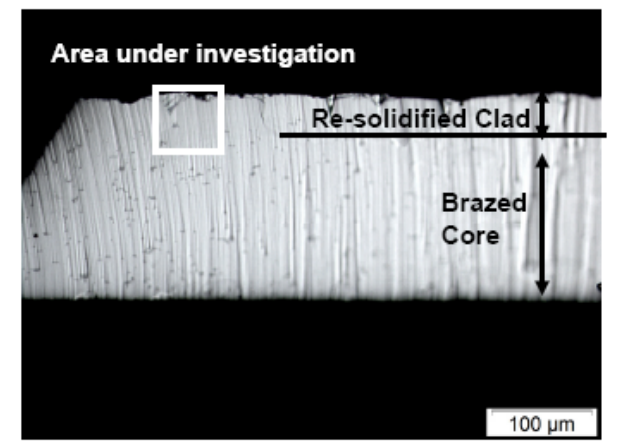

(a)

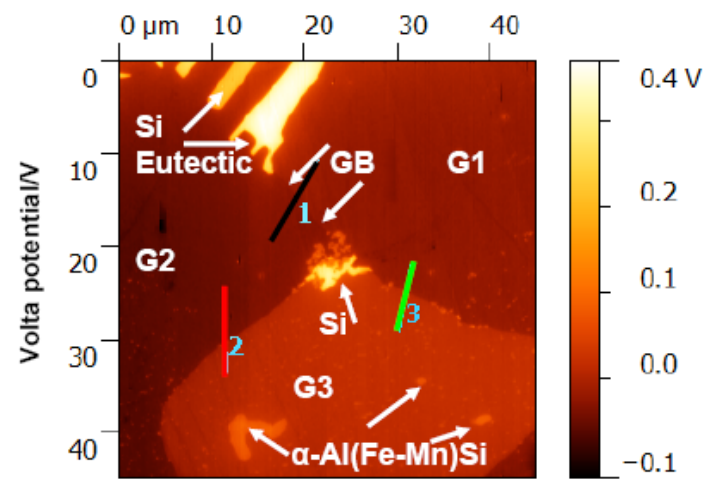

(c)

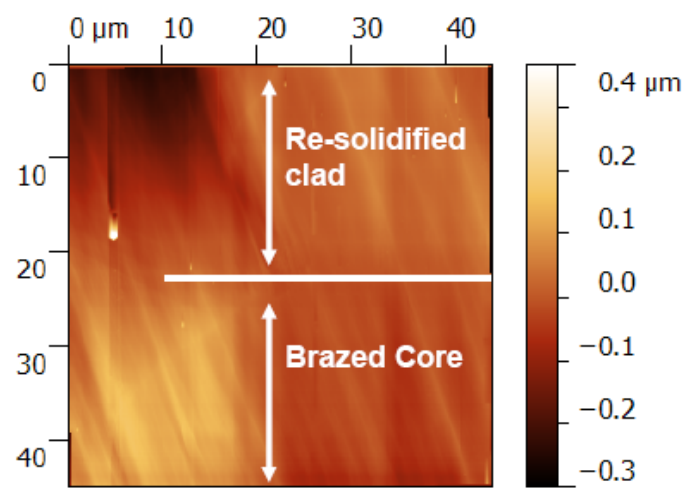

(b)

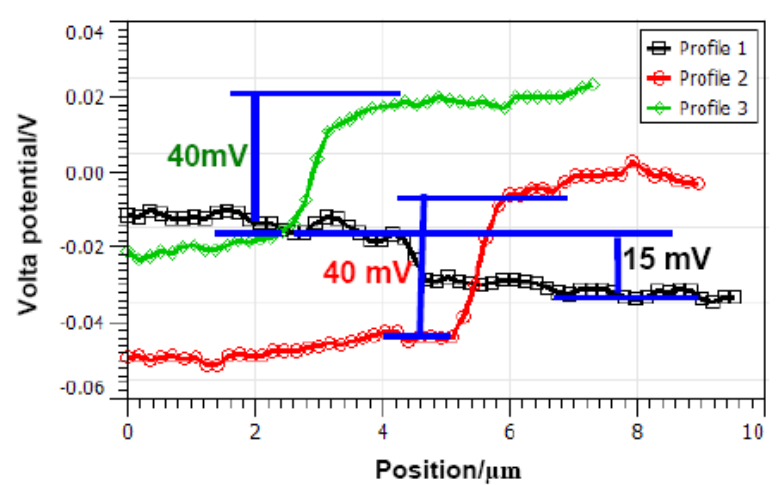

(d)

Figure 6.14. Ion-polished cross section of the brazed AA4xxx/AA3xxx aluminium material (a), topographical map (b) Volta potential map (c) and section analysis result $(\mathrm{d})$ over the area under investigation.

Figure 6.14a shows the optical micrograph of the ion polished cross section and the area which was selected for AFM/SKPFM investigation. The boundary between the re-solidified clad material and the brazed core are shown in this 
image. The topography and VPD maps are presented in Figures $6.14 \mathrm{~b}$ and c respectively. The topographical map shows that ion polishing has caused a noticeable height difference $(\sim 700 \mathrm{~nm})$ at some parts of the area under investigation. The presence of grain boundaries (GB) are identified in Figure 6.14c. The adjacent grains are designated as G1-G3. The eutectic Si needles are formed at the grain boundary (GB) between G1 and G2 which is highlighted in Figure $6.14 \mathrm{c}$. The presence of $\mathrm{Si}$ and $\alpha-\mathrm{Al}(\mathrm{Fe}-\mathrm{Mn}) \mathrm{Si}$ particles at the grain boundaries of the G3 grain, is also evident. The results of three VPD section analysis are presented in Figure 6.14d. The position of these line scans across the grain boundaries are shown in Figure 6.14c. The VPD difference between the grain in the brazed core material (G3) and the ones in the re-solidified clad (G1 and G2) is about $40 \mathrm{mV}$ (VPD profiles 2 and 3). The analysis of the VPD line scan crossing G1 and G2 grains (VPD profile 1) shows about $15 \mathrm{mV}$ difference.

\subsubsection{Electrochemical characterization}

The anodic and cathodic polarization responses of both brazed and non-brazed materials are shown in Figure 6.15.

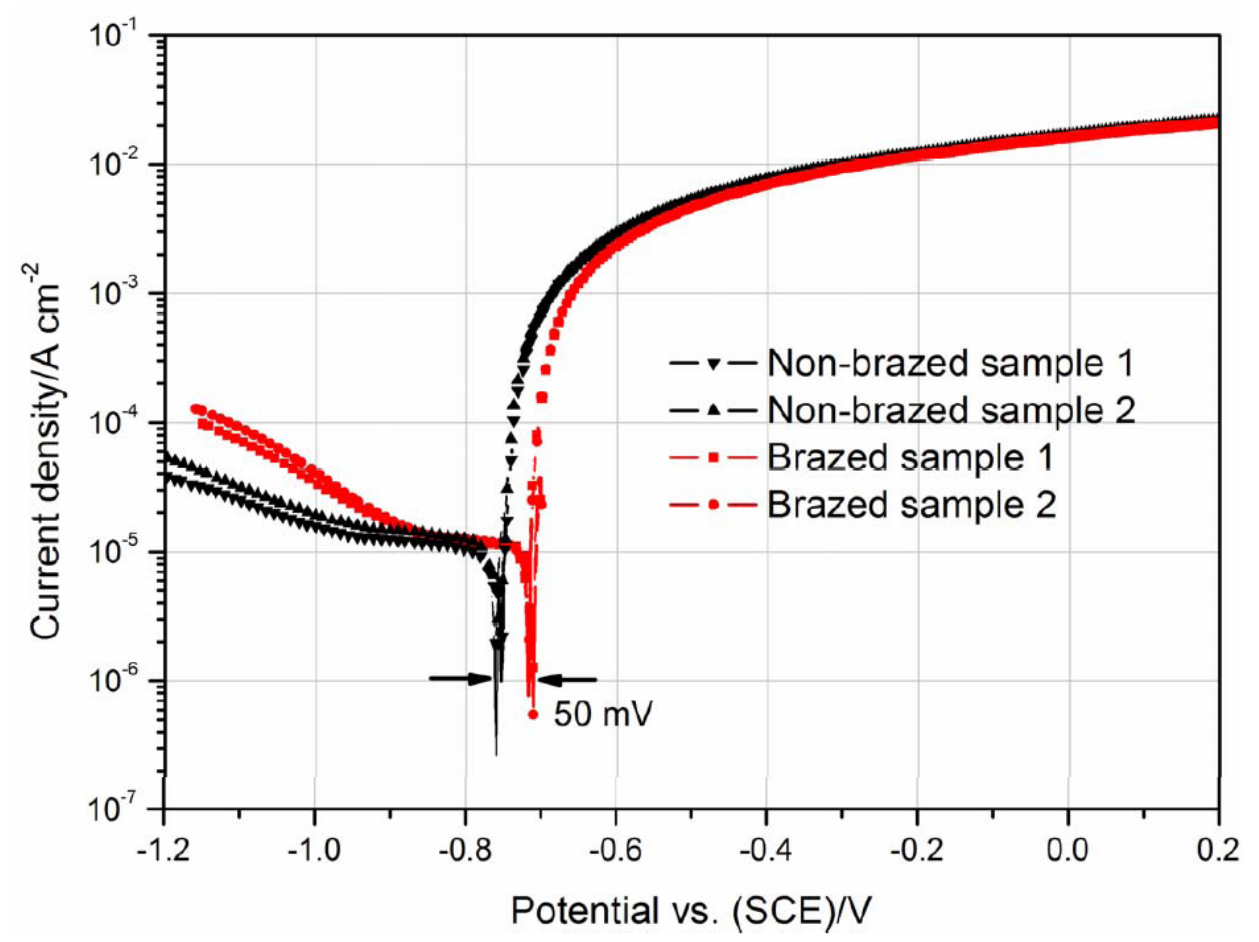

Figure 6.15- Anodic and cathodic polarization curves before and after brazing after 15 min of OCP measurement in $42 \mathrm{~g} / 1 \mathrm{NaCl}$ solution at $\mathrm{pH} 2.8$ (scan rate $0.5 \mathrm{mV} / \mathrm{s}$ ).

Figure 6.15 shows that the anodic responses of the brazed and non-brazed material are quite similar. A sharp increase of the current density at potentials close to the 
OCP values is observed. The cathodic polarization responses of the brazed material show higher reactivity comparing to that of the non-brazed material. The OCP $(\sim 50 \mathrm{mV})$ between the brazed and non brazed material is indicated in this figure. Figure 6.15 shows that the brazed samples have a nobler OCP compared to that of the non-brazed material.

\subsubsection{Corrosion morphology}

The optical micrographs of the cross sections after anodic polarisation up to $1 \mathrm{~V}$ [1] above the OCP values are shown in Figure 6.16. The cross-sections of the corroded samples in Figure 6.16 show that the clad material in the brazed samples does not provide a proper protection to the core material. The random presence of none, partly and fully attacked pre-eutectic aluminium grains and continuation of corrosion attack in a localized form (IGC, pitting and local dissolution of the clad) towards the core material are observed.

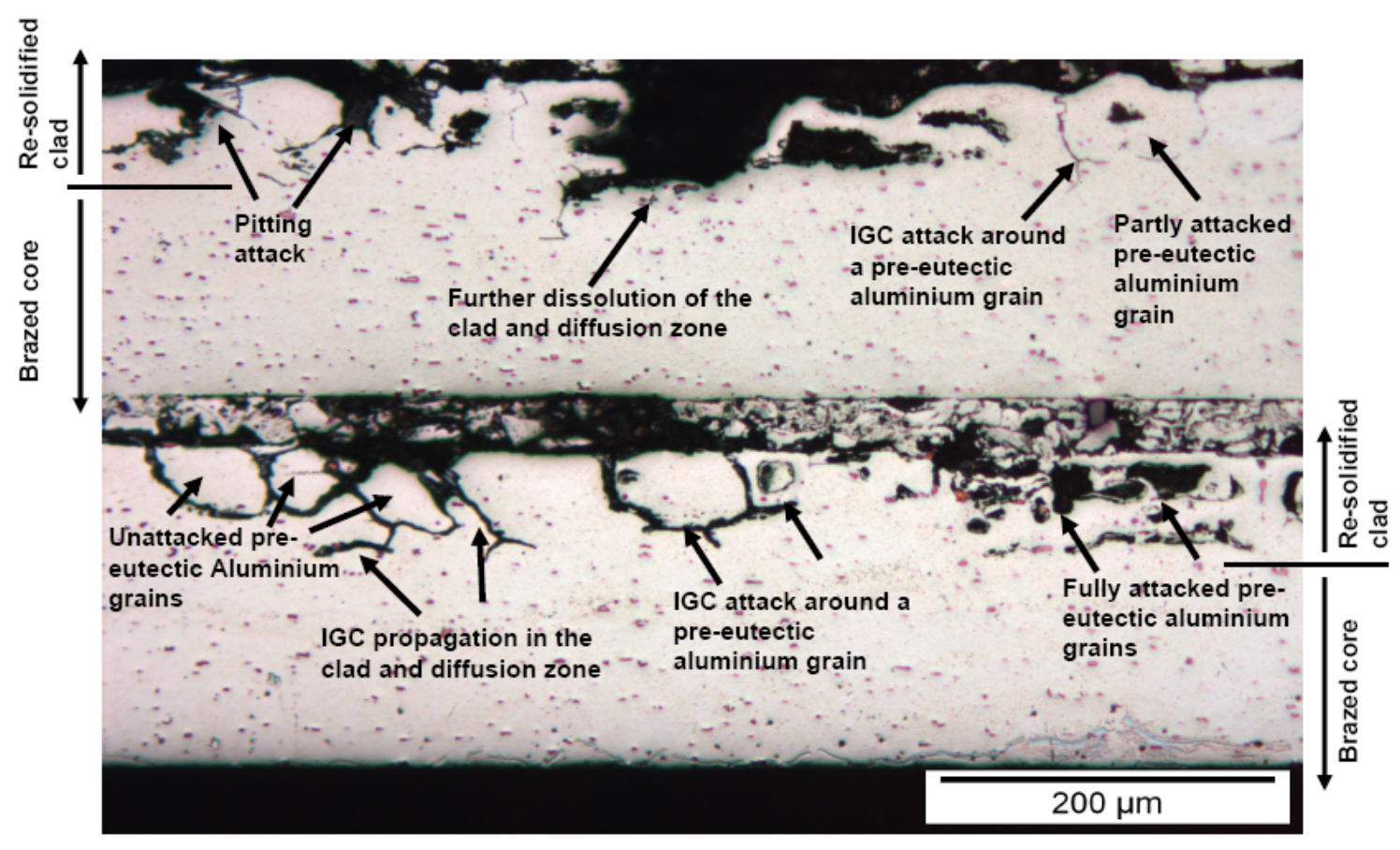

Figure 6.16. Optical micrograph of the aluminium brazing sheet samples after anodic polarisation up to $1 \mathrm{~V}$ above the $\mathrm{OCP}$ values in a $42 \mathrm{~g} / 1 \mathrm{NaCl}$ solution at $\mathrm{pH}$ 2.8 .

\subsection{Discussion}

\subsubsection{Microstructural features and their electrochemical consequences}

\subsubsection{Intermetallic particles at the surface}


Based on microstructural characterization of the brazed material $[1,8], \mathrm{Al}_{2} \mathrm{Cu}, \alpha-$ $\mathrm{Al}(\mathrm{Fe}-\mathrm{Mn}) \mathrm{Si}$ and $\mathrm{Si}$ have been shown to be the dominant particles present at the top surfaces (outer $10 \mu \mathrm{m}$ ) of the re-solidified clad material. The high density of these particles at the surface of the re-solidified clad material (Figures 6.1d and $6.2 \mathrm{a})$ and the heterogeneous composition within the $\alpha$-Al(Fe-Mn)Si particles [1, $8]$, are expected to provide numerous micro galvanic cells over the surface of the brazed structure when it is exposed to an electrolyte. IMPs represent a point of susceptibility since the oxide layer covering them may contain flaws or intrinsically offer less protection [35] while the electrochemical characteristics of the particles themselves often differ largely from the surrounding aluminium matrix [36]. These IMPs are generally considered to be the initiation sites for localized corrosion in commercial alloys since flaws in the oxide surrounding these particles and the galvanic coupling between IMPs and the surrounding matrix promote this form of corrosion $[35,36]$.

\subsubsection{Solidification shrinkage voids}

The presence of solidification shrinkage voids, which are mostly decorated with IMPs at their edges (Figures 6.2b and c), is a consequence of different thermal expansion coefficients between the aluminium $\left(23 \times 10^{-6} 1 /{ }^{\circ} \mathrm{C}\right)$ and silicon $(2.6 \times$ $10^{-6} 1 /{ }^{\circ} \mathrm{C}$ ) [37] in the eutectic structure. These voids provide a direct path towards the internal surfaces of the brazed material and expose the internal layers to the corrosive environment. This will result in galvanic coupling between internal surfaces and the cathodic IMPs i.e. $\mathrm{Al}_{2} \mathrm{Cu}, \alpha-\mathrm{Al}(\mathrm{Fe}-\mathrm{Mn}) \mathrm{Si}$, and to a lesser extent $\mathrm{Si}$, and may drive the corrosion attack deep into the structure. The close proximity of some voids to grain boundaries (Figure $6.2 \mathrm{~b}$ and c), may provoke intergranular corrosion attack. This can be initiated by differences in chemistry between the front and back of the void. The front of the void has an acidic environment due to hydrolysis of aluminium ions. This suggests that there will be a $\mathrm{pH}$ gradient within the void which is expected to make a concentration galvanic cell.

\subsubsection{Al-Si eutectic, continuous GB networks and formation of weak spots}

The non-uniform nucleation of single or clustered IMPs in the Al-Si eutectic phase will cause different electrochemical responses of eutectic areas when exposed to a corrosive environment. The eutectic areas which are decorated with the IMPs are expected to function as initiation sites of corrosion attack while exposed to an electrolyte. This is because these IMPs can provide the necessary cathodic activity to make the corrosion attack evolve and proceed. It is also worth noting that the presence of these IMPs lowers the solute levels in the matrix within the region of the cluster [38]. This reduces the nobility of the matrix and provides a stronger galvanic coupling between it and the IMPs. When comparing the corrosion resistance of the eutectic phases that are and are not decorated with IMPs, a higher 
resistance is expected for the precipitate-free phases. This explains the reason behind the presence of pseudo-randomly attacked eutectic phases, evident on the cross-sectional micrographs (Figure 6.16) of the corroded samples from the SWAAT test. It is also important to notice that some of the eutectic phases with IMPs may come in contact with a continuous grain boundary network which crosses the whole thickness of the material (Figure 6.3a and c). Depending on the type and density of these IMPs and the strength of the cathodic reactivity that they can support, corrosion attack may proceed well into the material through the continuous path of grain boundaries resulting in quick failure of the structure. This arrangement of microstructural features (co-existence of IMPs in contact with continuous GBs in an Al-Si eutectic phase) is expected to be the root cause of early failure of brazing sheet in both SWAAT testing and actual service. This basis for increased susceptibility has already been referred to as weak spots in chapter 2 and a previous publication of the author [32].

\subsubsection{4. $\mathrm{Cu}$ distribution}

Further investigation of the Al-Si eutectic regions shows that some of these eutectic phases are rich in $\mathrm{Cu}$ (Figures 6.6 and 6.9). It is important to note that these regions are those which are also decorated with IMPs. Precipitation of these IMPs is a sign of higher concentration (probably saturated) of alloying elements $(\mathrm{Mn}, \mathrm{Fe}$ and $\mathrm{Cu})$ in these areas. Referring to the phase diagrams, it is clear that increasing the concentration of these elements in the aluminium matrix will decrease the liquidus temperature of the alloy. This makes the molten alloy in the eutectic areas stable for longer than the precipitate-free Al-Si eutectic phase during solidification. Considering the high solubility of $\mathrm{Cu}(\sim 20 \mathrm{wt} . \%$ [1]) in the molten aluminium accompanied by high diffusivity of $\mathrm{Cu}\left(6.42 \times 10^{-13} \mathrm{~m}^{2} / \mathrm{s}\right.$ at brazing temperature [1]) in aluminium matrix, the higher $\mathrm{Cu}$ concentration of the IMP decorated eutectic phases can be understood. As $\mathrm{Cu}$ and $\mathrm{Cu}$-containing phases tend to have a more positive OCP than the aluminium matrix [39], the higher concentration of $\mathrm{Cu}$ in $\mathrm{Al}-\mathrm{Si}$ eutectic areas, decorated with IMPs, enhances the galvanic activity of this phase and makes it more cathodic. The $\mathrm{Cu}$ enrichment at the surface of the brazed structure (Figure 6.9) is also expected to be a consequence of the afore mentioned phenomenon. In this case, the high concentration of $\mathrm{Si}$ at the surface of the material reduces the liquidus temperature and makes the Al-Si eutectic regions the last to solidify and therefore the favoured location for accumulation of $\mathrm{Cu}$. This is the $\mathrm{Cu}$ which has diffused from the core material towards the clad in the course of the brazing process. The high concentration of $\mathrm{Cu}$ at the surface of the brazed structure combined with the high density of cathodic IMPs is expected to provide a large cathodic surface area and therefore a high cathodic reactivity.

Another important aspect worthy of discussion is the presence of $\mathrm{Cu}$-lean areas in the structure of re-solidified brazed material (Figures 6.6 and 6.9). These areas are 
the body of the pre-eutectic aluminium grains. As these grains solidify at the earliest stage of the re-solidification, they get the chance to expel the alloying elements present with greater concentration than their solubility limit, into the liquid phase during solidification. This early solidification behaviour accompanied with the higher solubility of $\mathrm{Cu}$ in the liquid phase explains the presence of the $\mathrm{Cu}$ lean areas. This non-uniformity in the $\mathrm{Cu}$ distribution in the re-solidified clad material is expected to result in a non-uniform dissolution of this material upon exposure to a corrosive environment.

Quantitative analysis (Figures 6.7 and 6.8) reveals an increase of $0.06 \mathrm{wt} \%$ in the $\mathrm{Cu}$ content of the re-solidified clad material. The higher concentration of $\mathrm{Cu}(0.55$ $\mathrm{wt} \%)$ in the eutectic aluminium compared with the concentration of the $\mathrm{Cu}(0.3$ $\mathrm{wt} \%$ ) in the HAZ ( pre-eutectic grains), confirms the higher concentration of $\mathrm{Cu}$ in the phases which solidify during the latter stages of solidification.

\subsubsection{Si distribution}

Qualitative analysis of the chemical composition in the structure of the materials before and after brazing (Figure 6.5) shows a noticeable increase in concentration of $\mathrm{Si}$ in the matrix of the re-solidified clad material. Considering the ennobling effect of $\mathrm{Si}$ on the corrosion potential of the aluminium matrix [7], this phenomenon is expected to increase the OCP values measured on the re-solidified clad material. Quantitative compositional analysis (Figures 6.7 and 6.8) of the elemental distribution in the structure of the brazing sheet material shows $1 \mathrm{wt} \%$ increase in the $\mathrm{Si}$ content of the re-solidified clad material. The Al-Si phase diagram is a classic eutectic system where each element has little solubility in the other. This means that the $1.12 \mathrm{wt} \% \mathrm{Si}$ which has been measured by the EPMA analysis is supersaturated and thus thermodynamically unstable. This is expected to be the result of a relatively high cooling rate $\left(60^{\circ} \mathrm{C} / \mathrm{min}\right)$ from the brazing temperature $\left(600{ }^{\circ} \mathrm{C}\right)$ to room temperature. The maximum solubility of $\mathrm{Si}$ in $\mathrm{Al}$ is $\sim 1.65 \mathrm{wt} \%$ at $577{ }^{\circ} \mathrm{C}$, and the solubility decreases with decreasing temperature [40].

\subsubsection{SKPFM analysis}

\subsubsection{Cross-sectional VPD measurements}

Investigation of the electrochemical responses of the cross-sections of the brazing material both before and after brazing shows that silicon needles have VPD values which are nobler in comparison with the surrounding aluminium matrix. Si can be considered as a relatively pure stable phase with minimum compositional changes in the structure of the material both before and after brazing [10]. This provides the advantage of a reliable local reference in both structures to compare the changes in Volta potential difference as a function of thermal treatment for aluminium brazing 
sheet [10]. The $20 \mathrm{mV}$ difference between the measured VPD values for $\mathrm{Si}$ particles in the structure of the non-brazed $(820 \mathrm{mV})$ and brazed $(840 \mathrm{mV})$ material emphasizes the importance of applying a stable local reference for comparison of the measured VPD values on different samples. It is important to articulate that the measured VPD values are not absolute but comparative values, measured relative to the Volta potential of the AFM tip. The tips are only pseudoreferences, since their Volta potential may vary from tip to tip due to slight difference in the oxide layer covering them or contaminants deposited on the tip during scanning and also instabilities in the instrument electronics [13, 41]. This means that the measured VPD between the tip and the microstructural features at the surface may not necessarily be a meaningful value but just a basis of comparison of VPD differences within the same VPD map. In order to reduce the errors associated with variations in the tip and stability of the system, the Volta potential measurements are normally calibrated by comparison to the potential measured on a reference with stable Volta potential. In the current research, the emphasis is on the VPD difference between the Si particles (as a stable local reference) and the matrix. Following this strategy and comparing the VPD differences between the matrix and Si particles in the structure of the brazed (300 $\mathrm{mV}$ ) and non-brazed $(370 \mathrm{mV})$ material, an average increase of $70 \mathrm{mV}$ in the VPD of the matrices (Figure 6.13) can be detected. This $70 \mathrm{mV}$ increase is proposed to be the result of $\mathrm{Si}$ diffusion and, to a lesser extent, $\mathrm{Cu}$ diffusion into the clad material. This Volta potential increase is quite consistent with the previously reported VPD difference $(58 \mathrm{mV})$ for the surfaces of the brazed and non-brazed structures as well as the $50 \mathrm{mV}$ increase in the OCP profile of the brazed clad surface which has already been reported [10]. This change is expected to lessen the extent to which the re-solidified clad material cathodically protects the core. The purpose of the clad material is to sacrificially protect the core structure and prevent any possible contact between the deeper layers of the material which have already been shown to have an active pitting potential [9]. Therefore, the increase of the OCP profiles is detrimental. This is more clearly reflected in the $25 \mathrm{mV}$ reduction (changing from $40 \mathrm{mV}$ to $15 \mathrm{mV}$ ) in the OCP profile differences between the clad and the core materials as a result of brazing [10].

\subsubsection{AFM/SKPFM analysis across grain boundaries}

The ion bombardment-induced sputtering erosion is capable of revealing the grain boundaries in a structure as a result of slight differences between the sputtering rates of different grains. The height differences $(\sim 700 \mathrm{~nm})$ which have been detected in some areas of the topographical map (Figure 6.14b) can affect the measurement of VPD (Figure 6.14c) [29]. This means that comparison of the VPD values between areas of the map with noticeable height difference $(>300 \mathrm{~nm})$ should be avoided. So the position of line profiles for VPD section analysis incorporate only areas of comparable height. Following this strategy, the $40 \mathrm{mV}$ VPD difference between the grains (G1 and G2) in re-solidified clad material and 
the grain (G3) in the core material is considered to be a valid result. This difference is due to a higher concentration of $\mathrm{Cu}$ and $\mathrm{Mn}$ in the structure of the core material compared to the clad. The $15 \mathrm{mV}$ VPD difference between the grains (G1 and G2) in the re-solidified clad (profile 1, Figure 6.14d) results from the presence of $\mathrm{Cu}$. Although the $\mathrm{Cu}$ distribution is expected to be non-uniform and higher close to the eutectic areas (Si particles), the detailed SKPFM analysis of the grains and grain boundaries (Figure 6.14d) does not reveal any evidence of this. This is supported by the fact that the VPD profiles across grain boundaries exhibit gradual changes in VPD rather than sudden changes (VPD peaks). This is attributed to the stray capacitance error [29] which implies that, no conclusive interpretation over the alloying element segregation at grain boundaries can be achieved with SKPFM.

\subsubsection{Potentiodynamic polarization measurement analysis}

The anodic polarization responses are representative of a localized degradation (IGC or pitting) of the material under investigation. Although the increase in current density with increasing potential above $-700 \mathrm{mV}$ is small, high values of current density between $10^{-3}$ and $10^{-1} \mathrm{Acm}^{-2}$ have been reached. The similarity of the anodic polarization responses for the brazed and non-brazed core materials shows that a similar rate of corrosion in the SWAAT environment can be expected. The presence of a sharp increase in the corrosion current density at potentials close to the OCP values in these anodic potentiodynamic responses shows the susceptibility of both materials to localized corrosion attacks.

\subsubsection{Corrosion attack mechanism}

The corroded cross sections (Figure 6.16) show that brazing has a negative effect on the cathodic protection of the core by the clad material. The brazed clad material has a high sensitivity to localized corrosion and the attack has developed into the structure of the core material as intergranular corrosion. It is known that intergranular corrosion can proceed on aluminium alloys in either of two forms [42]. The first, crystallographic intergranular corrosion, is characteristic of lowalloy or pure aluminium and is controlled by recrystallization. High-angle boundaries of growing re-crystallized grains accumulate numerous vacancies which partly coagulate. This causes thermodynamic instability of the boundaries, and their electrode potential approaches the potential of active corrosion. The second form of intergranular corrosion, structure decomposition, is characteristic of medium- or high-alloy aluminium and is controlled by peculiarities of the decomposition of supersaturated solid solutions [42]. The attack is usually related to the segregation of specific elements or the formation of a compound in the boundary. Corrosion then occurs by preferential attack on the grain-boundary phase, or in a zone adjacent to it that has lost an element necessary for adequate corrosion resistance - thus making the grain boundary zone anodic relative to the 
remainder of the surface material. In this study, $\alpha-\mathrm{Al}(\mathrm{Fe}-\mathrm{Mn}) \mathrm{Si}, \mathrm{Si}$ and $\mathrm{Al}_{2} \mathrm{Cu}$ precipitates at grain boundaries and some $\mathrm{Cu}$-rich GBs (Figures 6.6 and 6.9) in the structure of the re-solidified clad material were detected. These microstructural features explain the IGC susceptibility of the clad material. The localized corrosion susceptibility of the cladding may also originate from a higher sensitivity to pitting of the eutectic (Al) in solutions containing chloride. This has been explained by a lower pitting potential for eutectic (Al) than for the primary aluminium [6,7]. Using transmission electron microscopy (TEM) and EDX analysis, precipitation of highly cathodic $\mathrm{Al}_{2} \mathrm{Cu}$ IMPs at the grain boundaries in a core material of composition $\mathrm{A} 1-1 \% \mathrm{Mn}-0.5 \% \mathrm{Si}-0.5 \% \mathrm{Cu}$ has been reported by Iwao et al. [43]. Considering the low solubility of the $\mathrm{Si}$ in the aluminium matrix, diffusion of $\mathrm{Si}$ from the clad material into the core will also cause precipitation of the Si particles at the grain boundaries. These precipitation phenomena explain the IGC susceptibility of the brazed core structure.

\subsubsection{Corrosion protection enhancement of the modified brazing sheet}

As discussed in Sections 6.4.1.4 and 6.4.1.5., the alloying elements $\mathrm{Cu}$ and $\mathrm{Si}$ play an important role in determining the electrochemical response and corrosion resistance of the brazed material. $\mathrm{Cu}$ is generally added to control the corrosion and mechanical resistance of the structure [44, 45]. The mechanical resistance is achieved by the precipitation of small coherent particles dispersed throughout the matrix [44]. It is well documented that $\mathrm{Cu}$ in solid solution increases the localized corrosion resistance of the $\mathrm{Al}$ matrix [46]. However, $\mathrm{Cu}$ with other alloying elements precipitates as IMPs and attains high surface densities [47]. The difference between the electrochemical reactivity of these IMPs and the matrix gives rise to localized corrosion phenomena [44]. Moreover, the high solubility of $\mathrm{Cu}$ in liquid aluminium has been shown to result in non-uniform distribution and accumulation of $\mathrm{Cu}$ in certain areas (Al-Si eutectic, GBs and Surface) in the structure of re-solidified clad material $[1,43]$. This was proposed to result in nonuniform dissolution and localized corrosion susceptibility of the re-solidified clad material. The high concentration of $\mathrm{Si}$ in the matrix of the brazed clad was also shown to have detrimental effects. The fact that this high concentration is thermodynamically unfavourable suggests that a post braze heat treatment may help to improve the corrosion resistance of this material. Such a treatment should result in a uniform distribution of $\mathrm{Cu}$ and supply enough energy to precipitate $\mathrm{Si}$ from the supersaturated state, improving the functionality of the clad material to sacrificially protect the core after brazing.

\section{5. Conclusions}

Applying SKPFM and potentiodynamic polarization measurements combined with FE-EPMA, SEM, EDX analysis, the electrochemical and microstructural properties of the clad and core from a modified AA3xxx/AA4xxx brazing sheet 
were investigated before and after brazing. Si needles were used as a stable local reference to compare the changes in Volta potential difference. The result was discussed with respect to prior detailed microstructural and electrochemical characterizations $[1,8-10]$. The following results were obtained:

1. The suitability of SKPFM analysis for electrochemical investigation of the aluminium brazing sheet material in a SWAAT environment and the necessity of considering a stable localized reference for comparison of the measured VPD values were highlighted.

2. When compared to the non brazed material, brazing was found to increase the VPD of the clad matrix by $70 \mathrm{mV}$ which reduces the cathodic protection power of the re-solidified clad material. This corresponds with changes in OCP profiles.

3. Using ion-polishing to reveal the GBs in the samples and applying SKPFM analysis no alloying element segregation at GBs in the brazed structure could be detected. This was attributed to the stray capacitance effect from surrounding grains.

4. The IGC susceptibility of the brazed core structure results from IMP precipitation at grain boundaries.

5. Brazing may result in precipitation of IMPs in Al-Si eutectic phases which are formed around GBs that are continuous through the whole thickness of the brazed material. This was proposed to be a root source of corrosion susceptibility (weak spot) for the brazed structure.

6. Solidification shrinkage voids decorated with IMPs were found to have a detrimental effect on corrosion resistance of the brazed aluminium sheet.

7. The corrosion attack on the Al-Si eutectic phases in the re-solidified clad material was found to result from the distribution of intermetallic particles.

8. Brazing was found to result in a non-uniform distribution of $\mathrm{Cu}$ in the resolidified clad structure. The reasons behind such a distribution and the resulting electrochemical consequences were discussed.

9. Brazing was found to result in a $1 \mathrm{wt} \%$ increase in the $\mathrm{Si}$ content of the resolidified clad matrix.

10. It is proposed that a post-braze heat treatment may improve the corrosion resistance of the aluminium brazing sheet. 


\subsection{References}

[1]. F. Norouzi Afshar, J.H.W. de Wit, H. Terryn, J.M.C. Mol, The effect of brazing process on microstructure evolution and corrosion performance of a modified A4xxx/AA3xxx brazing sheet, Corrosion Science, 58 (2012) 242-250.

[2] A.C. Scott, R.A. Woods, J.F. Harris, Accelerated corrosion test methods for evaluating external corrosion resistance of vaccumed brazed aluminium heat exchangers, Conference Proceedings of SAE international Congress, SAE, Warrendale, USA, 1991, paper No. 910590.

[3] Y. Isobe, K. Takeuchi, M. Tanaka, M. Mori, S. Yamauchi, K. Namba, Development of corrosion resistant brazing sheet for drawn cup type evaporators part 2: Application to evaporator, SAE: Conference Proceedings of SAE international Congress, SAE, Warrendale, USA, 1993, paper No. 930149.

[4] F.M. Al-Kharafi, W.A. Badawy, Corrosion and Passivation of Al and Al-Si Alloys in Nitric Acid Solutions: 2 - Effect of Chloride Ions, Electrochimica Acta, 40 (1995) 18111817.

[5] S.S. Abdel Rehim, H.H. Hassan, M.A. Amin, Chronoamperometric studies of pitting corrosion of $\mathrm{Al}$ and (Al-Si) alloys by halide ions in neutral sulphate solutions, Corrosion Science, 46 (2004) 1921-1938.

[6] S. Kuroda, K. Tohma, Aluminium Alloys, Conference Proceedings of ICAA6, Japan Institute of Light Metals, Toyohashi, Japan, 1998, p. 1543.

[7] S. Meijers, Corrosion of aluminium brazing sheet, PhD Thesis, TU Delft, 2002, ISBN 90-805661-3-6.

[8]. F.N. Afshar, E. Szala, A. Wittebrood, C.J.G. Van Hoek, J. Van der Hoeven, A. Buerger, J.M.C. Mol, H. Terryn, J.H.W. de Wit, New approach in microstructural analysis of a modified AA4xxx/AA3xxx brazing sheet before and after brazing, Vehicle Thermal Management Systems proceedings (VTMS 10), Gaydon, UK, 2011.

[9]. F. Norouzi Afshar, R. Ambat, C. Kwakernaak, J.H.W. de Wit, J.M.C. Mol, H. Terryn, Electrochemical depth profiling of multilayer metallic structures: An aluminum brazing sheet, Electrochimica Acta, 77 (2012), 285.

[10]. F. Norouzi Afshar, J.H.W. de Wit, H. Terryn, J.M.C. Mol, Scanning Kelvin probe force microscopy as a means of predicting the electrochemical characteristics of the surface of a modified AA4xxx/AA3xxx (Al alloys) brazing sheet, Electrochimica Acta, 88 (2013) 330.

[11]. P. Schmutz, G.S. Frankel, Corrosion study of AA2024-T3 by scanning Kelvin probe force microscopy and in situ atomic force microscopy scratching, Journal of The Electrochemical Society, 145 (1998) 2295.

[12]. P. Schmutz, G.S. Frankel, Characterization of AA2024-T3 by scanning Kelvin probe force microscopy, Journal of The Electrochemical Society, 145 (7) (1998) 2285.

[13]. V. Guillaumin, P. Schmutz, G.S. Frankel, Characterization of Corrosion Interfaces by the Scanning Kelvin Probe Force Microscopy Technique, Journal of The Electrochemical Society, 148 (5) (2001) B163.

[14]. P. Schmutz, G.S. Frankel, Influence of Dichromate Ions on Corrosion of Pure Aluminum and AA2024-T3 in NaCl Solution Studied by AFM Scratching, Journal of The Electrochemical Society, 146 (12) (1999) 4461.

[15]. P. Leblanc, G.S. Frankel, A study of corrosion and pitting initiation of AA2024-T3 
using atomic force microscopy, Journal of Electrochemical Society, 149 (6) (2002) B239. [16]. R.G. Buchheit, Compilation of corrosion potentials reported for intermetallic phases in aluminum alloys, Journal of The Electrochemical Society, 142 (1995) 3994.

[17]. J.X. Jia, A. Atrens, G. Song, T.H. Muster, Simulation of galvanic corrosion of magnesium coupled to a steel fastener in NaCI solution, Materials Corrosion, 56 (2005) 468.

[18]. J.H.W. de Wit, Local potential measurements with the SKPFM on aluminium alloys, Electrochimica Acta, 49 (2004) 2841.

[19]. P. Campestrini, E.P.M. van Westing, H.W. van Rooijen, J.H.W. de Wit, Relation between microstructural aspects of AA2024 and its corrosion behaviour investigated using AFM scanning potential technique, Corrosion Science, 42 (2000) 1853.

[20]. L. Lacroix, L. Ressier, C. Blanc, G. Mankowski, Combination of AFM, SKPFM, and SIMS to study the corrosion behavior of S-phase particles in AA2024-T351, Journal of The Electrochemical Society, 155 (2008) C131.

[21]. M. Femenia, C. Canalias, J. Pan, C. Leygraf, Scanning Kelvin probe force microscopy and magnetic force microscopy for characterization of duplex stainless steels, Journal of The Electrochemical Society, 150 (2003) B274.

[22]. N. Sathirachinda, R. Pettersson, S. Wessman, U. Kivisäkk, J. Pan, Scanning Kelvin probe force microscopy study of chromium nitrides in 2507 super duplex stainless steel implications and limitations, Electrochimica Acta, 56 (2011) 1792.

[23]. N. Sathirachinda, R. Pettersson, J. Pan, Depletion effects at phase boundaries in 2205 duplex stainless steel characterized with SKPFM and TEM/EDS, Corrosion Science, 51 (2009) 1850.

[24]. S. Mato, G. Alcalá, T.G. Woodcock, A. Gebert, J. Eckert, L. Schultz, Corrosion behaviour of a Ti-base nanostructure-dendrite composite, Electrochimica Acta, 50 (2005) 2461.

[25]. F. Andreatta, H. Terryn, J. H. W. de Wit, Effect of solution heat treatment on galvanic coupling between intermetallics and matrix in AA7075-T6, Corrosion Science, 45 (2003) 1773.

[26]. F. Andreatta, H. Terryn, J. H. W. de Wit, Corrosion behaviour of different tempers of AA7075 aluminium alloy, Electrochimica Acta, 49 (2004) 2851.

[27]. Premendra, B. S. Tanem, J. M. C. Mol, H. Terryn, J. H. W. de Wit and L. Katgerman, A combined TEM and SKPFM investigation of the surface layers on rolled AA5050 aluminium alloy using ultra-microtomy, Surface and Interface Analysis, 40 (2008) 1157-1163.

[28]. A.B. Cook, Z. Barrett, S.B. Lyon, H.N. McMurray, J. Walton, G. Williams, Calibration of the scanning Kelvin probe force microscope under controlled environmental conditions, Electrochimica Acta, 66 (2012) 100-105.

[29]. M. Rohwerder, F. Turcu, High-resolution Kelvin probe microscopy in corrosion science: Scanning Kelvin probe force microscopy (SKPFM) versus classical scanning Kelvin probe (SKP), Electrochimica Acta, 53 (2007) 290.

[30]. J. Lacaze, S. Tierce, M.C. Lafont, Y. Thebault, N. Pebere, G. Mankowski, C. Blanc, H. Robidou, D. Vaumousse, D. Daloz, Study of the microstructure resulting from brazed aluminium materials used in heat exchangers, Materials Science and Engineering A, 317 (2005) 413-414.

[31]. I.R. Harrowfield, C.M. MacRae and N.C. Wilson, "Chemical imaging in electron microprobes" Proceedings of the 27th Annual MAS Meeting, Microbeam Analysis 
Society, New York, pp. 547-548, 1993.

[32]. F.N. Afshar, E. Szala, A. Wittebrood, R. Mulder, J.M.C. Mol, H. Terryn, J.H.W. de Wit, Influence of material related parameters in sea water acidified accelerated test, reliability analysis and electrochemical evaluation of the test for aluminum brazing sheet, Corrosion Science, 53 (2011) 3923.

[33]. A. Wittebrood, Microstructural changes in brazing sheet due to solid-liquid interaction, PhD thesis, TU Delft, 2009, ISBN: 978-90-805661-6-3.

[34]. D.J. Schmatz, Grain boundary penetration during brazing of aluminum, Welding Journal, 10 (1983) 267s.

[35]. Peter C. King, Ivan S. Cole, Penny A. Corrigan, Anthony E. Hughes, Tim H. Muster, FIB/SEM study of AA2024 corrosion under a seawater drop: Part I, Corrosion Science, 53 (2011) 1086-1095.

[36]. N. Birbilis, R.G. Buchheit, Electrochemical characteristics of intermetallic phases in aluminum alloys: An experimental survey and discussion, Journal of The Electrochemical Society, 152 (2005) B140-B151.

[37]. Okada, Y. and Y. Tokumaru, Precise determination of lattice parameter and thermal expansion coefficient of silicon between 300 and $1500 \mathrm{~K}$, Journal of Applied Physics, 56, 2 (1984) 314-320.

[38]. A.E. Hughes, A. Boag, A.M. Glenn, D. McCulloch, T.H. Muster, C. Ryan, C. Luo, X. Zhou,G.E. Thompson, Corrosion of AA2024-T3 Part II: Co-operative corrosion, Corrosion Science, 53 (2011) 27-39.

[39]. F.M. Queiroz, M. Magnani, I. Costa, H.G. de Melo, Investigation of the corrosion behaviour of AA 2024-T3 in low concentrated chloride media, Corrosion Science, 50 (2008) 2646-2657.

[40]. J.L. Murray, A.J. McAlister, Vol. 8, Metals Handbook, 8th ed., 1973, p. 263

[41]. M. Rohwerder, E. Hornung, M. Stratmann, Microscopic aspects of electrochemical delamination: An SKPFM study, Electrochimica Acta, 48 (2003) 1235.

[42]. V. S. Sinyavskii, V. V. Ulanova, and V. D. Kalinin, On the Mechanism of Intergranular Corrosion of Aluminum Alloys, Protection of Metals, 40 (2004) 481-490.

[43]. S. Iwao, M. Asano, Influence of heat treatment on corrosion resistance of aluminum alloy brazing sheet, Journal of Japan Institute of Light Metals, 57 (2007) 589.

[44]. F.M. Queiroz, M. Magnani, I. Costa, H.G. de Melo, Investigation of the corrosion behaviour of AA 2024-T3 in low concentrated chloride media, Corrosion Science, 50 (2008) 2646-2657.

[45]. A. Barbucci, P.L. Cabot, G. Bruzzone, G. Cerisola, Role of intermetallics in the activation of Al-Mg-Zn alloys, Journal of Alloys and Compounds, 268 (1998) 295-301.

[46]. T. Suter, R. Alkire, Micro-electrochemical studies of pit initiation at single inclusions in Al 2024-T3, Journal of The Electrochemical Society, 148 (2001) B36-B42.

[47]. G.S. Chen, M. Gao, R.P. Wei, Microconstituent-Induced Pitting Corrosion in Aluminum Alloy 2024-T3, Corrosion Journal, 52 (1996) 8-15. 


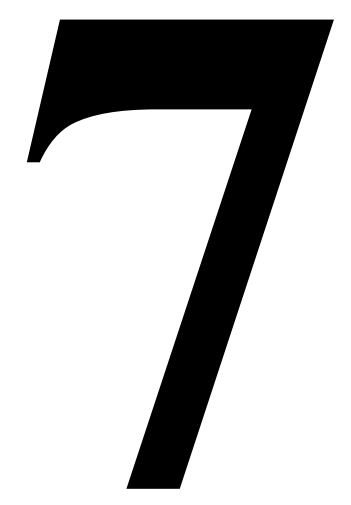

*This chapter has been submitted as a scientific paper:

F. Norouzi Afshar, F.D. Tichelaar, A. M. Glenn, J.H.W. de Wit, H. Terryn, J.M.C. Mol, Enhanced corrosion protection by microstructural control of a modified AA4xxx/AA3xxx aluminium brazing sheet: Towards a green generation of cost effective and corrosion resistant aluminium brazing sheet, Corrosion Science (2013). 



\section{Corrosion protection enhancement}

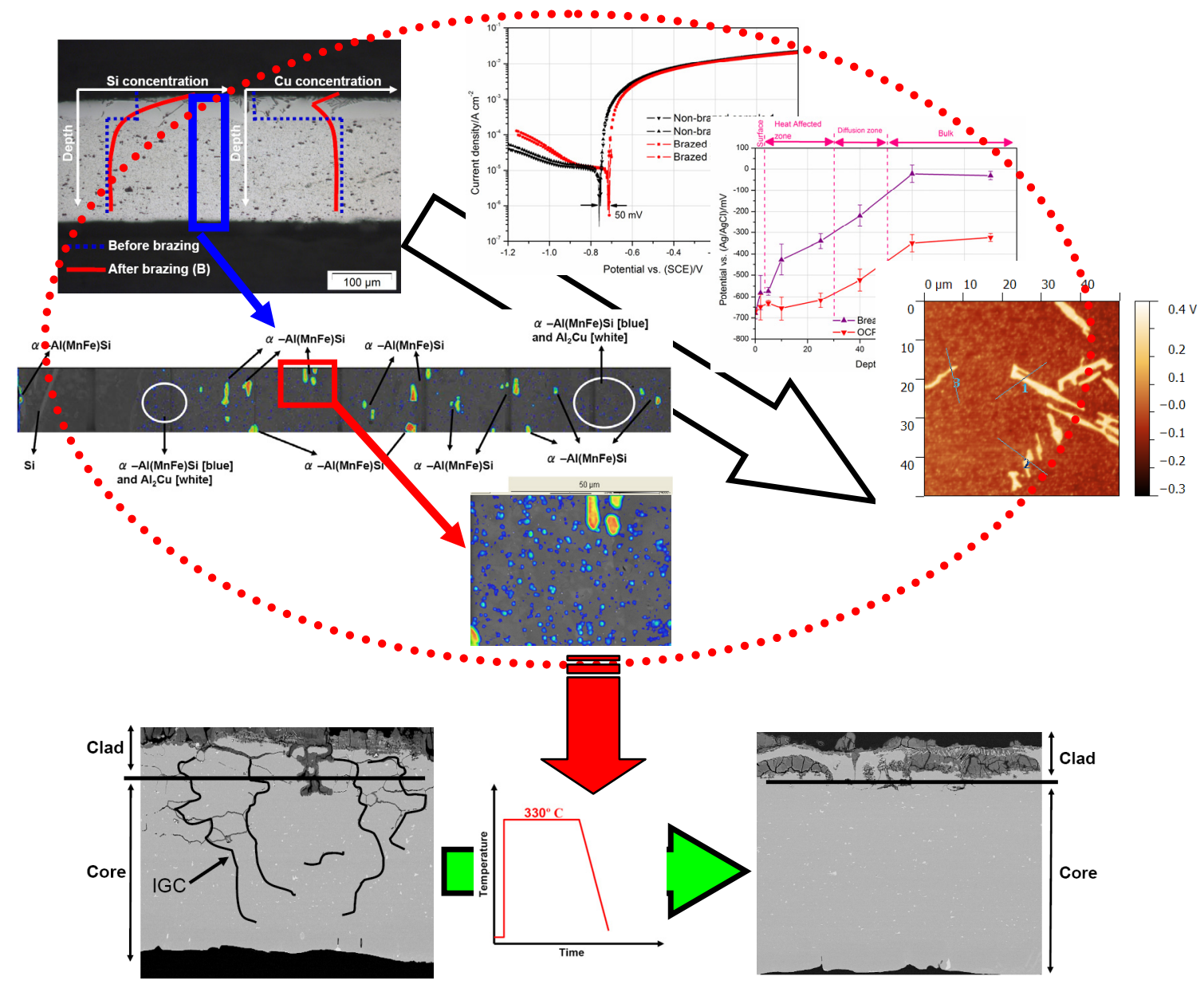

\section{Abstract}

An innovative technique for improving corrosion resistance of a modified AA4xxx/AA3xxx aluminium brazing sheet has been developed. In this process the controlled atmosphere brazed (CAB) material is subjected to a thermal postbrazing treatment. The temperature and timing range for the treatment process were estimated based on thermodynamic calculations and Volta potential measurements respectively. The brazed material was treated at about $336^{\circ} \mathrm{C}$ for 5 , 10 , and 20 hours. 
Scanning Kelvin probe force microscopy (SKPFM), potentiodynamic (PD) measurement, field emission electron probe micro-analysis (FE-EPMA) and transmission electron microscopy (TEM) were used. The electrochemical nature of the overall microstructure and through depth microstructural heterogeneities for the brazed material both before and after the post-braze heat treatment was investigated and compared. The Volta potential difference (VPD) distribution at the surface and through the depth of the brazed and heat treated structures was measured. The changes in the VPD maps were correlated to the distribution of alloying elements and the microstructural features that evolve as a result of the post-braze heat treatment. By performing sea water acidified accelerated tests (SWAAT), potentiodynamic polarization experiments and microscopic analysis of the corroded cross sections, the changes in corrosion attack mechanism of the postbraze heat treated structure were evaluated in further detail.

The investigation revealed that the major consequences of post-braze heat treatment are: a decrease in the Si content of the matrix in the heat affected zone (HAZ); elimination of accumulated $\mathrm{Cu}$ in Al-Si eutectics and around the grain boundaries; dissolution of $\mathrm{Al}_{2} \mathrm{Cu}$ particles in the grain boundaries; and increasing the precipitation density of $\mathrm{Si}$ and $\alpha-\mathrm{Al}(\mathrm{Fe}-\mathrm{Mn}) \mathrm{Si}$ particles. The effects on local electrochemical activity and corrosion properties of these treatment consequences were: a decrease in the VPD of the re-solidified clad matrix; elimination of localized corrosion attack susceptibility of the brazed structure; and an increase in the cathodic protection power of the re-solidified clad towards the core material.

This new generation of aluminium brazing sheet is able to tolerate a higher amount of previously considered detrimental alloying elements (i.e. Fe and $\mathrm{Si}$ ) and lowers the need for purification during primary and recycling processing, saving energy, material and labor costs. Therefore the material can be referred to as a green, cost effective and corrosion resistant aluminium brazing sheet.

\subsection{Introduction}

\subsubsection{Long life aluminium brazing sheet and the need for a replacement}

The thermal management in a car consists of a number of heat exchangers placed in designated sections of the car body. In the past 30 years the use of aluminium in automotive heat exchanger applications has been steadily growing [1]. In modern automobiles, the heat exchangers are made up of aluminium brazing sheet. Aluminium brazing sheet comprises of a core alloy clad on one or both sides with a lower melting aluminium-silicon (Al-Si) alloy. The core alloy provides the strength and the clad material acts as a filler material. This thin clad layer usually makes up 5-10\% of the total thickness of the brazing sheet. It melts and flows during the brazing process, to provide a metallic bond between the components upon cooling. Typical clad and core alloys are the AA4xxx and AA3xxx series, 
respectively $[1,2]$.

One of the main performance criteria for heat exchanger units is the life time of the product [3]. Today the life time of a typical heat exchanger has to be the same as the life time of the car, namely around 15 years. The main improvement to reach 15 years of life time performance is the development of the so-called long life (LL) alloys. These LL alloys are modified AA3003 and AA3005 alloys, which are low in iron and silicon [2]. This low level of both iron and silicon make these alloys more expensive than the traditional AA3003 and AA3005 alloys. The main feature of the LL alloys is that they have a substantial amount of manganese in solid solution at the time of brazing. Due to the inward silicon diffusion during the brazing cycle, the manganese will precipitate in the diffusion layer [2]. The reduction of manganese in solid solution will lower the corrosion potential locally with respect to the remaining core alloy. This diffusion band will now be sacrificial to the core alloy and thus protecting the core alloy [2]. In the modern automobile industry cost reductions are key and the LL alloys become less competitive. There is a strong demand for low cost alloys but still with the excellent corrosion protection properties of the expensive LL alloys. The corrosion resistance becomes even more sensitive when the demand for down gauging of heat exchangers is considered. This is aimed at production of more fuel-efficient vehicles to reduce the energy consumption and air pollution. Standard AA3003 and AA3005 alloy show poor corrosion resistance [2], but are more cost effective compared to the LL alloys. Therefore investigating the possibilities for improving the corrosion resistance of cost effective aluminium brazing sheet materials are of both scientific and industrial interest.

\subsubsection{Effects of thermal treatment on corrosion resistance of aluminium brazing sheet}

Finnegan and Woods [4] developed a post braze thermal treatment for improving the corrosion resistance in vacuum brazed heat exchangers. The mechanism behind this improved corrosion performance was explained to be the massive precipitation of dispersoid phases during the thermal treatment. The treatment was claimed to eliminate all sensitivity to the classic intergranular corrosion that is normally associated with brazed aluminium components. This was attributed to profusion of local micro-galvanic cells overruling any effect between the normal grain boundary solute enrichment/precipitates and the adjacent relatively precipitate free grains that exist following conventional brazing. The effect of heat treatment on intergranular corrosion (IGC) susceptibility of $\mathrm{AlMgSiCu}$ alloys were investigated by Svenningsen et al. [5, 6, 7]. IGC was related to micro-galvanic coupling between the grain boundary precipitates and the adjacent depleted zone. Svenningsen et al. concluded that the IGC resistance is obtained either by keeping the $\mathrm{Cu}$ content low or by applying proper heat treatment to samples with high $\mathrm{Cu}$ content $[5,6,7]$. Increased IGC resistance was achieved by coarsening of the grain 
boundary $\mathrm{Cu}$-depleted film caused due to coarsening of the intermetallic particles at the grain bodies as a result of heat treatment. Iwao and Asano [8] applied SWAAT [3] to evaluate the corrosion resistance of post-braze heat treated aluminium brazing sheets. They observed that the maximum corrosion depth in A1$1 \% \mathrm{Mn}$ and $\mathrm{Al}-1 \% \mathrm{Mn}-0.5 \% \mathrm{Si}$ core alloys decreased while it increased in Al$1 \% \mathrm{Mn}-0.5 \% \mathrm{Si}-0.5 \% \mathrm{Cu}$ core alloy. Remarkable IGC attack of the core material was observed in the latter alloy. In another study, Iwao and Asano [9] investigated the effect of addition of $\mathrm{Cu}$ and $\mathrm{Mg}$ on intergranular corrosion susceptibility in AA3xxx alloys exposed to SWAAT after heating at $600^{\circ} \mathrm{C}$ (brazing temperature), followed by reheating at $200^{\circ} \mathrm{C}$ (post-braze heat treatment). Intergranular corrosion occurred in Al-Mn-Si-Cu alloy after post-braze heat treatment for 1 to 10 hours. Pitting corrosion was observed in $\mathrm{Al}-\mathrm{Mn}-\mathrm{Si}-\mathrm{Cu}-\mathrm{Mg}$ alloy. Intergranular corrosion in the former alloy was caused by selective dissolution of $\mathrm{Cu}$ depleted zones. In the latter alloy precipitates including $\mathrm{Cu}$ were observed not only in the grain boundary but also in the grain body even after shorter treatment time at $200^{\circ} \mathrm{C}$. Therefore, decreasing intergranular corrosion susceptibility of the alloy was caused by a smaller potential difference between depleted zone and grain matrix. The authors concluded that addition of $\mathrm{Mg}$ in $\mathrm{Al}-\mathrm{Mn}-\mathrm{Si}-\mathrm{Cu}$ alloy improves the corrosion resistance after applying a heat treatment [9].

\subsubsection{Summary of the previous characterization results}

The highlights of the previous microstructural characterization are summarized and presented in Figure 7.1.

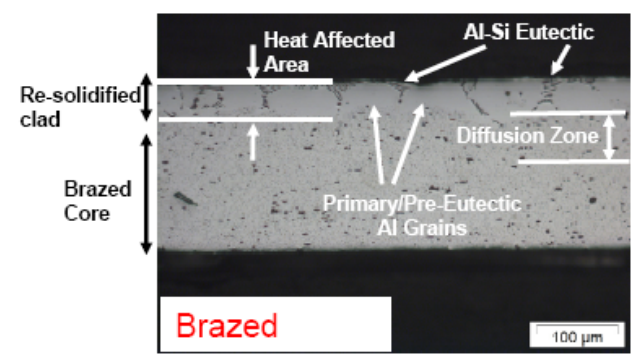

(a)

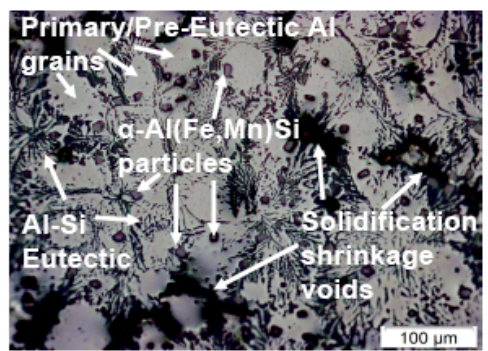

(b)

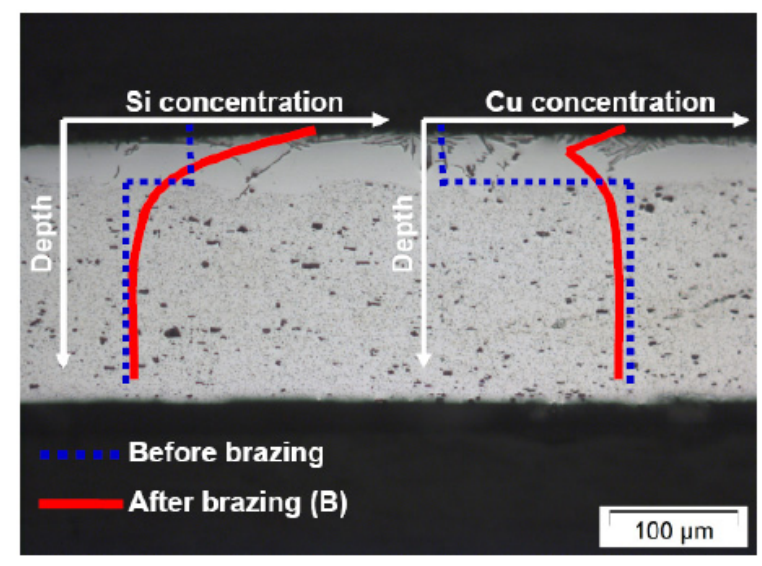

(c)

Fig 7.1. Summary of the important microstructural features on the cross-sectional optical images (a and c) and optical micrograph of the surface (b) of the brazing sheet structure after brazing. 
Figure 7.1 shows the optical images of the surface (Figure 7.1b) and cross-sections (Figure 7.1a and c) of the material under investigation after brazing treatment. At brazing temperature the liquid clad is in intimate contact with the solid core material. During this stage where the two phases co-exist, an interaction between the two can take place. The liquid originating at the clad-core interface progresses into the core alloy as a film, changing the element distribution on its way $[11,12]$. This area is the precipitate-free heat affected area/zone (HAZ) which has been designated in Figure 7.1a. The Al-Si eutectic phase accumulates at the surface and in between the pre-eutectic aluminium grains (Figure 7.1a). From the elements that diffuse into the core, Si has the highest diffusion coefficient and so the diffusion path of this element is considered to represent the diffusion layer. This layer was measured to be about $40 \mu \mathrm{m}[1,10]$. After the brazing process and formation of Al-Si eutectic phase, the structure of the surface will change to the one which has been shown in Figure 7.1b. Solidification of the molten clad material starts with the formation of the pre-eutectic aluminium grains and ends with accumulation of Al-Si eutectic phase at the surface and in grain boundaries. This results in solidification void formation which has been shown in Figure 7.1b. The high density of $\alpha-\mathrm{Al}(\mathrm{Fe}-\mathrm{Mn}) \mathrm{Si}$ particles with dark contrast (Figure 7.1b) at the surface of the re-solidified clad material is also noticeable. Schematic diagrams, representative of $\mathrm{Si}$ and $\mathrm{Cu}$ distribution across the material both before and after brazing, are depicted in Figure 7.1c. The reported distribution profiles of $\mathrm{Si}$ and $\mathrm{Cu}$ are based on the previous characterisation work which has already been discussed (chapter 6) and published by the author [1, 13-15]. Figure 7.1 summarizes the most important elemental distribution features that develop after brazing treatment. Comparing the $\mathrm{Si}$ distribution profile before and after brazing treatment, a noticeable increase $(\sim 1 \mathrm{wt} \%$ [15]) in the Si content of the re-solidified clad material is observed. The Si profile represents a smooth descending function as further depth of the material is reached. In contrast to the Si distribution profile the $\mathrm{Cu}$ distribution profile presents an unsmooth function with a minimum $\mathrm{Cu}$ content in the middle of the pre-eutectic aluminium grains. The maximum $\mathrm{Cu}$ content $(\sim 0.6 \mathrm{wt} \%$ [13]) is reached in Al-Si eutectics (at the surface and in grain boundaries).

A full electrochemical characterization of the material at macro [1] (chapter 3), localized [13] (chapter 4) and micro [14, 15] (chapter 5 and 6) scales has been achieved and correlated to the microstructural features developed as consequences of brazing treatment. The investigations [1, 3, 10, 13-15] revealed that brazing treatment will introduce localized corrosion attack susceptibility on the brazed core and clad structures and reduce the cathodic protection power of the re-solidified clad material towards the core material. Considering the correlation between the evolved microstructure and the electrochemical reactivity of the structure, it has been proposed that applying a proper post-braze heat treatment could potentially improve the corrosion resistance of the modified aluminium brazing sheet [15] (chapter 6). 


\subsubsection{The purpose of the current study}

The current research aims at investigating a proper post-braze heat treatment to improve the corrosion resistance of a modified aluminium brazing sheet. Applying thermodynamic calculations, microstructural and electrochemical characterisation techniques, the purpose of this chapter is to define the proper temperature and timing ranges for a feasible post-braze heat treatment and to analyze the changes in corrosion resistance and corrosion attack mechanism of the treated structure.

Although a post-braze treatment is not desirable in the industry, the metallurgical changes responsible for the increased corrosion protection are of great importance. This information might allow the production of more cost effective alloys by modifying thermo-mechanical processing of standard alloys. In spite of the associated costs with this additional thermal treatment, its benefits include a significant improvement in the corrosion resistance of the brazed structure and reduced need for purification during primary and recycling processing. Savings in energy, material and labour costs, can be achieved as a results.

\subsection{Experimental}

\subsubsection{Materials}

Sheet of dimentions $210 \times 297 \mathrm{~mm}$ was cut from rolled modified AA3xxx aluminium alloy (185 $\mu \mathrm{m}$ thick) clad on one side with an AA4xxx (15 $\mu \mathrm{m}$ thick). The bulk chemical analysis of the clad and the core materials was obtained by XRay Fluorescence (XRF) analysis of $3 \mathrm{~cm}$ diameter discs of the material. PW2400 equipment with a Rhodium anode and a $60 \mathrm{kV}$ acceleration voltage was used. The data were analyzed with UniQuant software and are presented in Table 7.1.

Table 7.1. Chemical composition (wt \%) of the AA3xxx (core) and AA4xxx (clad) material.

\begin{tabular}{ccccccccc}
\hline & $\mathrm{Si}$ & $\mathrm{Fe}$ & $\mathrm{Cu}$ & $\mathrm{Ti}$ & $\mathrm{V}$ & $\mathrm{Cr}$ & $\mathrm{Mn}$ & $\mathrm{Al}$ \\
\hline Clad & 7.70 & 0.18 & - & 0.01 & - & - & 0.14 & Bal. \\
Core & 0.44 & 0.32 & 0.6 & 0.08 & 0.01 & 0.07 & 1.03 & Bal. \\
\hline
\end{tabular}

\subsubsection{Brazing procedure}

The sheet was cleaned in an ultrasonic bath with ethanol, dried and placed in a Controlled Atmosphere Brazing (CAB) furnace. CAB consists of brazing in a dry, inert, nitrogen gas atmosphere. The material is heated up to $600{ }^{\circ} \mathrm{C}$ and is kept at that temperature for $3 \mathrm{~min}$ and then cooled with a specified ramp $\left(60^{\circ} \mathrm{C} / \mathrm{min}\right)$. The holding temperature was selected to be close to the liquidus temperature of the clad material, reported as $612{ }^{\circ} \mathrm{C}$ by Lacaze et al. [16] while far below the solidus 
temperature of the core material which is about $640{ }^{\circ} \mathrm{C}[1]$.

\subsubsection{Thermodynamic calculations}

JmatPro (Version 6.0) software was used. JmatPro calculates a wide range of microstructural properties (e.g. equilibrium phases, their weight percentages, chemical composition and the temperature ranges over which various phases are stable) for alloys and is particularly aimed at multi-component alloys used in industrial practice. The software has an extended database for the calculation of physical properties that can be linked to its thermodynamic calculation capability. The calculations are based on minimization of free energy of the matter at a certain temperature and composition: the state of minimum free energy is the equilibrium state of the system [1]. Using the chemical composition and the temperature range of interest, the software predicts the material characteristics including stable and metastable phase equilibrium. The software can also predict the changes in chemical composition for a certain phase over a defined range of temperature.

\subsubsection{Microstructure and composition analysis}

\subsubsection{X-ray micro analysis (XMA)}

For chemical characterisation (elemental analysis) EDS mapping was conducted on polished cross sections using an FEI quanta 400, field emission, environmental SEM equipped with a Bruker silicon drift EDS detector and Bruker software (Esprit ver. 1.9). Before SEM analysis, samples were coated with a conductive carbon layer of approximately $15 \mathrm{~nm}$ thickness. Mapping conditions were: an electron beam energy of $15 \mathrm{kV}$; a probe current of approximately $10 \mathrm{nA}$; a step size of approximately $0.27 \mu \mathrm{m}$; a total of $800 \times 690$ pixels in $\mathrm{X}$ and $\mathrm{Y}$, respectively.

\subsubsection{FE-EPMA analysis}

EPMA maps were collected using a JEOL 8500F, field emission, electron microprobe, equipped with 5 wavelength dispersive spectrometers (WDS); 2 silicon drift, energy dispersive spectrometers (EDS); an optically encoded stage; and top-referenced sample holder. Mapping parameters used were: electron beam energy of $7 \mathrm{keV}$, probe current of $100.5 \mathrm{nA}$, step size of $160 \mathrm{~nm}$, a total field size of $256 \times 224 \mu \mathrm{m}$ and a dwell time of $50 \mathrm{~ms}$. The WDS spectrometers were tuned to collect the signals of $\mathrm{Mn} \mathrm{L} \alpha, \mathrm{Fe} \mathrm{L} \alpha, \mathrm{Cr} \mathrm{L} \alpha, \mathrm{Si} \mathrm{K} \alpha$ and $\mathrm{Cu} \mathrm{L} \alpha$ characteristic $\mathrm{x}-$ rays. All other elements were analysed using EDS. Pure element standards were used for the calculation of K-ratios. All post processing of EPMA maps was conducted using proprietary software, Chimage [17]. 


\subsubsection{TEM analysis}

TEM examination was conducted in a Tecnai-F20ST TEM/STEM operated at $200 \mathrm{KV}$. The samples were prepared by gluing glass on both sides of the brazing sheet material and cutting cross-sections with a thickness of $0.5 \mathrm{~mm}$. The crosssections then were ground and polished down to a thickness of about $20 \mu \mathrm{m}$. The thinning was continued until electron transparency using a Gatan PIPS 691 ion mill operated with Ar. Bright field (BF) and high angle annular dark field (HAADF) images were taken. In the BF mode, the undiffracted beam is selected to make a diffraction contrast image. In the case of HAADF mode, for each pixel in the image the high angle scattered electrons are detected on a ring shape detector. Hence, the brightness of each pixel represents the amount of high angle scattered electrons at that position. For a certain TEM foil thickness, a high brightness means an element with high atomic number is present.

Elemental composition was studied with X-ray energy dispersive spectroscopy (EDS) using a local electron probe and an EDAX system integrated with the Tecnai operating software.

\subsubsection{AFM and SKPFM analysis}

Atomic force microscopy, digital instrument Nanoscope III multimode, was used to investigate the electrochemical nature of the silicon and intermetallics, in particular their Volta potential with respect to the aluminium matrix. The maps of the Volta potential of the specimens with respect to the AFM tip were recorded. The detailed explanation of the AFM/SKPFM principles of operation and measurement settings has been already reported in chapter 5 . All the measurements were carried out in air at ambient temperature, pressure and humidity. The potential difference and the topographical maps were sampled with the same pixel density of $256 \times 256$ pixels per image and at a scan frequency of $0.5 \mathrm{~Hz}$. For all measurements antimony (n) doped silicon tips, coated on both sides with $20 \mathrm{~nm}$ platinum/iridium, were used. The tip is characterised by a resistivity of 0.01-0.025 $\Omega . \mathrm{cm}$ and supported on a cantilever 200-250 $\mu \mathrm{m}$ long, 23-33 $\mu \mathrm{m}$ wide and 2.5-3.5 $\mu \mathrm{m}$ thick. The measurements were performed on polished surfaces (using the finest grade of $0.25 \mu \mathrm{m}$ ) and ion-polished cross sections. Polishing of the surfaces was intended to remove only a very thin layer of the clad material and provide a smooth surface for AFM/SKPFM measurements. The cross-sectional ion polishing method utilizes a low voltage $\mathrm{Ar}$ ion beam $(<5 \mathrm{kV})$ to polish and etch materials, eliminating the need for mechanical polishing and chemical etching. Ion-polished surfaces provide a clear view of the global microstructure, including grain boundaries and phase boundaries with enhanced orientation contrast. Crosssections of the brazed and post braze heat treated samples were prepared by applying a cross-section ion polisher (JEOL, SM-09010). The polishing was intended to provide a smooth surface for the AFM/SKPFM measurements. The 
samples were ultrasonically cleaned in ethanol and air dried to limit any effect of adsorbed species on the Volta potential measurements. The representation of topography and potential is defined such that the brightness is proportional to height and potential, respectively. In order to clarify the nature of the measured Volta potential values a uniform designation system is introduced. The Volta potential difference between sample surface features and the AFM tip is referred to as "VPD" whereas the Volta potential difference between sample surface features is referred to as "VPD difference".

\subsubsection{Electrochemical analysis}

Using a Solartron potentiostat and a three-electrode electrochemical cell, potentiodynamic polarization measurements were performed. Considering the emphasis of this research on the microstructural effects on the electrochemical performance of the aluminium brazing sheet, the cathodic and the anodic polarization responses of the materials have been measured and investigated separately. The working electrodes (samples) were circular plates with a diameter of $2 \mathrm{~cm}$. The reference electrode was a saturated calomel electrode (SCE) and the counter electrode was platinum. SWAAT solution [3] was chosen as electrolyte. The samples were scanned in the potential range between $10 \mathrm{mV}$ below and $1 \mathrm{~V}$ above the open circuit potential (OCP) for the anodic scans and between $10 \mathrm{mV}$ above and $450 \mathrm{mV}$ below the OCP for the cathodic scans. The scans started after $15 \mathrm{~min}$ of OCP measurement. A scan rate of $0.5 \mathrm{mV} / \mathrm{s}$ was used. The reproducibility of the test results was checked by triplication of each experiment.

\subsubsection{Corrosion attack mechanism investigation}

The most common way to measure the corrosion resistance of heat exchanger materials, both for tube and fin alloys is the Sea Water Acidified Accelerated Test SWAAT [3]. Comparing the corrosion mechanism and morphology of attack it has been proven that the SWAAT performance of the aluminium brazing sheet material can be reflected in potentiodynamic responses [3]. Optical micrographs from the cross-sectional analysis of the samples after anodic polarization were investigated. The corrosion of this material starts from the re-solidified clad layer. This is the surface which is exposed to the corrosive environment. Therefore for the corrosion investigation, the cross-sectional analysis of the samples after the anodic polarization of the clad side of the material has been investigated. The corrosion resistance investigation was further continued by direct exposure of both brazed and post-braze heat treated samples to SWAAT solution in a simulated SWAAT cabinet [3]. Optical micrographs from the cross-sectional analysis of the samples after different exposure times were investigated. 


\subsection{Results}

\subsubsection{Determination of the post-braze heat treatment parameters (temperature and time)}

\subsubsection{Determination of the appropriate post-braze heat treatment temperature}

Thermodynamic calculations were performed to predict the equilibrium phases and the compositional changes of the phases that can take place over the $25-600{ }^{\circ} \mathrm{C}$ temperature range. The results are presented in Figures 7.2 and 7.3.

Figure 7.2 shows that $\mathrm{Si}, \alpha-\mathrm{Al}(\mathrm{Mn}-\mathrm{Fe}) \mathrm{Si}$ and $\mathrm{Al}_{2} \mathrm{Cu}$ are the equilibrium phases that exist in the structure of the re-solidified clad material. It can be noticed that at temperatures above $330{ }^{\circ} \mathrm{C}$, a complete dissolution of the $\mathrm{Al}_{2} \mathrm{Cu}$ particles will take place. Above $570{ }^{\circ} \mathrm{C}$ a sudden increase in the Si solubility in the matrix of the aluminium brazing sheet material can be observed. For the $\alpha-\mathrm{Al}(\mathrm{Mn}-\mathrm{Fe}) \mathrm{Si}$ particles, the maximum particle density can be achieved at about $330{ }^{\circ} \mathrm{C}$.

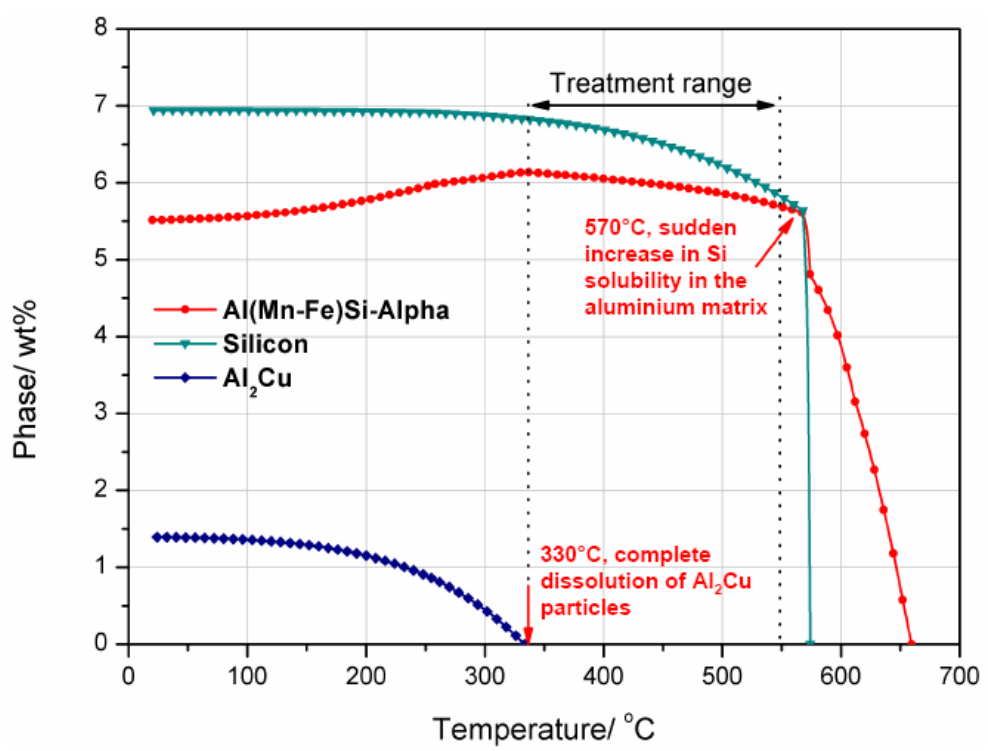

Figure 7.2. JmatPro calculation for equilibrium phases in re-solidified clad in AA4xxx/AA3xxx brazing sheet. Chemical composition (table 7.1) and the temperature range $\left(25-650^{\circ} \mathrm{C}\right)$ are the input parameters for the JmatPro software calculations.

Figure 7.3 shows the elemental composition changes in the $\alpha-\mathrm{Al}(\mathrm{Mn}-\mathrm{Fe}) \mathrm{Si}$ particles over $100-600{ }^{\circ} \mathrm{C}$ temperature range. The maximum $\mathrm{Si}$ and $\mathrm{Cu}$ content in the structure of the $\alpha-\mathrm{Al}(\mathrm{Mn}-\mathrm{Fe}) \mathrm{Si}$ particles occurs at $218{ }^{\circ} \mathrm{C}$ and $336{ }^{\circ} \mathrm{C}$ respectively. Figure 7.3 indicates that keeping the $\alpha-\mathrm{Al}(\mathrm{Mn}-\mathrm{Fe}) \mathrm{Si}$ particles at high temperatures $\left(>500{ }^{\circ} \mathrm{C}\right)$ will increase the Fe content and decrease the Mn content 
of the $\alpha-\mathrm{Al}(\mathrm{Mn}-\mathrm{Fe}) \mathrm{Si}$ particles. This information has been used to select the proper temperature range $\left(330-570{ }^{\circ} \mathrm{C}\right)$ and the most appropriate temperature $\left(336^{\circ} \mathrm{C}\right)$ that may improve the corrosion resistance of the modified aluminium brazing sheet under investigation.

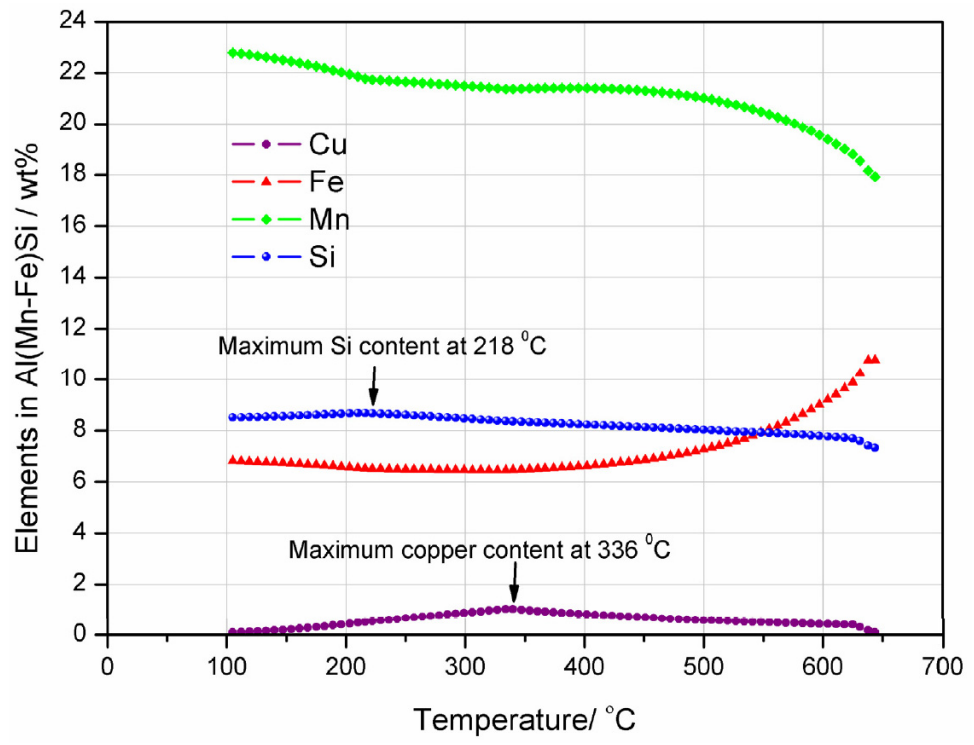

Figure 7.3. JmatPro calculation for predicting the elemental composition changes in $\alpha-\mathrm{Al}(\mathrm{Fe}, \mathrm{Mn}) \mathrm{Si}$ phase as a result of a heat treatment. Chemical composition (table 7.1$)$ and the temperature range $\left(100-650^{\circ} \mathrm{C}\right)$ are the input parameters for the JmatPro software calculations.

\subsubsection{Determination of the appropriate post braze heat treatment time}

The most appropriate heat treatment time was estimated by applying SKPFM analysis. The VPD values and the results of line scan section analysis on the polished surfaces after different post-braze heat treatment times are presented in Figures 7.4 and 7.5. In order to avoid any artificial changes of the measured Volta potential differences, no data post-treatment has been applied on the presented Volta potential results. The Si particles/needles are shown in bright contrast in the VPD maps. The VPD of Si is considered as the local reference in each VPD map. This will be the bases of the comparison for the changes in VPD differences which has occurred as a result of braze and post-braze heat treatments. The detail of this analysis approach has already been discussed in chapter 5 and a prior publication of the author [14]. Comparison of the VPD differences between Si particles and the matrices for the materials before and after brazing and after post-braze heat treatments $\left(5,10\right.$, and 20 hours at $\left.336^{\circ} \mathrm{C}\right)$ was performed by applying section analysis. The positions of the sectioning profiles are indicated in Figure 7.4. Three line profiles per each sample were investigated. The results are presented in Figure 7.5. The peak potentials correspond to the VPD of Si in all graphs. This potential is about $300 \mathrm{mV}$. Comparing the graphs in Figure 7.5 shows that brazing increases the VPD of the matrix while the post-braze heat treatment counteracts this effect. 
Keeping the brazed samples at $336{ }^{\circ} \mathrm{C}$ for 5, 10 and 20 hours has increased the VPD difference between $\mathrm{Si}$ and the matrix by 20,50 and $60 \mathrm{mV}$ respectively. These values are in comparison with the $300 \mathrm{mV}$ VPD difference between Si and the matrix in the as brazed structure.

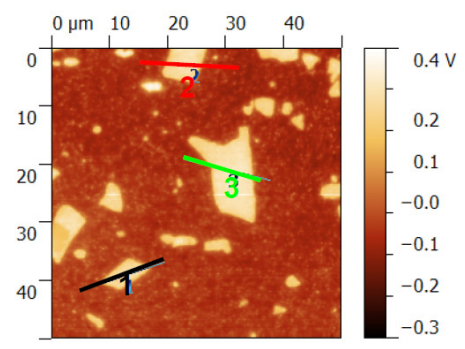

Non-brazed

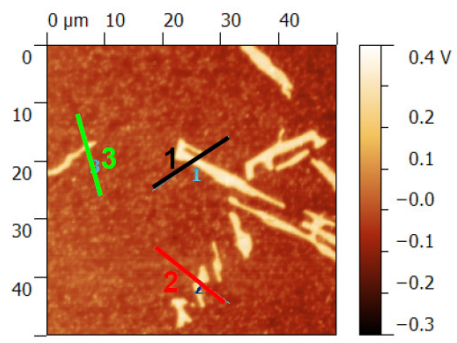

As-brazed

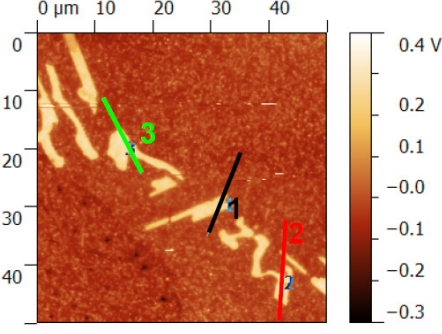

5 hrs treatment

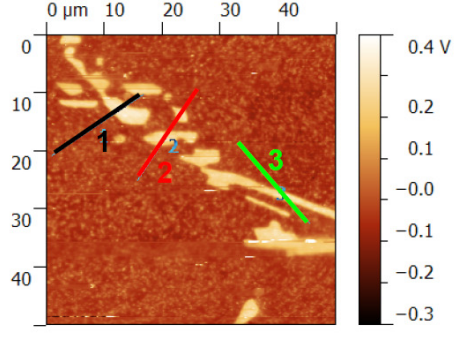

10 hrs treatment

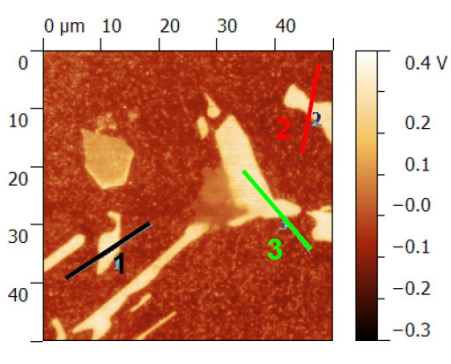

20 hrs treatment

Figure 7.4. Volta potential difference (VPD) maps and position indication for section analysis profiles before and after different heat treatment processes

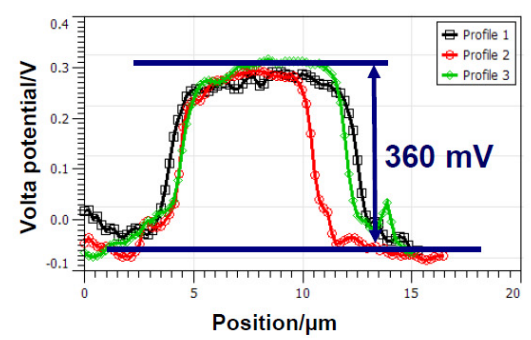

Non-brazed

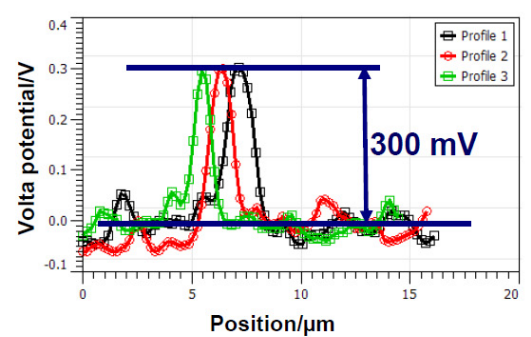

As-brazed

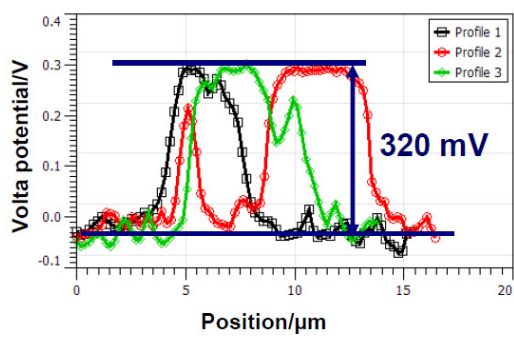

5 hrs treatment

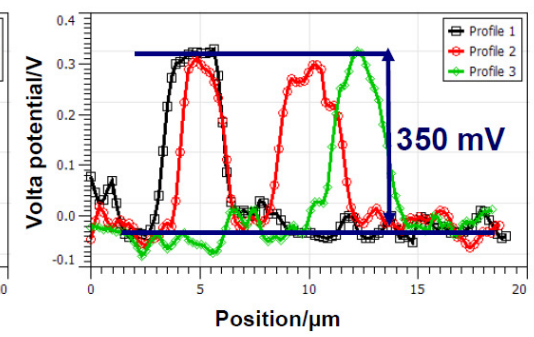

10 hrs treatment

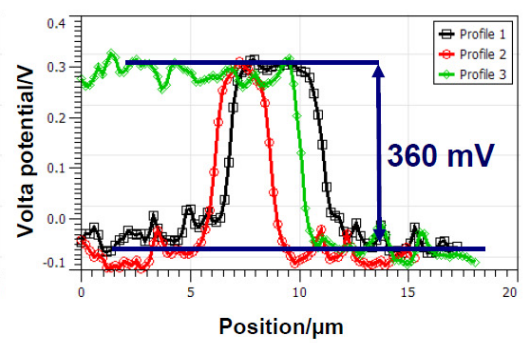

20 hrs treatment

Figure 7.5. line scan section analysis results, obtained from SKPFM analysis of the polished surfaces after different heat treatment processes 


\subsubsection{Characterization of the post-braze heat treated samples}

\subsubsection{Microstructural characterization}

\subsection{X-ray micro analysis}

The results of X-ray micro analysis mapping for $\mathrm{Si}$ and $\mathrm{Cu}$ alloying elements and the SEM backscattered electron images of the areas under investigation for both as-brazed and post-brazed heat treated $\left(20\right.$ hours at $\left.336^{\circ} \mathrm{C}\right)$ conditions are presented in Figure 7.6.

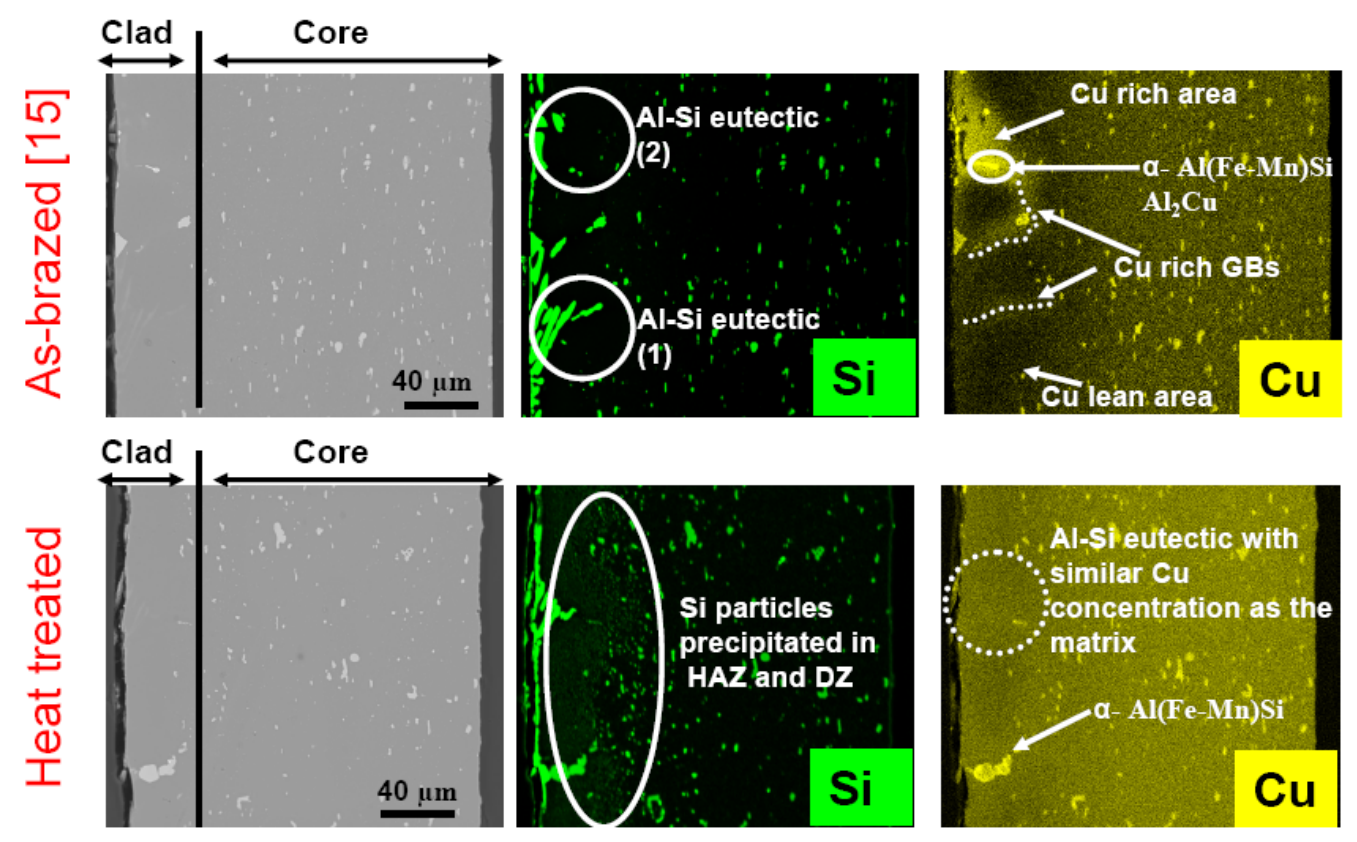

Figure 7.6. X-ray micro-analysis mapping for the $\mathrm{Si}$ and $\mathrm{Cu}$ alloying elements in as-brazed and post-braze heat treated conditions.

The position of the re-solidified clad and the core materials are clearly distinguished. Two Al-Si eutectic regions (1 and 2) are highlighted in the Si map of the as-brazed sample. A noticeable difference between these two eutectic regions is the $\mathrm{Cu}$ content. The $\mathrm{Cu}$ map shows, the Al-Si eutectic (2) is rich in $\mathrm{Cu}$ while the Al-Si eutectic (1) is $\mathrm{Cu}$ lean. The position of some of the grain boundaries in the re-solidified clad on the $\mathrm{Cu}$ map has been highlighted by drawing white curved dashed lines. The grain boundary distinction is based on the fact that the eutectic Al-Si phases form during the last stage of solidification and in between the pre-eutectic aluminium grains and therefore crossing the grain boundaries. The important brazing effects that need to be noted on the $\mathrm{Cu}$ map of as-brazed sample in Figure 7.6 are: Non-uniform distribution of $\mathrm{Cu}$ (presence of $\mathrm{Cu}$ rich and $\mathrm{Cu}$ lean areas) in the re-solidified clad material; and accumulation of $\mathrm{Cu}$ at grain boundaries $(\mathrm{Cu}$ rich $\mathrm{GBs})$ with intermetallic precipitates (mostly 
$\mathrm{Al}_{2} \mathrm{Cu}, \alpha-\mathrm{Al}(\mathrm{Fe}-\mathrm{Mn}) \mathrm{Si}$. The $\mathrm{Si}$ map of the post-braze heat treated sample shows a higher density of Si particles in the HAZ and diffusion zone compared with that of the as-brazed material. The $\mathrm{Cu}$ map of the heat treated samples shows a more uniform distribution of $\mathrm{Cu}$ in the re-solidified clad material. No $\mathrm{Cu}$ concentration differences between the Al-Si eutectic regions, with and without IMPs, can be distinguished.

\subsection{EPMA analysis}

The FE-EPMA analysis maps of $\mathrm{Cu}$ and $\mathrm{Si}$ in the as-brazed and after a post-braze heat treatment $\left(20\right.$ hours at $336{ }^{\circ} \mathrm{C}$ ) are shown in Figures 7.7 and 7.8. The $\mathrm{Cu}$ concentration map of the as-brazed sample shows that the major consequences of the brazing treatment are: formation of $\mathrm{Cu}$-lean areas; accumulation of $\mathrm{Cu}$ at the surface of the re-solidified clad material and Al-Si eutectic regions and in between the eutectic aluminium grains (GBs); and precipitation of intermetallic particles with relatively higher $\mathrm{Cu}$ content. The $\mathrm{Cu}$ concentration map after the post-braze heat treatment does not show any accumulation of $\mathrm{Cu}$ at the surface and in the Al$\mathrm{Si}$ eutectic regions. Although the non-uniform $\mathrm{Cu}$ distribution in the re-solidified clad material is still distinguishable, but the concentration difference seems to be less intensive.

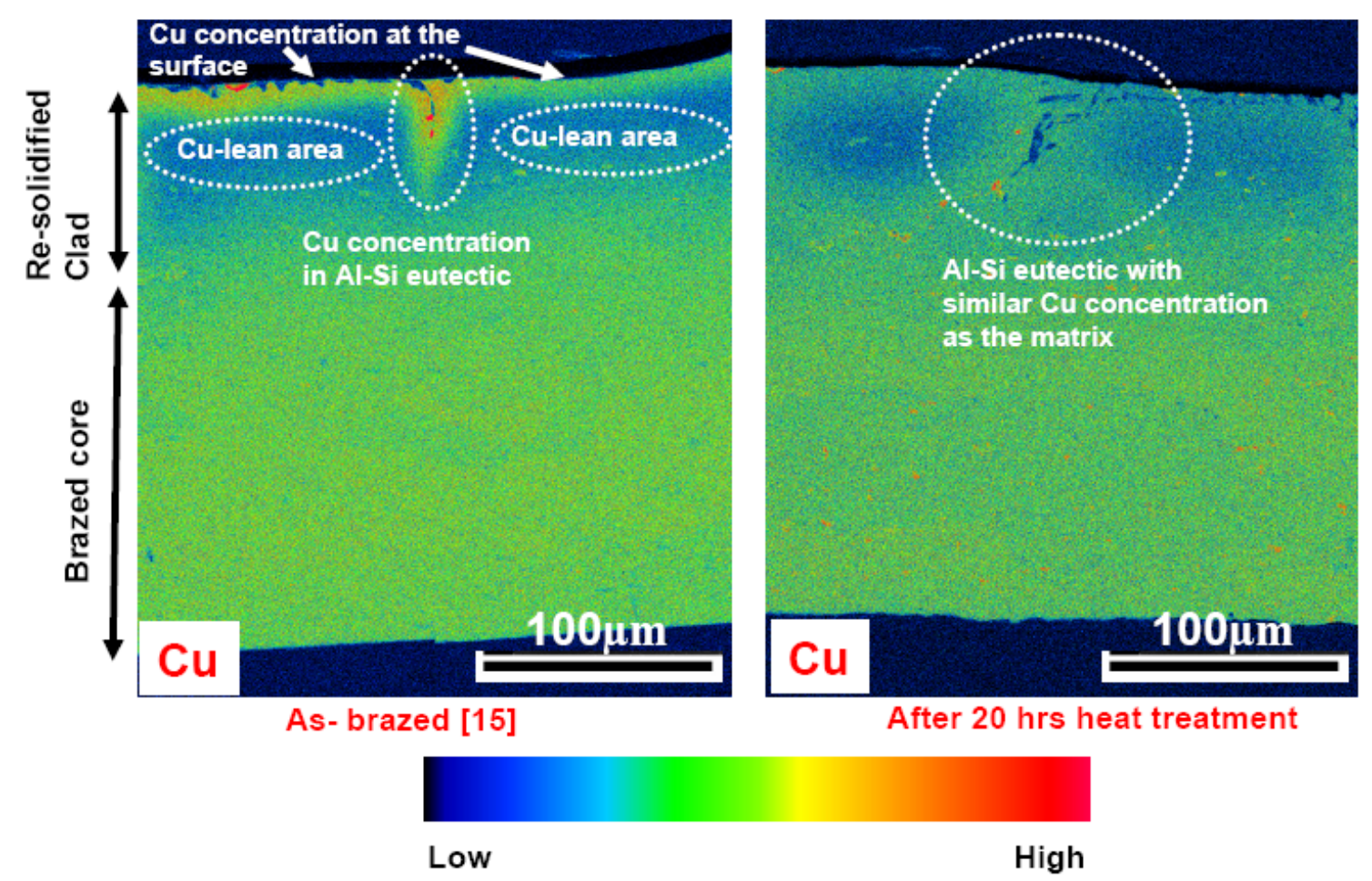

Figure 7.7 EPMA analysis maps of $\mathrm{Cu}$ in the as-brazed and post-braze heat treated AA4 $x x x / A A 3 x x x$ aluminium material. 
Comparing the FE-EPMA analysis maps of Si for the as-brazed and post-braze heat treated samples in Figure 7.8 confirms heavy precipitation of the Si particles in the HAZ and diffusion zone (DZ) has occurred as a result of the post-braze heat treatment.

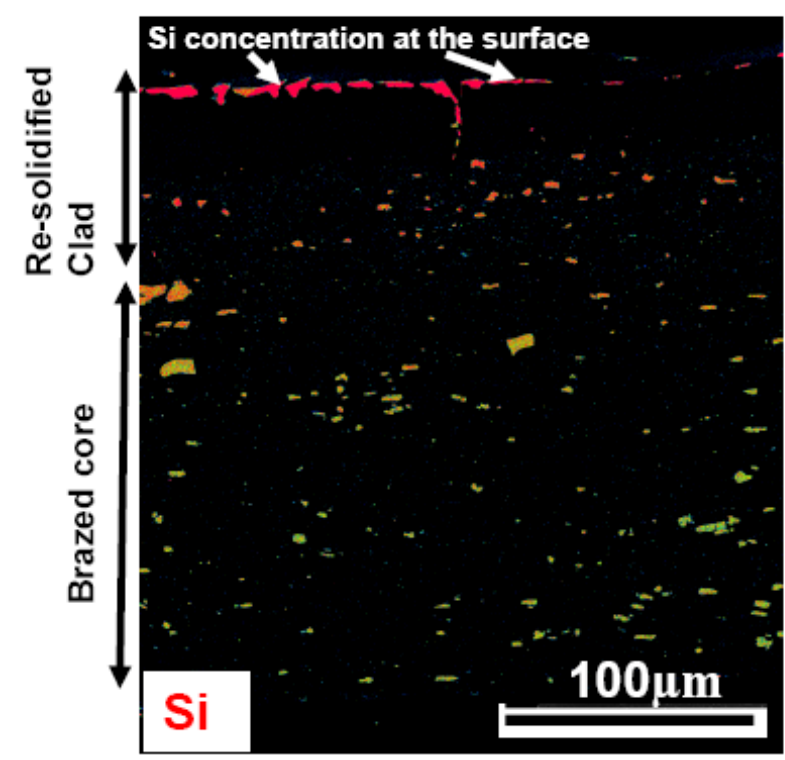

As- brazed [15]

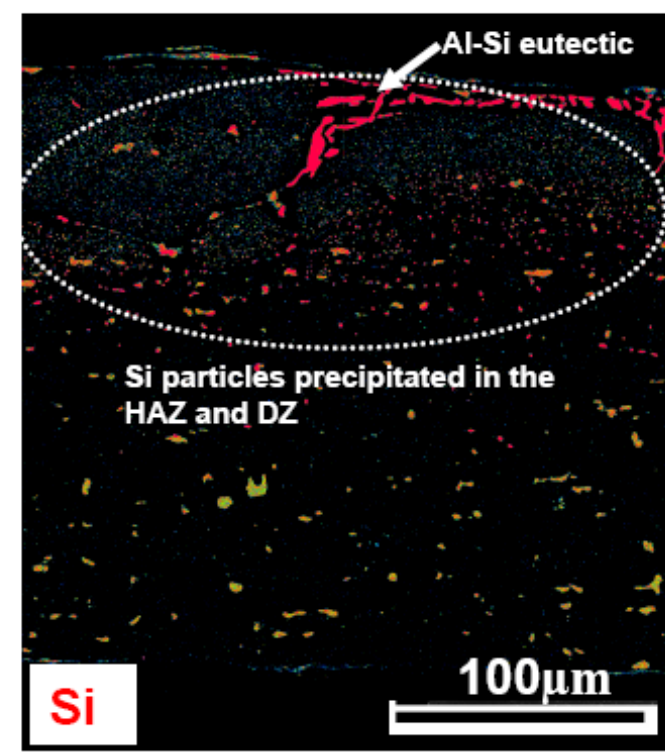

After 20 hrs heat treatment

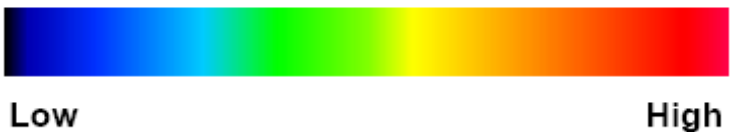

Figure 7.8. EPMA analysis maps of $\mathrm{Si}$ in the as-brazed and post-braze heat treated AA4xxx/AA3xxx aluminium material.

\subsection{TEM analysis}

The results from TEM investigation are presented in Figures 7.9-7.11. Typical TEM micrographs of the core and clad regions in the as-brazed (a and c) and postbraze heat treated ( $b$ and d) samples are presented in Figure 7.9. For the as-brazed material (Figure 7.9a and c) a strong mosaic structure is present in both the clad and the core materials. This structure is the result of the presence of dislocation walls forming sub grains of typically $300 \mathrm{~nm}$ diameter. Si and $\alpha$-Al(Fe-Mn)Si particles near high-angle grain boundaries (GB) can also be detected in the asbrazed clad material, see Figure 7.9a for an example (GB not in the image). The mosaic structure of the as-brazed core material makes the distinction of the intermetallic particles difficult. The TEM micrographs of the post-braze heat treated structures do not show any mosaic structure (Figure $7.9 \mathrm{~b}$ and $\mathrm{d}$ ), as a result of the annealing. 


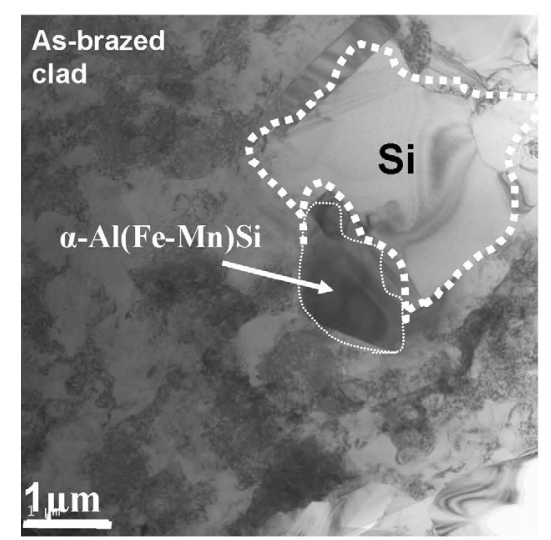

(a)

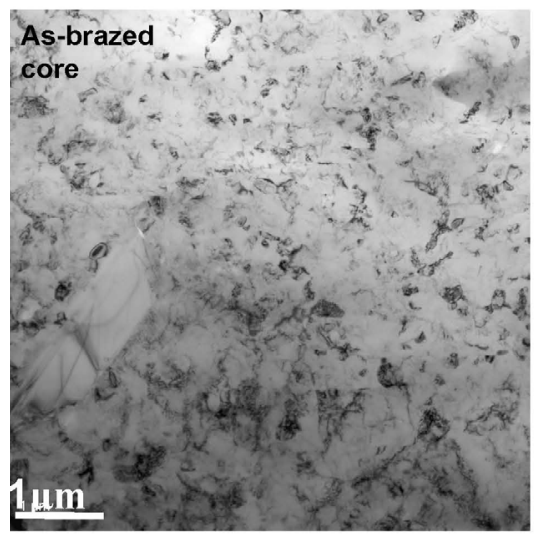

(c)

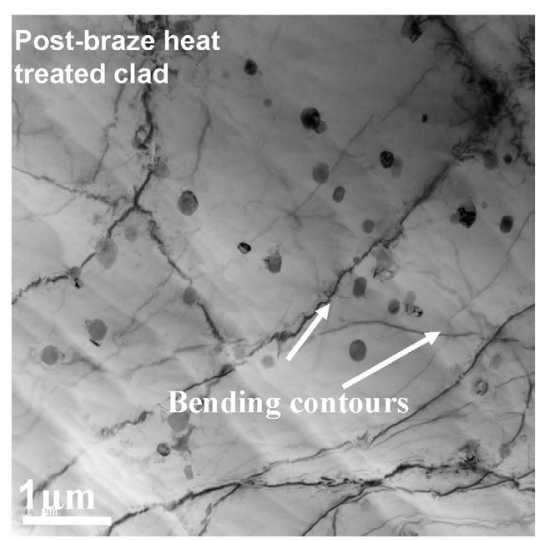

(b)

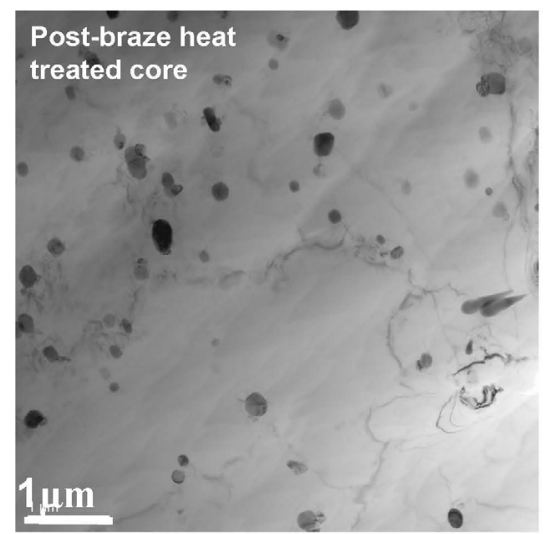

(d)

Figure 7.9. BF-TEM micrographs taken from the core and clad regions in the asbrazed ( $a$ and $c$ ) and post-braze heat treated (b and d) conditions

However, dislocations can still be detected in the post-brazed heat treated samples (lower grain in Figure 7.10). The post-braze heat treated samples from the clad material show regions with more $100-300 \mathrm{~nm}$ particles, compared to the as-brazed clad material. These are $\mathrm{Si}$ and $\mathrm{Si}$ containing $(\alpha-\mathrm{Al}(\mathrm{Mn}, \mathrm{Fe}) \mathrm{Si})$ particles. Examples of the GB investigation in the clad and the core structures of the post-braze heat treated samples are presented in Figures 7.10 and 7.11 respectively. A high angle GB between the two grains is demonstrated in Figure 7.10. The orientation difference between the grains has caused a strong contrast in the micrograph. In the upper grain the dislocations are out of contrast. Two line scan elemental analysis measurements across the GB were carried out. The result and the position of one of the analysis are presented in Figure 7.10. About 4 measurements near the centre of the $\mathrm{Cu}$ line scan are located on the GB (note that the GB is inclined with respect to the viewing direction and had a projected width of $\sim 40 \mathrm{~nm}$ ). No $\mathrm{Cu}$ segregation was found at the GB. Investigation of GBs in the core structure of a post-braze heat treated sample is presented in Figure 7.11. The presence of the $\mathrm{Si}$ (Figure 7.11a) and $\alpha-\mathrm{Al}(\mathrm{Fe}-\mathrm{Mn}) \mathrm{Si}$ (Figure 7.11c) particles in the grain boundaries 
after the post-braze heat treatment can be confirmed. Several line scans analysis (one shown in Figure 7.11d) do not show any $\mathrm{Cu}$ segregation in the GBs of the post-braze heat treated core material.

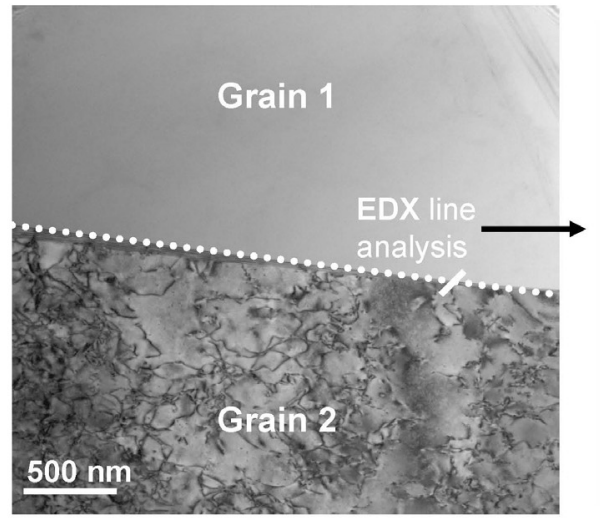

(a)

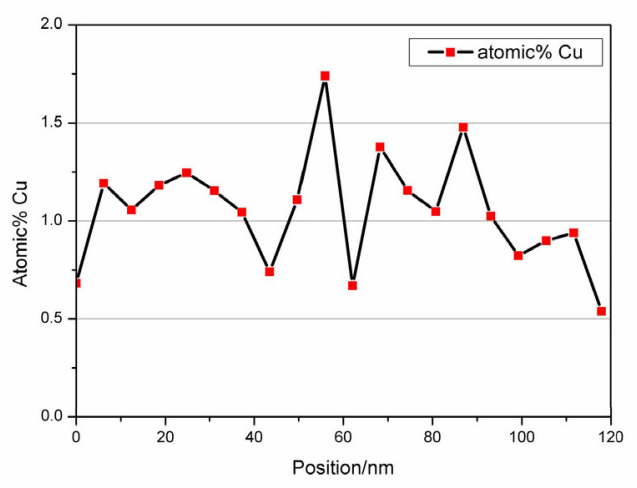

(b)

Figure 7.10. TEM micrograph (a) and the result from EDX line-scan analysis (b) of a grain boundary in the structure of the post-braze heat treated clad material.

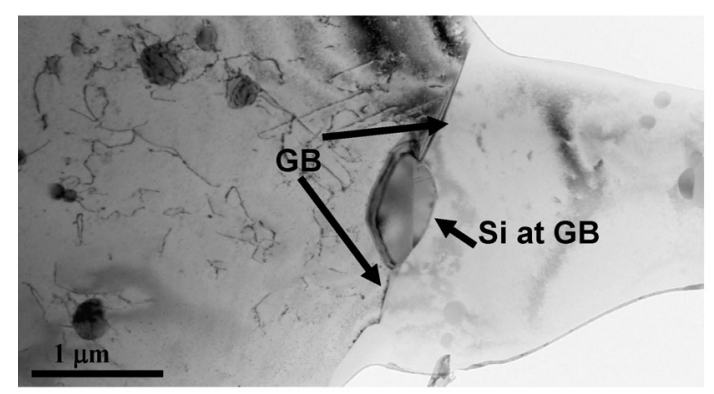

(a)

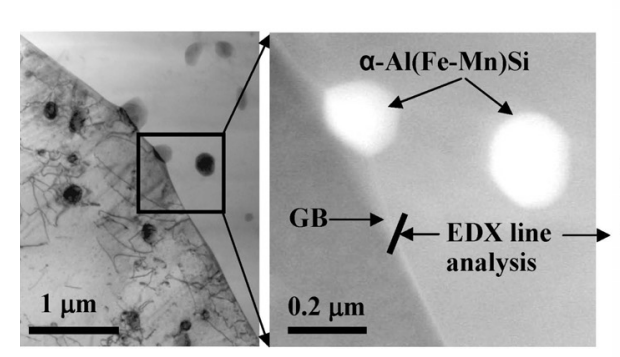

(b) (c)

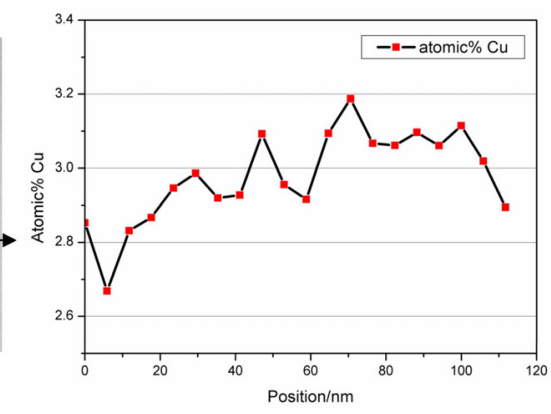

(d)

Figure 7.11. TEM bright field (a and b) micrographs. The HAADF (c) micrograph contains some diffraction contrast leading to different intensities of the two grains.

The heavier precipitates show up bright. The result from an EDX line-scan analysis of the $\mathrm{Cu} \mathrm{K}$-line across a grain boundary in the post-braze heat treated core material is shown in (d). Note the $\mathrm{Cu}$ atomic \% should be taken as relative within the profile: Some $\mathrm{Cu} \mathrm{X}$-rays are also generated from $\mathrm{Cu}$ containing parts in the specimen support grid. 


\subsubsection{Electrochemical characterization}

\subsection{OCP and PD measurements}

The OCP values after a stabilization time of 900 s for post-braze heat treated clad and the core material are presented in Figure 7.12. Figure 7.12 shows a $15 \mathrm{mV}$ potential difference between the clad and the core material after the heat treatment.

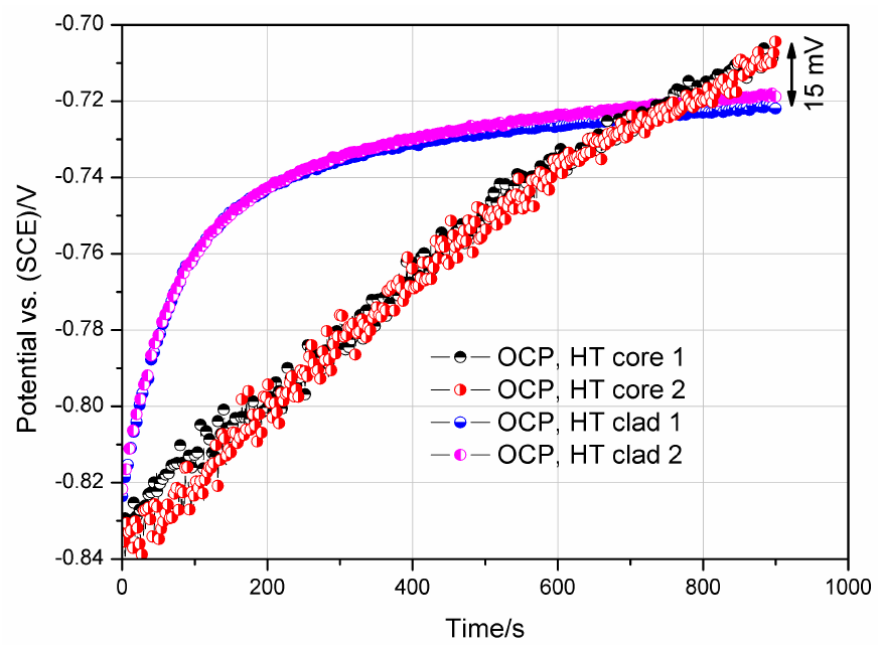

Figure 7.12. Open-circuit corrosion potentials of a post-braze heat treated clad and core materials after $15 \mathrm{~min}$ of immersion in $42 \mathrm{~g} / \mathrm{l} \mathrm{NaCl}$ solution at $\mathrm{pH} 2.8$, before anodic and cathodic polarizations.

The anodic and cathodic responses of both as-brazed and post-braze heat treated clad materials are presented in Figure 7.13a and b.

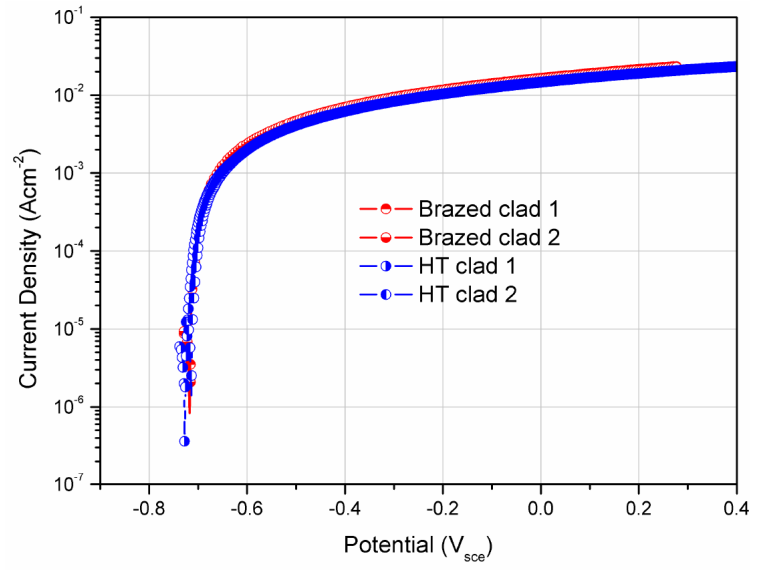

(a)

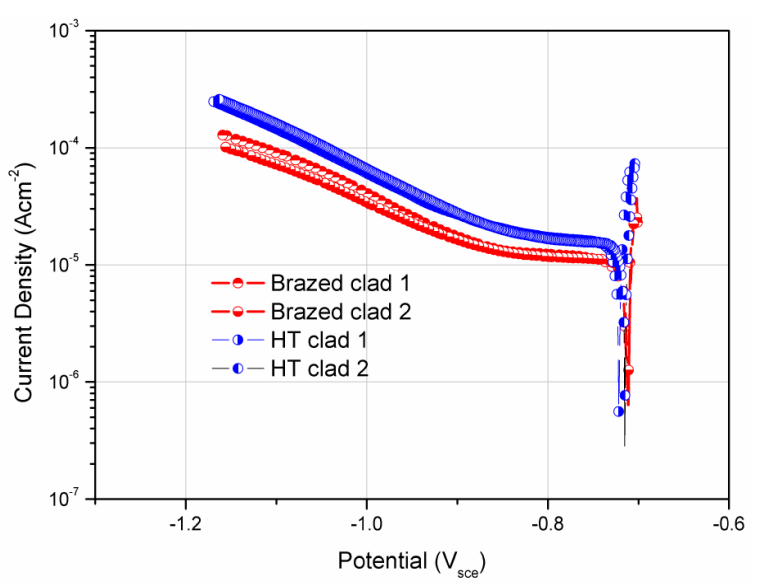

(b)

Figure 7.13. Anodic (a) and cathodic (b) polarization curves before (as-brazed) and after post-braze heat treatment after $15 \mathrm{~min}$ of OCP measurement in $42 \mathrm{~g} / \mathrm{l} \mathrm{NaCl}$ solution at $\mathrm{pH} 2.8$ (scan rate $0.5 \mathrm{mV} / \mathrm{s}$ ). 
Figure 7.13a shows that the anodic responses of the brazed and heat treated clad materials are quite similar. A sharp increase of the current density at potentials close to OCP valuses is observed. The cathodic polarization responses of the heat treated clad material shows a higher reactivity comparing to that of the as-brazed material.

\subsection{AFM and SKPFM analysis}

The VPD maps, topographical maps and the position of the line scan section analysis on the polished surfaces of the material in the as-brazed and post-braze heat treated conditions are presented in Figures 7.14.

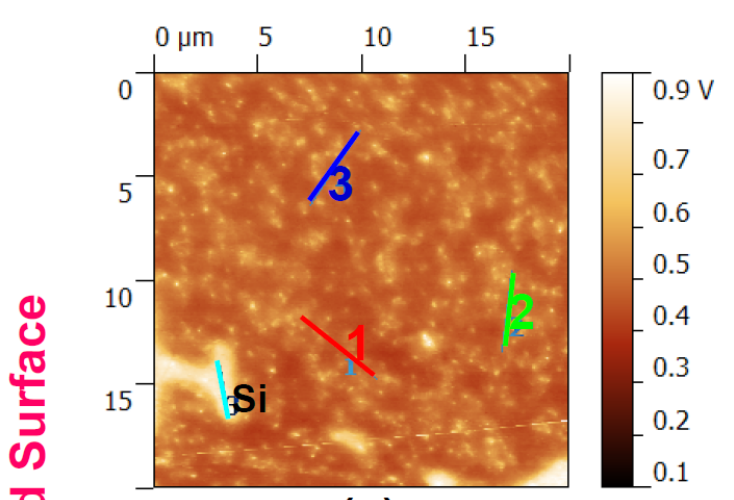

(a)

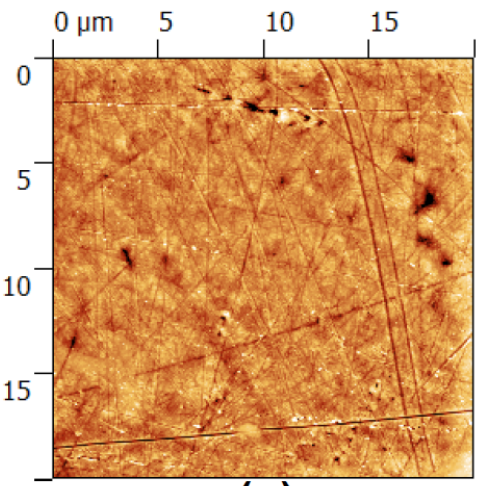

(c)

$-25.0$

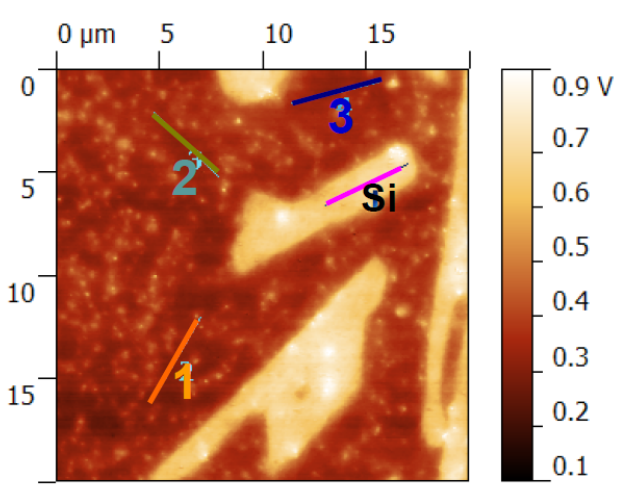

(b)

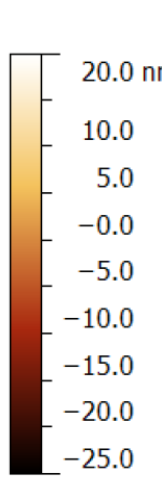

Figure 7.14. Volta potential maps with indication of line scan section analysis positions ( $a$ and $b$ ) and topographical map ( $c$ and d), obtained from AFM/SKPFM analysis of the polished surfaces before (as-brazed) and after post-braze heat treatment.

In order to avoid any artificial changes of the measured Volta potential differences, no data post-treatment has been applied on the presented Volta potential results. The Si particles/needles are shown with bright contrast in the VPD maps. Topographical images (Figures $7.14 \mathrm{c}$ and $\mathrm{d}$ ) shows a very smooth (nm roughness) preparation of the surfaces under investigation. This makes the Volta potential measurement more reliable and eliminates the possible height difference errors [14]. Comparison of the VPD differences between the Si particles and the matrix 
for the as-brazed and post-braze heat treated materials was performed, applying section analysis. The positions of the sectioning profiles are indicated in Figures 7.14a and $b$. Three line profiles per each sample were investigated. The VPD profile through the Si needles is considered as the reference in each VPD map. This will be the bases of comparison for the changes in VPD differences which have occurred as a result of post-braze heat treatment. The detail of this analysis approach has already been discussed in a prior publication of the author [14] (chapter 5). Comparison of the measured VPD values, while considering the statistical details of the available data is presented in Figure 7.15.

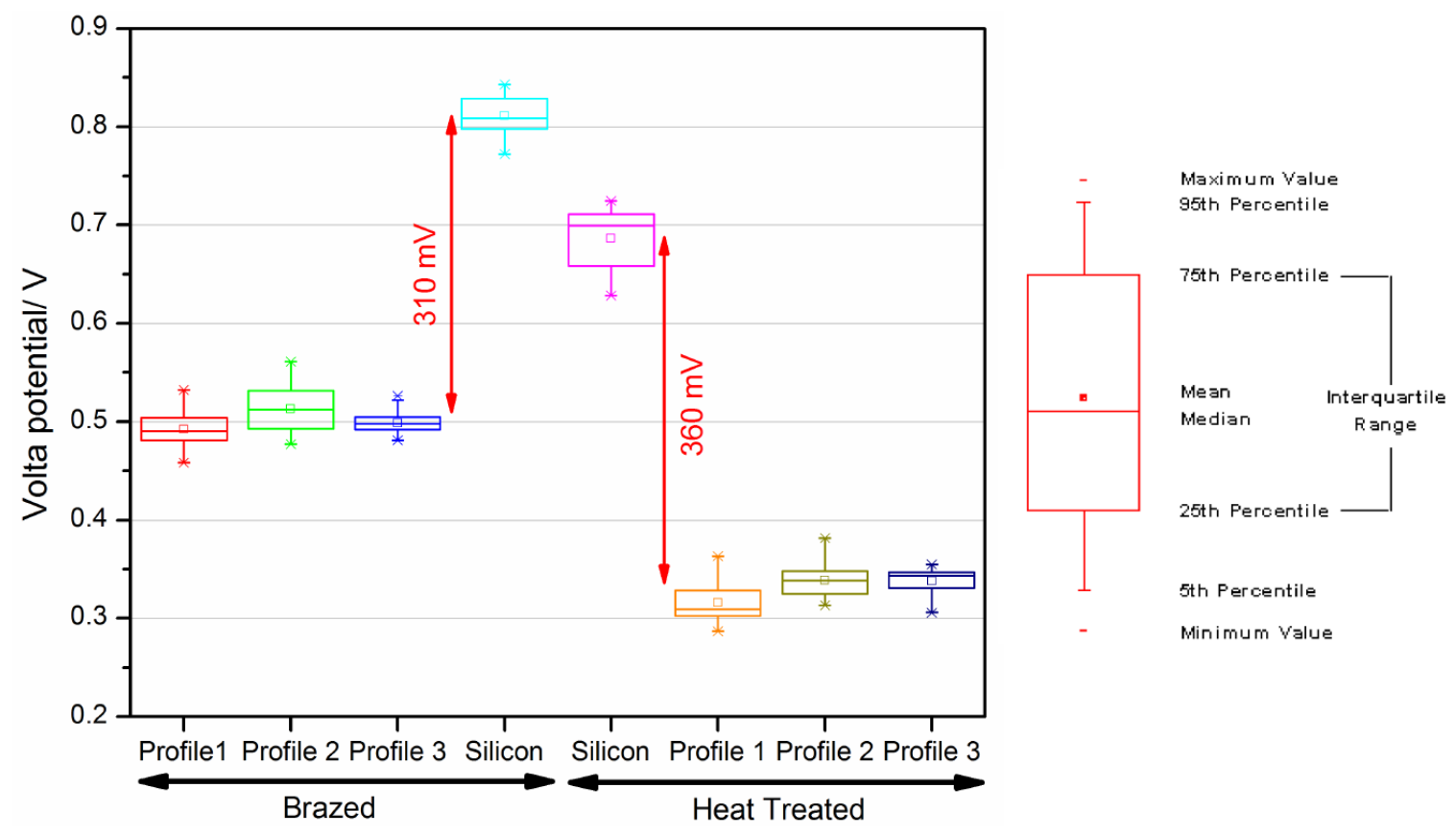

Fig 7.15. Box chart presentation of the Volta potential profiles from section analysis of the matrices in as-brazed and post-braze heat treated conditions.

The VPD values in both as-brazed and post-brazed heat treated samples are presented as box charts. Each profile of data is represented as a separate box. The profile names supplies the $X$ axis tick labels. The box is determined by the 25 th and 75 th percentiles. The whiskers are determined by the 5 th and 95 th percentiles. In statistics, a percentile is the value of a variable below which a certain percent of observations fall. For example, the 25 th percentile is the value below which 25 percent of the observations may be found. The maximum, minimum, mean and median values are also included in this representation. The data shows a clear decrease in the surface VPD values of the matrix of the heat treated clad material compared to that of the matrix of the as-brazed clad material. Comparison of the overall averages of the VPD values of the matrices before and after the post braze heat treatment shows a $50 \mathrm{mV}$ decrease (with reference to Si needles) in VPD difference of the post-braze heat treated surfaces as a result of the post braze heat 
treatment.

The topographical (a and b) and VPD (c and d) maps on the ion polished cross sections of the as-brazed and post-braze heat treated samples are presented in Figure 7.16. These measurements have been conducted in the heat affected zone (HAZ) in both as-brazed and post-braze heat treated materials. From the topographical images (Figure 7.16a and b) it can be noted that even after ultrasonic cleaning with ethanol some contamination is still left on the polished surfaces. These residuals are clearly visible with brighter contrast with respect to the matrix. The VPD maps in Figure 7.16 show a higher particle density with nobler VPD values in the post-braze heat treated material compared with the VPD map of the as-brazed sample.

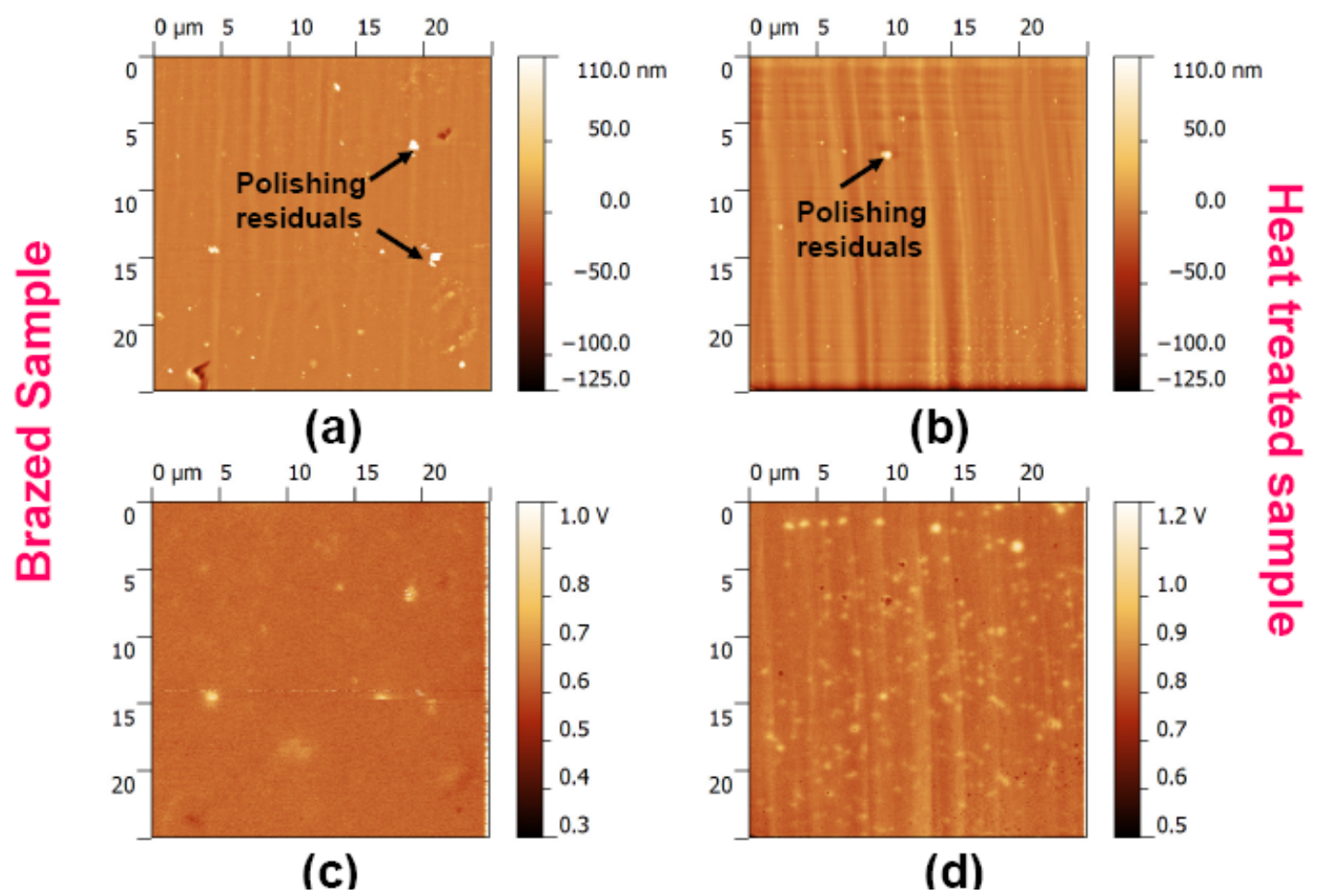

Figure 7.16. Topographical maps (a and b) and Volta potential maps (c and d) obtained from AFM/SKPFM analysis of the ion polished cross sections of the asbrazed and post-braze heat treated aluminium brazing sheet material.

\subsection{Corrosion morphology}

Optical micrographs of the cross sections of the brazed and post-braze heat treated materials after anodic polarization up to $1 \mathrm{~V}$ above the OCP values are shown in Figure $7.17 \mathrm{a}$ and $\mathrm{b}$ respectively. Investigating the cross sections of the corroded samples in Figure 7.17a demonstrates that the clad material in the brazed samples does not provide a proper protection to the core material. The presence of deep dissolved clad and core material, partly and fully attacked pre-eutectic aluminium 
grains and continuation of corrosion attack in a localized form (IGC, pitting and local dissolution of the clad) towards the core material are observed. Comparing the corroded cross sections in Figure 7.17 shows that the post-braze heat treated material is attacked more uniformly and less severely than the as-brazed material.

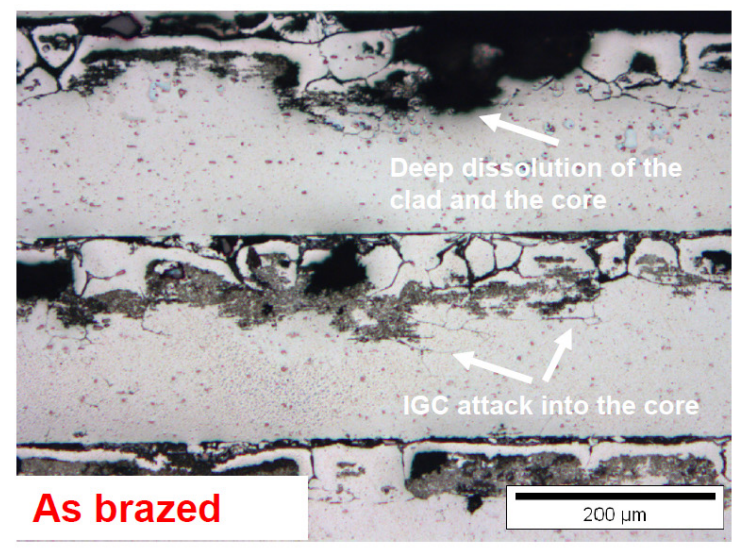

(a)

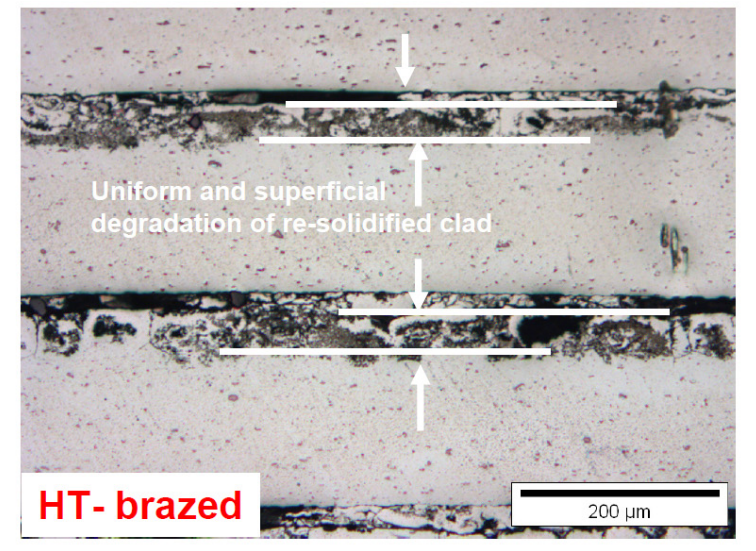

(b)

Figure 7.17. Cross sectional optical micrographs of the as-brazed and post-braze heat treated aluminium brazing sheet samples after anodic polarization up to $1 \mathrm{~V}$ above the OCP values in a $42 \mathrm{~g} / 1 \mathrm{NaCl}$ solution at $\mathrm{pH} 2.8$.

Optical micrographs from the cross sectional analysis of the as-brazed and postbraze heat treated samples after 30 days of simulated SWAAT are presented in Figure 7.18. Figure 7.18 clearly shows the enhancement of the corrosion resistance of the heat treated material. After 30 days of SWAAT exposure, the as-brazed material is disintegrated, while for the heat treated material only the uniform dissolution of the re-solidified clad can be observed.

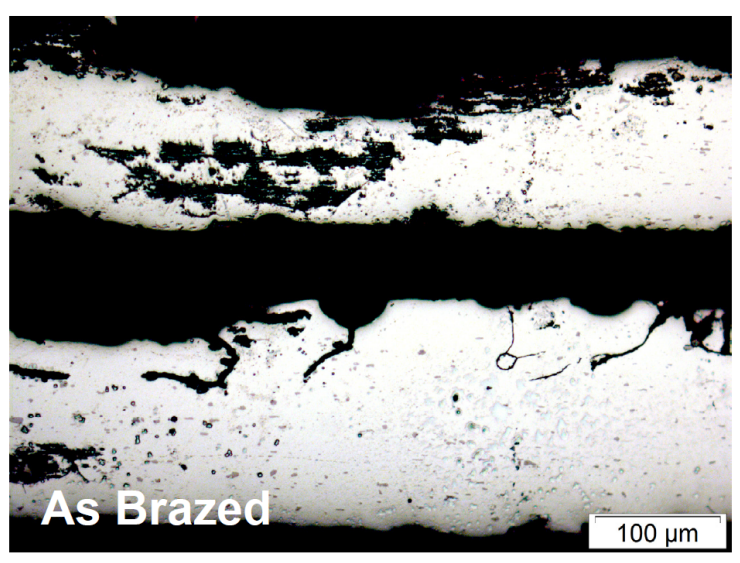

(a)

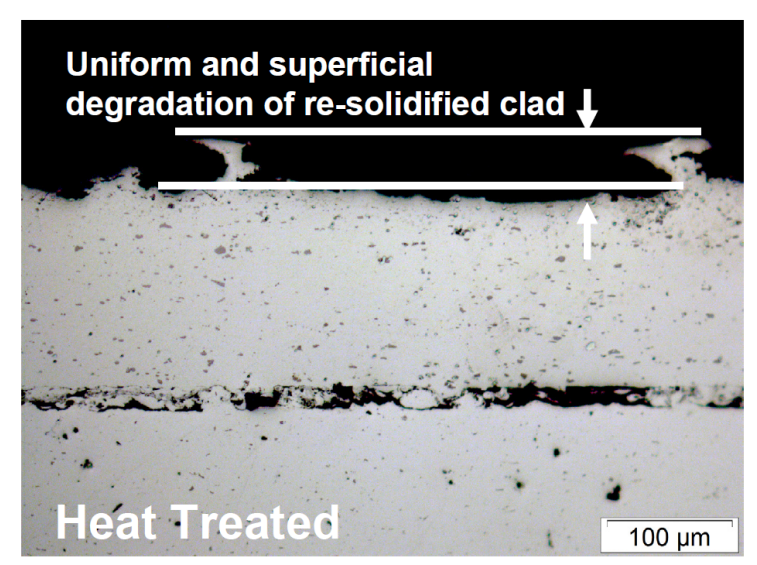

(b)

Figure 7.18- Optical micrographs of the as-brazed and post-braze heat treated aluminium brazing sheet samples after 30 days exposure to SWAAT solution. 


\subsection{Discussion}

\subsubsection{Determination of post braze heat treatment parameters}

\subsubsection{Temperature}

Determination of the appropriate temperature range is based on the elimination of the detrimental microstructural features that result in a poor corrosion resistance of the brazed structure. Based on the previous investigations [1, 10, 13-15], the major detrimental consequences of the brazing are: an increase in the $\mathrm{Si}$ and $\mathrm{Cu}$ content of the matrix in the HAZ; non-uniform distribution of $\mathrm{Cu}$ in the HAZ; precipitation of intermetallic particles $\left(\mathrm{Al}_{2} \mathrm{Cu}, \alpha-\mathrm{Al}(\mathrm{Fe}-\mathrm{Mn}) \mathrm{Si}\right.$ and $\left.\mathrm{Si}\right)$ at the grain boundaries; accumulation of $\mathrm{Cu}$ at the surface and in Al-Si eutectics; and non-uniform precipitation of intermetallics at Al-Si eutectic phases. These microstructural features were found to increase the VPD of the re-solidified clad matrix, introduce localized corrosion attack susceptibility on the brazed core and clad structures and reduce the cathodic protection power of the re-solidified clad material towards the core material $[14,15]$.

The thermodynamic calculations (Figure 7.2) indicate that by keeping the material at temperatures below $570{ }^{\circ} \mathrm{C}$, the equilibrium amount of $\mathrm{Si}$ particles in the structure will increase. Considering the saturated state of $\mathrm{Si}$ in solid solution [15], this treatment provides an option for reducing the Si content of the re-solidified clad material. This will result in a reduction of the corrosion potential of the resolidified clad material and the diffusion zone and therefore makes the outer layers of the post-braze heat treated structure more sacrificial towards the core material.

Another possibility for further improving the corrosion resistance of the brazed structure is by eliminating the $\mathrm{Al}_{2} \mathrm{Cu}$ precipitates. These are intermetallic particles with a high cathodic reactivity and have been observed to precipitate in grain boundaries [15]. Keeping the material at temperatures above $330{ }^{\circ} \mathrm{C}$ will result in dissolution of $\mathrm{Al}_{2} \mathrm{Cu}$ particles. This is expected to improve the localized corrosion susceptibility (IGC and pitting) of the both core and the clad material in the brazed structure. Heat treatment of the material in a temperature between $330{ }^{\circ} \mathrm{C}$ and 570 ${ }^{\circ} \mathrm{C}$ will also increase the density of $\alpha-\mathrm{Al}(\mathrm{Fe}-\mathrm{Mn}) \mathrm{Si}$ precipitates in the HAZ and diffusion zone ( regions of relatively high Si content). This will also lead to a matrix with a lower concentration of noble alloying elements ( $\mathrm{Si}$ and $\mathrm{Mn}$ ) and therefore, a further decrease of the corrosion potential of the HAZ and diffusion zone. This makes them more sacrificial (protective) towards the core material. The other important advantage of such a treatment which results in heavy precipitation of $\mathrm{Si}$ and $\alpha-\mathrm{Al}(\mathrm{Fe}-\mathrm{Mn}) \mathrm{Si}$ particles, is that it introduces many cathodic sites which are distributed throughout the HAZ and diffusion zone. This will result in profusion of local micro-galvanic cells overriding any effects between the normal grain boundary segregation or precipitation and the adjacent relatively precipitate 
free zones that exist after the brazing treatment [4]. This feature will in turn eliminate the localized corrosion susceptibility (pitting and IGC) of the brazed structure. The effect extends through the thickness of the post-braze heat treated material in the HAZ and diffusion zone areas. The treatment is also expected to provide the necessary time and energy for a more uniform distribution of $\mathrm{Cu}$ to be obtained in the re-solidified clad material.

Further thermodynamic calculations (Figure 7.3) showed that the chemical composition of the $\alpha-\mathrm{Al}(\mathrm{Fe}-\mathrm{Mn}) \mathrm{Si}$ particles are also temperature dependent. Although keeping the structure at $218{ }^{\circ} \mathrm{C}$ is expected to further decrease the $\mathrm{Si}$ content of the matrix (by increasing the Si content of the alpha particles) this temperature is below the dissolution temperature of the $\mathrm{Al}_{2} \mathrm{Cu}$ particles $\left(330{ }^{\circ} \mathrm{C}\right)$ and therefore not beneficial. However keeping the structure at $336{ }^{\circ} \mathrm{C}$ will increase the $\mathrm{Cu}$ content of the $\alpha-\mathrm{Al}(\mathrm{Fe}-\mathrm{Mn}) \mathrm{Si}$ particles to its maximum level. It has already been discussed that the $\alpha-\mathrm{Al}(\mathrm{Fe}-\mathrm{Mn}) \mathrm{Si}$ particles have the ability to accommodate a portion of the overall $\mathrm{Cu}$ content and that they heavily precipitate at the topmost surface of the brazed structure $[1,10,13]$. This is expected to help for further reduction of the $\mathrm{Cu}$ content accumulated at the outer surface of the brazed structure and therefore a more sacrificial behaviour of the topmost layer towards the core structure. So therefore $336{ }^{\circ} \mathrm{C}$ was chosen as the most appropriate treatment temperature.

\subsubsection{Time}

Keeping the brazed material at $336^{\circ} \mathrm{C}$ for 5,10 and $20 \mathrm{hrs}$, increases the VPD difference between $\mathrm{Si}$ and the clad matrix. This is expected to be the result of precipitation of $\mathrm{Si}$ and to a lesser extent $\alpha-\mathrm{Al}(\mathrm{Fe}-\mathrm{Mn}) \mathrm{Si}$ particles. This in return decreases the nobility of the matrix (reduces the VPD of the clad matrix) and makes it more protective toward the core material [14]. The $60 \mathrm{mV}$ potential reduction which was achieved after $20 \mathrm{hrs}$ of post-braze heat treatment (Figure 7.5) is expected to provide the maximum possible sacrificial protection that can be supported by the re-solidified clad material. This corresponds to the same protection condition before the brazing treatment (see non-brazed condition in Figure 7.5). Therefore $20 \mathrm{hrs}$ of heat treatment was selected to be the appropriate time for the current investigation. It should be noted that shorter treatment time (i.e. $10 \mathrm{hrs}$ ) could also provide the necessary protection. However in order to study the microstructural features and their electrochemical effects that develop as a result of the post-braze heat treatment in detail, the $20 \mathrm{hrs}$ treatment time was selected for microstructural and electrochemical characterization purposes.

\subsubsection{Characterization of the post-braze heat treated samples}

\subsubsection{Microstructural characterization}




\subsection{X-ray micro analysis}

Comparing the results of X-ray micro-analysis mapping for the $\mathrm{Si}$ and $\mathrm{Cu}$ before and after post-braze heat treatment demonstrates the positive effects of the applied post-braze heat treatment. A more uniform distribution of the $\mathrm{Cu}$ in the resolidified clad material, elimination of $\mathrm{Cu}$ rich eutectics/GBs and higher density of $\mathrm{Si}$ and Si containing particles are expected to provide a better corrosion protection and elimination of the localized corrosion susceptibility of the brazed structure.

\subsection{EPMA analysis}

The results of the FE-EPMA analysis for the $\mathrm{Cu}$ and $\mathrm{Si}$ contents and distributions, further confirm the predictions made over the effects of the post-braze heat treatment. Comparison of the $\mathrm{Cu}$ maps in the structures of the as-braze and postbraze heat treated samples clearly shows the elimination of the $\mathrm{Cu}$ concentration at the surface. The intensity of the $\mathrm{Cu}$ concentration difference between the Al-Si eutectic phases and the pre-eutectic aluminium grains is also reduced. This shows that the treatment has provided enough time and energy for the $\mathrm{Cu}$ atoms to diffuse and reach more uniform distribution in the re-solidified clad material. The FEEPMA analysis maps of the $\mathrm{Si}$ for the as-braze and post-braze heat treated samples, clearly demonstrates the increase of Si and Si containing particles $(\alpha-$ $\mathrm{Al}(\mathrm{Fe}-\mathrm{Mn}) \mathrm{Si}$ particles) in the HAZ and diffusion zone. Considering the ennobling effect of $\mathrm{Si}$ on the corrosion potential of the aluminium matrix [2], this phenomenon is expected to decrease the OCP values measured on the re-solidified clad material.

\subsection{TEM analysis}

The decrease of dislocation density and the absence of, the mosaic structure in the post-braze heat treated material (core and clad), compared to the as-brazed material, could also be interpreted as a thermodynamically more stable system. This is expected to result in a better corrosion resistivity of this structure. This can also be considered as another advantage of the treatment process which could not be revealed based on the previous characterisation techniques. The presence of higher particle density in the structure of the post-braze heat treated clad material (Figure 7.9b) further confirms the previous characterisation work.

No $\mathrm{Cu}$ segregation in the GBs of the clad and the core materials after post-braze heat treatment could be found. This is expected to be one of the main reasons for improvement of localized corrosion susceptibility of the post-braze heat treated core and clad structures.

The presence of Si particles in GBs of the post-braze heat treated samples is expected to result in selective dissolution of material adjacent to grain boundaries 
(IGC attack) which contained a lower concentration of $\mathrm{Si}$ in solid solution. However, IGC attack was not observed in these structures. This is because the treatment would remove the formation of Si depleted zones by stimulating further $\mathrm{Si}$ and $\alpha-\mathrm{Al}(\mathrm{Fe}-\mathrm{Mn}) \mathrm{Si}$ precipitation in and around the grain boundaries. This further supports the idea that the increase in the local micro-galvanic cells (more distributed cathodic sites) dominates the effects between the normal GB segregation or precipitation and the adjacent precipitate free zone.

\subsubsection{Electrochemical characterization}

\subsection{OCP and PD polarization}

The results of OCP analysis (Figure 7.12) does not show any significant change in potential difference between the clad and the core, compared with the potential difference of the clad and the core in the as-brazed structure which already has been reported to be also $15 \mathrm{mV}$ [14]. The OCP profile of the post-braze heat treated clad material stabilizes at around $-720 \mathrm{mV}$ while for the as-braze clad material the reported value is around $-710 \mathrm{mV}$ [14]. This shows that the post-braze heat treatment has caused $10 \mathrm{mV}$ decrease in the corrosion potential of the clad material. As these measurements are an average representative of the electrochemical behaviour of the phases present at the surface under investigation, they can not reveal the detailed changes that have occurred as a result of post-braze heat treatment. Therefore a more sensitive measurement with a higher resolution was carried out by using AFM/SKPFM analysis.

The anodic polarization responses (Figure 7.13a) are representative of a localized degradation (IGC or Pitting) of the material under investigation. Although the increase of the current density with increasing of potential above $-600 \mathrm{mV}$ is small, however, high values of current density $\left(10^{-3}<\mathrm{i}<10^{-1} \mathrm{Acm}^{-2}\right)$ have been reached. The similarity of the anodic polarization responses for the as-brazed and postbraze heat treated clad materials shows that a similar rate of corrosion in the SWAAT environment can be expected, although the attack mechanism could be different [1]. The presence of a sharp increase in the corrosion current density at potentials close to the OCP values in these anodic potentiodynamic responses shows the susceptibility of both materials to localized corrosion attack at least at the topmost surfaces. The higher cathodic reactivity of the post-braze heat treated clad material is expected to be the result of a higher density of cathodic precipitates ( $\mathrm{Si}$ and $\alpha-\mathrm{Al}(\mathrm{Fe}-\mathrm{Mn}) \mathrm{Si}$ ) which can sustain higher rates of cathodic reactivities at the surface of the material.

\subsection{AFM/SKPFM analysis}

Investigation of the electrochemical responses of the surfaces of the as-brazed and post-braze heat treated materials show that silicon needles have VPD values which 
are nobler in comparison with the surrounding aluminium matrix. Based on the AlSi binary phase diagram and the EDX elemental maps of the material under investigation [1], Si can actually contain a very small amount of aluminium (max $0.015 \mathrm{wt} \%$ ) and other alloying elements in solid solution [14]. Therefore Si can be considered as a relatively pure stable phase with minimum compositional changes in the structure of the material both before and after brazing treatment. This provides the advantage of having a reliable local reference in both structures to compare the changes in Volta potential differences as the result of different thermal treatment of aluminium brazing sheet [14]. The difference between the averaged VPD values for Si particles in the structure of the as-brazed $(810 \mathrm{mV})$ and post-braze heat treated $(690 \mathrm{mV})$ material emphasizes the importance of applying a stable local reference for comparison of the measured VPD values on different samples [15]. It is important to articulate that the measured VPD values are not absolute but comparative values, measured relative to the Volta potential of the AFM tip [14]. The tips are only pseudo-references, since their Volta potential may vary from tip to tip due to slight difference in the oxide layer covering them or contaminants deposited on the tip during scanning and also instabilities in the instrument electronics $[18,19]$. This means that the measured VPD between the tip and the microstructural features at the surface may not necessarily be a meaningful value but just a basis of comparison of VPD differences within the same VPD map. In order to reduce the errors associated with variations in the tip and stability of the system, the Volta potential measurements are normally calibrated by comparison to the potential measured on a reference with stable Volta potential. Considering the current research, the emphasis of the research is on the VPD difference between the Si particles (as a stable local reference) and the matrix. Following this strategy and comparing the VPD differences between the matrix and $\mathrm{Si}$ particles in the structure of the brazed $(310 \mathrm{mV})$ and post-braze heat treated $(360 \mathrm{mV})$ materials, an average decrease of $50 \mathrm{mV}$ in the VPD of the matrixes (Figure 7.15) can be detected. This $50 \mathrm{mV}$ decrease in the VPD between the asbrazed and post-braze heat treated clad matrices as a consequence of the $20 \mathrm{hrs}$ at $336{ }^{\circ} \mathrm{C}$ heat treatment, is expected to be the result of precipitation of $\mathrm{Si}$ and $\alpha$ $\mathrm{Al}(\mathrm{Fe}-\mathrm{Mn}) \mathrm{Si}$ particles in the clad material. This Volta potential decrease coresponds with the $10 \mathrm{mV}$ change in the OCP profile of the post-braze heat treated clad surface [14]. This change is expected to improve the cathodic protection power of the re-solidified clad material towards the core. The clad material is expected to sacrificially protect the core structure and prevent any possible contact between the deeper layers of the material which have already been shown to have an active pitting potential [13]. So therefore, the decrease of the OCP profiles is considered to be a constructive effect. This effect is not reflected in the OCP profile difference between the clad and the core materials after the post-braze heat treatment. This emphasizes the importance of a micro-level electrochemical investigation with the capability to distinguish the differences between detailed reactivities of existing structural features. It should be noted that a decrease in VPD of the clad matrix can also be interpreted as increase of the 
VPD difference between the Si particles and the clad matrix which in turn should increase the galvanic interaction between these cathodic sites and the clad matrix [14]. This may result in more localized corrosion attack and consequently, the demise of the corrosion resistance of the structure. Referring to previously published literature $[1,13-15]$ and the corrosion morphology investigation in the current work, this second interpretation is not valid. This can be explained by the fact that although Si particles have a nobler corrosion potential with respect to the aluminium matrix, the oxygen reduction current density on silicon is too low to anodically polarise aluminium $[1-2,13-15,20]$. Therefore $\mathrm{Si}$ particles are not effective cathodic sites and they have a weak galvanic interaction with the matrix.

Comparison of the cross-sectional VPD maps in the HAZ areas between the asbrazed and post-braze heat treated materials shows that the post-braze heat treatment has caused further precipitation of the particles which are nobler than the aluminium matrix. This further confirms the FE-EPMA and TEM microstructural characterization results.

\subsection{Corrosion morphology}

Pitting, localized dissolution of the material and intergranular corrosion (IGC) are the corrosion attack mechanisms for the as-brazed material. For the post-braze heat treated material a relatively uniform corrosion of the clad material is the dominant mechanism of the attack. Comparing the cross-sections of the corroded samples in Figure7.17 demonstrates that the brazed material has a high sensitivity to IGC and the attack has developed deep into the structure of the core material. For the post braze heat treated material a uniform attack has been restricted to the re-solidified clad layer.

It is generally accepted that SWAAT test provides similar corrosion attack and morphology within a few days that is representative of several years of service life [3]. Comparing the cross-sections of the as-brazed and post-braze heat treated material after SWAAT exposure shows that the post-braze heat treatment has improved the sacrificial protection of the core material by the re-solidified clad material. It is also important to note that the susceptibility of the core material toward localized corrosion has also been eliminated. This is attributed to the precipitation and new distribution of intermetallic particles ( $\mathrm{Si}$ and $\alpha-\mathrm{Al}(\mathrm{Fe}-\mathrm{Mn}) \mathrm{Si}$ ) and also re-distribution of the alloying elements $(\mathrm{Cu}$ and $\mathrm{Si})$ which will solve the problem of possible localized segregation [15].

\subsubsection{Green generation of cost effective and corrosion resistant aluminium brazing sheet}

The relatively high tolerance to increased $\mathrm{Si}$ and $\mathrm{Fe}$ alloying element concentrations in this post-braze heat treated structure will provide the opportunity 
for further use of recycled aluminium. Therefore this new material will be referred to as a green corrosion resistant aluminium brazing sheet. This new generation of aluminium brazing sheet will be able to tolerate a higher level of alloying elements that were considered to be detrimental. This reduces the need for purification during primary and recycling processing saving energy, material and labour costs.

\section{5. Conclusions}

An innovative technique for improving corrosion resistance of a modified AA4xxx/AA3xxx aluminium brazing sheet has been developed. Applying SKPFM and potentiodynamic polarization measurements combined with TEM, FE-EPMA, SEM, EDX analysis, the electrochemical nature of the overall microstructure and cross-sectional microstructural heterogeneities for the clad and the core of the structure in both as-brazed and post-braze heat treated conditions were investigated and compared. Si needles were used as a stable local reference to compare the changes in Volta potential differences (VPD). The result was interpreted and discussed with reference to the prior detailed microstructural and electrochemical characterization of the same material. The following results were obtained:

1. A green generation of cost effective and corrosion resistant aluminium brazing sheet was introduced.

2. It was shown that the corrosion resistance of a CAB brazed aluminium brazing sheet can be improved substantially by applying a post-braze heat treatment.

3. Using thermodynamic calculations and SKPFM analysis the post-braze heat treatment parameters (temperature and time) were estimated.

4. It was proved that the enhanced corrosion resistance is the result of formation of an efficient sacrificially protecting layer and elimination of the sensitivity of the brazed clad and core structures towards intergranular and pitting corrosion attacks.

5. The post-braze heat treatment decreases the VPD of the re-solidified clad matrix which in turn increases the cathodic protection power of the re-solidified clad material. The amount of decrease in VPD was determined to be $50 \mathrm{mV}$ on average compared to that of the as-brazed clad material. This is corresponds with the changes in OCP profiles.

6. The post-braze heat treatment was found to result in a more uniform distribution of $\mathrm{Cu}$ in the re-solidified clad structure, elimination of $\mathrm{Al}_{2} \mathrm{Cu}$ precipitates in the grain boundaries and an increase in the $\mathrm{Si}$ and $\alpha-\mathrm{Al}(\mathrm{Fe}-\mathrm{Mn}) \mathrm{Si}$ particle density in the heat affected zone (HAZ) and the diffusion zone. The resulting electrochemical consequences were discussed. 


\subsection{References}

[1]. F. Norouzi Afshar, J.H.W. de Wit, H. Terryn, J.M.C. Mol, The effect of brazing process on microstructure evolution and corrosion performance of a modified A4xxx/AA3xxx brazing sheet, Corrosion Science, 58 (2012) 242-250.

[2]. S. Meijers, Corrosion of aluminium brazing sheet, PhD Thesis, TU Delft, 2002, ISBN 90-805661-3-6.

[3]. F.N. Afshar, E. Szala, A. Wittebrood, R. Mulder, J.M.C. Mol, H. Terryn, J.H.W. de Wit, Influence of material related parameters in sea water acidified accelerated test, reliability analysis and electrochemical evaluation of the test for aluminum brazing sheet, Corrosion Science, 53 (2011) 3923.

[4]. W.D. Finnegan, R.A. Woods, Improvements in corrosion resistance by thermal treatment of heat exchangers, IMechE, 1995, C496/064.

[5]. G. Svenningsen, M.H. Larsen, J.H. Nordlien, K. Nisancioglu, Effect of high temperature heat treatment on intergranular corrosion of $\mathrm{AlMgSi}(\mathrm{Cu})$ model alloy, Corrosion Science, 48 (2006) 258-272.

[6]. G. Svenningsen, J.E. Lein , A. Bjørgum, J.H. Nordlien, Y. Yu, Kemal Nisancioglu, Effect of low copper content and heat treatment on intergranular corrosion of model AlMgSi alloys, Corrosion Science, 48 (2006) 226-242.

[7]. G. Svenningsen, M.H. Larsen, J.H. Nordlien, K. Nisancioglu, Effect of thermomechanical history on intergranular corrosion of extruded $\operatorname{AlMgSi}(\mathrm{Cu})$ model alloy, Corrosion Science, 48 (2006) 3969-3987.

[8]. S. Iwao, M. Asano, Influence of heat treatment on corrosion resistance of aluminum alloy brazing sheet, Journal of Japan Institute of Light Metals, 57 (2007) 589-594.

[9]. S. Iwao, M. Asano, Effect of additional $\mathrm{Cu}$ and $\mathrm{Mg}$ in Al-Mn-Si alloy on intergranular corrosion susceptibility after heating at $200^{\circ} \mathrm{C}$, Journal of Japan Institute of Light Metals, 59 (2009) 108-113.

[10]. F.N. Afshar, E. Szala, A. Wittebrood, C.J.G. Van Hoek, J. Van der Hoeven, A. Buerger, J.M.C. Mol, H. Terryn, J.H.W. de Wit, New approach in microstructural analysis of a modified AA4xxx/AA3xxx brazing sheet before and after brazing, Vehicle Thermal Management Systems proceedings (VTMS 10), Gaydon, UK, 2011.

[11]. A. Wittebrood, Microstructural changes in brazing sheet due to solid-liquid interaction, PhD thesis, TU Delft, 2009, ISBN: 978-90-805661-6-3.

[12]. D.J. Schmatz. Grain boundary penetration during brazing of aluminum, Welding Journal, 10 (1983) 267s.

[13]. F. Norouzi Afshar, R. Ambat, C. Kwakernaak, J.H.W. de Wit, J.M.C. Mol, H. Terryn, Electrochemical depth profiling of multilayer metallic structures: An aluminum brazing sheet, Electrochimica Acta, 77 (2012), 285.

[14]. F. Norouzi Afshar, J.H.W. de Wit, H. Terryn, J.M.C. Mol, Scanning Kelvin probe force microscopy as a means of predicting the electrochemical characteristics of the surface of a modified AA4xxx/AA3xxx brazing sheet, Electrochimica Acta, 88 (2013) 330-339.

[15]. F. Norouzi Afshar, A.M. Glenn, J.H.W. de Wit, H. Terryn, J.M.C. Mol, A combined electron probe micro analysis and scanning Kelvin probe force microscopy study of a modified AA4xxx/AA3xxx aluminium brazing sheet, Electrochimica Acta, 104 (2013) 48-63

[16]. J. Lacaze, S. Tierce, M.C. Lafont, Y. Thebault, N. Pebere, G. Mankowski, C. Blanc, 
H. Robidou, D. Vaumousse, D. Daloz, Study of the microstructure resulting from brazed aluminium materials used in heat exchangers, Material Science and Engineering A, 317 (2005) 413-414.

[17]. I.R. Harrowfield, C.M. MacRae and N.C. Wilson, "Chemical imaging in electron microprobes" Proceedings of the $27^{\text {th }}$ Annual MAS Meeting, Microbeam Analysis Society, New York, pp. 547-548, 1993.

[18]. V. Guillaumin, P. Schmutz, G.S. Frankel, Characterization of Corrosion Interfaces by the Scanning Kelvin Probe Force Microscopy Technique, Journal of the Electrochemical Society, 148 (5) (2001) B163.

[19]. M. Rohwerder, E. Hornung, M. Stratmann, Microscopic aspects of electrochemical delamination: An SKPFM study, Electrochimica Acta, 48 (2003) 1235.

[20] S. Kuroda, K. Tohma, Aluminium Alloys, Conference Proceedings of ICAA6, Japan Institute of Light Metals, Toyohashi, Japan, 1998, p. 1543. 


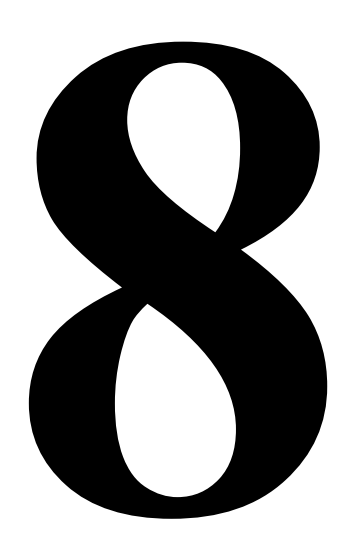





\section{Conclusions}

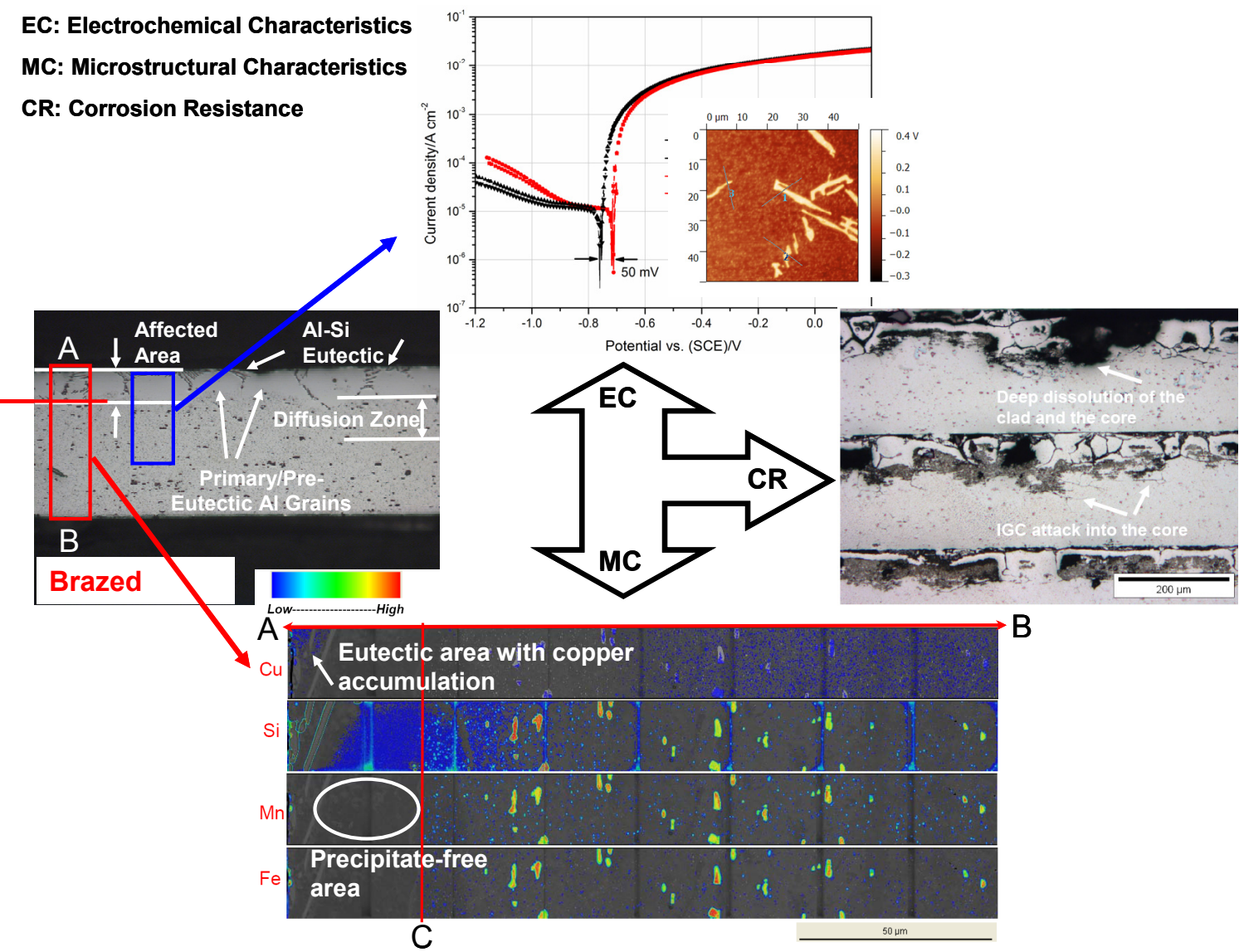

\subsection{SWAAT analysis}

This study elucidates how the variations of the SWAAT results are correlated to actual fundamental differences in the material conditions of the aluminium brazing sheet, i.e. temper and brazing condition. The possibility of the presence of some links between SWAAT and electrochemical characterization were also investigated. Corrosion mechanism and morphology of attack in SWAAT and potentiodynamic test were compared. The result confirmed that the SWAAT 
performance of the material can be reflected in potentiodynamic responses. Finally a new statistical reliability evaluation approach and a novel result interpretation method were developed. The results confirm that the SWAAT test may suffer from a scatter which was found to be material dependent.

There are two types of material related parameters that can potentially affect the SWAAT performance. Type 1 parameters such as processing route and material gauges are directly related to the initial material conditions and type 2 parameters such as brazing temperature and flux load are related to the secondary metallurgical changes which are applied to the material during product manufacturing. The SWAAT testing conditions and the type 2 material related parameters are easy to control. However the type 1 material related parameters are very difficult to control. Therefore there are still possibilities for scatter of the SWAAT results which are initiating from the primary production process condition. It was proven that in spite of the scatter, the test is still valid for product performance comparison purposes and can be applied in material development programs.

\subsection{Corrosion protection enhancement by microstructural control}

In this study the correlation between the microstructural features and the related electrochemical responses for a modified AA4xxx/AA3xxx aluminium brazing sheet was investigated. The research shows how the detail understanding over the interrelation between electrochemical responses and the microstructural features can provide a leverage for controlling the corrosion resistance of the aluminium brazing sheet. It also provides a deep understanding of the corrosion attack mechanism and the possibilities for increasing the corrosion resistance or changing the corrosion attack mechanism and therefore increasing the life time of the brazing material.

\subsubsection{Microstructural effects}

Re-solidification of an AA4xxx cladding as well as the related particle formation and elemental distribution in a modified AA3xxx core material before and after brazing were studied. The results showed that besides silicon (which is the most dominant particle), $\beta-\mathrm{AlFeSi}$ and $\alpha-\mathrm{Al}(\mathrm{Fe}-\mathrm{Mn}) \mathrm{Si}$ are the other existing primary particles in the non-brazed clad material. $\alpha-\mathrm{Al}(\mathrm{Fe}-\mathrm{Mn}) \mathrm{Si}$ and $\mathrm{Al}_{2} \mathrm{Cu}$ were found to be the primary dominant particles that exist in the non-brazed core structure. Regarding the size, two types of particles were distinguished. One was the particles which are larger than 1-2 $\mu \mathrm{m}$ and their sizes can reach up to $20 \mu \mathrm{m}$. These are mainly $\alpha-\mathrm{Al}(\mathrm{Fe}-\mathrm{Mn}) \mathrm{Si}$ particles. The second group contains particles with sizes below $1 \mu \mathrm{m}$. These are mainly $\mathrm{Al}_{2} \mathrm{Cu}$ and $\alpha-\mathrm{Al}(\mathrm{Fe}-\mathrm{Mn}) \mathrm{Si}$ particles. The $\alpha-\mathrm{Al}(\mathrm{Fe}-$ $\mathrm{Mn}) \mathrm{Si}$ particles are mainly accumulated at the surface and in the core material. 
At brazing temperature the liquid clad is in intimate contact with the solid core material. The liquid originating at the clad-core interface progresses into the core alloy as a film, changing the element distribution on its way. This area is the precipitate-free heat affected zone (HAZ). Solidification of the molten clad material starts with the formation of the pre-eutectic aluminium grains and ends with accumulation of Al-Si eutectic phase at the surface and in grain boundaries. This results in solidification void formation because of different thermal expansion coefficients between aluminium and silicon in the eutectic structure. Most of these voids were shown to be decorated with IMPs at their edges.

The investigation revealed that the major consequences of brazing for the microstructure are: high density of $\mathrm{Al}_{2} \mathrm{Cu}, \alpha-\mathrm{Al}(\mathrm{Fe}-\mathrm{Mn}) \mathrm{Si}$ and Si particles at the surface; an increase in the Si content of the matrix in the heat affected zone (HAZ); a non-uniform distribution of $\mathrm{Cu}$ in the HAZ; an accumulation of $\mathrm{Cu}$ in Al-Si eutectics and around the grain boundaries, including $\alpha-\mathrm{Al}(\mathrm{Mn}, \mathrm{Fe}) \mathrm{Si}$ and $\mathrm{Al}_{2} \mathrm{Cu}$ intermetallics; the presence of some continuous grain boundaries in both the clad and core of the sheet; and the non-uniform precipitation of intermetallics at Al-Si eutectic phases.

\subsubsection{Electrochemical characterization}

The research revealed the strong microstructural influence on the electrochemical reactivities of the brazing sheet structure and the resulting corrosion resistance. The investigation results acknowledged the necessity of applying complementary analysis techniques with different resolution levels to come up with a correct understanding of the metallurgical features and their related electrochemical responses.

By using potentiodynamic measurements on the topmost surfaces, the overall electrochemical reactivities of the top surface in SWAAT solution $(42 \mathrm{~g} / 1$ of NaCl, $\mathrm{pH}=2.8)$ were revealed and correlated to the microstructural features. Formation of $\alpha-\mathrm{Al}(\mathrm{Fe}-\mathrm{Mn}) \mathrm{Si}, \mathrm{Si}$ and $\mathrm{Al}_{2} \mathrm{Cu}$ particles on the surface of the brazed material was shown to increase the cathodic reactivity of the surface. Copper accumulation in the eutectic phases was proved to be the cause for the IGC susceptibility of the resolidified clad material. Si and $\mathrm{Cu}$ diffusion to the clad material were demonstrated to result in a $50 \mathrm{mV}$ increase in the open circuit corrosion potential of the resolidified clad material.

Considering the changes in elemental composition and phases across the brazed aluminium sheet, through depth electrochemical investigation seemed to be necessary. Therefore further electrochemical investigation continued by applying localized potentiodynamic measurements. Combinatory localized electrochemical cell and glow discharge optical emission spectrometry (GDOES) measurements were performed to obtain a thorough in depth electrochemical characterisation of 
the aluminium brazing sheet. By defining electrochemical criteria i.e. breakdown potential, corrosion potential, cathodic and anodic reactivities, and tracking their changes as a function of depth, the evolution of electrochemical responses through out the material thickness were analyzed and correlated to the corresponding microstructural features. The result highlighted that combination of microcapillary measurement and GDOES can be applied as a successful electrochemical depth profiling analysis approach for prediction of corrosion behaviour of the aluminium brazing sheet. It was shown that the presence of high density of $\mathrm{Al}_{2} \mathrm{Cu}$, $\alpha-\mathrm{Al}(\mathrm{Fe}-\mathrm{Mn}) \mathrm{Si}$ and Si particles on the surface areas (up to $5 \mu \mathrm{m}$ depth) of the brazed AA4xxx/AA3xxx material provides active cathodic sites that can galvanically couple with the internal layers of the brazing sheet and cause dissolution and IGC attack of the internal layers of the brazing material. It was also highlighted that elimination of high localized corrosion susceptibility of the outer layer (up to $10 \mu \mathrm{m}$ below the surface) is key in improving the corrosion performance of the aluminium brazing sheet material.

The presence of micro- and nano-size particles in the brazed structure resulted in intermixed electrochemical responses. This made the micro-electrochemical investigation inevitable in order to investigate the electrochemical responses of individual phases such as the matrix. Therefore the micro-electrochemical characterisation of the top surface and cross-sections were further continued with Volta potential and topographic maps which were measured using SKPFM and atomic force microscopy (AFM) respectively. A cross-sectional microelectrochemical investigation correlated with a through depth microstructural characterisation was especially necessary for developing a detailed mechanistic understanding of the corrosion propagation mechanism for the brazed material.

The investigation revealed the suitability of SKPFM analysis for electrochemical investigation of the aluminium brazing sheet material in a SWAAT environment and the necessity of considering a stable localized reference for comparison of the measured VPD values were highlighted. The IGC susceptibility of the brazed core structure was found to be the result of IMP precipitation at GBs. It was also shown that the corrosion attack on the Al-Si eutectic phases in the re-solidified clad material was a result from the distribution of intermetallic particles.

The impact of the microstructural changes on the corrosion behaviour of the brazed sheet were: to increase the VPD of the re-solidified clad matrix; to introduce localized corrosion susceptibility on the brazed clad and core structures; and to reduce the cathodic protection power of the re-solidified clad material.

\subsubsection{Corrosion attack mechanism}

The first stage of the corrosion attack of the aluminium brazing sheet is pitting and dissolution of some of the eutectic aluminium. The eutectic aluminium is the last 
part of the filler alloy to solidify. This aluminium will be different from preeutectic aluminium. All the alloying elements that were not incorporated in the pre-eutectic aluminium during the first stage of solidification will be concenterated in the eutectic aluminium. These will be incorporated in solid solution and/or precipitate as small intermetallics. The corrosion potential of the intermetallics often differs significantly from the aluminium matrix. This results in galvanic coupling and local corrosion attack. So therefore the eutectic Al-Si phase which is decorated with IMPs will be attacked first. Si can also act as a cathode and promote the dissolution of aluminium. After this first stage of the corrosion attack and exposure of the internal layers of the material to the corrosive environment and the galvanic coupling with the cathodic sites which are mainly the $\mathrm{Al}_{2} \mathrm{Cu}, \alpha$ $\mathrm{Al}(\mathrm{Fe}-\mathrm{Mn}) \mathrm{Si}$ particles and in less extent $\mathrm{Si}$ needles, the corrosion proceeds into the core structure. This second stage of corrosion attack propagation takes place at eutectic phases which are decorated with IMPs and are in contact with GBs. It was shown that this is more serious as the GB crosses the whole thickness of the material. It was explained that the presence of the solidification voids decorated with IMPs and in contact with GBs on the top layers of the material $(<10 \mu \mathrm{m})$ will provide a similar detrimental galvanic coupling effects.

\subsubsection{Green generation of cost effective and corrosion resistant aluminium brazing sheet}

Using the generated knowledge over the correlation between the microstructural features and the consequent electrochemical responses, it was concluded that applying a proper post-braze heat treatment may help to improve the corrosion resistance of the aluminium brazing sheet.

An innovative technique for improving corrosion resistance of a modified AA4xxx/AA3xxx aluminium brazing sheet has been developed. In this process the controlled atmosphere brazed (CAB) material is subjected to a thermal postbrazing treatment. The temperature and timing range for the treatment process were estimated based on thermodynamic calculations and Volta potential measurements respectively. The investigation revealed that the major consequences of post-braze heat treatment are : a decrease in the Si content of the matrix in heat affected zone (HAZ); elimination of accumulated $\mathrm{Cu}$ in $\mathrm{Al}-\mathrm{Si}$ eutectics and around the grain boundaries; dissolution of $\mathrm{Al}_{2} \mathrm{Cu}$ particles in the grain boundaries; and increasing the precipitation density of $\mathrm{Si}$ and $\alpha-\mathrm{Al}(\mathrm{Fe}-\mathrm{Mn}) \mathrm{Si}$ particles. The electrochemical impacts of these treatment consequences were: a decrease in the VPD of the re-solidified clad matrix; elimination of localized corrosion attack susceptibility of the brazed structure; and an increase in the cathodic protection power of the re-solidified clad towards the core material.

The relatively high tolerance to increased $\mathrm{Si}$ and $\mathrm{Fe}$ alloying element concentrations in this post-braze heat treated structure will provide the opportunity 
for further usage of recycled aluminium in its production process. Therefore this new material will be referred to as a green corrosion resistant aluminium brazing sheet. This new generation of aluminium brazing sheet will be able to tolerate a higher amount of previously considered detrimental alloying elements and thus a lower need for purification during primary and recycling processing saving energy, material and labor costs.

The investigations of the corrosion resistance of the post-braze heat treated material confirmed the effectiveness of the developed thermal treatment for improving the corrosion resistance of the brazing sheet material.

\subsection{Further research for future}

The work conducted in this $\mathrm{PhD}$ indicates that future research in the field of corrosion protection enhancement of aluminium brazing sheet should focus on applying/developing of models capable of predicting the micro-structural evolution of aluminium brazing materials during secondary processing phases such as brazing and post-braze heat treatment, in relation to its electrochemical properties. The most important microstructural parameters that should be predicted are: the amount of alloying elements in solid solution; the type, distribution and volume fraction of precipitates, grain size and dislocation density. These microstructural parameters are the most influential elements that determine the electrochemical reactivities and therefore the corrosion resistance of the structure. The experimental data required to back up such a model demand electrochemical measurements in micro and nano-level. This is to determine the exact electrochemical role that each of the individual phases plays as they encounter a certain electrolyte. Therefore down-scaling the size of the local electrochemical measurement and applying a micro- and nono-capillaries, which will strongly improve the resolution of the capillary cell, seems to be important. Using microcapillaries that enables the flow of the electrolyte in the capillary could be very helpful to overcome the limits of the capillary cells with regard to the deposition of corrosion products and evolution of gas bubbles.

It is also important to notice that the Volta potential differences that are measured by SKPFM technique are not the best representative of electrochemical reactivity of the phases. This is because corrosion behaviour depends sensitively on the environment ( $\mathrm{pH}$, kind of ions, etc.) and is also determined by the kinetics of the reactions involved. Therefore the usage of other complementary techniques for revealing the exact electrochemical reactivity of the phases in micro and nano scales is suggested. This will provide a better understanding of the individual electrochemical impacts that forms the overall corrosion resistance of the structure. To this end the usage of high resolution Scanning Vibrating Electrode Technique (SVET) to measure the local current densities above the particular phase under investigation is recommended. Currently the maximum resolution available from 
SVET analysis is about $40 \mu \mathrm{m}$. This is still below the resolution $(<1 \mu \mathrm{m})$ which is needed for investigating the electrochemical reactivities of the microstructural features that exit in the aluminium brazing sheet material and determine the overall corrosion behaviour. The surface roughness is another barrier which will prevent direct electrochemical measurements on the surface. This problem can be solved by polishing the surface. However the electrochemical responses will not be the same as the ones that presents on the surface of the unpolished surface.

The presence of phase domains (non-uniform chemical composition) in the IMPs is another important microstructural feature that needs further investigation. This could clarify any possible change of polarity that can take place in the course of corrosion process for a certain IMP. Such information will be crucial for exact determination of corrosion initiation mechanism for aluminium brazing sheet material. Such data can be obtained by using Scanning Electrochemical microscopy (SECM). This is related to the capability of SECM technique for spatial mapping and quantification of local kinetics and transport phenomena. Although application of the SECM tip with resolution of $1 \mu \mathrm{m}$ and higher is theoretically possible but it has proved to be a challenge in practice. The surface roughness issue is also a difficulty that needs to be overcome.

Considering the important role of oxide layers on determining the electrochemical reactivity of the phases, further investigation of the possible changes in the oxide layer is also necessary. In particular, it is important to study the effect of possible changes in the chemical composition and thickness of the oxide layers as a result of post braze heat treatment and the consequences of these changes for the electrochemical reactivities of these phases. To this aim, using Field Emission Auger (FEAuger) microscopy and TEM are proposed.

Another interesting possibility is using a quasi in situ method to follow electrochemically induced microstructural changes on a nanometer scale using analytical transmission electron microscopy (TEM). By following a specific specimen area after repeated exposure to certain electrolyte, in detail investigation of the changes of microstructural features can be performed. This information will provide a solid base for understanding of corrosion initiation and propagation mechanism. Such technique will also assist to understand the critical electrochemical changes induced by microstructural variation that will take place as results of applying a certain thermal or mechanical treatment.

Based on the generated knowledge on the interrelation between microstructural features and the resulting electrochemical responses of the brazing sheet material and the additional information that could be extracted from afore mentioned experimental approaches, it should be possible to take one step further and investigate the feasibility to improve the corrosion resistance of the brazing sheet material directly by brazing treatment. Such a research work will be focused on 
engineering the material structure during the thermo-mechanical production process. The material structure should be designed in a way that brazing treatment as the final stage of the product manufacturing, results in an optimized corrosion resistance. 


\section{Summary}

Aluminium brazing sheet is a sandwich material made out of two aluminium alloys (AA4xxx/AA3xxx) and is widely used in automotive heat exchangers. One of the main performance criteria for heat exchanger units is the lifetime of the product. The lifetime of the heat exchanger units is determined by their corrosion resistance. The most common way to measure the corrosion resistance of heat exchanger materials is the so called Sea Water Acidified Accelerated Test (SWAAT). Unfortunately there is no agreement on how corrosion performance should be evaluated in SWAAT. The first aim of the current research work was to perform a statistical and in-depth analysis of the critical parameters of the SWAAT. By keeping the climatic parameters constant, the correlation between the variation of the test results and the actual fundamental differences in the material condition i.e. temper and brazing condition was elucidated. Parameters that potentially could influence the outcome of the SWAAT test were investigated. The results were used to narrow the operation window of the test and making it more reproducible and reliable. The possibility of the presence of some links between SWAAT and electrochemical characterization were also investigated. Corrosion mechanism and morphology of attack in SWAAT and potentiodynamic test were compared. The result confirmed that the SWAAT performance of the material can be reflected in potentiodynamic responses. Finally a new statistical reliability evaluation approach and a novel result interpretation method were developed.

Nowadays cost reductions are key within automotive industry and the current corrosion resistant alloys become less competitive. There is a strong demand for low cost alloys but still with the excellent corrosion protection properties of the expensive alloys. In depth knowledge of how alloy composition, microstructure and thermo-mechanical processing alter the corrosion resistance of aluminium brazing sheet is crucial to allow production of cost effective alloys with sufficient properties in the near future. Therefore the second aim of this research was to develop a fundamental understanding over the correlation between microstructural features and the resulting electrochemical responses of aluminium brazing sheet materials. The detailed and fundamental mechanistic understanding of the effects of microstructural variations and the consequent electrochemical reactivities was aimed at providing solutions for enhanced corrosion protection by microstructural control of aluminium brazing sheet. 
A full microstructural characterization of the material was obtained. A complete electrochemical characterization of the structure at macro, localized and micro scales was achieved and correlated to the microstructural features developed as consequences of brazing treatment. The results were used to explain the corrosion propagation mechanism through the structure of the brazed material and to investigate possibilities for improving the corrosion resistance of the brazed structure. Using the generated knowledge over the correlation between the microstructural features and the electrochemical responses, it was concluded that applying a proper post-braze heat treatment may improve the corrosion resistance of the aluminium brazing sheet.

An innovative technique for improving corrosion resistance of a modified AA4xxx/AA3xxx aluminium brazing sheet has been developed. In this process the controlled atmosphere brazed (CAB) material is subjected to a thermal postbrazing treatment. The investigations of the corrosion resistance of the post-braze heat treated material confirmed the effectiveness of the developed thermal treatment for improving the corrosion resistance of the brazing sheet material.

The relatively high tolerance to increased $\mathrm{Si}$ and $\mathrm{Fe}$ alloying element concentrations in this post-braze heat treated structure will provide the opportunity for further usage of recycled aluminium in its production process. Therefore this new material is referred to as a green corrosion resistant aluminium brazing sheet. This new generation of aluminium brazing sheet is able to tolerate a higher amount of previously considered detrimental alloying elements and thus a lower need for purification during primary and recycling processing saving energy, material and labor costs. 


\section{Samenvatting}

Aluminium "brazing sheet" is een sandwich materiaal bestaande uit twee aluminium legeringen (AA4xxx/AA3 $\mathrm{xxx}$ ) en wordt met name toegepast in warmtewisselaars in de automobielindustrie. Een van de belangrijkste prestatiecriteria voor warmtewisselaars is de levensduur van het product. De levensduur van de warmtewisselaar wordt voornamelijk bepaald door de corrosieweerstand. De meest gebruikelijke testmethode om de corrosieweerstand van een warmtewisselaar te bepalen is de Sea Water Acidified Accelerated Test (SWAAT). Echter, er is geen consensus over de bepaling van de corrosieweerstand met behulp van de SWAAT test. Het eerste doel van dit onderzoek was de uitvoering van een statistische en diepgaande analyse van de kritische parameters van de SWAAT testmethode. Door het constant houden van klimatologische testparameters is de correlatie tussen de variatie in de testresultaten en daadwerkelijk fundamentele verschillen in de materiaalcondities, met name geïntroduceerd door warmtebehandeling en brazing, vastgesteld. De potentiële parameters die de uitkomst van de SWAAT test konden beïnvloeden zijn onderzocht. De resultaten zijn gebruikt om de operationele vrijheidsgraden van de test te vernauwen en de test meer reproduceerbaar en betrouwbaar te maken. Ook de correlatie tussen de SWAAT test en elektrochemische karakterisering is onderzocht. De corrosiemechanismen en de aantastingsmorfologie zoals waargenomen in de SWAAT test en potentiodynamische polarisatiemetingen zijn met elkaar vergeleken. De resultaten hebben bevestigd dat het materiaalgedrag in de SWAAT test vergeleken kan worden met dat in de potentiodynamische polarisatiemetingen. Tenslotte zijn een nieuwe statistische betrouwbaarheids- en interpretatiemethode ontwikkeld.

Heden ten dage is kostenreductie in de automobielindustrie van groot belang en worden de bestaande corrosiebestendige legeringen minder competitief. Er is grote behoefte aan goedkope legeringen, die ook de excellente corrosiebescherming bieden van de dure legeringen. Fundamentele kennis over de wijze waarop legeringssamenstelling, microstructuur en thermo-mechanische behandelingen de corrosieweerstand van aluminium brazing sheet beïnvloeden is cruciaal om de productie van kosteneffectieve legeringen met adequate eigenschappen in de nabije toekomst mogelijk te maken. Hiertoe was het tweede doel van het onderzoek de ontwikkeling van fundamentele kennis over de correlatie tussen microstructuur en de electrochemische eigenschappen van aluminium brazing sheet materialen. Het gedetailleerde en fundamentele begrip van de effecten van microstructurele variaties op de elektrochemische reactiviteit was gericht op het 
verkrijgen van verbeterde corrosie-eigenschappen door mcirostructurele controle van aluminium brazing sheet.

Een volledige microstructurele karakterisering van het materiaal is uitgevoerd. Een complete elektrochemische karakterisering van de structuur op macro-, lokaal en micro-niveau is verkregen en gecorreleerd aan de microstructurele heterogeniteiten die zich vormden tijdens het brazingproces. De resultaten zijn gebruikt om het corrosiepropagatiemechanisme door de microstructuur van het gebrazede materiaal te verklaren en mogelijkheden te onderzoeken om de corrosieweerstand van de gebrazede structuur te verbeteren. Door de gegenereerde kennis van de correlatie tussen de microstructuur en elektrochemische eigenschappen nader te analyseren, is geconcludeerd dat door toepassing van een bepaalde post-braze warmtebehandeling de corrosieweerstand van de aluminium brazing sheet verbeterd kon worden.

Een innovatieve techniek voor verbetering van de corrosieweerstand van een gemodificeerde AA4xxx/AA3xxx aluminium brazing sheet is ontwikkeld. In dit proces wordt het onder gecontroleerde atmosfeer gebrazede materiaal onderworpen aan een thermische post-brazing behandeling. Het onderzoek naar de corrosieweerstand van het post-braze warmtebehandelde materiaal heeft de effectiviteit van de ontwikkelde warmtebehandeling voor verbetering van de corrosieweerstand bevestigd.

De relatief hoge tolerantie voor hogere $\mathrm{Si}$ en Fe legeringselementconcentraties in deze post-braze behandelde structuren biedt de mogelijkheid voor toenemend gebruik van gerecycleerd aluminium in het productieproces. Hierdoor kan het nieuwe materiaal een 'groene' corrosieresistente aluminium brazing sheet genoemd worden. Deze nieuwe generatie van aluminium brazing sheet kan hogere concentraties van eerder schadelijk geachte legeringselementen tolereren en behoeft zodoende minder zuivering tijdens primaire en recycleerprocessen hetgeen energie, materiaal- en arbeidskosten bespaart. 


\section{List of publications}

\section{Peer reviewed articles:}

1. F. Norouzi Afshar, E. Szala, A. Wittebrood, R. Mulder, J.M.C. Mol, H. Terryn, J.H.W. de Wit, Influence of material related parameters in sea water acidified accelerated test, reliability analysis and electrochemical evaluation of the test for aluminum brazing sheet, Corrosion Science 53 (2011) 39233933.

2. F. Norouzi Afshar, E. Szala, A. Wittebrood, A. Buerger, C.J.G. Van Hoek, J.M.C. Mol, H. Terryn, J.H.W. de Wit, New approach in microstructural analysis of a modified AA4xxx/AA3xxx brazing sheet before and after brazing, Institution of Mechanical Engineers -VTMS 10, Vehicle Thermal Management Systems Conference and Exhibition, (2011) 69-79. The paper was awarded a nomination for the best technical paper.

3. F. Norouzi Afshar, J.H.W. de Wit, H. Terryn, J.M.C. Mol, The effect of brazing process on microstructure evolution and corrosion performance of a modified AA4xxx/AA3xxx brazing sheet, Corrosion Science 58 (2012) 242-250.

4. F. Norouzi Afshar, R. Ambat, C. Kwakernaak, J.H.W. de Wit, J.M.C. Mol, H. Terryn, Electrochemical depth profiling of multilayer metallic structures: an aluminium brazing sheet, Electrochimica Acta 77 (2012) 285-293.

5. F. Norouzi Afshar, J.H.W. de Wit, H. Terryn, J.M.C. Mol, Scanning Kelvin probe force microscopy as a means of predicting the electrochemical characteristics of the surface of a modified AA4xxx/AA3xxx brazing sheet, Electrochimica Acta 88 (2013) 330-339.

6. F. Norouzi Afshar, J.H.W. de Wit, H. Terryn, J.M.C. Mol, Enhanced corrosion protection by microstructural control of aluminium brazing sheet, Institution of Mechanical Engineers -VTMS 11, Vehicle Thermal Management Systems Conference and Exhibition, (2013) 91-102. The paper was awarded a nomination for the best technical paper.

7. F. Norouzi Afshar, A.M. Glenn, J.H.W. de Wit, H. Terryn, J.M.C. Mol, A combined electron probe micro analysis and scanning Kelvin probe force microscopy study of a modified AA4xxx/AA3xxx aluminium brazing sheet, Electrochimica Acta 104 (2013) 48-63. 
8. F. Norouzi Afshar, F.D. Tichelaar, A.M. Glenn, J.H.W. de Wit, H. Terryn, J.M.C. Mol, Enhanced corrosion protection by microstructural control of a modified AA4xxx/AA3xxx aluminium brazing sheet: Towards a green generation of corrosion resistant aluminium brazing sheet, Corrosion Science, under review (2013)

\section{Conference presentations and proceedings:}

1. F. Norouzi Afshar, E. Szala, A. Wittebrood, J.M.C. Mol, H. Terryn, J.H.W. de Wit, Analysis of the reliability of the sea water acidified accelerated test (SWAAT) for aluminium brazing sheet, Eurocorr 2010, Moscow, Russia, (2010).

2. F. Norouiz Afshar, E. Szala, A. Wittebrood, J.M.C. Mol, H. Terryn, J.H.W. de Wit, Corrosion mechanism evaluation of a new modified AA4xxx/AA3xxx brazing sheet, Eurocorr 2011, Stockholm, Sweden, (2011).

3. F. Norouzi Afshar, J.M.C. Mol, J.H.W. de Wit, H. Terry, Electrochemical characterization of a modified AA4xxx/AA3xxx brazing sheet, ASST 2012, Sorrento, Italy.

4. F. Norouzi Afshar, J.H.W. de Wit, H. Terryn, J.M.C. Mol, Corrosion resistance evaluation and electrochemical characterization of an aluminium brazing sheet, EMCR 2012, Maragogi, Brazil.

5. F. Norouzi Afshar, J.H.W. de Wit, H. Terryn, J.M.C. Mol, Towards a green generation of aluminium brazing sheet, Eurocorr 2012, Istanbul, Turkey.

6. F. Norouzi Afshar, J.H.W. de Wit, J.M.C. Mol, H. Terryn, Towards a green generation of corrosion resistant aluminium brazing sheet, The 2nd International Conference and Exhibition, Aluminium-21/WELDING AND BRAZING, Saint Petersburg, Russia, 2012.

7. F. Norouzi Afshar, J.M.C. Mol, J.H.W. de Wit, H. Terryn, Enhanced corrosion protection of aluminium brazing sheet, M2i conference, Netherlands. 2012

8. F. Norouzi Afshar, J.H.W. de Wit, H. Terryn, J.M.C. Mol, Scanning Kelvin probe force microscopy as a means to predict corrosion resistance of multi layer metallic structures: an aluminium brazing sheet, Eurocorr 2013, Estoril, Portugal. 
9. F. Norouzi Afshar, J.H.W. de Wit, H. Terryn, J.M.C. Mol, Corrosion and electrochemical analysis of aluminium brazing sheet in relation to microstructural features by complementary techniques, Eurocorr 2013, Estoril, Portugal. 


\section{Acknowledgments}

The $\mathrm{PhD}$ project that was started roughly 4 years ago in October 2009, has finally ended in the publication of this thesis. Although during a $\mathrm{PhD}$ you are often on your own for solving problems and finding solutions, many other people apart from yourself determine the successful end of this difficult and challenging task. Performing the work presented in this thesis was hardly possible without direct and indirect contribution of a number of people who deserve a special mention.

First, I would like to thank M2i for the financial support of this project. My special thanks to Monica Reulink, HR officer of M2i, for all her time and support.

Next, I would like to express my sincere gratitude to my daily supervisor Dr. Arjan Mol and my promoters Prof. Herman Terryn and Prof. Hans de Wit. To all of you, I am forever indebted for providing me with such a stimulating and supportive environment. For teaching me to think independently, for letting me to take decisions on my own, and for helping me to overcome all the problems that I faced during these four years. I learnt a lot from you including the art of writing in a way that is clear, understandable and convincing the reader with regard to the relevance and the importance. It was a great pleasure and a fantastic opportunity to work with you all.

Special thanks go to Eizabeth Szala, Dr. Aad Wittebrood, Job van der Hoeven, Corrie van Hoek, Patricia Romano Triguero, Theo de Haan, and Gerard Brussaard from Tata steel company for all their scientific and experimental help and support. I benefited significantly from discussions and collaboration with you.

Many thanks to Dr. Wim Sloof, Kees Kwakernaak, Vahid Aghaei Lashgari for the SEM sessions. I also would like to thank Dr. Rajan Ambat and his colleagues for their hospitality during my stay in Denmark technical university, and also for valuable scientific discussions and constructive comments.

Other special thanks to Dr. Matthew Glenn and Dr. Tonny Hughes from commonwealth scientific and industrial research organization (CSIRO) in Australia for all their valuable discussions, help, and support with the FE-EPMA characterization work.

Dr. Frans Tichelaar, from Kavli Institute of Nanoscience, your assistance with the TEM investigation is highly appreciated.

Bart Norbart and Lambert Schipperheijn, without you and your bright technical solutions I could not overcome many challenges in this project. Thank you. 
I would also like to thank all my friends in $3 \mathrm{ME}$ who made my time here enjoyable and always made me feel at home. Special thanks to CTE group members: David, Peyman, Yaiza, Olga, Onnaz, Jose and the new members: Shoshan and Peter. I enjoyed every minutes of being with you, especially the conferences, brain storms and the crazy stuff that we experienced together.

Finally I would like to express my sincere gratitude to my family and dedicate this work to my parents and my sister for all their love, help and support that they have offered during this $\mathrm{PhD}$ work.

Farid Afshar

Delft, March 2013 


\section{Ph.D. Researcher}

Developing a new generation of cost effective long life (corrosion resistant) aluminium brazing sheet material

Graduate Teaching Assistance, TU Delft University of Technology, Faculty 3mE, Department MSE, Netherlands, 2010 to 2013.

Deach introduction to Atomic Force Microscopy (AFM) and Scanning Kelvin Probe Force Microscopy (SKPFM) and application in corrosion science

Teach introduction to corrosion and electrochemistry

$>$ Teach microstructure and corrosion (Metal science)

\section{Shell International Exploration \& Production, Netherlands}

Dec 2008 - Aug 2009

\section{Material Engineer (Trainee)}

Investigating the brazing process of the threaded tubular connections

$>$ Improving the mechanical and metallurgical properties of the brazed joints

$>$ Developing test strategies for mechanical characterization of the brazed joints

$>$ Performing material and mechanical characterization and data analysis

Pars Oil \& Gas Company, Iran

Corrosion and Inspection Engineer

\section{Education}

Ph.D. Material Science and Engineering (Corrosion and Electrochemistry) - August 2013

TU Delft University of Technology (Netherlands)

Dissertation: Enhanced corrosion protection by microstructural control of aluminium brazing sheet.

MSc. Material Science and Engineering- July 2009

TU Delft University of Technology (Netherlands)

Dissertation: Characterization of joints on threaded X52 steel pipes / Joining and Mechanical properties. 


\section{CURRICULUM VITAE}

BSc. Safety and Technical Inspection Engineering- July 2004

Petroleum University of Technology (Iran)

Dissertation: Current - voltage variations in cathodic protection of underground pipelines

\section{Additional training}

- Business awareness course, Delft, Netherlands, November 2012.

- The $11^{\text {th }}$ international summer school on aluminium alloy technology, Trondheim/Norway, 2011.

- Graduate Course in Corrosion Science, Royal Institute of Technology (KTH), Stockholm/Sweden, September 2011.

- Training at the aluminium brazing seminar (theory and practice), European association for brazing and soldering (ESAB), Hannover/Germany, 2010.

- Micro-cell electrochemical measurement training, Technical University of Denmark (DTU), Lyngby/Denmark, 2010.

- Presentation Skills Course, M2i, Delft/Netherlands, 2009.

\section{Academic Achievements, Honors and Awards}

A full scholarship (Petroleum Scholarship) for 4 years of BSc study in Petroleum University of Technology, Iran, 2000-2004

$>$ University Scholar, Petroleum University of Technology, 2000-2004

A full scholarship (Royal Dutch Shell Scholarship) for 2 years of MSc study in TU Delft University of Technology, Netherlands, 2007-2009

$>$ Presentation of a paper in VTMS 10 conference/England and nomination for the best technical paper (2011)

$>$ Development of a green generation of cost effective and corrosion resistant aluminium brazing sheet as the final result of the Ph.D. research project, 20092013

Presentation of a paper in VTMS 11 conference/England and nomination for the best technical paper (2013) 